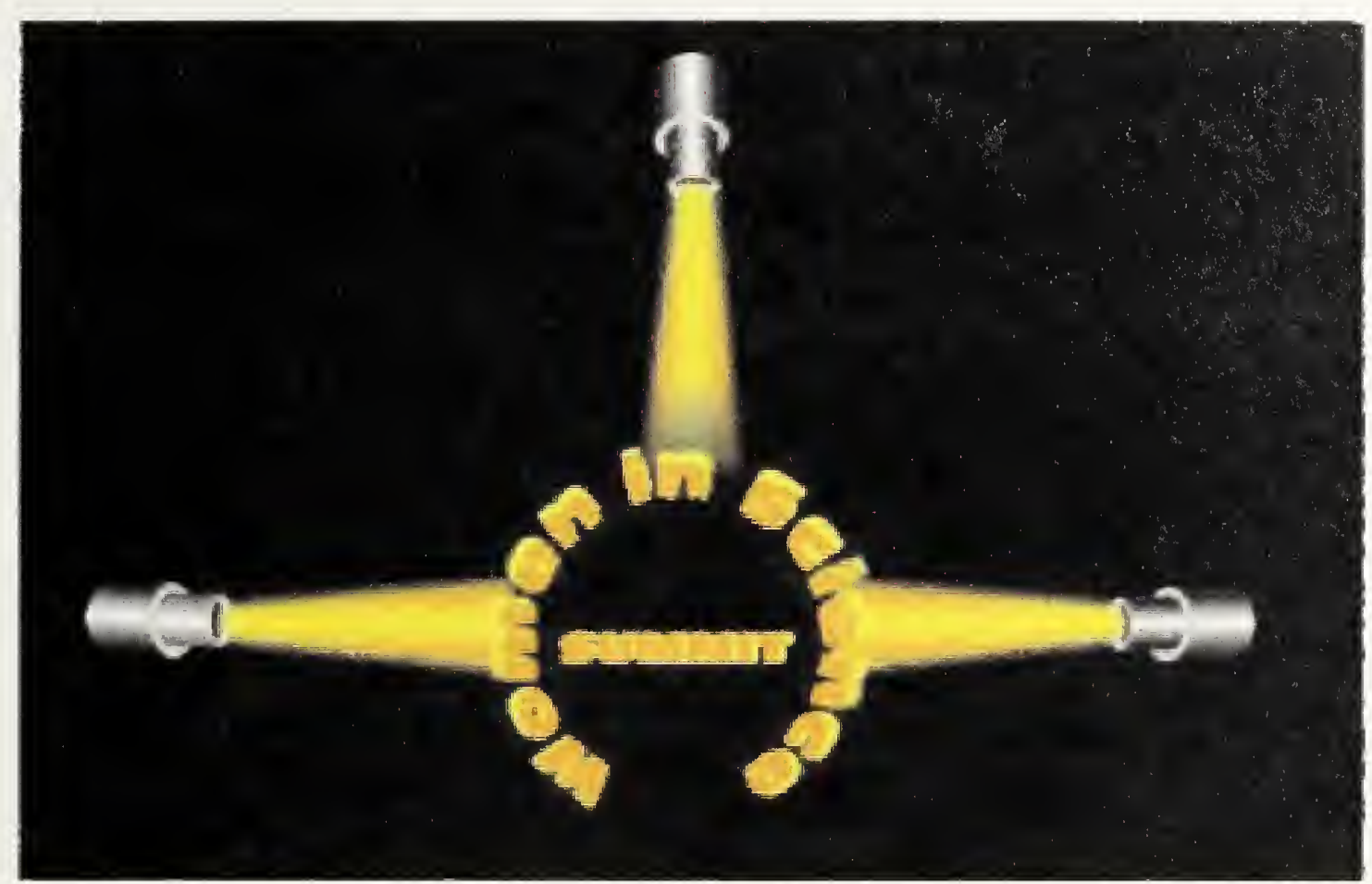

NISTIR 6918

\title{
Proceedings
}

\section{Women in Science, Redefined:}

Tactics and Alliances to Address and Change Systemic Trends Affecting Women in Science, Engineering, and Technology

March 12-13, 2002, Gaithersburg, MD

\author{
Sponsored by \\ NIST Diversity Program Office \\ Women's History Month
}

QC

100

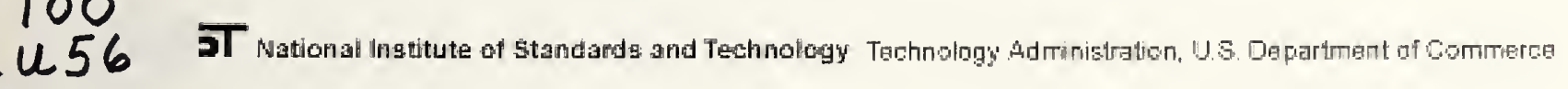

*6918

2002 



\section{Proceedings}

\section{Women in Science, Redefined: Tactics and Alliances to Address and Change Systemic Trends Affecting Women in Science, Engineering, and Technology} March 12-13, 2002, Gaithersburg, MD

\section{Edited by}

Sol del Ande Eaton, NIST Diversity Program Manager

and

Fran Nielsen, Chairperson, NIST Diversity Advisory Board

Sponsored by

NIST Diversity Program Office

Women's History Month

Issued October 2002

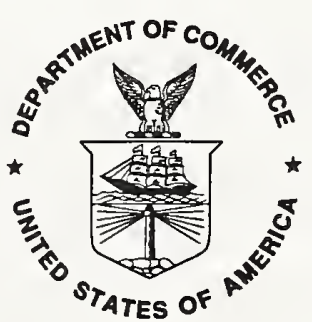

U.S. DEPARTMENT OF COMMERCE

Donald L. Evans, Secretary

TECHNOLOGY ADMINISTRATION

Phillip J. Bond, Under Secretary of Commerce for Technology

NATIONAL INSTITUTE OF STANDARDS AND TECHNOLOGY

Arden L. Bement, Jr., Director 
Any identification of commercial equipment, instruments, or materials in this document is not intended to imply recommendation or endorsement by the National Institute of Standards and Technology.

The editors wish to acknowledge gratefully the assistance of Patricia D. Fenn, contractor, who helped organize the conference, edited the raw transcriptions, and compiled the proceedings. Also we wish to thank Judy L. Crain of the NIST Occupational Health and Safety Division, who was instrumental in arranging for closed captioning of the conference proceedings videotape. 


\section{Foreword}

The first NIST Women's Summit, "Women in Science, Redefined: Tactics and Alliances to Address and Change Systemic Trends Affecting Women in Science, Engineering, and Technology," was held March 12 and 13, 2002, at the National Institute of Standards and Technology in Gaithersburg, MD.

The two-day event brought together eminent speakers who addressed the issues facing women in science, engineering and technology (SET). The stage was set for the Summit by descriptions of SET women from the national, Federal, NIST, and private sector perspectives. The topics of follow-on sessions were mentoring, coaching, pipeline, and balancing work and life.

During the Summit, a breakout session to brainstorm NIST-specific issues was conducted. The results of the breakout session are reported as a set of observations, available resources, and recommended actions both for NIST and for individuals.

Presentations made by the various speakers at the Summit are direct transcriptions based on closed captioning and videotapes.

Contact Diversity Program Manager Sol del Ande Eaton for any questions, copies of videotapes, overhead charts, handouts, or other resources from the Summit available in the NIST Diversity Office, 301-975-5481; sol.eaton@nist.gov. 


\section{Contents}

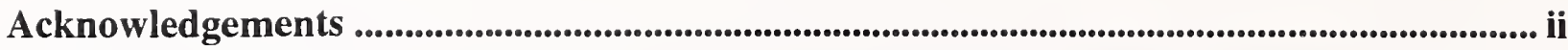

Executive Summary ........................................................................................................................................... iii

Summit Description ..................................................................................................................................... vii

Background ............................................................................................................................ vii

NIST Women's Summit Planning Committee ...................................................................... viii

The Summit -Day One ........................................................................................................... viii

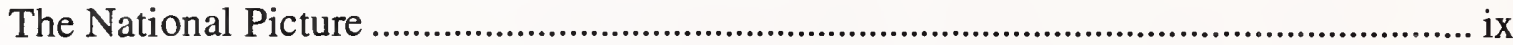

The Agency Picture .............................................................................................................. ix

The Private Sector Picture ………………......................................................................... ix

The Federal Picture ............................................................................................................... $\mathrm{x}$

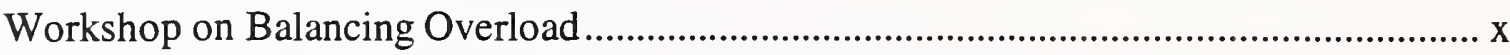

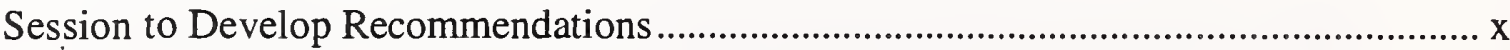

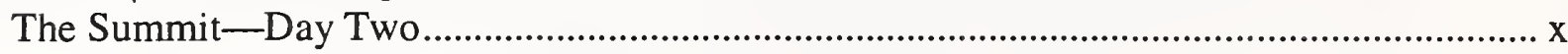

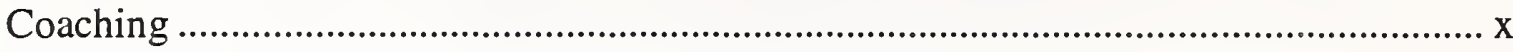

Mentoring.....................................................................................................................

Pipeline and Community Outreach ….............................................................................. xi

Concluding Remarks........................................................................................................... xii

Observations, Resources and Recommended Actions ....................................................... xii

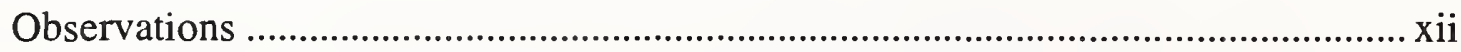

Resources Available Now ...................................................................................... xiii

Actions for Improvement (NIST) ........................................................................ xiii

Actions for Improvement (Individuals) ...................................................................... Xv

Opening Remarks, Sol del Ande Eaton, NIST Diversity Program Manager ..............................1

Welcoming Presentation, Dr. Arden L. Bement, Jr., NIST Director ...............................................

"The National Picture," Dr. Kathie L. Olsen, Chief Scientist, NASA ..........................................6

Presentation Visuals...............................................................................................14

“NIST_Past, Present, and Future: From 1993 to Today,” Dr. Karen H. Brown,

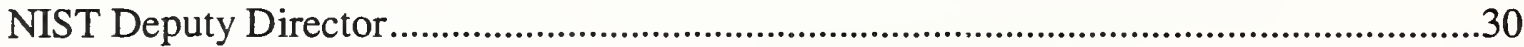

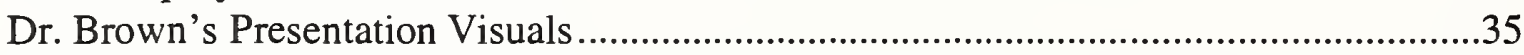

"Women Scientists at NIST," Dr. Carol Handwerker, Chief, NIST Metallurgy Division ......43

"Women in Science, Engineering, and Technology in the Private Sector," Dr.

Chinatsu Aone, Vice President of Natural Language Programming, SRA

International, Inc.

"Negotiating Program Overload and Professional Change," June Ramos, Consultant,

Zoe Training and Consulting ……….................................................................................50

Introduction of Hon. Constance A. Morella, Dr. Arden L. Bement, Jr., Director, NIST..........67

"The Federal Picture," Hon. Constance A. Morella.............................................................68

“ABC's of Coaching," Pat Battle, President, Pat Battle \& Associates .....................................76

"ABC's of Coaching," Tim Wright, Consultant .........................................................................83

Questions and Answers After the Coaching Presentations ...................................................8

"Mentoring," Dr. David King, Former Director and Founder, NIST Summer

Undergraduate Research Fellowship (SURF) ..................................................................91

"SURFing the Physics Laboratory" (Presentation Visuals), Dr. David King ...................95

"Investing in Our Future," Darlene Floyd, President, Horizons Management and

Training Consultants. 
"Investing in Our Future," Bettie L. White, Assistant to the Director, Stennis Space Center, NASA.

Mentoring Presentation Questions and Answers

"Meeting the Crisis in Human Capital: K-12 to Graduate School," Dr. Julia V. Clark,

Program Director, Teacher Enhancement Program, National Science Foundation....

"On Education," Jonetta Russell, Magnet School Coordinator, Montgomery-Blair

High School, Montgomery County Public Schools, Maryland.

Questions and Answers About Pipeline and Community Outreach

"Summation of Panel Presentations and Group Recommendations," Dr. Fran Nielsen,

Deputy Chief, Computer Security Division, NIST

Summation Visuals, Dr. Fran Nielsen

"Presentation and Introduction of Dr. Katharine Gebbie," Radhika Char, Graduating

Senior, Montgomery-Blair High School, Maryland.

"Closing Remarks," Dr. Katharine B. Gebbie, Director, NIST Physics Laboratory..

"Closing Presentation and Acknowledgements," Sol del Ande Eaton

Appendix: Summit Booklet

Welcoming Statements

NIST Women's Summit Planning Committee

Acknowledgements of Supporters

Keynote Speakers' Biographies

Summit Agenda

Seminar Summaries and Presenters' Biographies

[Other Resources Available in the NIST Diversity Program Office, Building 101, Room A537, Telephone 301-975-4581

1. CAWMSET Testimony by Dr. Sandra Begay-Cambell, Executive Director, American Indian Science and Engineering Society

2. CAWMSET Testimony by Dr. Sheryl Burgstahler, Director, DO-IT, Disabilities Opportunities, Internetworking and Technology

3. CAWMSET Testimony by Dr. Lily Chu, Program Director, Regional Alliance of Science, Mathematics and Technology for People with Disabilities

4. CAWMSET Testimony by Dr. Jane Daniels, Purdue University Women in Engineering Program

5. CAWMSET Testimony by Dorothy Doyle, American Society for Cell Biology

6. CAWMSET Testimony by Dr. Martha Krebs, Director of Office of Science, U.S. Department of Energy

7. CAWMSET Testimony by Ms. Elaine Mendoza, Chairperson

8. CAWMSET Testimony by Dr. Michael L. Moore, Gallaudet University, Washington, DC

9. CAWMSET Testimony by Ms. Sadwiga S. Sebrechts, President, Women's College Coalition

10. CAWMSET Testimony by Mr. Charles E. Vela, Executive Director, Center for the Advancement of Hispanics in Science and Engineering Education

11. Committee Members, U.S. Senate Committee on Commerce, Science and Transportation

12. Resource List: Women in Science and Technology, NASA

13. "Shedding Light on Imbalance: Top Female Scientists Explore Why They Are Not a Minority," by Curt Suplee, Washington Post 


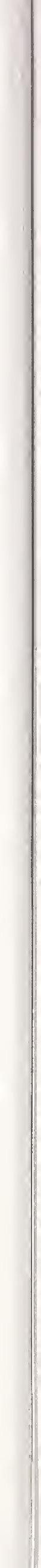




\section{Women in Science, Redefined: Tactics and Alliances to Address and Change Systemic Trends Affecting Women in Science, Engineering, and Technology}

\section{Executive Summary}

The first NIST Women's Summit, "Women in Science, Redefined: Tactics and Alliances to Address and Change Systemic Trends Affecting Women in Science, Engineering and Technology," was held March 12 and 13, 2002, at the National Institute of Standards and Technology in Gaithersburg, MD. This document summarizes the activities of the two-day event and presents some observations and recommended actions to be taken by NIST management and individuals to foster a more supportive work environment.

[Note: in addition to this written record of the Summit, the event was videotaped. The tape is available from the NIST Diversity Program Office.]

\section{BACKGROUND}

The genesis of the NIST "Women In Science" Summit can be attributed to three factors:

(1) In 1997, NIST established the Diversity Program Office and hired a full-time Diversity Program Manager (DPM) to provide diversity leadership to the organization. The DPM became aware of two internal NIST Reports ${ }^{1}$ related to diversity; however, it was unclear to the DPM what progress had been made with regard to the recommendations proposed in these reports.

(2) In October 1998, Congress passed Public Law 105-255 that created the National Commission for the Advancement of Women and Minorities in Science, Engineering and Technology (SET) [CAWMSET].

(3) In September 2000, CAWMSET ${ }^{2}$ recommended to Congress some comprehensive and far-reaching recommendations ${ }^{3}$ that could be considered a blueprint to SET-based agencies such as NIST. While many of the CAWMSET recommendations focus on improvements in education, one is directly aimed at SET employers:

\footnotetext{
${ }^{1}$ NIST African-American Affirmative Employment Committee Report, 4/7/93; and NIST Report by the Ad Hoc Affirmative Employment Committee for Female Scientists and Engineers, 8/1/93.

${ }^{2}$ The Commission for the Advancement of Women and Minorities in Science, Engineering and Technology (CAWMSET) is also called the Morella Commission, after the Honorable Constance A. Morella, (R-MD). Ms. Morella was a co-sponsor of the enabling legislation and is a member of the U.S. House Science Committee.

${ }^{3}$ See "Land of Plenty: Diversity as America's Competitive Edge in Science, Engineering and Technology," pp. 88-91.
} 
"The Commission recommends that both public and private SET employers be held accountable for the career development and advancement of their employees who are women, underrepresented minorities, and persons with disabilities."

Another key CAWMSET recommendation relates to the transformation of "the image of the SET professions and their practitioners so that the image is positive and inclusive for women, underrepresented minorities, and persons with disabilities."

Given this climate of interest, the DPM hosted a series of meetings in conjunction with training and focus groups of key scientists and NIST SET women to discuss concerns and issues. Both the Gaithersburg campus and the Boulder campus were involved in these fact-finding sessions. Based on the input from these events, the DPM proposed a "Women in Science" Summit and formed a planning committee. The initial idea for the Summit program focused on a series of speakers and panelists to address the concerns voiced in the focus groups. Some of the issues and concerns echoed those highlighted in the 1993 reports, and many replicated the sentiment described by CAWMSET.

\section{NIST WOMEN'S SUMMIT PLANNING COMMITTEE}

The Planning Committee was comprised primarily from members of the NIST Diversity Advisory Board (DAB) who are representatives from the various NIST Organizational Units. The DAB is responsible for providing advice to the Director of NIST on diversity related plans, policies and programs, and the Board serves as an advocate for diversity and mentoring issues at NIST.

\section{Planning Committee Members:}

- Connie K.N. Chang, President, NIST Committee for Women

- Dean W. Claus, DAB, Diversity Coordinator (Boulder)

- Sol del Ande Eaton, Diversity Program Manager

- Celani Dominguez, Baldrige National Quality Program, Einstein Fellow

- David M. Gilliam, DAB, representing Physics Laboratory

- Albert Lee, DAB, representing Chemical Science and Technology Laboratory

- Deborah A. Martin, DAB, representing Human Resource Management

- Fran Nielsen, DAB, representing Information Technology Laboratory

- Ann-Marie Regan, DAB, representing Baldrige National Quality Program

- Jennifer Scott, Vice Chair, DAB, representing Chemical Science and Technology Laboratory (Boulder)

- Hratch G. Semerjian, Director, Chemical Science and Technology Laboratory

- Robin R. Wolf, Civil Rights Office (Boulder)

- Patricia D. Fenn, "Women in Science" Contractor

\section{THE SUMMIT - DAY ONE}

Diversity Program Manager Sol del Ande Eaton opened the Summit by stating, "Gender no longer determines what we get out of life," and she introduced Dr. Arden L. Bement, NIST Director, who welcomed attendees to the two-day event. Dr. Bement told the audience that "diversity is a key policy for NIST" where trust, respect, and understanding are as important as 
technical accomplishments. Letters of welcome by Dr. Bement and from Dr. Nancy Hopkins, Biology Faculty, MIT, were included in Summit materials. See page 1.

Setting the stage for the Summit on Day One, several presentations were given describing the national picture, the agency picture, the private sector picture and the Federal picture of SET women. Afterwards, June Ramos led the audience in a workshop called "Negotiating Program Overload and Change." Part of the session included a film titled "Power Dead Even Rule," featuring Pat Heim. This entertaining film illustrated differences, based on gender and socialization, in hearing and speaking with associated work interactions.

The National Picture. Dr. Kathie L. Olsen, the nominee for Associate Director of the White House Office of Science and Technology Policy, briefed the audience on the CAWMSET recommendations, on her experiences as a female scientist, and on the differences of men and women. Noting that "our future is based on science and technology," Dr. Olsen described the opportunity for women as moving from "scarcity" to "visibility." See page 6.

The Agency Picture. NIST Deputy Director Dr. Karen H. Brown showed historical statistics including salary data for women scientists at NIST. Dr. Brown gave examples of how NIST has evolved since the 1993 Draft Report on Women at NIST was produced. She pointed out that although the number of post-docs has doubled in that timeframe, the overall percentage of SET women has remained about the same. From the statistics, Dr. Brown showed that the performance scores for men and women scientists are similar, but the pay-for-performance differs. She concluded that this information should be made more visible and subjected to a more detailed analysis. See page 30 .

Dr. Carol A. Handwerker, Chief, Metallurgy Division, MSEL, described the NIST culture and talked about barriers and what keeps employees here. She recounted her early years as a post-doc mother of a four-month-old infant, proclaiming the alternate work schedule as the "best positive change" made since her arrival at NIST. Dr. Handwerker said that in the early 1990 s movement of women into the management ranks was achieved. She pointed out that the number of women has grown by only 2 percent, but "it feels like more" because of critical mass in certain areas, such as the Advanced Technology Program, that is comprised of numerous women scientists. Dr. Handwerker has observed in outside organizations that women need to achieve a critical size of about 25 percent of the work force (currently NIST is about 16 per cent and holding) before cultural changes will be seen. She indicated that issues remain with bias toward women about marital status, about parenthood (if you have children, you are less serious about your job), and about part-time (judged by the number of hours worked rather than accomplishments). She suggested that enlightened management is needed. She also noted that women may have to take positive action and remind managers that they are eager and able to take on more responsibilities. See page 43 .

The Private Sector Picture. Dr. Chinatsu Aone, Vice President and Director of Natural Languages at SRA International, told attendees that the private sector is profit-focused with an emphasis on the ability to solve practical problems. For the third consecutive year, Fortune 500 named SRA International as one of "The 100 Best Places to Work." Dr. Aone shared advice on the skills the private sector prizes most. These skills are adaptability, ability to be a quick learner, good written and oral communications, and teamwork. See page 47. 
The Federal Picture. Introduced as the "Angel of NIST," The Honorable Constance A. Morella (R-MD), U.S. House of Representatives, Eighth District, praised the organizers of the Summit for their efforts to highlight "the importance of recruiting and retaining the best and the brightest in government." Highlighting the work of the CAWMSET and describing several programs aimed at advancing opportunities for women, Ms. Morella stated that there is no higher calling than public service. She announced that three of the four metro-DC Intel Science Award winners (all from Montgomery County) are female. She discussed some proposed legislation focusing on female issues, such as violence against women and maternity leave. Ms. Morella's parting words to attendees were to be a role model in our schools by telling students about our professions and about what happens at NIST. See page 67.

Workshop on Balancing Overload. Balancing career and family responsibilities is crucial to a professional woman's career choices. Acknowledging the men in the audience and thanking them for attending, June Ramos, a consultant with ZOE Training and Consulting and the Summit facilitator, began the workshop by calling for a language of inclusion. She presented skills for prioritizing and making time for career enrichment. She gave the audience a definition of "hurry sickness" that exists in our "worlds of overwhelm" and recommended some resources and references for healing. Telling the audience that they must do things differently and that they must be proactive, Ms. Ramos said, "Nothing changes, if nothing changes." See page 50.

Session to Develop Recommendations. During the afternoon session of the workshop, the Summit attendees divided into smaller groups and brain-stormed recommendations about concerns to NIST SET women. For details, see the summation by Dr. Nielsen, page 127; and the section on Observations, Resources and Recommended Actions, page xii.

\section{THE SUMMIT - DAY TWO}

Ms. Connie Chang, President of NIST's Committee for Women, opened the second day of the Summit by sharing with the audience the origins of Women's History Month and providing her observations of highlights of the first day.

Panel sessions on coaching, mentoring, community outreach, and pipeline were key agenda items for Day Two of the Summit.

Coaching. Pat Clarke Battle and Tim Wright presented "The ABC's of Coaching." Both panelists are presidents of their own consulting companies as well as veteran coaches in the human resources profession. Dr. Battle said coaches take the roles of sounding board, cheerleader, agitator, mirror, partner, and guide. She referred to a coach as a "hired gun" who is part of your support system. Mr. Wright called coaching a form of "scotch guard" or "bullet proofing" and an aid to resolving "career confusion." He gave advice on three questions about coaching. The questions were: 1) Can coaching make a difference in your life? 2) What is a good coaching relationship? 3) What good is a coaching relationship? Dr. Battle and Mr. Wright distinguished the ways mentoring and coaching are substantively different from each other. See pages 76 and 83 .

Mentoring. The founder and director of the first NIST SURF program, Dr. David S. King, described the birth of the program and gave a short history of it. Dr. King told the audience that "one person can make a difference." He encouraged more mentoring at NIST and urged mentors 
to adopt the philosophy of "it's more important to be committed and dedicated than to be just like me." See page 91.

Informing the audience that the transformation of the image of women in the SET profession is still a major issue, Darlene V. Floyd stated a Barbie Doll that "hates math" is being marketed. Ms. Floyd cited many obstacles to improving the situation, including "opportunity"- -being in the right place at the right time. For example, men can network with other men on the golf course, whereas equivalent opportunities for networking do not generally exist for women. According to Ms. Floyd, statistics show that women leave science careers about three times more often than men. Another obstacle is the lack of "a sense of belonging" because women scientists are in a career where few exist, leading to feelings of isolation and exclusion. Internalized doubt-being told so often that you can't-is another barrier. She also mentioned that sexual harassment still exists. Mentoring is seen as one of the most effective ways to help advance, unify, and help overcome these obstacles. See page 97.

Ms. Bettie White, the former Director of NASA's mentoring program for historically black colleges and other minority serving institutions, provided an agency-wide view of mentoring. She told attendees that 25 percent of the NASA astronaut core is female, and 16 percent of the scientific staff are women. Ms. White said that NASA has a model mentoring program, committing nearly $\$ 85$ million in FY02 to mentoring and educational outreach through its Minority University Research and Education Division (MURED). She applauded NASA for its visionary administration and focus on investment in its future workforce. Her advice for setting up a mentoring program is a five-step approach: 1) have specific goals, 2) create a balance of structure and informality, 3) encourage a diversity of participants, 4) sponsor a variety of activities, and 5) perform measurement and evaluation. She pointed to the American Association of University Women and the Association of Women in Science as two excellent sources of information on mentoring. See page 104.

Pipeline and Community Outreach. Dr. Julia V. Clark, Program Director at the National Science Foundation and a Congressional Fellow assigned to the office of Congressman Robert Etheridge (R-NC), concurred with other Summit presenters on the under-representation of women, minorities, and persons with disabilities in scientific occupations. She told the audience that at age 9, boys and girls demonstrate the same proficiency for science and math; however, by age 13, a significant difference is apparent. Girls stop taking advanced courses, leading to a loss of confidence and less interest in science. A key point Dr. Clark made was that the classroom atmosphere makes a difference. She gave a scholarly view of how Congress has reached out legislatively to SET women. See page 112.

Ms. Jonetta Russell spoke about the value of scientific internships for students. At the end of 2001, Ms. Russell retired from the Montgomery County school system after 45 years in the classroom as a science teacher. For many years she taught at Montgomery-Blair High School, a designated magnet school for science and computer science and the nation's leading high school for Westinghouse finalists, renamed as Intel finalists. She told the audience how she overcame teacher shortages, class size, money, scheduling, space, technology, curricula, and ethics issues to produce a monopoly of Intel finalists. She also shared information about the F.I.S.T. (Females in Science and Technology) Program. The county public school system has been placing SET high school interns at NIST since 1980. See page 117. 
Concluding Remarks. Dr. Katharine B. Gebbie, Director of the Physics Laboratory, closed the Summit. She was introduced by graduating high school senior Ms. Radhika Char, who shared some observations of her own as an aspiring scientist. See page 141.

Using her experience at an international conference in Paris earlier in the previous week, where the topic of women in science was being discussed, Dr. Gebbie recounted stories of women scientists from other cultures who face even more daunting challenges and barriers. She concluded that American women scientists can be thankful about many things and that the future is bright for them. See page 143.

Observations, Resources, and Recommended Actions. As part of the two-day summit, attendees joined small breakout teams to discuss concerns, to offer observations and to make suggestions that could lead to an improved NIST. To kick off the discussions, attendees were reminded of issues that had arisen during the earlier presentations. Groups were told they could discuss any concerns, and they were asked to produce a list of issues as well as ideas for addressing them. Reports were collected from each team.

At the conclusion of the Summit, Dr. Fran Nielsen summarized the ideas and suggestions received from the breakout discussions. (Note: Boulder attendance was via videoconferencing with NIST Gaithersburg, and the Boulder breakout team report was received after the summit concluded. Boulder input is included in the information below.)

The ideas suggested by the Summit breakout teams cover a broad spectrum, but they can be loosely grouped into observations, resources available now, and recommended actions. Some issues were described without any accompanying recommendation for action; these are labeled "Observations." Some suggestions were made that already have been implemented; these are labeled "Resources Available Now." Finally, those ideas not already captured have been listed under "Actions for Improvement." Some of the actions are recommended for NIST as an organization and some are suggestions for personal improvement. The ideas generated by the breakout groups are presented in their entirety. No attempt to prioritize the ideas was made.

Observations-These comments reflect the opinions of the members of the breakout teams. No recommended actions were given to cover these concerns; however, they are significant issues that NIST should address.

- Leadership and management skills are not prized as keys to advancement.

- The NIST culture is conflict-averse (male-female).

- The NIST culture is one where employees stay "forever" or leave early so the culture does not really change.

- No chain-of-command exists for decision-making.

- Part-time workers both feel and are treated like "second-class" employees.

- Some managers need "socialization skills."

- It is difficult to accomplish meaningful work with so many demands for seemingly "busy" administrative work.

- Very few men attended the Women's Summit, yet the concerns expressed by attendees demonstrate that these are not just women's issues. 
Resources Available Now-These suggestions or comments indicate that some employees are not aware that resources or procedures are already available, or that the solution does not adequately address the issue/concern, or that the action is not uniformly implemented across NIST.

- A NIST criteria for staff excellence appears to be advanced degrees. While some OUs have broad policies and opportunities for staff to take academic courses, others do not. (NIST Human Resources Division has details on training opportunities and academic coursework leading to advanced degrees.)

- Offer/teach time management. (Time management courses are offered at NIST. This course would be counted toward the requirement for employees to take 24 hours of training per year.)

- Offer communication training for all levels of employees. (Several communicationsrelated courses are offered throughout the year. The Effective Communications course, taught as part of the Leadership/Management curriculum, is open to all NIST staff.)

- Offer division-level diversity training (e.g., some divisions in EEEL). (Diversity training is open to all NIST staff.)

- Specify NIST-goals to create equity and accountability. (The make-up of the NIST workforce, goals for achieving appropriate racial and gender representation, and deficiencies are cited in regular reports produced by the NIST Civil Rights Office. NIST management receives these reports, and staff can request copies.)

- Make data available about women and minorities and require managers to review it. (Periodic reports are made by the NIST Civil Rights Office, and NIST management receives these reports.)

- Make ranking information available. (Ranking about self is available to employees. This information is available from NIST Human Resources and from the ranking official.)

- Give points of contact for discussion concerns about pay and rank discrepancies. (Contact information is available on the NIST Human Resources Web page.)

- Make requirements/guidelines for promotions available. (Some OUs do this explicitly, i.e., in writing.)

- Create specific, step-by-step guidelines and mentoring programs. (NIST has a mentoring program for support staff.)

- Structure mentoring program with women a part of it. (NIST has a mentoring program for support staff.)

- Develop individual performance plans to include task for promotion and commitment from management. (Some OUs do this.)

- Link a new employee with another employee (non-supervisor) to "show them the ropes." (A NIST Human Resources Division "buddy system" exists. The hiring OUs are asked to assign a buddy to new employees. One of the responsibilities of the "buddy" is to escort the employee from the new employee orientation session to the workplace. Further, the ITL Diversity Committee has designed a "buddy checklist" that covers key information to pass along to new employees.)

\section{Actions for Improvement (NIST)-}

- Communication remains an issue at NIST. Summit attendees watched an excellent and entertaining video about communication differences among men and women.
- Recommended action: Have all NIST employees view the Pat Heim communication video. 
- Recommended action: develop/obtain tools for improved dialogue.

- Recommended action: hire/contract for a communication specialist who would be available as a resource for those who might want help in dealing with and/or understanding communication issues.

- A NIST criterion for staff excellence appears to be advanced degrees. While some OUs have broad policies and opportunities for staff to take academic courses, others do not. While the HRMD has information about various degree programs, consistency and opportunity to take advantage of these programs vary.

- Recommended action: create specific programs to support current NIST employees seeking advanced degrees (e.g., consider time, compensation).

- A NIST criterion for staff excellence appears to be advanced degrees, yet many excellent employees and potential employees have learned through experience rather than education.

- Recommended action: hire more non-PhDs to increase diversity and promote from within.

- Resources and funding are always issues. The NASA example shows that legislation can help. NASA has legislative funding for awards and incentives to universities that encourage improved SET relationships.

- Recommended action: use legislation and funding to promote SETs.

- Knowledge is power; however, many individuals do not know where to turn for personalized career advice.

- Recommended action: create a career-counseling center at NIST.

- Recommended action: NIST should explore the use of coaches.

- It is best if all employees have some diversity training, not just those who choose to go. Some people choose not to attend diversity training.

- Recommended action: include diversity training in all performance plans.

- Pay and ranking discrepancies exist.

- Recommended action: ensure that divisions receive the feedback of the recent statistics on ratings and pay increases and implement actions to eliminate the discrepancies.

- Some NIST OUs are doing the right things and doing them well. These experiences and "best practices" should be shared across NIST.

- Recommended action: OUs should document "best practices" for professional development; these should be publicized and shared across NIST.

- Experience is a great teacher, and developmental assignments are key to career growth.

- Recommended action: provide more opportunities for assignments in outside details as well as in other parts of NIST.

- Reprogramming and reorganizations are inevitable; however, there must be better ways to match people with new programs and organizations.

- Recommended action: enhance NIST reprogramming efforts through creation of an employee database to match skills and willingness to work with new or current efforts in other parts of NIST.

- Networking and a sense of connection is important.

- Recommended action: the DPO should invite a representative from an NRL Women in Science and Engineering (WISE) Chapter to describe the purpose of its organization and its functions and NIST should consider establishing a WISE Chapter. 
- The Boulder campus is a part of the NIST family.

- Recommended action: future Summits should be held simultaneously with Boulder or the venue should alternate between Boulder and Gaithersburg.

Actions for Improvement (individuals)_-

- An important developmental opportunity is participation in professional societies and boards.

- Recommended action: staff are encouraged to serve on professional boards and committees.

- Communication is important and shared knowledge is power.

- Recommended action: share success stories; advertise role models.

- Many women (and men) appear to be victims who do not realize they have choices as well as a responsibility for shaping their career.

- Recommended action: get out of the comfort zone and take responsibility for your own career.

- Recommended action: learn to say no, appropriately.

- Recommended action: be assertive and tell your supervisor what you want-you might get it! 


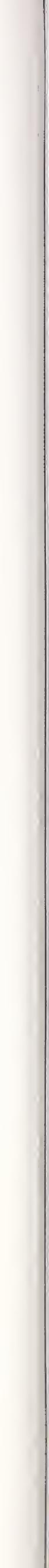




\section{WELCOME, INTRODUCTIONS, AND OPENING REMARKS}

\section{Sol del Ande Eaton, Diversity Program Manager \\ NIST}

Good morning, Everyone. Buenos dias. We are delighted that you accepted the invitation to come and participate in NIST's first Women's Summit. Women's History Month is about celebrating the achievements of women throughout our history, while recognizing the equally significant obstacles that they had to overcome along the road to success, as we honor the past, celebrate the present, and concentrate on the future.

Especially after the tragedy of September 11, we must plan on the choices we make today, at this Summit or with any other activity that is related to improving the future. We must take into consideration the enormous impact on the destiny of our daughters, our granddaughters, our sons, and our grandsons. We must rededicate ourselves to forging a society in which gender no longer predetermines a person's opportunities or stations in life. This Summit is about getting a lot of information and using it to benefit all of us. And this Summit is the product of the support that many organizations here at NIST have given us.

I love working here at NIST, because when we do things like this, everybody really, really helps. It is just like a big family. I want to thank all of the people that helped make this possible-there are too many to list, but they are in your program. And the introductions will be very short, because the brochure will give you all the information about all the extraordinary talent that we have here today.

It gives me great satisfaction and a great pleasure to introduce to you our new director, Dr. Arden Bement. He is the twelfth director of NIST, and he was sworn in just last December. So we think that he is a newcomer here-but to us NIST employees he's no stranger. He's been doing a whole lot for NIST from way back, folks! And we thank him for that and we thank him for this conference. And I also want to tell you that Jorge Urrutia ${ }^{4}$ unfortunately cannot be here today, but he sends his regards and he also took a big part in developing this conference. So let's welcome Dr. Bement him with a nice, warm applause, because he does deserve it.

${ }^{4}$ Jorge Urrutia, Director of Administration and Chief Financial Officer, the sponsoring department for the NIST Women's Summit. 


\title{
WELCOMING PRESENTATION
}

\author{
Dr. Arden L. Bement \\ Director, NIST
}

[Applause] Mucho Gusto. Good Morning, everyone, and welcome to this historic summit. I also wish to extend a special welcome to our Boulder Labs. I was looking for them on the video. It's 6:30 A.M. out at Boulder, so they may be tuning in a little bit later.

I'm very pleased to be part of this event. You'll notice on your program that Dr. Nancy Hopkins from the Massachusetts Institute of Technology also welcomes you. Dr. Hopkins was part ofwas actually responsible for-a study on women faculty in science at MIT. ${ }^{5}$ Unfortunately, she is unable to be with us this morning but she sends her personal welcome. I'm especially honored to join with her in wishing you a very successful summit.

At my confirmation hearing in December [2001], before the U.S. Senate, I remarked about the character of NIST, and I think some of the comments I made at that time are worth repeating. I believe that NIST continues to be a young organization which has the ability not only to think "out of the box" fundamentally but also "out of the Beltway" in terms of our ability to work through our extended networks and active collaborations with industry, academia, and other government agencies.

NIST also has a tradition of adapting to changing environments through its focus on constituent needs. This ability is demonstrated by the many prestigious prizes won by our NIST scientists and engineers as well as prizes won by others based on NIST's advances in science and technology. I think our staff has enabled as many Nobel prizes as we won and perhaps even more. And it's a great privilege to be associated with an institution that now has two Nobel laureates, Bill Phillips and Eric Comell.

Yes-to NIST's success is a strong and diverse workforce. Continuing to strengthen NIST's diversity policy is a top priority for me as Director, and I've just included that as one of my key messages on our Web site. We consider diversity to include all characteristics and experiences that define each of us as individuals. We consistently work to define diversity and align efforts across NIST in a focused, agency-wide program. Our goal in managing diversity is to strategically create systems and processes that allow every worker to make a meaningful contribution to the NIST mission, and to be recognized for that contribution. We aim to foster an environment where trust, respect, and understanding are as important as our technical accomplishments.

Throughout NIST's 100-year history our women scientists and engineers have played an important role in helping us fulfill our mission. Women like Evans Hayward, Marilyn Jacox, Johanna Lavelte-Sengers, Mary Natrella, Charlotte More Sitterly, to name just a few. And if you visit our Hall of Fame, which is right outside our cafeteria, you'll have an opportunity to see

\footnotetext{
${ }^{5}$ Women in Academia. Written testimony by Dr. Nancy Hopkins, MIT, to National Commission for the Advancement of Women and Minorities in Science, Engineering and Technology, 7/20/99. Copy of testimony and report available from NIST Diversity Program Office, 301-975-5481 or by e-mail: sol.eaton@nist.gov
} 
what their contributions have been. And of course women on our staff today continue to carry on the fine traditions set by these earlier NIST women. This is especially exemplified by Dr.

Katharine Gebbie, who has just returned from Paris where she attended an IUPAP ${ }^{6}$ meeting, and she was one of the international representatives of women in science, and there were about 200 to 300 women from around the world. So we're very proud of her, and she's a living testimony that women have a promising future at NIST in science, engineering, and technology. We also are very proud of several mentoring and outreach programs at NIST, including the Summer Undergraduate Research Fellowship, known as SURF, which Dr. Gebbie has also pioneered and fostered, started in 1993 to help train future generations of scientists and engineers, with special emphasis on women and minorities. Last summer the program included 64 students from 31 different institutions of higher learning.

We have an ongoing relationship with Montgomery County Public Schools, including Montgomery-Blair High School, the county's magnet high school for science, math, and computers. FIST, which stands for "Females in Science and Technology" at Montgomery-Blair High School, is a program for all seventh grade girls, and many of its instructors are high school seniors. This program is more than a decade old, although Montgomery-Blair has been placing interns with us since 1980 . Tomorrow you will be hearing from Ms. Jonetta Russell, the recently retired coordinator of the Magnet School Program at Montgomery-Blair. This high school holds the nation's record for semifinalists and finalists at the Intel Science Talent Search, and I was at their annual banquet last evening, and I can report to you that 15 of the 40 finalists from around the United States were women. Fifteen out of 43 were from the State of Maryland, which is quite remarkable, considering how many States compete. And among the 10 finalists who won prestigious scholarship awards in amounts up to $\$ 100,000$, of those 10 , three were women. So you have every reason to be proud.

Another program, Adventures in Science, which NIST helped sponsor, was started 21 years ago, and is a region-wide program that provides students with first-hand experience in their search methods, and also makes presentations about their science projects. Examples of these projects range from hard science such as "Calibration of Forced-Feed Back Controllers," to the influence of science on everyday factors like "Sports-Drink Effects on Performance" and "Which AntiBacteria Sanitizer Has the Best Effect?" to, finally, the fun of science, namely, "Does Ketchup Have Bug Parts?" I would have enjoyed seeing what came out of that project! [Laughter]

We are very pleased to have as a keynote speaker for this summer, our own Congresswoman Constance A. Morella of the Eighth Congressional District. Congresswoman Morella, a longstanding member of the U.S. House Science Committee, sponsored legislation that established the National Commission on the Advancement of Women and Minorities in Science, Engineering, and Technology Development.

As the Summit continues today and tomorrow, I join the Summit Planning Committee in urging you to attend the seminars. Some of these have fascinating topics like "Negotiating Program Overload and Change"-I would personally benefit from that seminar! [Laughter] "The ABC's of Coaching," and "Pipeline and Community Outreach," all very important topics.

${ }^{6}$ International Union of Pure and Applied Physics 
And finally, I know that many of you have overcome significant obstacles to further your careers. Today we salute you for your creativity as visionaries, for your courage as pioneers, and for your gifts as mentors. I am proud and humble to be in your company, and I wish you every success in your meeting today and tomorrow. Thank you. [Applause] 


\title{
GREETINGS FROM PRESIDING CONSULTANT JUNE RAMOS and INTRODUCTION OF DR. KATHIE L. OLSEN
}

\author{
June Ramos \\ Consultant, Zoe Training and Consulting
}

Good Morning! How are you doing? Great? Good! My name is June Ramos, and I am from Evergreen, Colorado. I had the opportunity to meet a few of you at the Boulder campus, and I was promoted this morning by Patricia Fenn who said I was the presiding consultant, and I thought, "Wow, does that sound good!" I don't know what that is, but I'm going to do it! I had an opportunity to meet Sol in Boulder, and we talked about this conference, and I was struck by the words of Jim Collins who wrote the book Built To Last. He said that organizations, both privatesector and public-sector organizations, that are focused on a clear set of values are the ones that will succeed. So, diversity, the focus on respect in the workplace for women and minorities, and other people, and everybody will survive at the highest levels because of that success.

My job here is, in addition to presenting that information about program overload and how to negotiate the changes that you are facing, is also to introduce several of our great speakers. My instructions from Sol were keep it short, which I'm delighted to do, because I think the biographies and the speakers will speak for themselves, and I don't want to take away from the content that they have; but I do want to wish us all, for the next two days, great success in a great conference; and I'm excited about the agenda.

I have the honor of introducing Dr. Kathie L. Olsen, and she is also in your biography and in all your materials, and she wanted me to clarify that there is an intent for her nomination; that she is not a formal nominee yet, and there is a fine distinction. But we wish you luck in that, and Dr. Olsen has been studying the biological and chemical differences between men and women in the brain; and gender differences, so I'm looking forward to her presentation. She has co-edited a book entitled The Development of Sex Differences and Similarities in Behavior. Please put your hands together to welcome Dr. Kathie L. Olsen. [Applause] 


\section{THE NATIONAL PICTURE}

\section{Dr. Kathie L. Olsen, Ph.D \\ Chief Scientist, NASA \\ And Nominee, Associate Director, White House Office of Science and Technology Policy}

Before I start, I want to thank Sol Eaton for organizing the first meeting. What I would like is, maybe in five or 10 years, that we're not going to have to organize meetings like this, because it will be so commonplace that we have men, women, under-represented minorities, and handicapped people within the workforce, and so it is not even an issue.

I also want to thank Myra Montrose, who is also here from NASA. She has worked in my office on these issues for NASA. What I'm going to talk about today is a Commission ${ }^{7}$ that I had the honor to serve on; and Myra Montrose was actually the representative when I couldn't make it. This was a commission that Representative Connie Morella has started-she made a statement that is so incredibly true: "Until our scientific and technological workplace reflects our diversity, we are not working to our potential as a Nation."

What I'm going to do is show some data slides, which really take this home. The Commission was established 1998. The mandate was to research and recommend ways to improve the recruitment, retention, and representation of women, under-represented minorities, and persons with disabilities in science, engineering, technology, education and employment. We have had so many reports, and we had so many studies, and we're still [lacking diversity], and the question is, "How long do we have these reports that we need to have more women and under-represented minorities, et cetera, in terms of the science and technology workforce?"

I was very impressed with this Commission because they really took it to heart, looked at all the other reports, and wanted to think out-of-the-box, wanted to do something different, so it is not just another report that is filed in the library.

The Commission spent an entire year listening to experts in the field, coming up with their own ideas. And I saw a number of the written testimonies that I think are just outstanding, and they actually finalized their report-and it is on the web-last year. But why was this Commission set up? This is getting back to the statistics and Connie Morella's statement. Here are the jobs requiring technical skills in the next few years, and if you look at our future, you see it really is based on science and technology and in terms of computer science, engineering, the health fields; these are the potential jobs of the future. Employment in science and engineering is expected to increase by almost four times the current rate. Yet if we don't have women and underrepresented minorities as part of this workforce, we're not going to be able to fill those positions.

\footnotetext{
${ }^{7}$ National Commission for the Advancement of Women and Minorities in Science, Engineering, and Technology. Approved by U.S. Congress by Public Law 105-255, 10/14/98. Support assigned to the National Science Foundation. Copy of Commission's report, Land of Plenty, available at NIST Diversity Program Office, 301-975-5481; or by e-mail request to sol.eaton@ nist.gov or from National Science Foundation, 703-306-0597; or www.nsf.gov/od/cawmset.
} 
Here is another example of the workforce, and this is science and engineering. You can see in terms of the total workforce there is very little difference in terms of men and women. When we look at science and engineering we see a major difference in those two categories. And when you look at the potential jobs that are going to be available and then you see this difference in representation, it is kind of scary.

So what did the Commission recommend? They recommended looking at three different stages. Number one, at the pre-college education; and one of the major points is really focusing on the teachers, and having teachers knowledgeable about science teaching the students. I don't remember in seventh and eighth grades any science in my curriculum. In fact the only thing I remember about science in my entire grade-school career was the sixth-grade science fair that I participated in. My mother was the one who helped me in that. And that is so important, because I wasn't even recognizing science as something of interest during those years between first and eighth grade. This has actually changed, but we still need to work on this in terms of our precollege education.

Again, here are some figures that look at men and women in the science track, and we see in ninth grade there is really, again, not that much difference between boys and girls interested in science. By the time we get to science in college there is a major drop. And when we look at the bachelor of science and Ph.D. in science, I also want to point out that these statistics are scary in another way. In fact, there are so few men, as well, now going into the science fields. This is a point I want to make: it has always been an issue for women and under-represented minorities, but today it is also becoming an issue for men as well. And again, looking at the positions, the occupations that we will need to fill.

But I want you to know that there are differences between men and women, so I have this slide. This is actually from a 1930's textbook, and I include this when I talk about differences in males and females. It is very clear that the back of the male is very different from the front of the female. And so that is a difference that we have to take with us, as we continue with this presentation.

But the Commission, you know, has three parts: one, they're looking at K-1 through K-12, and they're looking at K-1 through K-9, but they're also looking at those high school years. And they feel that we need to get individuals prepared so they will be able to face a curriculum, and look at science and education-science for a profession.

This is a picture of my high school-I want to pause a little because I was thinking, "What about my own high school career?" Every day I'd walk through this door, and I'd look up and see that it says, "What we are to be, we are now becoming." Actually when I go back home to visit in Oregon, I look at this. And I ran into a friend of mine from high school-it was really interesting. I was giving a talk as chief scientist to the AAU, and he is an astronomer at the University of Texas in Austin; and he follows me up and he says, "Kathie Olsen?"

And I said, "Yes."And he said, "Kathie Olsen from Portland, Oregon?" And I'm looking at this guy and I go, "Yes." And he goes, "Kathie Olsen from Portland, Oregon and Cleveland High School?" And I'm looking at this guy and I go, "Yes." He says, "I'm Dan Lester!" And I'm going, "Yes?" And he says, "I was in your math class, your science class, your French class, your English class!" And I'm looking at this guy and I think, who is he? And I say, "Oh, you're little 
Danny Lester!" And he turned and he said, "We were all little back in high school!" And I said, "No, Danny, you were little! I was the same height I am now."

And he didn't skip a beat, and he said, "In my wildest imagination," he said, "when you talked to us last year, I just couldn't believe that you were the chief scientist at NASA!" And I looked at Dan-and I called him "Danny," and now the head of space science calls him "Danny," so he's a little upset with me on that one-but I looked at Danny, and I said, "After Mr. Miles and Mr. McCullough, it's amazing that any of us from our high school became scientists." And he agreed and he said, "You know, I wanted to be an astronomer since I was six years old, and I didn't let that stop me." And what was interesting is, I hated science class but I turned to him and I said, "You know, what would be more surprising is if I and Ellen Culver, the only other woman in the science class, were not scientists."

This was a very large school. We had over 2,000 kids from ninth grade through senior year. And yet, in my science class - and it was an advanced science class-it was Ellen Culver and I, and my math class included Ellen Culver and Nancy Mann and I, and that was it. And I went back again to Danny and I said, "You know, isn't this amazing?" Would it be more frightening? But Mr. McCullough coached track and Mr. Miles coached-I think-freshman basketball. And I don't think they had any science background at all. That was who was trying to get me excited about that class. It was interesting.

Here's another point-again for me it was a personal thing. I'm from a poor family, and my brother was two years ahead of me in Portland, Oregon, and he was accepted at Columbia University. When I came to my counselor during my senior year, she said I should go to Portland Community College. And I kind of looked at her and I said, "Wait a second. I'm in advanced math. I'm taking calculus my senior year, and my brother did not. I have better SAT scores than my brother. I have better grades than my brother. And my brother is going to an ivy-league school." And she said, "Your brother made it. That's what was important for your family. And you should think about your family and go to Portland Community College."

Obviously, I didn't listen to her, even though Portland Community College is excellent-it is now Portland State University. But maybe you're thinking if I was a different kind of woman, I might have listened to her, I might have been intimidated. What I did is I said, "Okay. I needed a full scholarship." And I applied to various schools, and Chatham College in Pittsburgh, Pennsylvania, which is a small women's college, gave me a full scholarship. And that opened my door to science, because it turned out it wasn't high school that helped me. But just think, if high school had already stimulated my interests in this area. Ellen Culver, the other woman, actually has a master's in physics, and she's the head of software at Intel; and the guys in our class-well, Danny is an associate professor, and some of the other ones I see around when I'm visiting Portland. But it's something to take note of in terms of some of the issues.

Here is the percent of women that are enrolled in college, and you can see that women now are more than 50 percent of the individuals in college, and so this is outstanding. But we still have a problem; again, you can see the percent of women is moving up, in terms of college, in terms of getting bachelor's degrees. But if we look at the number in terms of science and engineering, it still is reduced, and if we look even further, at the number of Ph.D.'s, again it is rising, and this is outstanding, but it still is not reflecting the increase that we now see attending college. 
Here's another statistic-and again I think it is outstanding in terms of the number of women that are now entering the professions. But when we actually look at the percentage in math, although it is rising, still it is only 20 percent, and physics it is 22 percent, in 1995 . And in life sciences we are doing a lot better.

In my field of neuroscience we're about 30 percent or 40 percent women, yet I see a lot of issues with our key meetings. Women are not the speakers, they are not the chairs of the sessions, they are not being promoted. When I was at the National Science Foundation (NSF), we were responsible for some science and technology centers, and NSF had a policy in biological timing that, depending upon the number of women in the field, if NSF was going to sponsor the meeting, there had to be representation in terms of speakers and chairs and sessions. And we took that very seriously. I had an opportunity to review a proposal that included 75 invited individuals. And in a field that is about 30 percent women, of the 75 , there were only three women, and two of them were not from the United States. We did not support that program. The next year they came back and they actually paid attention, because money was associated with their having to think, and I believe that is very important in terms of biological timing. It was an area where I was director of the science and technology center. The first meeting they had was all males. I mean, it was all males, and I walked out of the meeting, flew back early, and faxed them a message. And when they were sponsoring the Society for Biological Timing, I was told that when they were developing the makeup, a lot of people would say, "Kathie Olsen will kill us. Start thinking." And it was very interesting that at their next meeting they had the representation and now, it is not that, "Kathie Olsen will kill us." Now it is basically-it's not even a thought. Now the society president is Dr. Rae Silver from Columbia University, and she's doing an outstanding job. But it took that initial push which now is not even an issue anymore. And that's where we want to see women and minorities in the science and technology workforce.

Again, in terms of doctorate degrees, in terms of science and technology, in terms of men and women you can really see the dramatic difference between the two groups. When I mention, too, the fact that we also have another problem and that is that males [*?] are not pursuing careers in science and technology. And this is also something that we need to be addressing when we look at issues of involving women and minorities.

Here's the example of electrical engineering. More people now are majoring in parks, recreation, leisure, and fitness than they are in electrical engineering. If you are not frightened by this, you should be.

So back to the Commission-the Morella Commission. They looked at K-1 through K-12 in terms of the college years, but also looking at professional life and. This is the year of the Ph.D. Again, you can see this is the percent of men and women who are married. You can see now it is converging. However, what you see in terms of full-time employment is men, whether single, married, have older or younger children, does not affect their employment rate. But as we look at women who have younger or older children, we see they have to drop out of the workforce.

Today, Myra Montrose's daughter has the flu, and it was very lucky that her husband.was able to stay home so she could attend here. But it does put that pressure on women, and it is something that I think that we need to really consider in terms of full-time employment. We have to look at these issues. 
Another issue I'm amazed about is this statistic from 1997-this is the difference in salaries. There should not be a major difference between men and women. I was telling Myra that when I was an assistant professor at the State University of New York at Stoneybrook, I was so excited because I was making $\$ 16,000$. I had gone up from $\$ 10,000$ that I was making from my post-doc. And I was "rich." And I was very successful. My first grant was funded by NIH. Then I went in as a co-investigator with a man. And so I had my own grant. I was co-PI on another grant. But since he was the major PI, I had never really looked at the budget of the grant. And one day he was out and we had to examine the budget, and I realized that the two post-docs, male post-docs that were being funded off the grant were making more money than I was. I was appalled. And I just went to the chair and said, "I've got a farm in Oregon, and I think I'm going there." I said, "When this gets settled, give me a call." And I walked out. By the time I got home I actually had a raise. But the problem is kind of frightening because I thought I was doing so well at $\$ 16,000$. I was so proud, and I didn't realize that I was making less than a post-doc as an assistant professor.

And it was interesting when I was moving to the National Science Foundation they offered me $\$ 50,000$, and I was so excited, and the chair of neurology turned to me and said, "You make that here! Tell 'em you need this amount," and I did, and they gave it to me. And the chairman turned and said, "Obviously you didn't ask for enough." These are the sort of issues that I'm still uncomfortable talking about, what my levels are, or what my salary is, and I tend to accept whatever they give me and say, that is really great!

Another example was at the State University of New York (SUNY) at Stoneybrook. I had just gotten my raise because of the post-doc thing, and I was being paid by this Long Island research institute. Then we did a reorganization, and now I was going to be paid by the SUNY state system, and so they were going to re-look at salaries. I was actually shaking because, as I said, I had just gotten my raise, and a lot of the men were going around saying, because they were going to have to reduce some of the salaries, "Kathie is single and I've got a family, so we need to consider this." And I turned and I said, "Your wife is an M.D., and your wife is a lawyer." I said, "I have to live on my own." I said, "I should get more money." And all these things were kind of going around. Well, it turned out that I had gone from $\$ 16,000$ to $\$ 20,000$, and when we refocused, I jumped up to $\$ 40,000$ because what I was looking at was the post-docs.

What I wasn't looking at were the other male assistant professors and, again, I'm using this as an example of things that I was incredibly naive about. Even today it is uncomfortable when I talk about salaries or what level I am or what kind of promotions. But that was kind of a shock, and I guess this is still a shock that in 1997-and you know the report from MIT $^{8}$-we still have this discrepancy in terms of the salaries. So the committee also is looking at how we help the professional woman, also in terms of identifying and establishing a body representing public and non-public sectors to coordinate efforts to transform the image of set professionals and their petitioners. And the image to science is positive. The other day I was at a session at $\mathrm{OPM}^{9}$, and one of the speakers came up to me. He is a major person at OPM. The first statement he said to me was, "I'm surprised that you are a scientist. You don't look like a scientist!" And I said, "Well, what does a scientist look like?" And I was sort of shocked about that, but I sort of enjoyed it.

\footnotetext{
${ }^{8}$ Women in Academia. Copy available in NIST Diversity Program Office: 301-975-5481.

${ }^{9}$ Office of Personnel Management, an independent Federal agency.
} 
I had an opportunity to go to a third-grade class at Ellis School in Pittsburgh. It is all girls, and they were asked before I came to draw a picture of a scientist, and every girl in that class except three drew a woman scientist. The three girls that drew pictures of boys had just transferred into that school. And I thought that was very interesting in terms of what is a scientist-what does a scientist look like, but I get that a lot.

This slide is from a textbook in the1930's, and it is hard to see, but it looks at masculinity and femininity and it actually measures it by career. And I point that out, because women Ph.D.'s are minus- 30 on the femininity scale [laughter], and the closest to us are "male inverts," and they're a minus- 20 on the femininity scale. But if you look at the femininity, domestics are the highest and then dressmakers and hairdressers and as you go down, teachers are starting to lose it, they're minus-70, and then nurses, but as women become more-the "who's who" of women, we become less feminine. On the other side we look at masculinity in terms of men, and college athletes are number one. Engineers are the top. I was giving this talk at Goddard [Space Flight Center $]^{10}$ and I said, "Where are the engineers?" And I said, "My god, you guys are the top in terms of the masculinity scale." And one says, "Well, since this is about in 1915, it is probably train engineers." [Laughter] They become less masculine because they have a personal side. But again, this is an image that we have to address, and once again, that the Morella Commission is trying to do that.

And so again, we need to identify and establish a collaborative body to continue the efforts of the Commission. I was really impressed, working with the Commission, because again they didn't want to do the same old thing. They just didn't want to put a bunch of statistics on the board. They actually wanted to do something. And so what they've done is they have developed the BEST $^{11}$ initiative-Building Engineering and Science Talent. It was launched in 2001, and all the Federal agencies including Commerce, NASA, NIH, and NSF provided funds, and I personally am watching them very closely, because I want them to be successful. This the program's progress to date. They have kicked off a blue-ribbon panel. I think we have information about best available out there. What they're trying to do is look at best practices. What works, what doesn't in K-12. That is going to be difficult, because it really depends upon the local areas, the local school systems. So we're going to have to do a lot within the states, within the cities, within the towns that you work in. People in Helena, Montana, and Boston, Massachusetts, should be able to have the same high-quality education received by everyone else in this country.

Finally - and this is the take-home lesson-this is why I am glad I am a female scientist and Myra is glad she is a female engineer. We don't die! [Laughter] Indeed, careers in science offer immortality! This was a letter to the editor that actually analyzed the number of obituaries of scientists, and it turns out that we don't die. We just keep living forever! And so, on that point, I think that is one of the good take-home lessons that we can tell women, why it is important to enter the field! Thank you very much. [Applause]

\footnotetext{
${ }^{10}$ The father of modern rocket propulsion is the American, Dr. Robert Hutchings Goddard. Goddard was the first scientist who not only realized the potentialities of missiles and space flight but also contributed directly in bringing them to practical realization. The dedicated labors of this modest man went largely unrecognized in the United States until the dawn of what is now called the "space age." In memory of the brilliant scientist, a major space science laboratory, NASA's Goddard Space Flight Center, Greenbelt, Maryland, was established May 1, 1959.
} 
As NASA's chief scientist I want you to know the number-one question that I was asked: "Was there sex in space?" I know that all of you are interested in the answer: Yes. We have pollinated a plant and got a flower! [Laughter] And we took some frog eggs and provided sperm and had tadpoles that developed into frogs. So that question that everyone wants to know, it is true sex in space. [Laughter] Thank you very much! [Applause] Thank you.

We have time for one or two quick questions. We've got microphones set up so everybody can hear your question, or speak very loudly. I'll moderate and just keep an eye on time.

\section{[Question inaudible—could Dr. Olsen provide her slides?]}

Yes, in fact, if you give me your card I will. I probably have 15 or 20 more data slides that I didn't show because I wanted to make some points. The last slide which I didn't show was actually a picture over deep space, and it said the universe is boundless and the opportunities are out there, and that is a point that I really want to leave with you know-what a fun job we all have! We need to let people know it is actually fun being a scientist and an engineer in terms of what we do.

I would like to say I enjoyed your talk very much. A couple of observations and one question. I do believe as you said that, especially for minority segments of the population, the education system is very critical, and I think of things like the digital divide, especially in urban centers. I have many friends who teach in urban schools, and I think that is a problem that feeds the other problem. And in terms of teachers, they do need to see role models. It doesn't matter whether it's male or female. My experience has been it has to be someone who inspires you to believe that you can achieve, and I don't believe that is always the case. But I was curious-in your slides you don't map the master's. Perhaps I'm thinking there is a story there between the bachelor's and the Ph.D., and I'm also wondering how much of the story as a whole was driven economically. There are many tempting salaries out there, and some people may be trading off. Does your research give you any indication of that?

Actually, I do have a backup slide that has the information on the master's. It is a little bit better than the bachelor's, and for example in engineering, where a master's, you know, is important, in terms of science, if you don't have the Ph.D., a master's barely opens up the door, becomes more of a technician. But we are making some progress there. When we weigh our choices in terms of what do you want to do, in your profession, in your career, the master's might be an excellent opportunity for you as well as you weigh that.

I also want to follow up something that you said. I told you in high school I hated science, yet I became biologist. What [changed my attitude] was my sophomore year in college, I became really fat during my freshman year in college, and my mother said I had to take some kind of PE [physical education], and the only thing that would fit in with badminton and tennis was general biology. I hated science, but I had a very strong mother, and I [laughing] looked and I said, I've got to lose weight, I've got to do it. That biology teacher was so incredibly inspiring. That teacher-such confidence, and every day learning something new, and I came to love biology, and that made all the difference. It is so important in terms of schools that we get teachers who are comfortable about science, instead of the coach of the track team. Thank you. 
I wanted to make a few quick comments. First I think that was an excellent talk, and I think you show that we clearly have a ways to go. But I was struck particularly by your comments about your high school experiences, and I just wanted to compare them to my own because I think that is pretty common, and I think we have made a lot of progress since then. For example, I have brothers and sisters, and totally different standards were applied to them in terms of what was going to happen in their careers. I went to an Ivy League school and my sisters went to secretarial school or they went to study to become nurses. And very easily they could have become doctors. My father was a chemical engineer, and yet this was still happening. We're pushed away from technical areas. In contrast I have a son and a daughter. The son decided to become a graphic designer. My daughter decided to become a chemist. And what happened was, she went to Gaithersburg High School here. And just to show the difference, nine out of the top 10 students at Gaithersburg High School were girls. And many of them were very focused in on science and mathematics and computer science. And so she went to the University of Maryland. She's a senior. Right now she's just starting to interview with graduate schools, and she just recently returned from a trip to Boston College. She wants to be an organic chemist, and they have a good program there, and she came back and she said that one of the things that they were very proud of at Boston College was that more than half people in graduate school there are women. And so, we definitely have made some progress, but it really starts probably with the culture, you know, within the society. Within the family, and what happens in the schools starting in elementary school.

I agree. And that is a good way of ending on a credible, positive note. I look forward to one day reading some of her outstanding papers! 


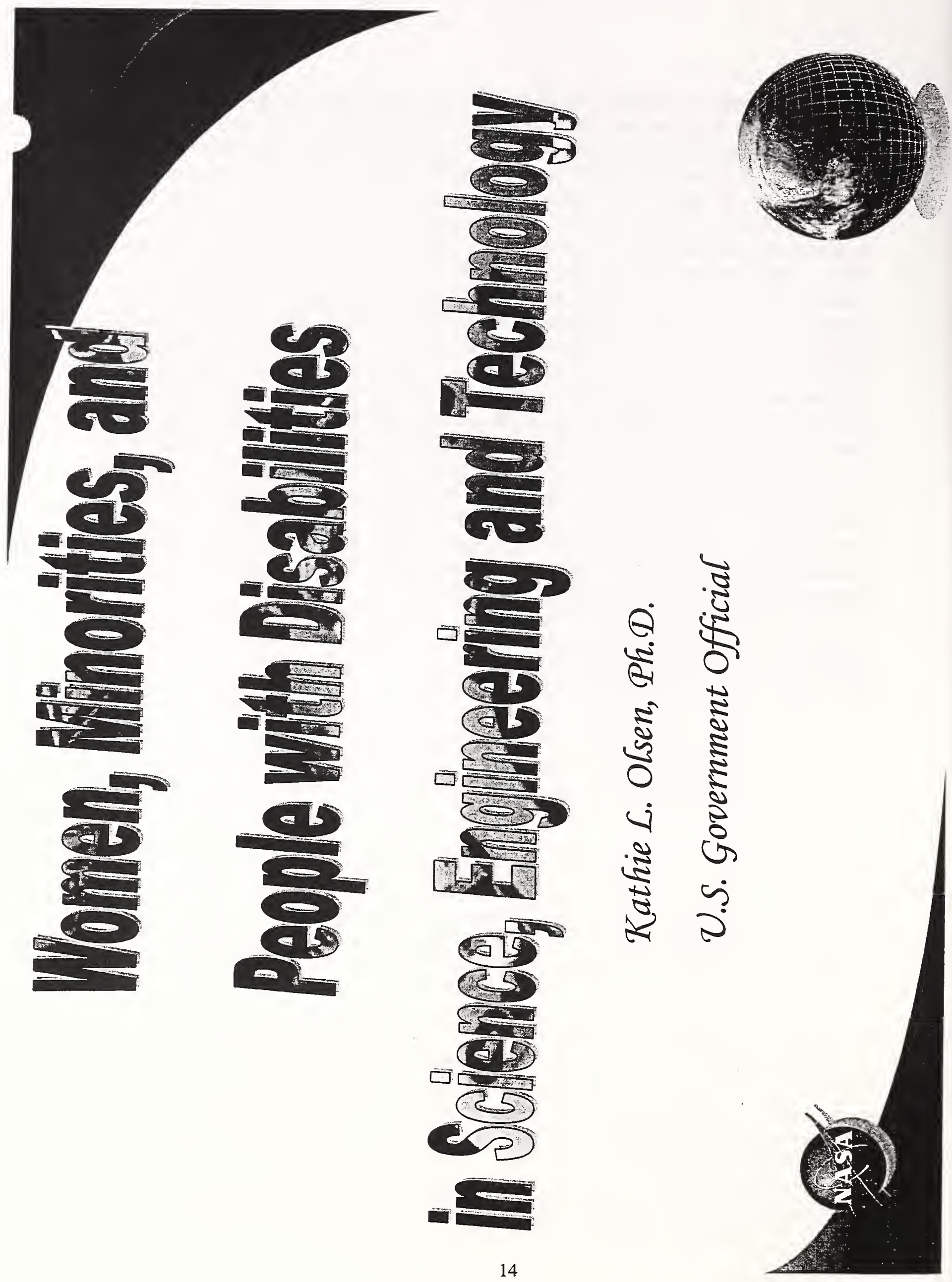



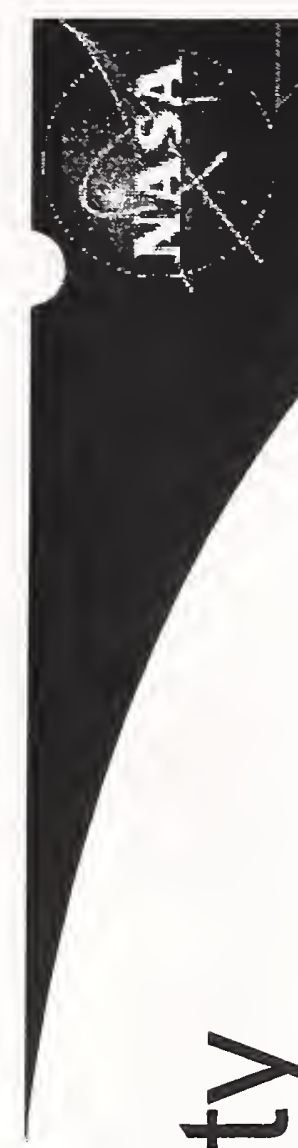

4 0

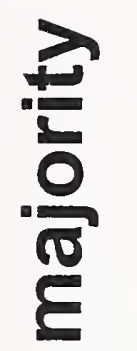

- 0 0 0

$\forall$ है

(4) 0 तै ह क

है 0 क

$\geqslant$ m 0

80

$0+$

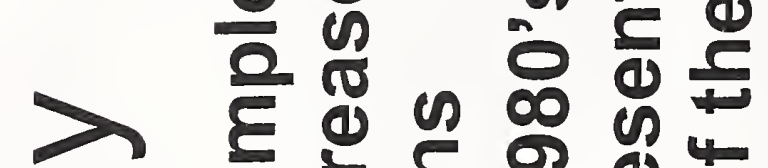

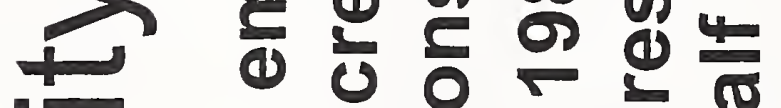

- 10 \%

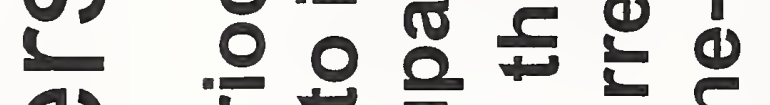

(1) $150 \frac{5}{0}$ क क है

$\rightarrow$ a d 000

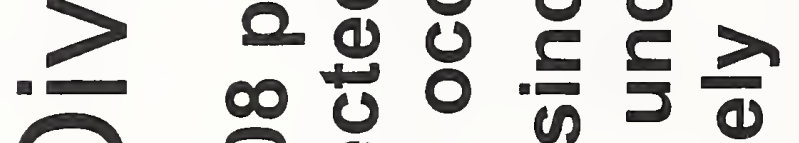

$\square$

00000

V 20

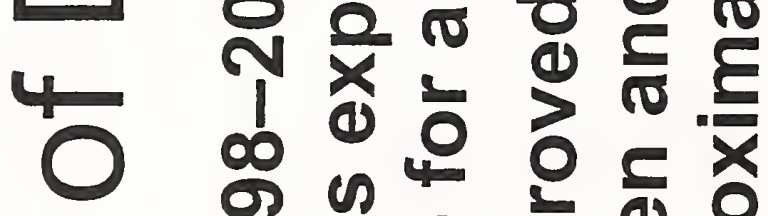

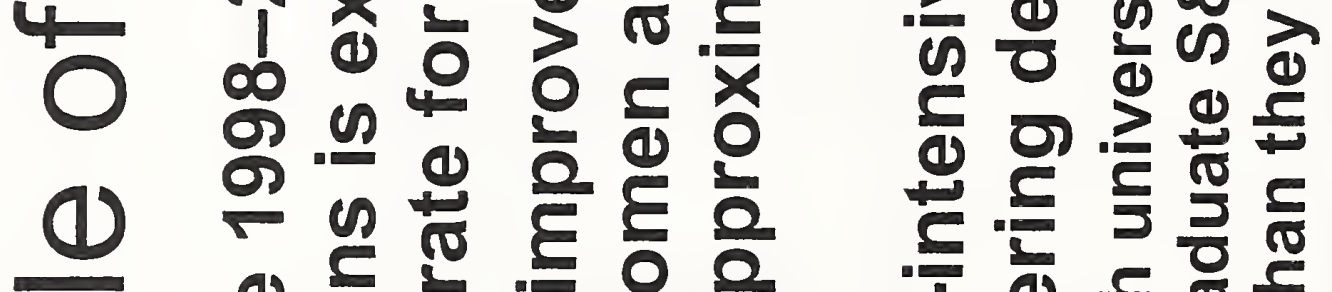

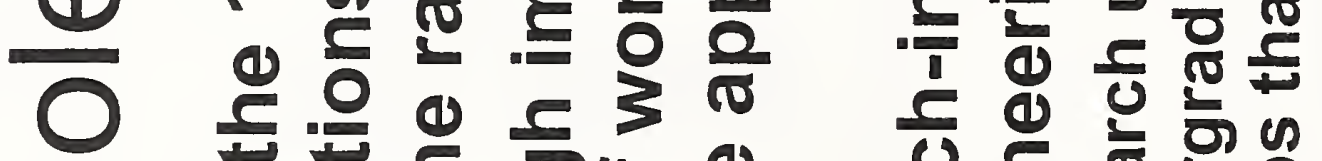

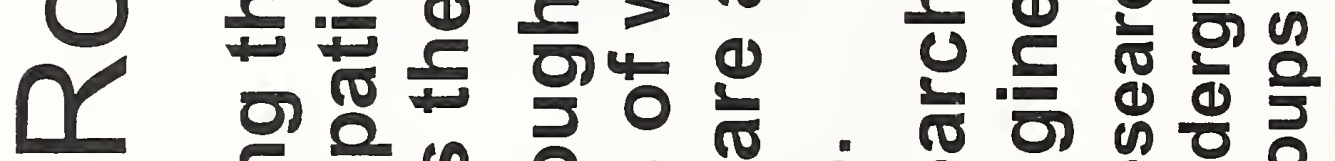

(1) $10 \%$

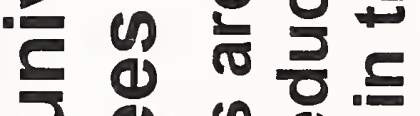

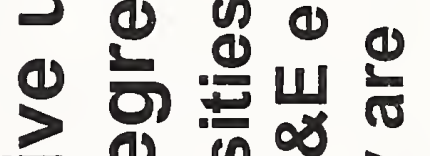

(4) ${ }^{2}$

인

- $\infty$ c

(1) $\quad 00$

(1)

3 들

0 क के क

의 0

르응

- a 000

(1) 0 क क क

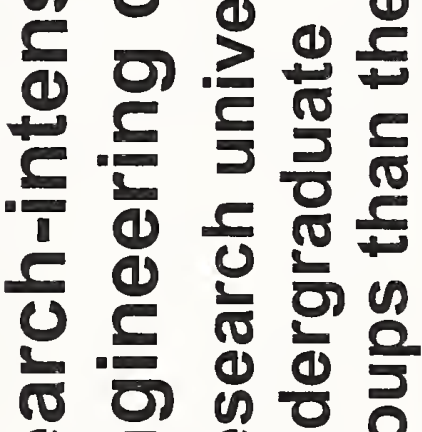

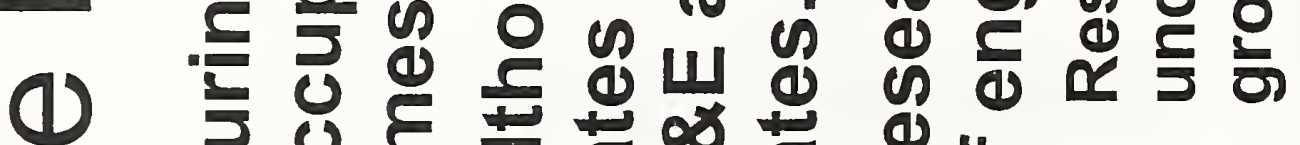

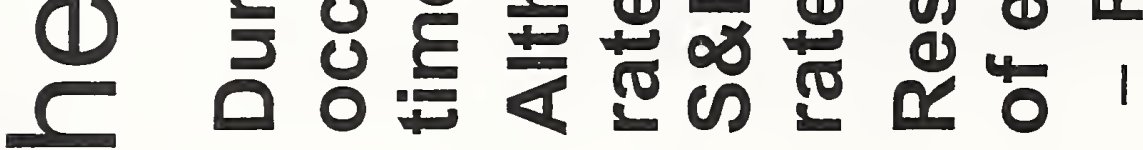




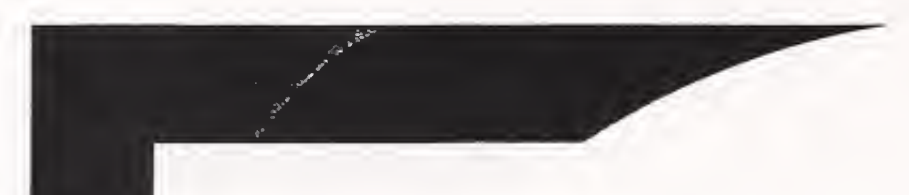

E
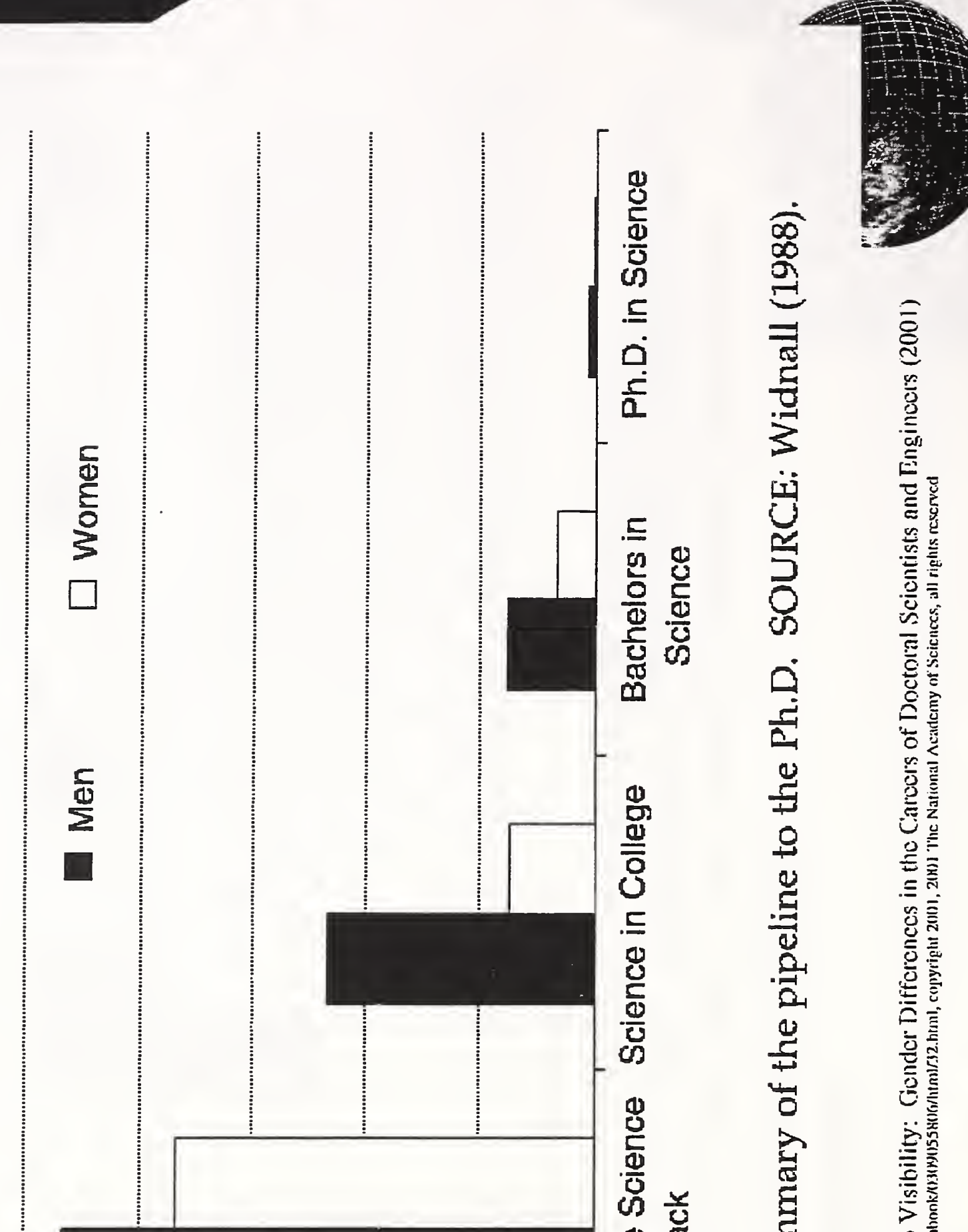

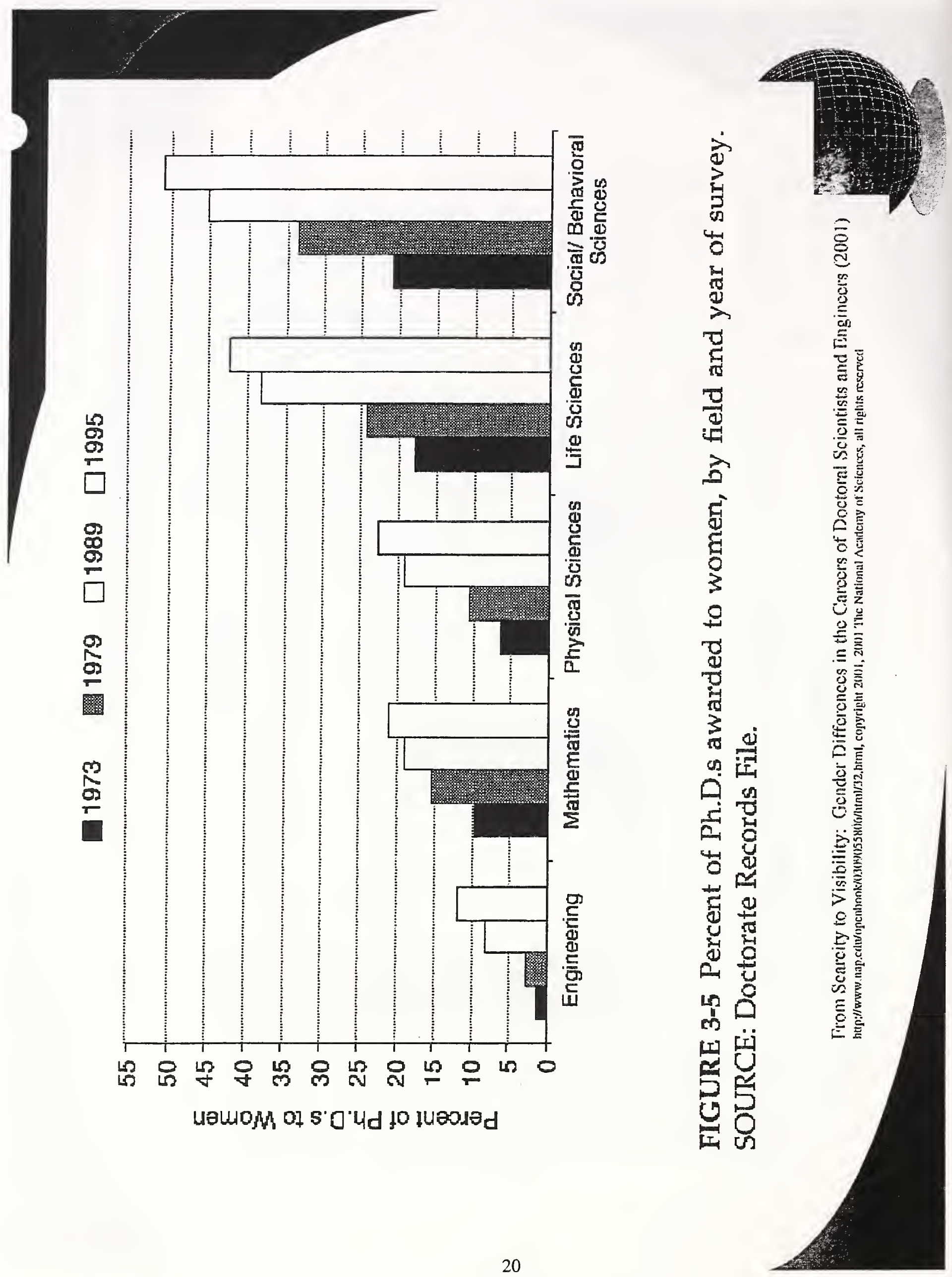


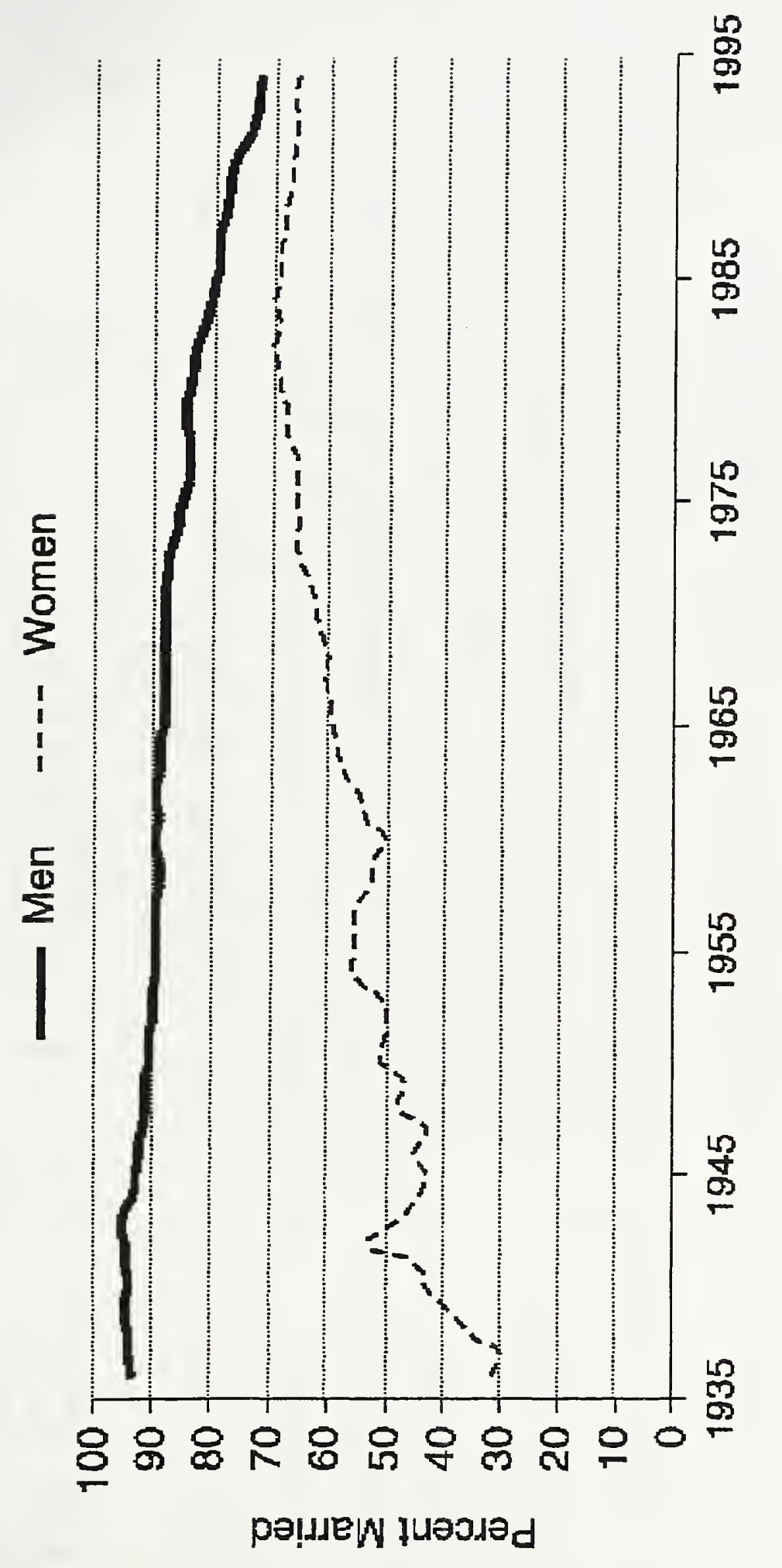



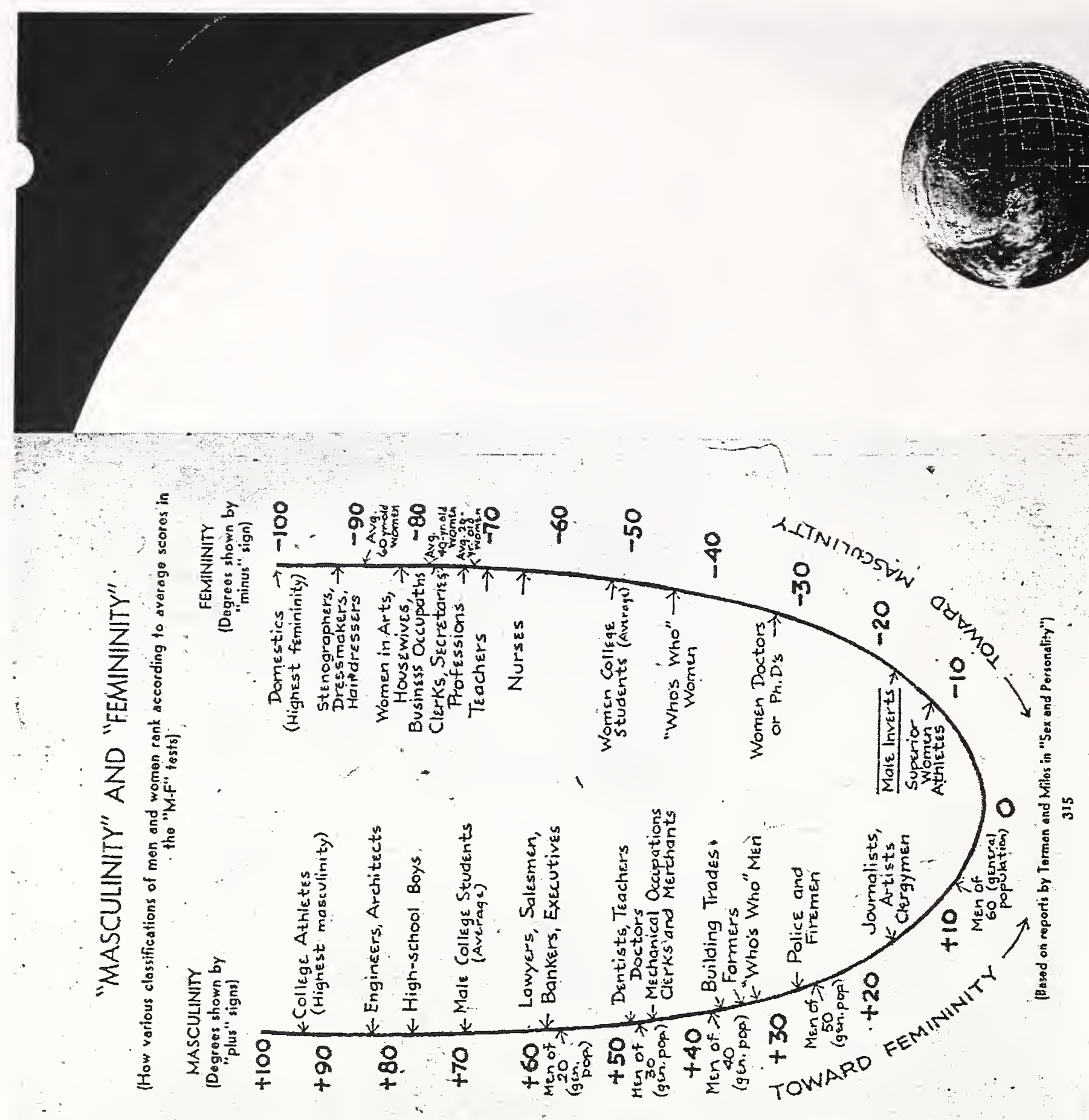


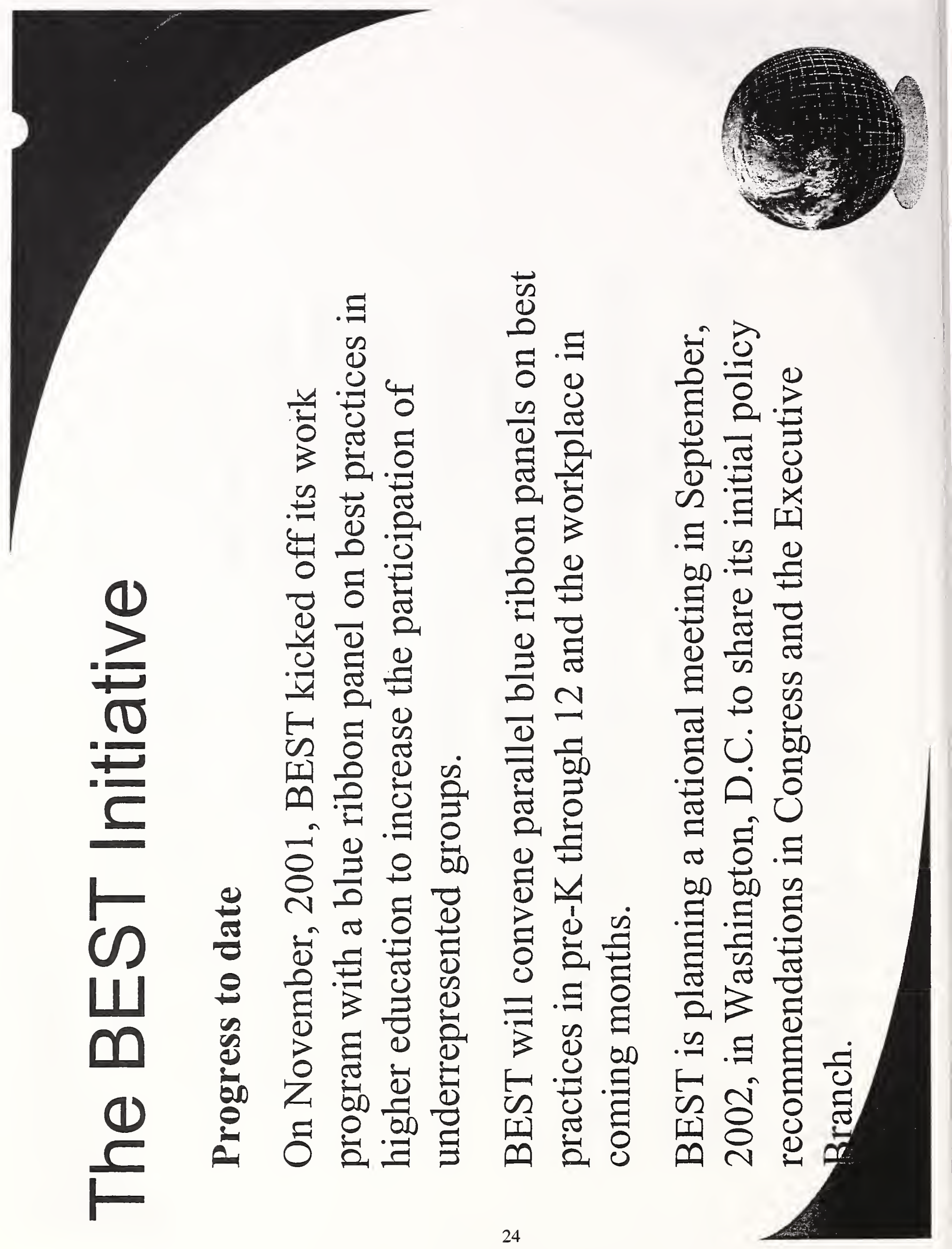




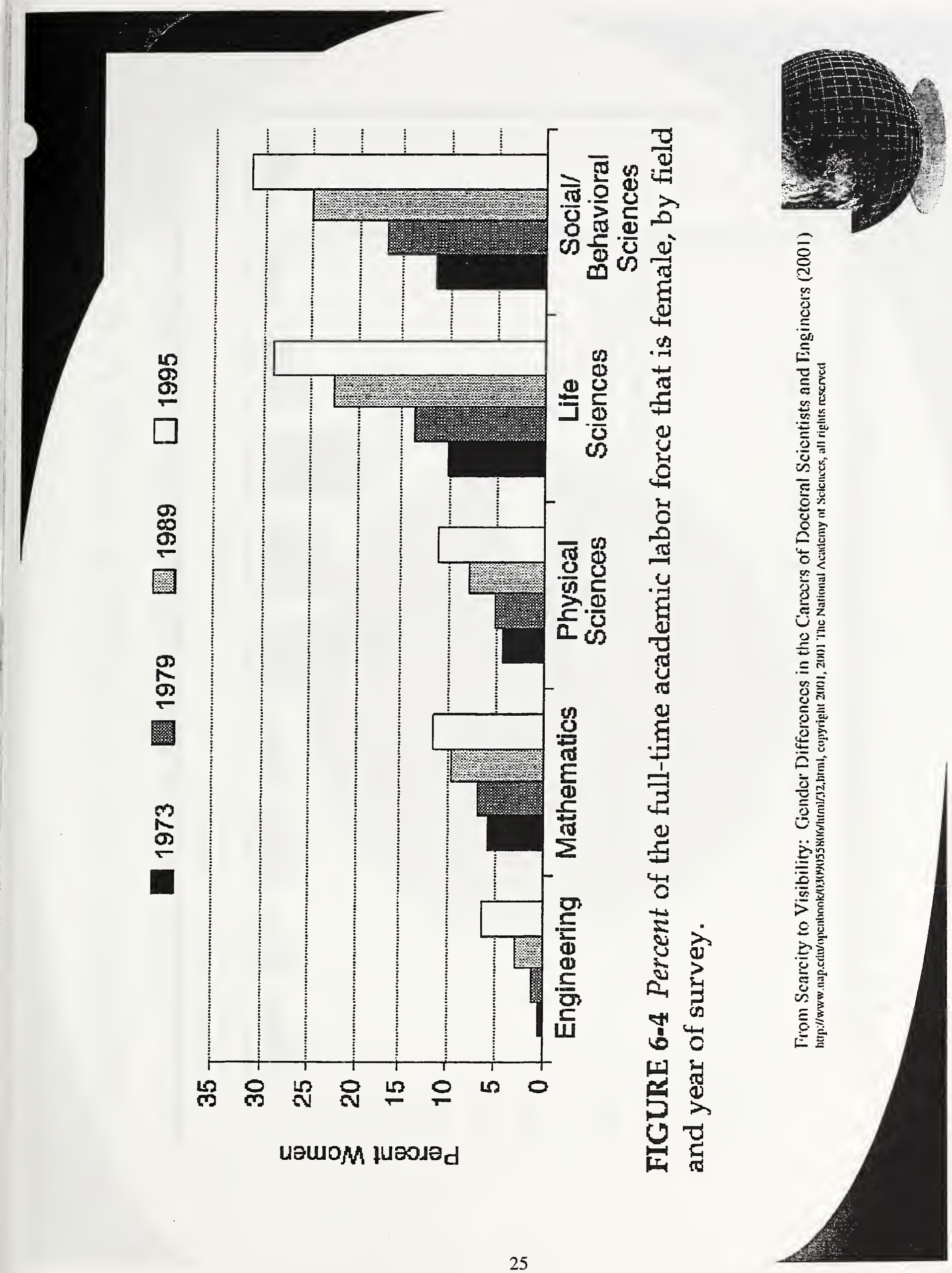




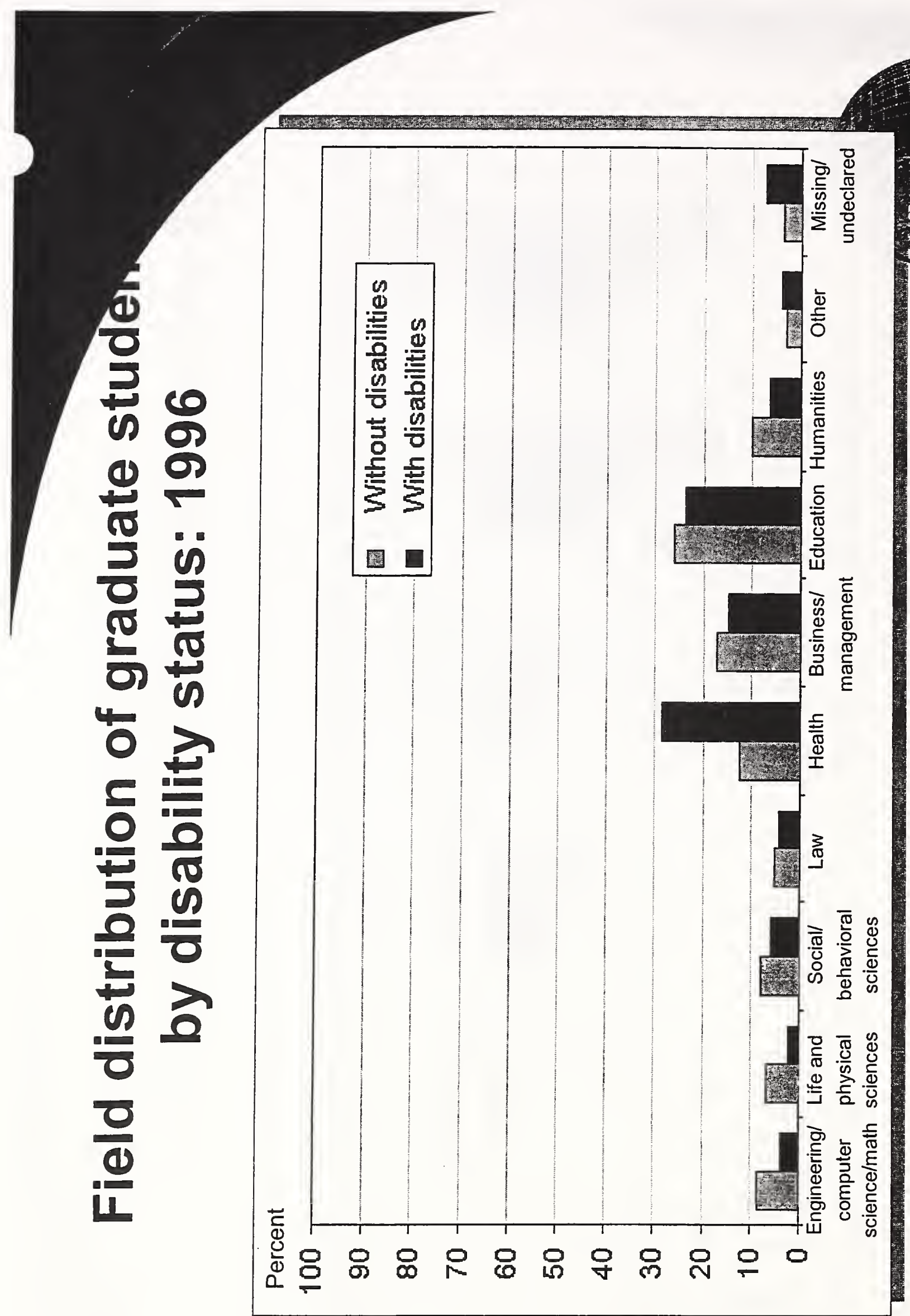




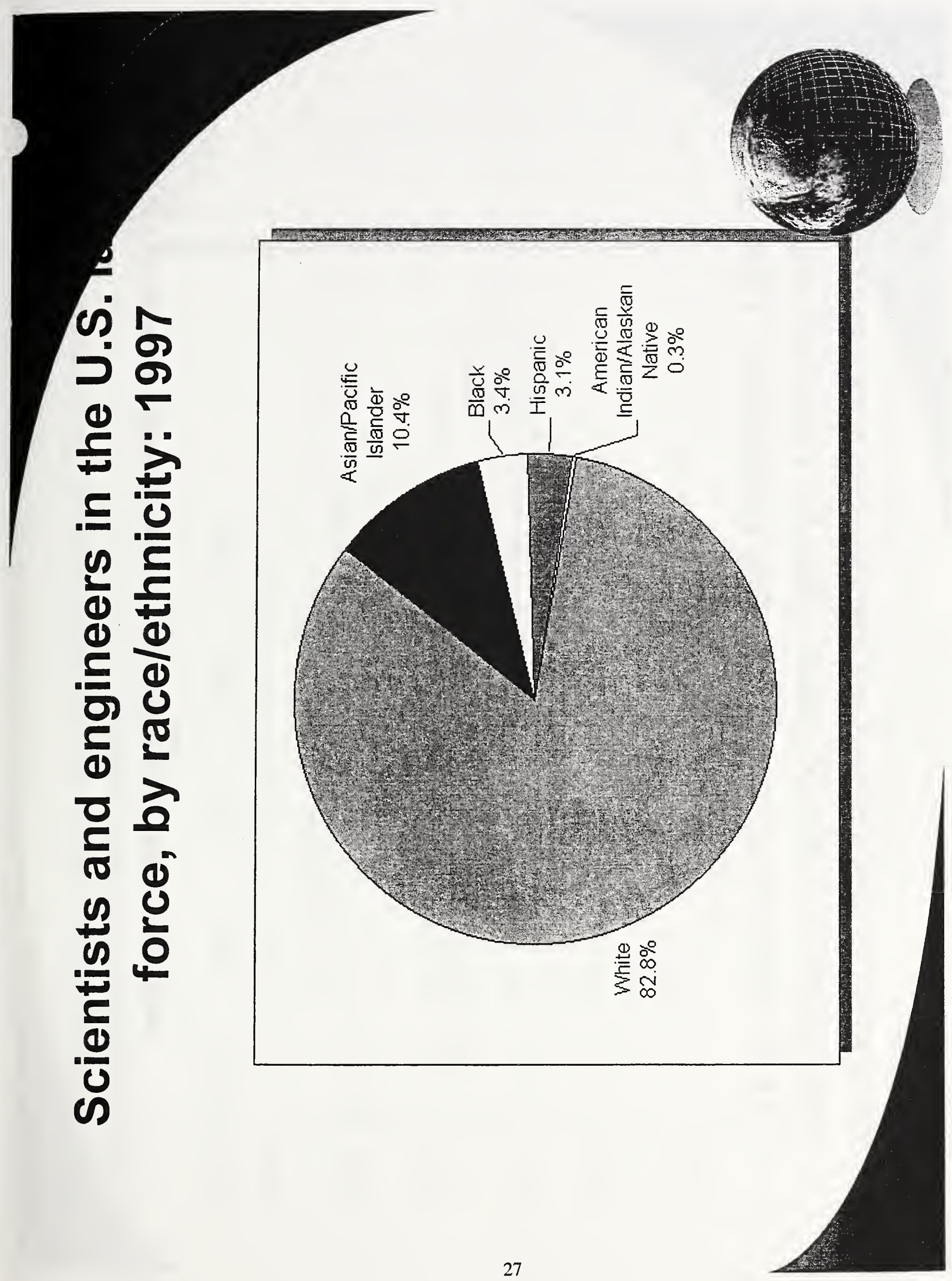




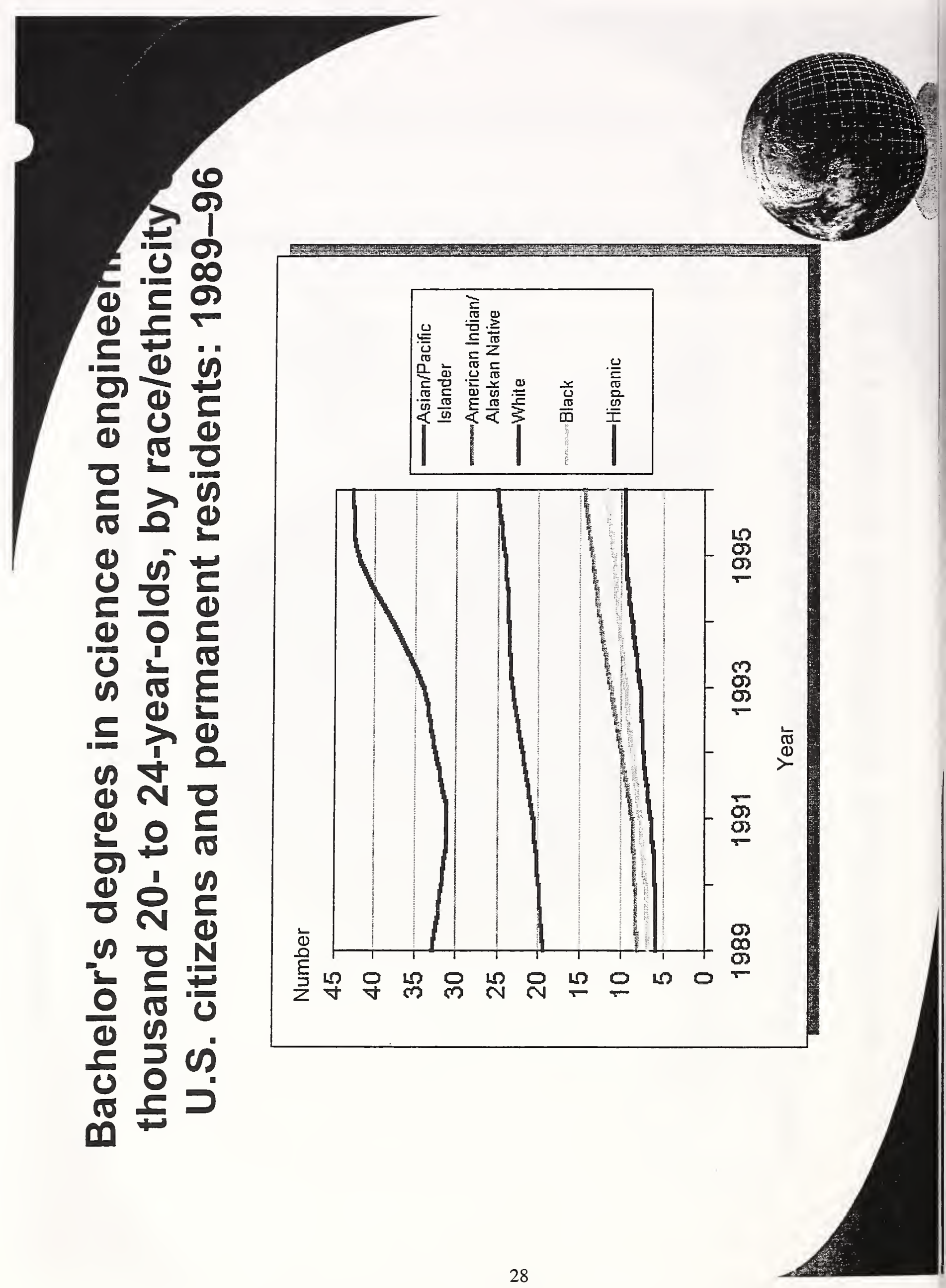




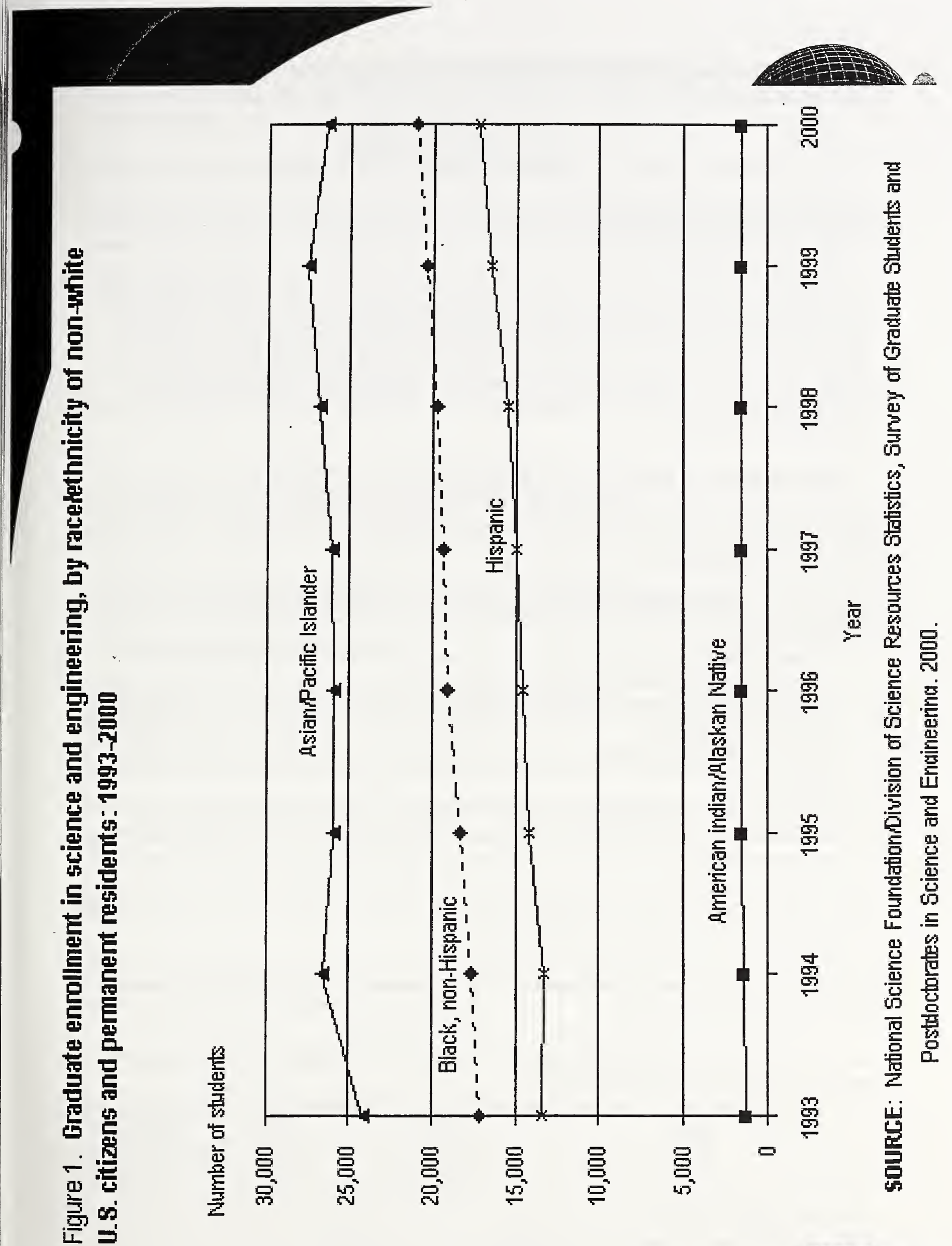




\title{
NIST—PAST, PRESENT, AND FUTURE: FROM 1993 TO TODAY
}

\author{
Dr. Karen Brown \\ Deputy Director, NIST
}

Good Morning. I'm going to start with a couple remarks here, and then I have some overheads. So this is kind of an informal talk.

I was asked to talk about NIST, past, present and future. And as most of you all know, since I joined NIST only in 1999, I don't have a long past with NIST. However, some of the people working on this Committee and the NIST Committee for Women (NCW), and particularly Connie Chang ${ }^{12}$ actually went back and summarized some of the things for me from the 1993 Report on Ad Hoc Affirmative Action Committee for Female Science and Engineers. So I just wanted to mention some of the key points that were brought up or needs that were pointed out in 1993 by this Committee.

I'm going to show you some data-I would guess a lot of you haven't seen-that raised my concerns in 1999, and then just talk a little bit about some of the things we are trying to do to make a difference. There were three major recommendations of the 1993 Report with suggested ideas for implementation

Number one: Top management should demonstrate a commitment in diversity. Some of the suggestions were:

- Use performance plans, appraisals, and bonuses of $\mathrm{OU}^{13}$ directors to emphasize their responsibility for ensuring progress;

- Take every opportunity to affirm and reaffirm, for managers and staff alike, a strong policy statement on diversity;

- Explore the development of a formal or informal mentoring program, specifically for scientific staff;

- Establish a flexible NIST policy on leave, alternative work schedules, and home tours;

- Demonstrate that discrimination of any kind from disparate pay to overt harassment will not be tolerated at NIST.

Now, on performance, plans, appraisals, and bonuses, in 2001, 8 years later: The old board was looking into evaluation criteria-more on that later;

On development of a formal or informal mentoring program: in 2001, the Diversity Advisory Board created a subcommittee;

On Establish a flexible NIST policy on leave, alternative work schedules and home tours: a memo was expected in 2001 and et cetera.

${ }^{12}$ Current president of NCW.

${ }^{13}$ In-house NIST term: Organizational Unit. There are 13 OU's at NIST. 
The second key point was: Require training in diversity for all line managers and recommend training for all staff to increase awareness of gender bias and its many subtle manifestations.

Human resources management in 1997 was charged with implementing a training program.

Number three: Each O.U. should be held responsible for developing, implementing its own plan for increasing the representation of women, and ensuring equal opportunity for advancement. There is a list here of about 7 items. I'll mention just two because I'm going to talk about this later:

- Establish a means of tracking salary increases bonuses and promotions of female staff. In parentheses here, the civil rights office collects this data and the Diversity Advisory Board recommends making it available.

- Ensure that women understand the criteria on which salary increases bonuses and promotions are awarded.

Now, I wasn't here in 1993 and I am a little bit ashamed to say that I was here for a couple of years before I actually paid [attention to these recommendations].

About March or April 2001, I looked at the equal opportunity report, the diversity report that the Civil Rights Office does. I'm going to show a couple of charts and tell you what my reaction was, and then give you some other data based on some work we had done after we saw this. This is a chart that shows the NIST ZA [administrative professional] career path and percentages of women and gives some information.

\begin{tabular}{|l|l|l|l|}
\hline ZA Series [384] & \% of workforce & Average length of service & Average salary \\
\hline WHITE MEN & $24 \%$ & 17 years & $\$ 71 \mathrm{~K}$ \\
\hline WHITE WOMEN & $63 \%$ & 19 years & $\$ 65 \mathrm{~K}$ \\
\hline BLACKS & $7 \%$ & 19 years & $\$ 60 \mathrm{~K}$ \\
\hline
\end{tabular}

So white men are 24 percent of the workforce. Their average length of service is 17 years. Their average salary is $\$ 71 \mathrm{~K}$. White women are 63 percent of the workforce; average length of service is 19 years. Their average salary is $\$ 65 \mathrm{~K}$. Just to show we're equal opportunity here. Blacks are 7 percent of the workforce. Their average length of service is 19 years and their average salary is $\$ 60 \mathrm{~K}$.

There are other data there, but the total number is 384 people in this category here at NIST, so, if there weren't some significant numbers, I didn't [break it down further]. Among blacks, average salary for men is $\$ 75 \mathrm{~K}$ and for women is $\$ 53 \mathrm{~K}$.

[The next chart shows the NIST ZP, or scientific, career path.]

\begin{tabular}{|l|l|l|l|}
\hline ZP Series [1448] & \% of workforce & Average length of service & Average salary \\
\hline WHITE MEN & $69 \%$ & 17 years & $\$ 90 \mathrm{~K}$ \\
\hline WHITE WOMEN & $16 \%$ & 15 years & $\$ 80 \mathrm{~K}$ \\
\hline BLACKS & $4 \%$ & 17 years & $\$ 74 \mathrm{~K}$ \\
\hline
\end{tabular}


Under ZP, or scientists, the total number is 1448 when this was done. White men are 69 percent of this work force. Their average salary is $\$ 90 \mathrm{~K}$. White women are 16 percent of this workforce. Their average salary is $\$ 80 \mathrm{~K}$. And blacks are 4 percent of this workforce. And their average salary is $\$ 74 \mathrm{~K}$. The average lengths of service are all approximately close- $17,15,17$. So, as a result of this data, and discussing this with some people here at NIST, obviously these data are just averages, and you can look at the ages and you can look at the years of service and you can do different things.

So I asked the civil rights office to work with our statistics division here at NIST and do a regression analysis on the actual data. So for the rest of the time I'm going-they did this on the $\mathrm{ZP} / \mathrm{ST}$ group of people, because that is the largest statistically valid group, with almost 1,500 people in it. We haven't done the other career paths yet.

So this is non-supervisors in ZP or ST, and this follows the senior technician career path at NIST. The total number of people with a Ph.D. is 597, according to these data. And the average salary is $\$ 95,360$ with a standard deviation of $\$ 1,435$. Pretty tight range of distribution. And the green line here is white males, and the blue line which goes along here and down, the lower of the two lines that are close together, is white females. And the other is Asians. So look at the data in a little more detail-I'm just going to flip through these quickly because you'll get the picture pretty quickly.

These are white male supervisors. This is the actual data points, and the regression curve from the other chart. Okay? That is white males, Ph.D.'s, non-supervisors. White females. Okay? So the white females are significantly lower. And if you know the salary levels, this is a Band 5, this is a Band 4, and this is a Band 3. Our entry level for most Ph.D.'s is around a Band 3 and you see that there are no ST's, female ST's. I dotted the little things green last night. So you can sort of see the difference.

But basically on the female curve there are very few Band 5's and no ST's. And they're heavily weighted toward the 4's and 3's. And if you look at master's degree data for males and females, you'll see it looks the same.

Now this is interesting. There is hope-if you become a manager you can break out. This is the curve for managers. There is one point here, which I can tell you is someone who got her Ph.D. here, who was a manager who had many years of service before she got her Ph.D. So she's been a long time in her job and a long time as a manager, and then got her Ph.D. The charts are all years since your degree, so in actual fact this point realistically should be over there someplace if you count some weighting of the two things. So that's why I dotted the line. Take that point away and it runs closer to the men. But basically the bottom line is that for men and women managers and supervisors, they are pretty close to the same curve. If you are not a supervisor, it is not close to the same curve. This is salary data.

But the hiring data look kind of similar. One of the interesting ones is post-docs. We have this NRC post-doc program. And if you look in 1985, for some reason, before 1985, the average percentage of women post-docs was about 4 percent or 5 percent. Then in 1985, it jumped up to about 11 percent or 12 percent. And then in 1990 it went up to-sort of averaging around 17 percent from 1990 on. We've doubled the number of post-docs, but the percentage of women in those post-docs has stayed the same: between 15 percent and 18 percent, since around 1990. So I 
was really intrigued about some of these things and also with our ability to do something about it. So we've done several things. The first thing I'll tell you about is, I asked-I said, well, I think this probably comes about because the salary-because people probably don't realize they're doing this. This is sort of a trend and people do it in little increments and they don't really realize that they are giving men a little more money or rewarding men a little better than they're rewarding women. We need to make this visible as part of the salary process here at NIST. And so Helena Inman and the human resources people have been working on an upgrade to our personnel system so that this year, when we do our personnel system, we will be able to pull data like this.

I'm not going to go through it all, but this is data from last year run with the new program. Years since degree and gender and sex are down the left-hand side, and I just thought the data was interesting. What this allows you to do is look at your distribution for equity. If you look at the top two lines, white male, white female, on the left-hand side, the white male score average was 82.32. The white female score was 82.0. These are all people who have worked zero to nine years at NIST. Zero to nine years since they got their degree. And the white males average 5.9 percent total compensation. This does not include COLAs ${ }^{14}$, just bonus and pay increase. And white females average 3.69 percent, and you can see the bonuses are quite different. The white male, population of 28 ; the average bonus was 1.42 . Among the white females, population of 17 , the average bonus was 49 .

These data are grouped by under $10 ; 10$ to $20 ; 20$ to $30 ; 30$ to 40 . So you can have a whole spreadsheet, and you can look at your population, and it will be available at a group leader level, a division level and an OU level. So people can look at what they're doing and understand what they're doing to make it visible.

And it is not just white males and females. If you look at Asian males and Asian females you have the same kind of thing. The scores were 80.47 and 80.43 . Asian males average compensation 4.11. Average Asian females, 2.86. So, this kind of program which will be implemented this year will allow managers to try to see what they're doing and be aware of what they're doing every year and understand and try to address these differences.

One last thing. One of the points in the 1993 report was to put strong elements in the OU director's plans. And this year, for 2002, the OU director's plans have a diversity element working with the Diversity Board. So there were several elements. I just want to read them to you:

- Reducing overall level of representation in minorities;

- Analyzing the data and conducting comparisons and putting plans in place to correct underrepresentation, encouraging and supporting mentoring as a core-value;

- Establishing mentoring programs, informal or formal;

- Improving name recognition and outreach in minority communities, and minority community colleges, and

- Improving awareness and understanding of diversity among all the staff in the OUs.

${ }^{14}$ Cost-of-living adjustment. 
So we've tried to increase the specificity and the diversity element in the OU director's plans to put more emphasis on solving both the under-representation and the pay situation.

Now I have to say it is really interesting in introducing Carol here, because on our surveys for the last two years. In the last two surveys that we did, employee surveys in 1999 and 2000, what you find when you analyze the data is, NIST is really a great place to work. The morale is very high, and there really isn't any significant difference in the satisfaction or the scores that people give based on gender.

So while we see these differences, pay doesn't make the whole story and under-representation doesn't make the whole story. NIST offers a very supportive environment in many ways, and I'm sure Carol is going to talk about that. [Applause] 

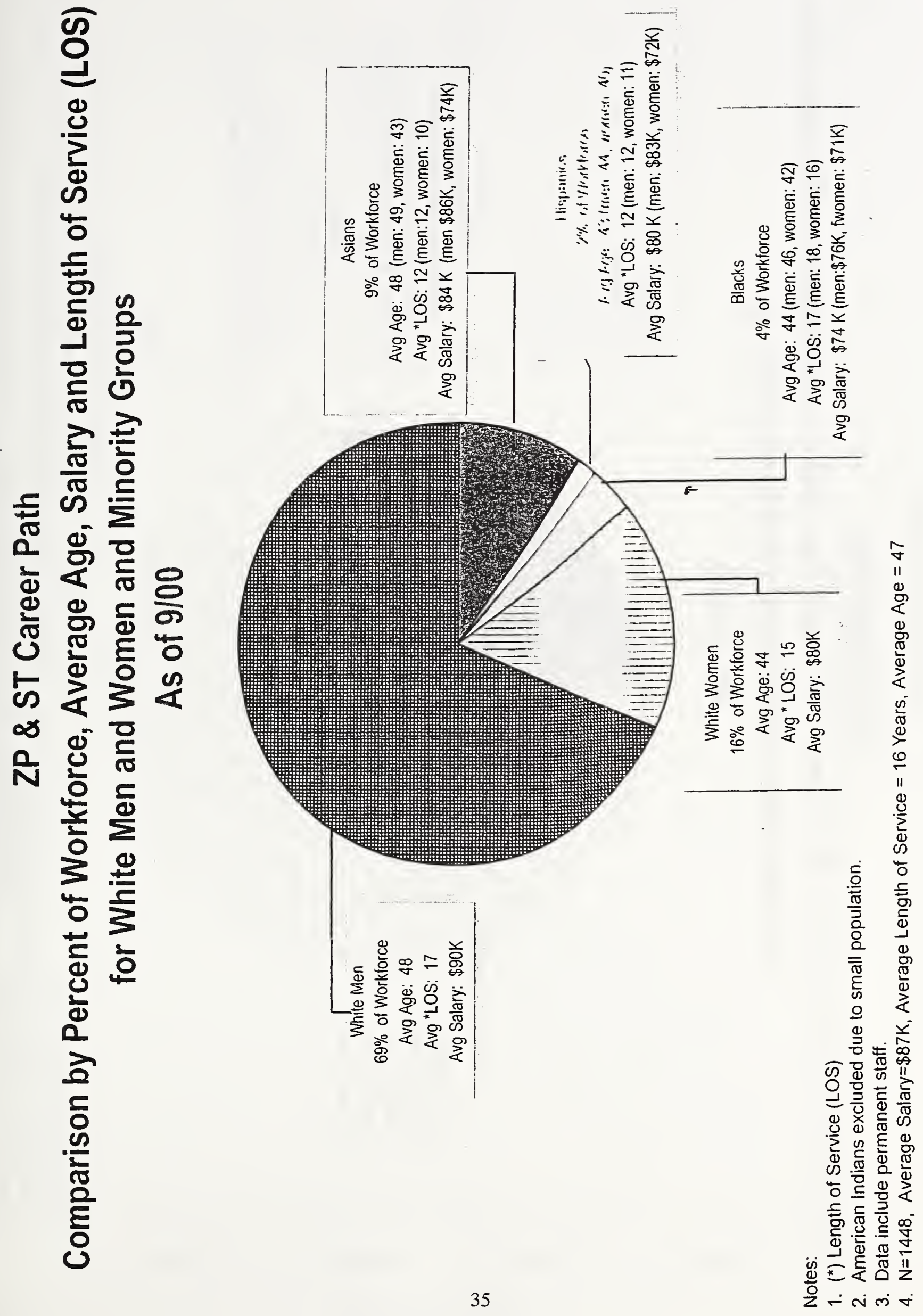

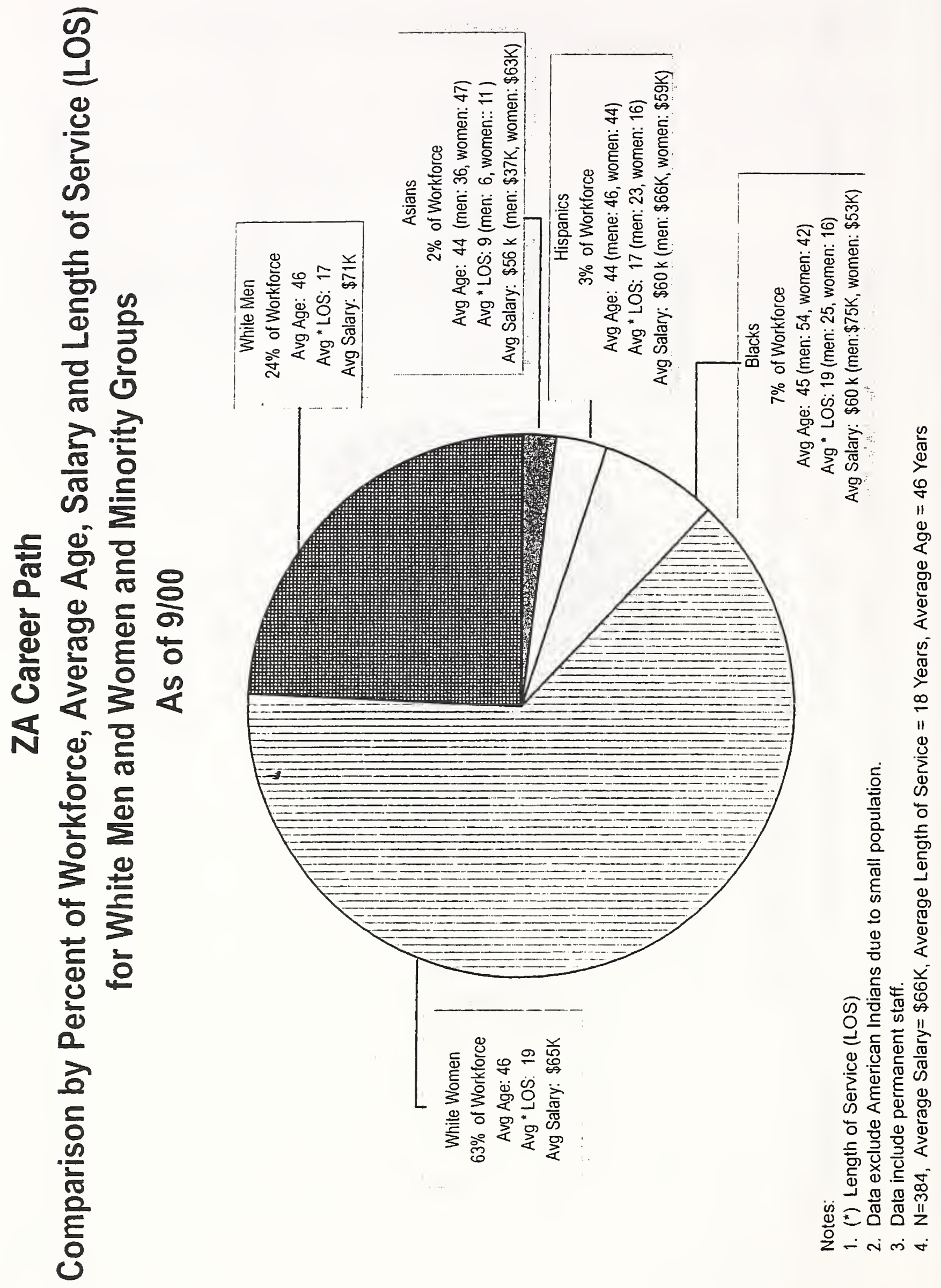


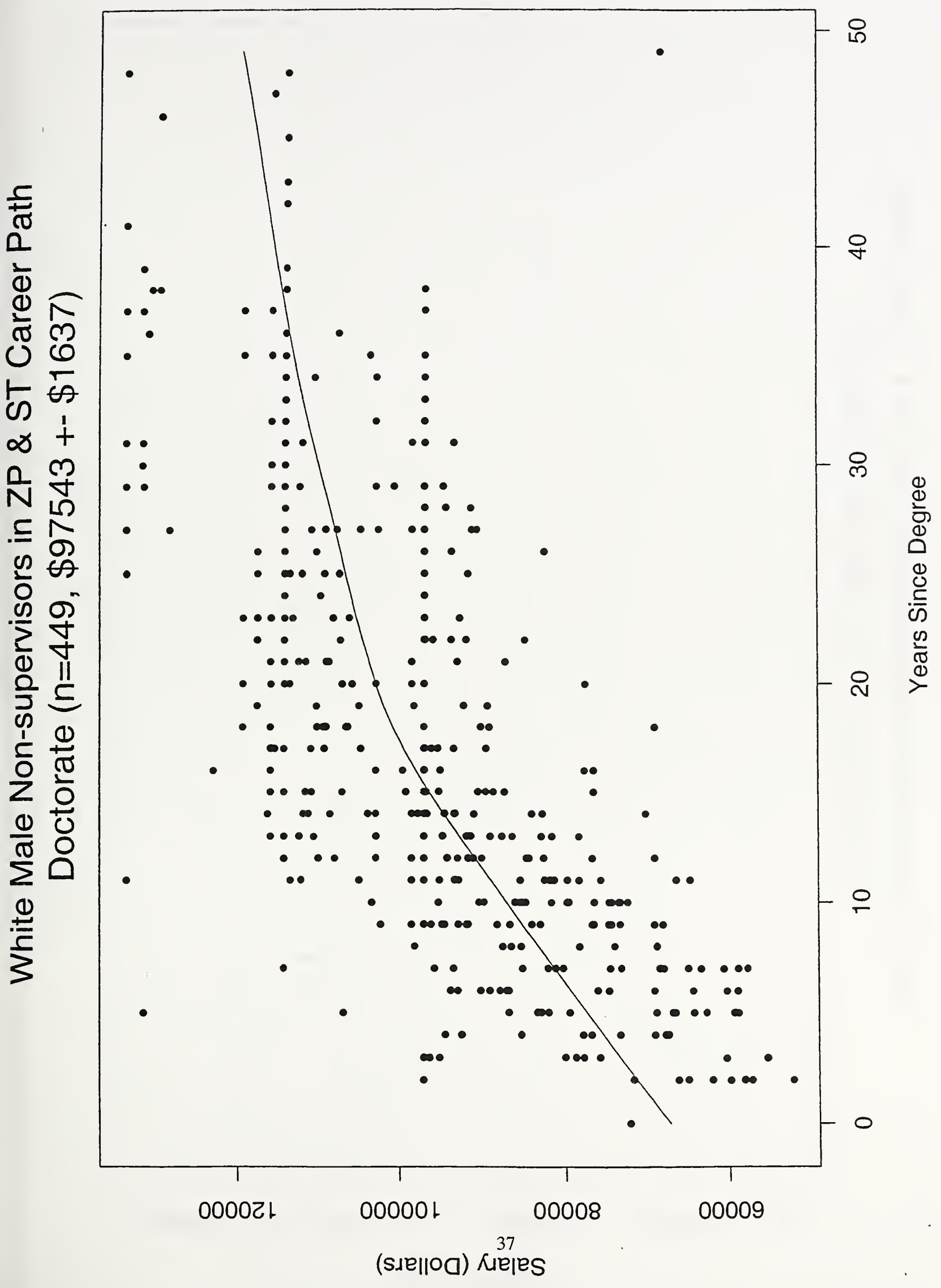




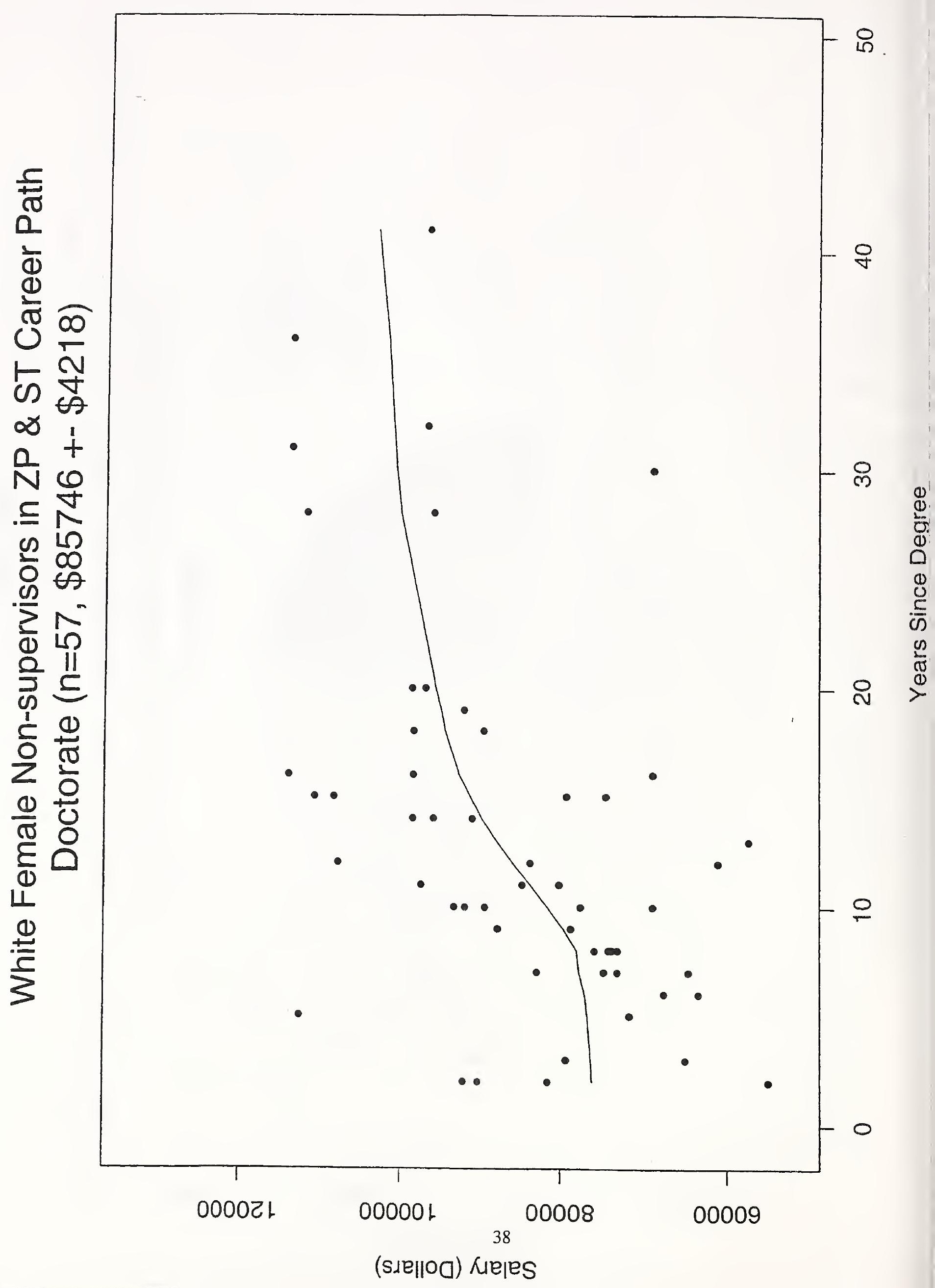




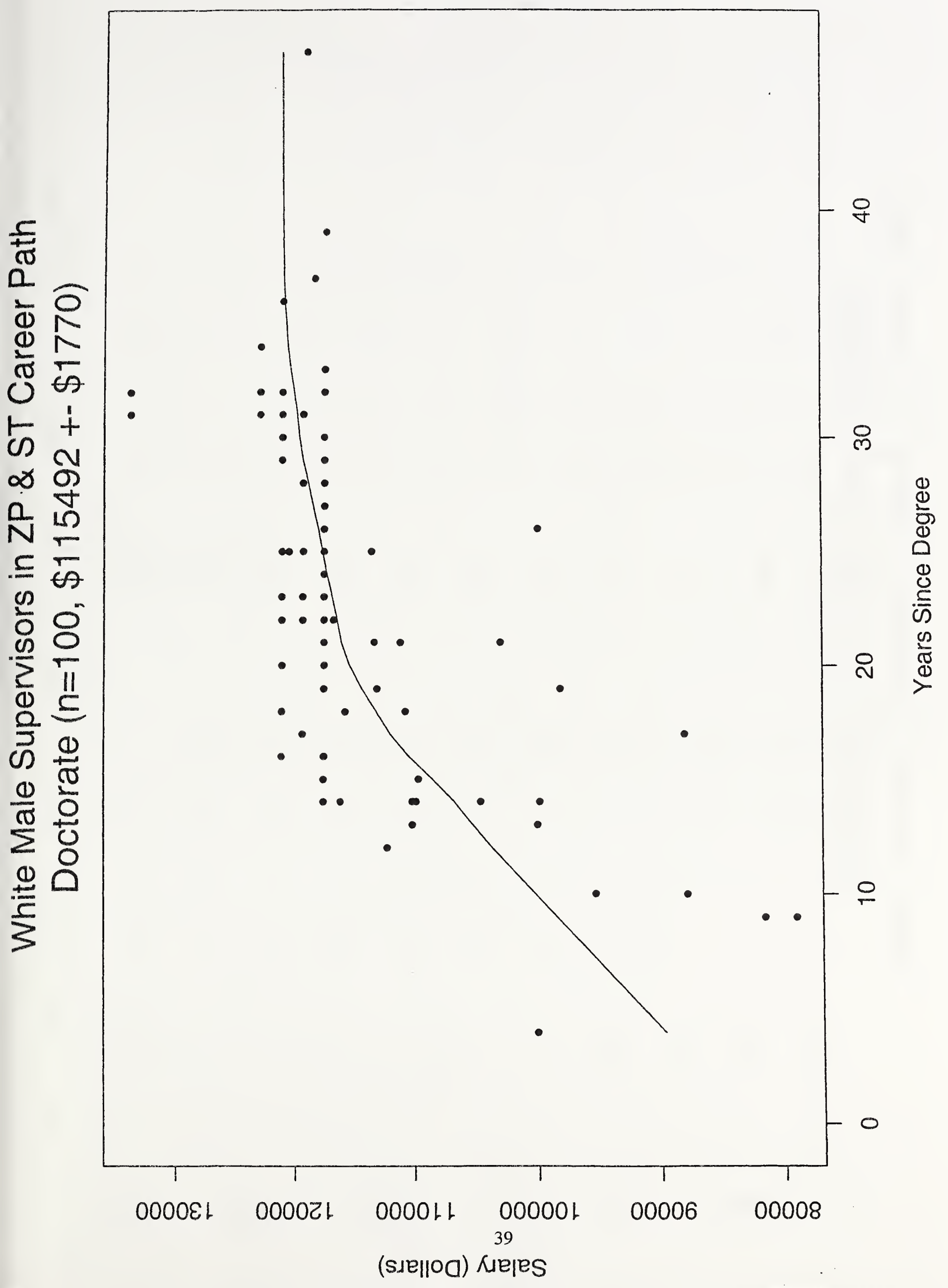




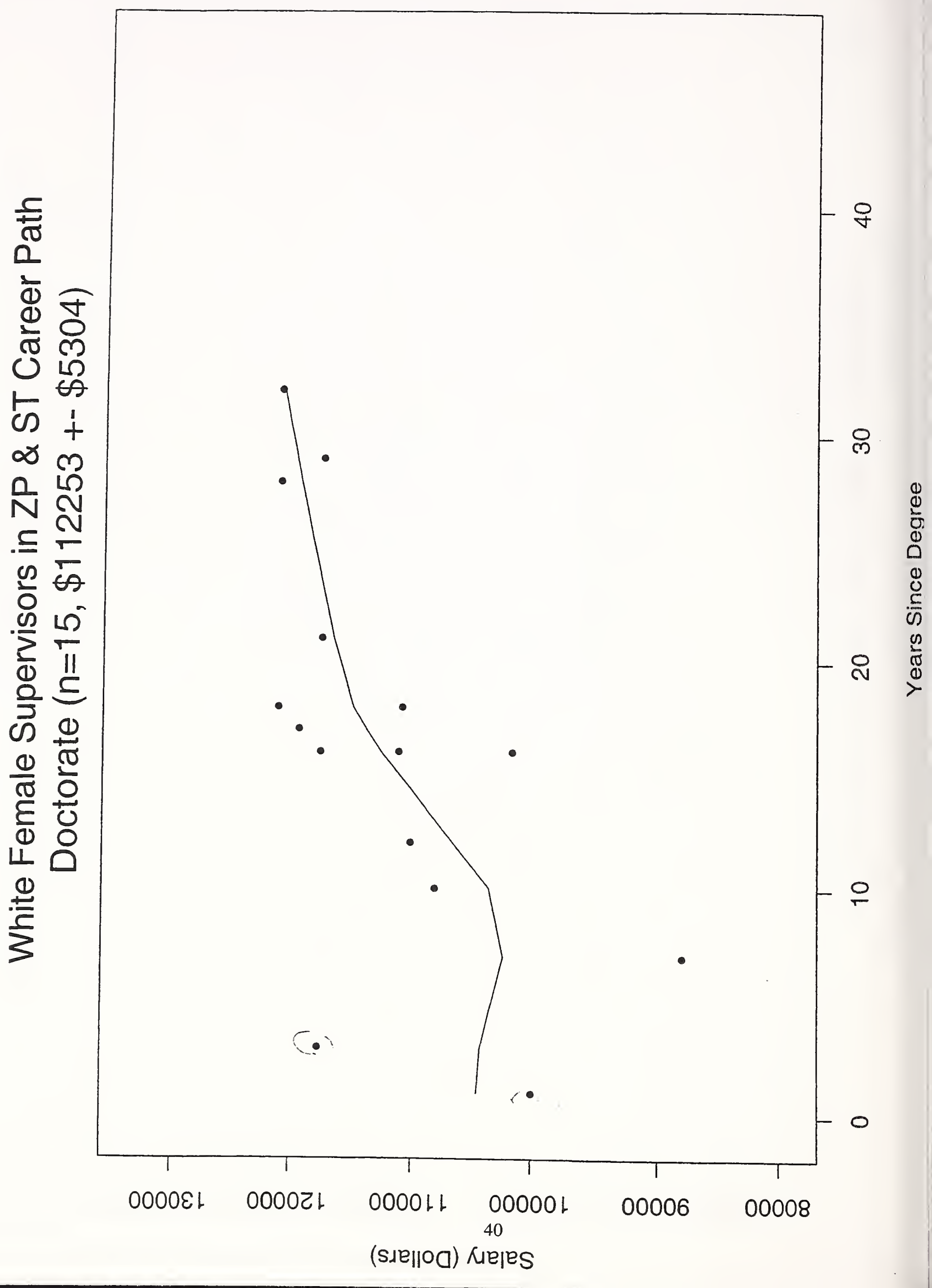




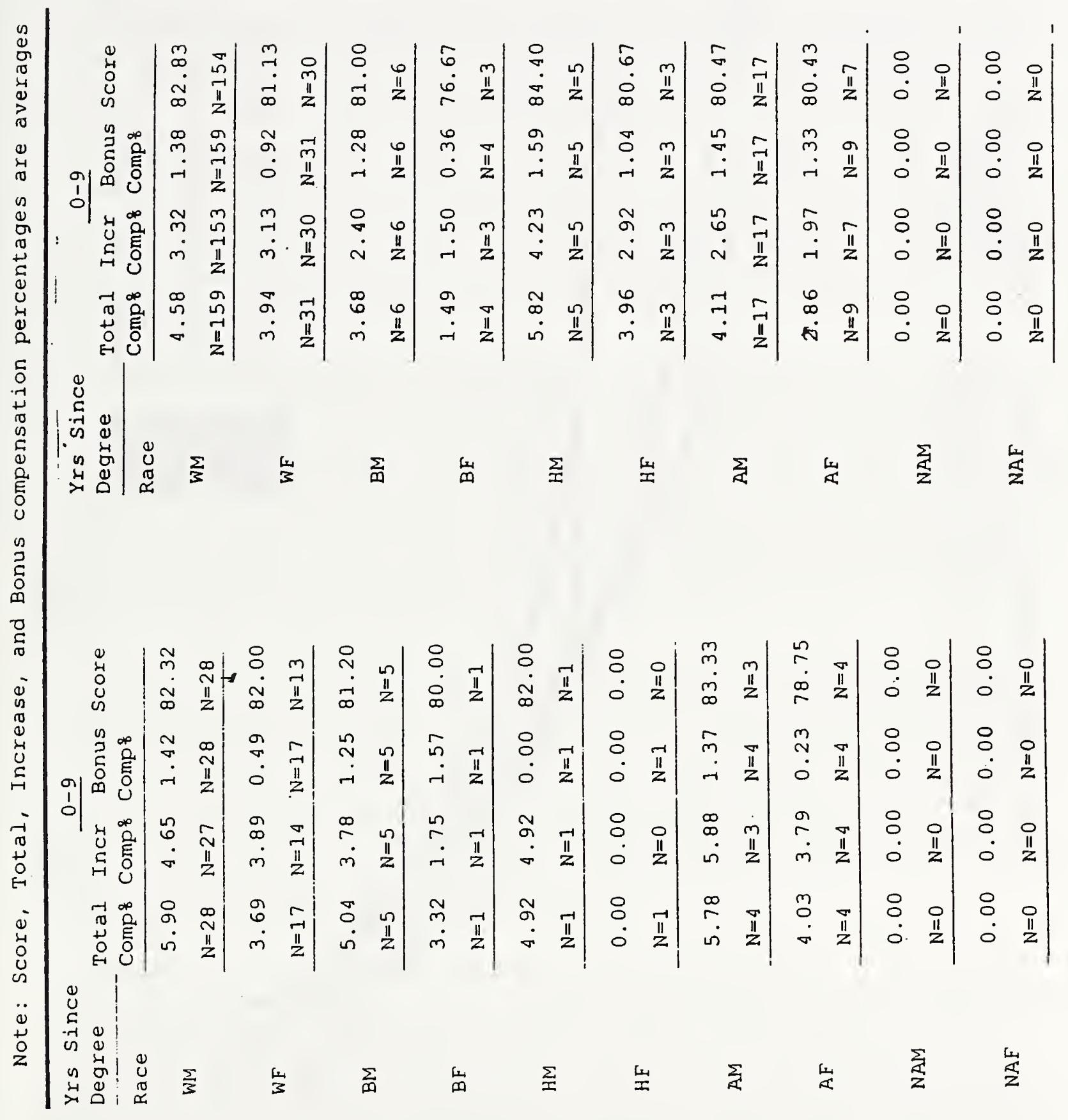




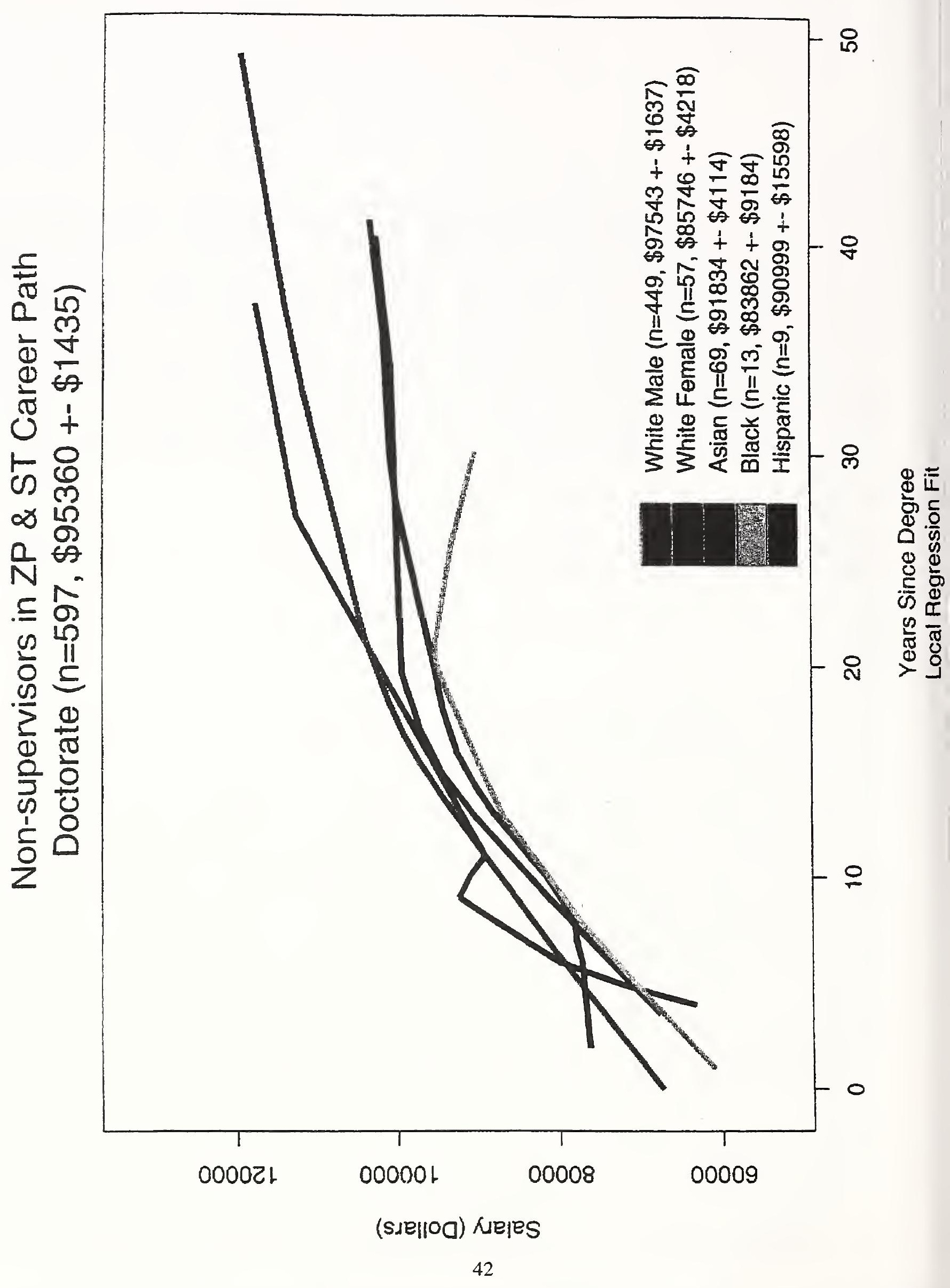




\section{WOMEN SCIENTISTS AT NIST}

\section{Dr. Carol Handwerker \\ Chief, Metallurgy Division \\ Materials Science and Engineering Laboratory, NIST}

Thank you, Karen. I appreciate being given the opportunity to talk today on behalf of my sister scientists here at NIST. As you saw from the data that Karen showed, we have been around here certainly for over 40 years, and as well as having a number of women who have been here for quite along time, there is Anneka Levelt-Sengers, Katharine Gebbie here in the audience, two of my role models since I came here. There are also quite a few women who have been here only a few months, and I would like to thank my friends and colleagues at MSEL [Materials Science and Engineering Laboratory] for being willing to talk to me about how they got to where they are. I talked to both men and women, and they gave me quite a few insights into their experiences here, and also, how they got here, and they've been very patient in answering my questions about what brought them to science, what barriers they faced and what keeps them here.

Now, Karen just gave a snapshot of the demographics, and the salary numbers aren't very different from what Kathie Olsen showed. And there is something very important to be said about what those statistics show. They show certain cultural similarities among different organizations all across the country. But what they don't show is the culture that we have here at NIST, and how our particular organization works with individuals. Now, NIST has been my scientific home for about 18 years. My husband and I arrived here as a NRC post-doc with a four-month-old daughter in tow. So the comments that I make today are really through these experiences that I have had as a mother, as a wife of a NIST scientist, as well as a post-doc, bench-level scientist, a group leader and a division chief.

Now in talking with a number of men and women, and from my own experience, probably the best thing that has happened in terms of just our quality of life is the alternative work schedule. It's really made our lives much easier, and not just for women with children. But from my point of view, in terms of improving the culture of women here at NIST, the greatest positive change has been that women have moved up in the ranks. And as you can see from the statistics, there are some issues about the four to five transition and the scientific ranks. But in the management ranks, the number of women who have moved up, especially since the early 1990's, has really, I think, made a tremendous difference to all of us here.

I remember several years ago, I was down at the Department of Commerce, and on the stage representing me were Ron Brown, Mary Good and Aretha Backer, and I remember feeling just profoundly proud because they reminded me of me, you know? It wasn't just, you know, the same old-well, white guys sitting up there. The number of women at NIST has increased but not very much. It has increased 2 percent, from 14 percent to 16 percent, and that step-change happened in about 1990. And one of the reasons why I think there has been a steady increase, is because it feels like there are more.

Now, there are two scientific analogies that I use to describe how I think women are operating here. The first one is the critical nucleus size for the formation of a new phase. I'm a nerd. What can I say? [Laughter] Once a cluster of atoms gets over a critical size it is easier for the cluster to 
grow. So, it attracts and keeps in more of those kind of its type. So I think that is where we are now. There are parts of the organization where the proportions of women are actually quite high. The Advanced Technology Program is one in particular. And I think that those clusters give a feeling to the organization that having a more widely distributed, uniform distribution just doesn't give. We're forming our own "new girls network" around here, and luckily we're forming an "old girls network" here as well.

The other analogy that has been used everywhere is the analogy of critical mass. I hear it from women scientists over and over again, and we aren't there yet. From other women who are at NIST now, and have worked at other organizations, they say that the critical mass is really about 25 percent, and we're at 16 percent and holding.

Now, the other thing that they've told me is that when an organization reaches that critical mass of about 25 percent, the culture changes dramatically. And I think that would be an interesting thing to test around here. Now, one of the things as well that came up in a number of our discussions-and this is one that I think Kathie Olsen brought up, too-is the biases toward women about their marital status. At first I thought it was, you know, married with children. But it isn't just that, it's, "Oh, you're single, you don't have any children, therefore you don't need as much money and-oh, and by the way, we'll give you more work to do as well." And then if you do have children, well, you're not serious. So you can't win either way. And it is culturally complex.

So in trying to understand whether my view-and my evolution of my view, I called up two of my role models from the outside scientific community. One is Millie Dresselhouse from MIT, and the other is Julia Workman from Northwestern University. When I was growing up in science at MIT, I heard the Millie Dresselhouse stories. Millie is a powerhouse. If you want to read her biography, it was in one of the recent Scientific American issues. Millie is an accomplished violinist and a gourmet cook as well as having been the president of the American Physical Society, member of the National Academy of Sciences, and had 57 papers last yearshe actually played a role in each one of those papers. And she just came back from being the Director of Science at the Department of Energy. The story that I had heard when I was growing up was that Millie, who is the mother of four, was working at Lincoln Laboratories, and on a Friday night she had been playing in her string quartet, and on Monday morning she came in, you know, normal time, and was standing around the coffee pot with her colleagues-her male colleagues, and she turned to them and said, "Don't you notice anything different?" And they looked rather strangely and she said, "No? Well, I had my baby over the weekend!" [Laughter] Before I told this story, I decided to call Millie up and ask her if it was true and she said, "Well, yes, indeed it was." In those days, in order to maintain one's credibility, you just couldn't show any weakness.

I've talked to a few other women of my age-and my daughter was born about 19 years ago-I talked to Gabrielle Long in detail about this, and when both of our first children were born, we took two whole weeks off. Things have gotten a lot better than that. When my second daughter was born I took four weeks off, and Gabrielle took the whole six weeks off. But then we came back full-time. The problem is, though, that within our culture, I think women's intent, their seriousness, is still questioned, and it is questioned here particularly for women who go on what is euphemistically called part-time. Part-time here at NIST is almost always 32 hours a week, which is not a very abbreviated work schedule. 
Now, I was advised by my group leader before I had my second child that I should not go parttime, that it would negatively affect my career, and that we would work things out, you know, that there would be flexibility. But he knew the culture and he was my mentor. He looked after me. I have seen this happen to a number of women around, that if they decide to go part-time, their seriousness is immediately questioned. This is widespread, and it is hard to eradicate. And I think the changes are going to be coming. Part of it-and it was great to see the slide that Kathie Olsen showed-but it's really based on some stereotypes of this masculinity-femininity scale. So, if you deviate at all from being that engineer, then you are not considered to be as serious. Even if you listen to people talk about their hobbies, you see they are sort of on that level. You knowthe sports.

And when talking about this as a human issue, one of the women said to me, "Well, you know these two men in the organization, they are artists, and they aren't taken as seriously because they are artists." This is really a human issue, and this idea persists that anything less than 100 percent dedication to science and engineering is not just a weakness, it is a failure and the "switch" turns off. You are no longer accepted. I think that is changing quite a bit here, and I think you can see that certainly with the supervisor slide, because quite a few have taken some time off, and it doesn't seem to have adversely affected their careers.

Now, not everybody needs to follow the same path. One of my other role models is Julia Workman, a member of the National Academy of Engineering, formerly on the NRC panel here. She took 13 years off to raise her children. During that time she wrote a book, and when she came back it took her five years from being a visiting professor to become a full professor with tenure. So I think for women right now I think we really need to pay some attention to it, is that we be judged on what we have accomplished, not by the number of official hours that we are working.

The other thing is that it takes enlightened management to understand that even if we women decide at some point we want to take time off to take care of our kids, that once we are off the "fast track," we don't always have to stay off the fast track. That once we decide to come back, that we should be given additional opportunities. I have a friend at IBM who asked her supervisor, "Why am I not on the fast track anymore?" And her supervisor said to her, "You wouldn't make the sacrifices necessary." And she said to him, "Nobody asked me!" So the next time it came up in personnel, her supervisor/mentor said, "Why don't you ask Katharine?" And they asked her, and she was back on the fast track. So it really takes this kind of enlightened management.

You have mentioned mentors, and I have always had fabulous mentors. John Cahn and John Manning from the Materials Science and Engineering Laboratory were incredible. John Cahn had this image that, when my husband and I came with my 4-month-old, we would share an office, and there would be a playpen in the corner. But we set him straight right away, but you know, you could sort of see what kind of person he was, and he continues to be now. So it is really important that we have people who care and who take the time out to look after our careers, and that doesn't always mean that they're going to say we have done a good job. They need to be honest with us, and they need to be willing to work with us, and to promote our work. I think many of us feel that we have reached a time where things are pretty good. I think it is the same place that MIT women were just a few years ago when this study came. We're starting to talk to 
one another. We start to have numbers, then we start to address some of the more systemic organizational issues. And I think that is a pretty good place to be, because the reason why we're all here is that we really love science. It speaks to something really deep within us. It fulfills us. And so having this organization become even stronger in its support of us can only be really a fabulous future for us.

One of the things, though, that I want to go back to-this is the very last-is from the report that Katharine Gebbie chaired in 1993. It is still true. In her keynote address at the National Conference on What Works, the beginning of the executive summary, on-in her keynote address at a National Conference on What Works: Women in Math, Science, and Engineering, NIH Director Bernadine Healy said, "The way to encourage women is to have more women. More women means more female role models, more mentors, and more networks. There are no quick fixes."

Problems as deep-rooted and subtle as gender bias will not be solved by the NIST Director designating funds or identifying positions exclusively for women. Increasing the representation of female scientists and engineers at NIST will require steadfast, ongoing, reiterated commitment at all levels of management.

The recommendations that were made in 1993 still hold, and it is good to see that they are being implemented. Thank you. [Applause] 


\title{
WOMEN IN SCIENCE, ENGINEERING, AND TECHNOLOGY IN THE PRIVATE SECTOR
}

\author{
Dr. Chinatsu Aone \\ Vice-President of Natural Language Programming \\ SRA International, Inc.
}

I am very honored to be invited to this Summit today. I was asked to share my somewhat unusual life story and my views-what is it like to work in the private sector.

Currently, I work for a company called SRA International. It's a contracting systems integration firm based in Fairfax, Virginia. We mostly work for the Federal government. It's a private company with about 2,300 employees. I'm the vice-president and director of the Natural Language Technologies Program.

Some people may be wondering, what is a natural language technology program? I'll get to that later in my speech. As you can see from my name and my accent, I was not born in the United States. I was born and grew up in Japan. My interest in languages started when I was in elementary school. When I was growing up in Japan, I used to watch this weekly TV show, and there was this one female reporter who traveled around the world and showed us many different cultures and countries. She looked very sophisticated and she knew many languages, and she showed a deep appreciation for different cultures every week. So I dreamed of having a job like hers, and I thought perhaps unconsciously that learning languages was very important to my future. Later on, when I was a junior in high school, I actually had to choose between science and humanity tracks.

In Japan it is necessary to prepare for college entrance examinations. In those days it was really expected that Japanese women would have a life-long career, and society usually preferred women to live with their parents until they were married and also quit their jobs after marriage. So in this respect, I was a bit different than most girls, because I really wanted to have a life-long career. So knowing this, my high school teacher told me that it's hard for women to make a career in a science field, and he said my chances would be better if I chose humanities.

So I chose the humanities track to prepare for the college entrance examination. So, but I really did not want a job as a so-called office worker in Japan. Everybody can say it's a good job for women in Japan, but it is really a supporting role. Its job requirements include serving tea to your bosses and colleagues, and it also means you're expected to quit your job after you get married. So I decided to study and major in English and become a high school English teacher. It was not necessarily the most exciting choice for me, but it was one of the very few, life-long, career opportunities available for women in Japan.

So I went to college and studied English, and when I was a junior in college I looked for and found an opportunity to study in the United States. I studied at the University of Michigan in Ann Arbor for a year. And there I came across a field called natural language processing, or NLP. It's a sub-field called artificial intelligence, and it's really to develop computer software to understand human languages. 
I was very, very excited to find this field, and I thought it'd be great if I could combine my internship of analyzing languages and computer technology. So after a year of studying at Ann Arbor I went back to Japan and finished my bachelor's degree.

One day a friend of mine pointed me to this textbook called Artificial Intelligence, by Dr. Elaine Rich. She was a computer science professor at the University of Texas in Austin, and she later moved on to a research consortium called MCC, also based in Austin, and she headed a natural language processing group in this consortium.

By this time it was clear to me that becoming a high school teacher was not what I really wanted for my career, so instead I decided to go to graduate school to study natural language processing in the United States. So I applied for and got a scholarship, and went to study at the University of Texas-Austin, and within two years I was working for Dr. Rich at MCC as a student intern.

After I graduated with my Ph.D degree, I got a full-time job with SRA, my current employer, in 1991; and this is how I ended up working in the computer technology field in the United States. SRA is actually the only company I worked for after graduate school. And I never worked in the public sector schools, and, but I think I have learned a lot during my career at SRA.

The Women's Summit organizer sent me a few questions. Maybe I can answer some of the questions for you right now. One of the questions I received was, "What are pros and cons of women in the private sector versus the public sector?"

I don't think I can speak of pros and cons, but I think there are definitely differences in emphasis in the private sector. For example, in the private sector, your ability to develop an applied technology to solve business problems is very important. And consequently, the emphasis is more on applied research and less on basic research. And research includes a shorter term. Also there is less emphasis on science and more emphasis on engineering.

In the private sector, being practical is very important because we have a contract with customers, so we have to deliver the best possible solution given the time and resources available. The interesting thing is that there is not always a correlation between the intrinsic sophistication of the system of the product used and customer satisfaction. And unlike an academic environment, the public sector does not count that much especially in a company like ours. Those are some of the differences between the public sector and the private sector.

Another questions was, "What skills do young women need to cultivate to be successful in the private sector? First of all, I highly recommend that students seek internship opportunities in companies. I, myself, spent four years as a student intern when I was a graduate student. Our company hires student interns from local universities, and sometimes we hire them as full-time employees when they graduate.

I really think internships give you not only deliverance of technical skills needed in the company, but also skills necessary to work in a corporate culture, such as interacting with a supervisor and so forth.

Another point: Being adaptable and a quick learner is very important because technology changes very fast, and having a particular degree, say computer science, is not always as important as 
being able to learn new things very quickly to adapt to your company's needs or customers' needs.

Of course, good written and oral communications are very important. When I was a graduate student I really never thought I'd write or give presentations as much as I do now, so sometimes these are neglected in the schools, especially in engineering schools, but they are very important skills.

And finally, teamwork: It is very essential. We typically work in teams when given projects, so a person with great technical skills but little ability to work with others can become very problematic for the project to succeed.

Another questions was, "What are the hardest skills to master?" There are three things that come to mind for me: The first one is discussing issues with upper management. It's still very hard for me. Your upper management offers you different communication styles, backgrounds, knowledge and perspectives. And you really have to understand these differences when talking to upper management.

The second thing is making personal connections with a wide range of colleagues. That's another difficult skill for me to master, in part because I'm pretty introverted. But for making alliances, having future collaborations, having influence-making personal connections is really important in the company.

The third hardest skill to master is marketing myself within the company. Compared to 10 years ago, I speak up more in meetings; I am much more assertive; and I pay attention to having a "presence" at meetings. For example, I do not sit at the back of a conference room anymore, but I am really being assertive, having presence. These are really important skills in my mind.

Another question was, "What skills do supervisory women need to develop better in the private sector perspective?" There are two things I really strive for, myself. First is the ability to see changing opportunities for your staff so they that can grow. Another thing is the ability to mentor people who you can trust and delegate your work to. It's sometimes hard to let go of what you know well or what you're really used to, but this will also enable you to accomplish more in this kind of corporate setting.

I think my time's up, so if there's any questions, I will take them now. Thank you so much. 


\title{
NEGOTIATING PROGRAM OVERLOAD AND PROFESSIONAL CHANGE
}

\author{
June Ramos \\ Consultant, Zoë Training and Consulting
}

Okay. How are you doing? Great? Good, that's good. Lots of energy, I like to hear that. Good morning so far? Yes? Thumbs up? Give them a hand. Thank you, good job. [Applause] Morning, and by the way, we want to say hello and acknowledge our people in Boulder. Hello, Boulder. How are you doing? I see them here on our television. This is a simulcast presentation. There are a lot of good people in Boulder who I have had an opportunity to work with.

This conference is focusing on some of the diversity issues; and what is required for success, for getting ahead. This conference raised the vision that in five to 10 years we won't need to have these kinds of conferences. As a person who has done a lot of diversity training in my business, one of the things I recognized early on is that we need to create a language of inclusion, rather than exclusion. And I want to make sure that we have a focus that diversity is not about either/or. It is both/and thinking. It's almost a dynamic tension or paradox-how do we create both/and thinking, because our task is not about women replacing, or under-represented minorities replacing, white males. And we never want to leave the impression that the white male is the bad guy. So first of all, I want to acknowledge any of you who fall into that category as a white male. Thank you for being here and creating the dialogue and the conversation and being willing to listen and support and do what is necessary to create the both/and mentality. So would you acknowledge the white males and everybody else who is in the room this morning? Important? Yes. All okay? Good job.

I was struck by the conversation of Dr. Aone when she was talking about what are the skills necessary for people to get ahead, not only in the private sector, but also certainly in the public sector. My background is as a consultant and trainer for over 25 years in the field of communication and corporate training for Fortune 500 companies. I and I started my own business 12 years ago. I'm still in the beginning of my $12^{\text {th }}$ anniversary, which is, how do you create success. How do you create professional success in whatever field you might have?

I was asked to speak regarding the issue of program overload. I am not a scientist. I'm not a technical person. I'm a person who does that soft stuff, the human stuff. So we're going to be looking at the issues related to some of the skills that Dr. Aone talked about. She mentioned flexibility and adaptability, communication, getting along with other people. I'm going to be looking at some areas that might assist you as you wind your way through the jungle out there toward whatever you define as professional and personal success.

And so my title for my program is "Negotiating Program Overload and Professional Change." Some of you are thinking, "What does that mean?" And we're going to talk about that. I represent a company, a broker of independent consultants, Zoë Training, out of Boulder, Colorado. I'm actually in Evergreen and have lived there about the last three years. We're going to be looking at some of the areas related to professional success and managing in a world of "hurry, faster." You have heard those terms. 
I want to ask you some questions. Raise your hand if this is true for you: How many of you recently have felt your heart skip a beat? Okay, have frequent headaches? And by the way, the medical doctors tell us-she's raising both hands back there-the doctors tell us that frequent headaches are more than 70 a year, and some of you are thinking, I get that many in a week! How many of you have difficulty sometimes catching your breath, or you find yourself hyperventilating? How many of you have difficulty keeping your hands and feet warm? Interestingly enough, this is a response when you find yourself in too much stress. And those of you who are familiar with the stress response, the fight or flight, that literally all of the blood goes into the main part of your body to protect your major organs. And your hands and your feet get little or no blood. That is why our feet and hands are always cold. We never re-circulate because we never come out of the stress symptoms of "hurry, faster!"

How many of you have ceased to be excited about events that once excited you and interested you? And that includes your spouse in this category. [Laughter] Yes. How many of you have found that your sleep is less restful, or you have difficulty falling asleep, or you wake up in the middle of the night-interrupted sleep? How many of you have poor eating habits-you are eating faster, maybe even talking with your mouth full and then an hour later can't even remember what you ate? Yes.

And I know this is a city-I come from Colorado where a lot of people still drive. But this is a city that has good metro transportation. But those of you who drive, when you drive for errands, how many of you find that your driving habits have gotten much worse? That you are weaving in and out of traffic just to get to your location at least five seconds earlier than the person behind you. Right? Yes. You are more reckless. You are taking more chances.

How many of you are trying to do two or three things at once? Yes. People come to my time management classes and they say, "My boss sent me here to get fixed. I have to learn how to multi-task." The truth is that when you are focused on important things you need your best concentration and attention, and it is difficult to multi-task. But we know what multi-task is. You know what that is: You're sitting at your desk, you are eating your lunch, you are checking your e-mail with your phone crooked over here, and you're also checking your voice mail and taking a quick look at your paper mail; and when somebody walks by and they ask; "Do you have a minute? Are you busy?" You say, "No, come on in, I am not doing a thing."

We have learned to multi-task. And all these are symptoms of what I call "hurry sickness." Hurry, hurry, and hurry. Do it faster. Do more. Do more with less. And we are in a world of overwhelm. And as a result of this overwhelm, we are creating a great deal more stress for ourselves-men and women included. And life is getting more challenging, yes? And it is difficult to focus, and not be distracted by many little things. And how do you know what is important?

And so my talk again is "negotiating program overload." Let me check an assumption, first. Sol [del Ande Eaton] told me many people in this organization are really challenged by work overload. Is there anybody in here who does not have work overload? You have got plenty of time on your hands and you're thinking, "What is she talking about?" Just checking. Right? No? The rest of us? All of us are dealing with this world of "hurry, faster," and maybe even the "world of more." Let me talk to you about some of the challenges that we are facing in organizations both in the private sector and in the public sector. And I do work in both. I have the 
opportunity to do that. On the left side is probably more of the traditional model of what our organizations and agencies look like. Maybe for some of you it still looks that way, maybe for some it looked that way five or 10 years ago. As we pass into the $21^{\text {st }}$ century we are moving more into the right side of the model and some of the challenges that create "hurry, faster," program overload, and all of the changes that you are currently facing.

We used to live in a world of organizational independence. "I'm here to do my job, just do my own thing, thank you very much. Just leave me alone. I'm going to produce some results." And now, organizations are asking for much more collaboration: teamwork. How many of you realize that you can't get things done unless you rely on other people? Absolutely; and thank goodness we have other people and their brains. But the challenge that you face as a result of collaboration and teamwork is that more people are counting on you, and if more people are counting on you they are asking more of you. They are asking for assistance and help. They want you to do things to assist them, and it requires more time, more of your time. And you are also dependent on other people for action and results. Is that not true? Dr. Aone said we have to learn how to be more assertive. We have to ask for what we need and want in our lives. That becomes very important, and we'll talk more about that.

Barry Osprey wrote a book about the "good old days" called Managing at the Speed of Change, and he's talking about the 1980's. He said in the good old days, change was more evolutionary and slow, and you had time to prepare for, and plan for, and incorporate and implement and even study the effects of, and evaluate smartly the result of your change effort. Now, we're in the process of change after change after change: multiple changes. Things are moving so quickly, and we don't have any time, don't have any breathing space. Jeff Davidson wrote a book called Breathing Space, and he suggests we don't have the time to incorporate and remove ourselves from the stress. We literally have to step back and objectify and make better choices. When you manage at the speed of change, we don't always make the best decisions, or the challenges that face us make it hard to follow the rules-the old traditional model. There was always a set of rules and regulations and policies and procedures, yes? And now everybody challenges you: outof-the-box-thinking. The problem with out-of the box thinking is the rules on how to get outside the box are written on the outside of the box. [Laughter]. No wonder we can't do out-of-the-boxthinking, yet we're asked to think differently, take more risks.

All of these are changes that you are dealing with, that impact you and your workload and organizations that were traditional, management-driven, hierarchical, bureaucratic, still exist in some areas. But now we're also asking employees to contribute at this level called empowerment. "Be empowered!" You know, the danger with empowerment is most people don't really know what it is. First of all, you cannot empower anybody. It is an internal choice. As a manager or supervisor or team leader, you can create an environment or an atmosphere for which empowerment will occur. But the empowerment typically associated in the organizations that I currently work with, I call it empowerment with a leash: Go out and do your best work. Use common sense and common judgment at all times, but check with me [the manager] first before making a decision.

And the challenges that you face with that, challenges of structured time and space, the traditional model of working from 8:00 to 5:00, you always had a place to go to. You had an office. You had a place to work. You had a place to put your stuff and your family pictures. And a lot of organizations that I'm currently working with, including some of the high-tech 
organizations including IBM, they're operating from a lot of flexible office structure and alternative work environments. And you were talking about that here. Now we're dealing with virtual offices and virtual teams, so communication becomes even more challenging for us. Where are people when I need them? I need to make a decision quickly. How do I communicate when people are not as available? And in some organizations, people aren't even assigned offices. They operate out of their home. They have drop-in workstations and they come in when they need to, but basically they're out doing the things that they do best.

Traditionally there used to be a right answer, or at least people thought there was a right answer, and now I'm not even sure there is a right answer. I think the challenge that is facing us is: Are we asking the right questions to move forward? And what are the questions we should be asking? So as we look at negotiating program overload and managing change, what does that mean for you?

One of the first things you need to look at is that human emotion called, how do I deal with change? Some of you love change for the sake of change. You love change-yes! "Let's do it differently. What a wonderful opportunity! What a great idea!"

Most of us, however, resist change, despite the fact that we like it, and we want to encourage it in many areas. Even when you are in charge of your change, sometimes you go through what is called the "valley of despair." "Oh, my gosh. I asked for it. Here it is." And, "What was I thinking?" Right?

When they are not in charge of the change, most often people resist, okay? That is almost an automatic. Let me give you an example. How many of you are wearing watches? Let's do a little experiment, if you are willing to do that: Take your watch off. This is going to be my version of "effective immediately." You know the memos we get in the organization? "Effective immediately, take off your watch." If you are not wearing one, okay. Now, put your watch on the opposite wrist. Some of you are already thinking, "I'm not going to do this silly exercise. I don't know what she is doing." Make sure you put it on so you can read it-a lot of people might put their watches on upside down. Okay? Now, how does it feel? Different? Uncomfortable? Okay. Here's my challenge to you. It's for you to practice change, and see how or if you resist change. What is your comfort zone around change, with something as simple as changing how you wear your watch. See if you can leave your watch on the other wrist until the conference is over today at 4:00. Some of you are thinking, "I'll take it off at lunch time. They won't see me and they won't know what wrist I had it on, initially." And some of you think, "It's not a problem. I can do that." Notice what happens, automatically at lunchtime when somebody asks, "Is it time to come back to the conference, we want to hear Dr. Morella at 1:30." You'll say, "Let me see what time it is-oops! Wrong hand!" We go on automatic, right?

Okay. We'll look at some of the aspects of relating to change. As we do that, what I would like you to do is to identify what are the five biggest changes that you are facing organizationally or personally today. Some of you got the handout. If you didn't get a copy yet, jot down on your sheet the top five changes that are impacting you, good, bad or indifferent. Take one moment to do that, please. Jot those down. And what is the impact of those changes on you? Sorry, folks in Boulder, we don't have a handout for you, but you can do this and talk to your partners about this.

Okay, I think we can probably do this without the microphones. Talk to me briefly about some of 
the changes that are currently impacting you, and what is the impact on you? Speak really loud so people can hear you.

Security is everywhere. Okay. Everywhere you look, right?

I'm getting older. [Laughter] And better, I'm sure! Right? I'm getting older. A big change. And by the way, are we change-resistant or change-resilient on that issue?

Approaching retirement. Looking forward to it? I don't know. I don't know. Big question mark! My kids are getting older. My kids are getting older. What else are some of the changes that you are currently facing, professionally or personally?

Marketing myself. We have another consultant in the audience, and she's changing direction in terms of where she wants to move her business and marketing herself. Talk about a big career change!

Okay. What is the impact of these changes on you? What does this mean for you? Well, part of what this means for you is, number one, you have to look at your ability to deal with the change and how you react to the change. What are the choices that you will make, and how are you going to live your life? We're going to look at negotiating program overload. One of your changes is that you are doing more with less and trying to get a lot more done with less resources? Absolutely. The majority of the people in the room are raising their hand. Right. So we need to look at some of those things.

One of the questions I always like to ask myself-I'm always reminded of this, "Who is in charge of my life?" Notice my typo at the top of my slide. I'm on the airline last night, already left Denver, And halfway from Denver to the Baltimore airport, and I'm going through my slides and refreshing myself on what I was going to say this morning, and I saw this typo "choices." Now let me tell you, in the good old days when I was a victim, and I was not in charge of my life, my immediate response is: "That darned spellchecker. All my computer's fault. You know, you just can't get good equipment, good software." Okay. Now, by the way, I want you to know I immediately went to "spellchecker problems." But the nice thing about what I'm going to talk about in a moment-it's called being proactive and being in charge of your life, which is being accountable and responsible for the choices you make regarding program overload and negotiating the changes that are going on in your life-is that you can no longer can be a victim and blame other people or other things. I made that mistake. But now I take full responsibility for it. And I'm going to rationalize and justify it to you - the mark of a creative mind is the ability of the person to spell the same word many ways! [Laughter] I blew it.

But, I want to talk about some choices that you can and should make relative to who is in charge of your life. And, there are some key things that are important: Stop, challenge, and choose. I'm going to talk more about that. And it says be proactive, another one of those buzz words that came out in the late 1990's. Empowerment, pro-activity_what the heck is it? I'll be talking to you about that, and also about how to say "no" appropriately.

And remember, Dr. Aone said one of the things that is important is to be much more assertive in our presentation of self. And I was listening to Dr. Olsen talk about her pay-raise and simply asking for what you need and want in your life. But you have to be clear about what you need and 
want in your life, so saying "no" is an appropriate response. And making the best use of the time that you have. How many of you have lives other than here at NIST? Thank you! Workaholics are going, "What does she mean by that question?" But, yes, you are balancing many opportunities and schedules. Some of you are involved in your churches and your spiritual development. You're involved in community and/or civic responsibilities. You serve on boards and associations. You participate in the local school area, you are parents, you have personal lives. What is the best use of your time right now? You must make the best use of the time that you have.

We need to learn how to manage change proactively. And what does that mean? What are we talking about here? Now, when you are dealing with all of the issues that you face, individually, professionally, and personally, you are going to make different choices-that key word, even if it is spelled wrong, is very important: choices. You must make choices, and I hope you will make informed choices.

But in order to get something else out of your life, you must change. Now some of you already knew this. This is not revolutionary material, is it? But notice how we resist. Was it Einstein who was attributed with a quotation: "Insanity is the art of doing the same thing over and over again, expecting a different result"? Now many of you are scientists, excuse me-and you know that you have to make some changes sometimes in your scientific process or your formulas. But what about our personal lives? This is what it looks like: It's morning and you are getting ready to go to work. You are running just a few moments late because of all that stress and the overload and all the things that you are trying to do at once, and you are looking for your car keys, and you are running around the house saying, "What did I do with those car keys? Oh, yeah, they're usually on my dresser bureau upstairs." And you race upstairs and they are not there. "Oh, wait, the coat I was wearing yesterday-maybe they're in the jacket." You go to the closet and look and there are no car keys. "I brought in groceries last night; maybe I left them on the kitchen counter." You go straight to the kitchen counter. No keys. "Oh, yes. When I came from the garage I probably put them on the little table on the foyer." And you go there. No car keys. And so what do we do? Insanity, the art of doing the same thing over and over again, expecting a different result. We scratch our heads wondering where the heck are my car keys. And we go back upstairs to the bedroom, to the exact bureau (that) we looked at five minutes ago, hoping miraculously that our car keys will have appeared. Insanity. I saw a great bumper sticker on a car in Boulder: "Nothing changes, if nothing changes." And we all know this to be true, yes? Yes. Okay. You must do things differently. So if you want to create different results in your life, you must make different responses.

Stop, challenge and choose. Be proactive. Learn how to say "no" appropriately. I'm going to talk about that and give you some scripts. We're going to make the best use of the time you have. You have to make choices about that. And finally, learn how to manage change proactively. So what does that mean? Proactive definitions: How many of you heard that term before, you just need to be more proactive? And you're thinking, "Okay. I can do that if I only knew what it is." I work with Jacqueline Reid, who is the founder of the Conference for Women in Government, and she did a series of symposiums and seminars on pro-activity. And this is her definition, and I'm on her faculty, so I am plagiarizing with permission here: "Pro-activity: the healthy, adaptive response to external change that empowers the responder and produces positive growth and well being." 
A "healthy response" — what does that mean? You are responsible for your choices, you're going to operate from a place of values and you can predict your future by creating it. Henry David Thoreau said, "I know of no more encouraging fact than the unquestionability of man-or woman - to elevate his life by conscious endeavor." We can make the appropriate mental shift to manage life differently. Make better choices and produce better results. So what that means for you is, number one, you are no longer a victim. You can't go out and blame other people. You must be responsible and accountable, okay? That is the good news. And you can no longer engage in this activity that I refer to as BCP\&M. Bitch, Complain, Piss and Moan.

Here's one of the clear directives I got from Sol when she was talking to me about planning this conference. She said, "June, there are a lot of things that are working in this organization and there are a lot of things that don't work. And what we don't want to create are bitch sessions where people complain and talk about how awful life is. We want to look at reality realistically, and then we want to make better choices and recommendations for the future." And whether that is in managing gender differences, hiring, firing, pay equity, job promotions, opportunity, mentoring and coaching, career advancement-whatever the issue is for you, you are the person who is in charge of your life. What choices will you make to further your career and get what you need and want? And manage a system that, by the way, historically has not been very accommodating to women and under-represented minorities and people with disabilities, et cetera. Let's get honest. We have to look at the reality. And thank you for some great statistics and references to what the world used to be. Let's talk about what the world could be through pro-activity and choice. Operate from a place of choice. Okay?

You have a copy of this pro-activity autobiography in your workbook handout. But for those of you especially in Boulder-you don't have a copy of this-let me refer this to you.

\section{Chapter 1.}

I walk down the street.

There is a deep hole in the sidewalk.

I fall in.

I am lost.

I am helpless and hopeless.

It isn't my fault.

It takes forever to find a way out.

\section{Chapter 2.}

I walk down the same street.

There is a deep hole in the sidewalk.

I pretend I don't see it.

I fall in again.

I can't believe I' $m$ in the same place.

But it isn't my fault.

It still takes along time to get out.

\section{Chapter 3.}

I walk down the same street.

There is a deep hole in the sidewalk.

I see that it is there. 
I still fall in.

It is a habit.

My eyes are open.

I know where I am.

It is my fault.

I get out immediately.

\section{Chapter 4.}

I walk down the same street.

There is a deep hole in the sidewalk.

I walk around it.

\section{Chapter 5.}

I walk down another street.

Okay? That's from the Tibetan Book of Living and Dying. Pro-activity is the result of making better choices. And as we look at the ability to make better choices, what do we do differently? By working from the Book of the Living and Dying, already we are using great examples. It is a wonderful representation of the model of stop, challenge and choose, which I want to talk about next.

Okay. Life happens, yes? There are good things in life; there are bad things that happen in our lives. Life happens. And our natural response and habit similar to the autobiography is that sometimes we operate on automatic. What does that mean? I want to focus on doing things differently.

Stop, challenge and choose. Let me give you an example of an automatic response where I am a victim. I'm in my BCP\&M mode, and I'm looking outside of myself to blame everybody. I'm going to talk about this in a moment, learning how to say "yes" and "no" appropriately, being assertive and negotiating for what you need and want in your life. Some of you might be thinking-or maybe you thought this in the past: "I can't say no to my division director. Because you know what? She'll fire me. You can't say no in this organization. And if she fires me-have you looked at the economy lately? And who is hiring and who is not hiring? I'm pretty sure that I'm not going to be able to find a job. Certainly not at my age and, you know, some of my computer skills are lacking. And they're looking for people they can bring into this organization at a much lower salary than me, so I'm probably not going to have an opportunity to find another job, and I'll have to stay at home. Oh, sure, it will be fun to watch "Oprah" for a little while--I don't know how long that will last. But pretty soon I'm pretty sure my family will find me boring. In fact, I'm pretty sure they'll take a vote. She's a boring mom, a boring partner in life. I bet the dog will even growl when I start walking in the door. They'll take a vote and kick me out and I'll become a bag lady on the streets of Washington, DC. The weather is not bad now. What happens if a storm comes, and I'm a bag lady, and some morning I just might wake up dead? I can't say no to my division director!"

That is what I call a disaster-fantasy. And we go straight in our brains about what we can and we can't do without first determining is it even possible? Could I say no? Could my division director or my boss, whomever that might be, be a wise person, a good manager, supervisor, who recognizes the importance of managing resources? But we go into automatic, so I'm going to 
suggest instead of that disaster-fantasy that, first of all, you have to stop yourself. Before you respond to an event without even thinking, you are your best intervention. Stop. My normal pattern is to immediately go into assumption, disaster-fantasy or whatever. You become your best intervention. And then, based on the next step, you challenge your own thinking process. What am I currently making up about this situation? What is true? What other data or interpretation or evidence do I have that will help me see this differently? And then I can choose or select a different response? And I want to do something different to produce a better result. Yes? Okay? So we stop, we challenge, and we choose.

Think about situations and scenarios in your own life where you go into an automatic reactive response. What do you tell yourself? What does it stop you from doing? What prevents you from exploring other alternatives? What you have to do is "reframe" your own brain and your thinking process. What can I do differently? Okay?

So, I'm a trainer. I am a consultantitrainer, and while I do frequent keynote speeches, I recognize that the mind can only absorb as much as the body can withstand. And if you have to sit all day long without participating and being passive, that you're going to start checking out mentally. So my opportunity for you is, I want to you do something for me. We'll do a quick little exercise so that you can see what you can do differently. Stop, challenge, and choose. I can stand up here and talk about this until the cows come home, but until you experience it for yourself, you will probably have difficulty making the next logical leap. So I want to you work with a partner. If that means you have to sit closer to somebody, indulge me on this, because it will be a very powerful exercise.

I want you to think of a recent experience where you went into automatic complaining, $B C P \& M^{15}$. It's all their fault, it's all about-whatever kind of disaster fantasy. Explain that scenario to your partner very briefly, and with the help of your partner, I want you to reframe it positively.

Stop, challenge, and choose. What are some other alternatives? What other choices do you have? What other perspectives and points of view? What is a reframe that is more positive than your automatic negative? Now if you don't go into negative thinking, then you're going to be a great resource to your partner who might. We're just going to do this for five minutes. I want you to practice the stop, challenge, and choose. Take a situation, operate from the complete reactivenegative mode of BCP\&M. Explain that and then work with your partner to think about a better way to stop, challenge, and choose. Use each other as resources. Take about five minutes to do that. People in Boulder, I can' t hear what you are saying but I would love to have you each choose a partner. Looks like you got a couple people there. Choose somebody to talk to and see if this exercise might be helpful for you, okay? Start with the negative and then refocus on the positive. [People chatting; five minutes elapsed.]

Okay. Can I draw your attention back up here-one minute? A woman who asked for what she needs and wants in life. I'm going to give you an extra minute. Thank you! She's learned how to negotiate and say no. Good job. One minute. Okay. They're finished! Asked for a minute, and because I'm so indulgent I gave you a minute and 45 Seconds. So now what did you discover as you went through that exercise? What kind of assistance or help did you give yourself or your

15 "Bitch, complain, piss and moan!" 
partners gave you to help yourself?

Stop, challenge, and choose. Choose a different response or reaction? Quick feedback? You got a different perspective and you got a great partner who could give you that great perspective. Be sure to thank your partner. Teamwork does work! Collaboration. Guess what? If we knew how to do this on our own we probably would have done it. So it's nice to know that there are other people who have great ideas that they can assist me to expand my perspective, see I differently, and make better choices. What else do you discover, anybody?

The problem doesn't always seem as big, once you start talking about it, as you were first led to believe. How many of you had that response? You started talking to a partner out loud and you're thinking to yourself, "Here is this voice in the back of your brain-how many of you had that voice? The one saying to you now, what voice? I don't talk to myself! [Laughter] As you are telling your partner, saying that doesn't sound nearly as bad as-she must think I'm a complete idiot, and he's looking at me funny. So, it actually does put it into perspective. So, you know, if you actually go to a psychologist/therapist, what, $\$ 100, \$ 150$ an hour? Think of this as five minutes of free therapy. Yes?

Okay. Maybe you got some validation that it is real, and if it is a real scenario, now you still have to make better choices about how you're going to handle it. "It's not my imagination. This is a tough situation. I don't feel like I have power or influence or control. Thank goodness she sees my same problem, she's just as sick as I-No! I've got validation."

And the next step is to brainstorm. "What will I do differently, and what additional action could I take, if anything?" Did it help you put perspective on that? Good. Any other thoughts? Here's what happens when you use this model, this thinking model, getting out of the natural habit of going into automatic, when you feel like you have the ability to make choices, when you feel that place in your brain or your heart, you can explore and create greater options. And then you feel that you have options from which to choose. There is a great deal of freedom in that whole process. So, if you walk away with nothing else take this perspective: What are the choices I have? Who is in charge of my life? I am. What choices can I make? What better choices can I make to assist me? Make sense? Okay.

Now, here's part of the process that men and women suffer from in this whole dynamic of managing change. Remember, I said the old rules no longer are working. We don't have a stepby-step policy or procedure or rule manual. Well, the nature of work is changing dramatically. The rules of work, the old versus the new, and to some extent of course, the left side is always going to be true. Again, it is a paradox, a dynamic tension. It is both/and, not necessarily either/or. But in the traditional model your job controls your hours versus the new approach, a very proactive approach, that says you choose how you spend your time. You're in charge of making your choices, managing your time and priorities. On the left side, choosing personal life means a less rewarding career. Carol talked about that this morning, when she was saying people who took time off away from the fast-track were considered less serious and lost some of their credibility. Today, we are creating more options where you can make better choices regarding the balance of home and personal life, however you define personal life. Because there is not enough time to do everything, you must neglect everything. Sacrifices. You heard those terms. What are you willing to sacrifice? And I would like to create a different language pattern. What are the trade-offs that you would like to make versus the sacrifice? Because the truth is, you have enough 
time to do everything that is important to you.

Those of you who used to remember the commercials that we saw on TV, in all of the women's feminist movement, you can have it all! I think you can have what you choose. You can have what is most important to you. And what are the trade-offs? Because you are at a place of choice that you are willing to make, to have what you need and want in your life, the old rules work. Beth Sawi wrote a book called Coming Up for Air: How to Build a Balanced Life in a Workaholic World, and she tells the story of a woman who went to one of her workshops. She says something like, "I used to think it was my boss who made me work late, but she joined another organization a few weeks ago. And I don't currently have a supervisor. The weird thing is, I still work long hours. Even though there is nothing urgent happening these days, I didn't go home until 7:00 last night. I thought about leaving earlier, but just didn't feel right. It was then I realized that I am the one who is making me work all of the long hours. I had been getting angry at my boss for something that she didn't even do."

Isn't that interesting? Yes! Because many of you operate from this thing called guilt. How many of you have guilt in your life? Guilt, the gift that keeps on giving, and giving, and giving, right? And many of you also operate not only from guilt. How many of you operate from another problem called perfectionism? I just need to get it right, more perfect than it already was. Right? And we spend another 85 percent of our time trying to make it 10 percent better. You might even say to yourself in the world of guilt and perfectionism, I'm going to just work a little bit later this evening until I get everything done.

You know, you'll never get everything done. You always have more to do. You must make choices about when you are going to leave and how you choose to spend your time. And what is the balance that you are looking for when you want to move away from the work and create that balance in life? And choosing the important things. A father went home frequently from working one of my seminars. And he said his little young son said, "Daddy, why do you always come home with that briefcase and you always have all those papers in it and you're always working at home?" And the father looked at his son and he says, "Honey, it is the nature of my job. I just can't get everything done at work." And the little boy looked at him and says, "Well, Daddy, why don't they put you in a slower class?" [Laughter] Right?

You know, sometimes because of this guilt, on the old side of the model we think that we are indispensable. Nobody can do it as well as me. I'm the only one who can get everything done. Perfectionism. A woman was talking about how she had recently been in a horrible car accident. She was crossing the road. After she went through the initial healing process she had to work part-time to ease back into work. And had to reduce her work schedule significantly. And she said, normally we worked from 50 to 60 hours a week. But because she was no longer able to uphold that type of schedule she said she had to make choices about what she could and couldn't do and delegate things, and she was worried about delegating because nobody can do it as well or the same, right? And what are the things I'm going to leave off of my plate? And she said after a few weeks of this, she discovered that the office went along famously without her. The stuff that she actually delegated to her staff was done quite well, thank you very much. And the stuff that she chose not to do on her list of things to do, nobody asked her about it.

What are we doing in terms of managing our work life? And what are the excuses that we use for working long hours and creating our own overload? Now again I want to be realistic. I do know 
that there is a lot of work overload that you can't get rid of. There is a lot of stuff happening, but how do you choose to spend your time? What are the choices that favor you getting the things done that you want-so you have the development that you need and want, and you produce the right results, and you can still go home at a reasonable hour and have a life?

Saying "no," appropriately. One of the key skills that will help to you do that is your ability to negotiate and just say "no." Is there anybody in this room who has difficulty saying "no"? Okay. And those of you who didn't raise your hand, you either rare, just really good at it, or you just didn't want to raise your hand, right? I can't say "no," but I'm not raising my hand. Just say "no." And I would add the word "appropriately."

You don't want to be perceived as a two-year-old kid who just learned the word no, because if your boss came to you and said, I want you to work on this project, and you said "no," I would think that that would be a "CLM," a "career-limiting move." And even if you were raised to be polite, "no, thank you" may not be the appropriate phrase. So, I'm going to give you some examples of how to re-script your "no," where you are truly in the process of negotiation rather than just saying "no." And understand that "no" is indeed a choice. Guess what? If you are saying "yes" to everybody else's demands, what are the demands on your list of things to do that you are saying "no" to? And sometimes, the first person that you have to learn how to say "no" to is yourself.

What is the best use of my time? What should I be spending my time on? Now, do think about the consequences. Make this an informed choice. There is always a cost-benefit analysis associated with using the word "no." If I say "no" to you, what do I lose? What is the downside? If I say "no," what is the upside? What is the positive reward? If I say "yes" to you, what's the downside? I can't get my work done. I have to give up something else. So there is always positive and negative. You have to make an informed choice. Deal with that quickly. So if you say "yes" to somebody else's demand, what are you saying "no" to on your list? And I'm going to talk about this in a moment. Focus on quadrant II. This is what Stephen Covey in The Seven Habits of Highly Effective People talks about. It is a lot easier to say "no" when you know your own personal priorities. Let me give you some examples of learning how to say "no." Because I learned early on in my career that saying "no" is indeed a choice. I worked for a boss who was actually-I inherited him. And I'm pretty sure that he learned his management skills from Attila the Hun: traditional manager; bureaucratic; go-for-this-do-this; no praise; no recognition. Well, he sent me to this class on time management and assessing your priority. This was early on in my career in the late 1970's - and I learned how to say "no"; and I think at that point he was really sorry he ever sent me to that class, because he was typical of the type of manager who would come in at the last minute and give me something to do. And it was urgent. This might be Friday afternoon-12:00 noon. I had planned my day. I had learned how to prioritize. I went to this class. I was clear on my priorities and what my work plan looked like for the remainder of the day. He came into my office-we were working in corporate communications at the time, and we wrote, frequently, position papers on community issues-interests primarily related to environmental impact, and those kinds of interests for our community. I was working in a hightech organization that had a lot of dangerous materials. So the citizen groups were very concerned about what was spewing into the atmosphere and into the water and into the soil. And so I was always writing position papers for the media and citizens action groups, et cetera. At noon on Friday he would come into my office and say, I need you to write a position paper on such-and-such topic and I need it by close of business today. Okay. 
I learned how to say "no." But I know that I also don't want to go around saying "no," so I wanted to gather some information so I could make an informed choice. And I remembered one thing about his Friday schedule. He usually came in with a van pool, a car pool on Mondays, Wednesdays and Fridays, and typically left at 4:00 p.m. on Fridays. This particular Friday I was leaving at 4:45. My day did not end until later. So I asked him what I thought was a smart question: "Is that my close of business, Jerry, or your close of business? And he says, "What do you mean?" And I said, "I'm not leaving until after you. You're going home in the van pool, aren't you?" And, "yes," he said. And I said, "I'm not leaving until 4:45." And he said "Oh, yeah. Have it on my desk when you leave. And I'm a smart woman. Why would I work so hard to change my schedule - oh, he must be working this weekend. So I asked what I thought was the next logical question: "Jerry, are you working this weekend?" You would have thought I was asking about his personal life and all the skeletons in his closet. "What do you mean?" "Jerry, if I put it on your desk after you leave, I'm going to assume that you will work on it this weekend." "Oh, I'm not working this weekend." I said, "Oh, great. So if I had it on your desk by Monday at 8:00 would that be okay?" He said, "Yeah, fine."

Now look what I just bought myself. I didn't have to change my schedule on Friday, and if I needed to I could work the weekend. You know what? I didn't want to work the weekend, so I asked the next logical question: "Jerry, when will you have a chance to look at this on Monday?" I knew that every morning at 8:00 to 10:00 in the morning he went to a general director's staff meeting. I said, "Will you have a chance to look at this before you go to general staff?" He says, "I doubt it."

And I said, "Great. So if I had it on your desk by the time you finished general staff, about 10:00, would that work for you?"

And he didn't miss a beat, and he said, "Yes, that's fine, but that's the last one." [Laughter] Now I'm a smart woman. I knew when to stop negotiating. And look what I bought myself, because I knew I could come in earlier Monday to complete the activity and still have it on his desk and not have to work the weekend or change my plans on Friday.

And interestingly enough the next time he gave me an assignment he came into my office, and in midstream he looked at me and goes, "You're going to do that thing with me, aren't you?" And I said, "No, Jerry, I'll ask you a simple question: Is this task negotiable? Can I say "no" to you? Is it okay to say "no"? And when the answer is "yes," let's negotiate. I want to exercise my influence and power. And if the answer is "no," then I also recognize what are the limits and boundaries."

But the first rule of negotiation, to manage any part of your life: change overload, work, and all priorities. You simply must ask for what you need and want in life to increase the probability of getting it. An interesting concept, and whether it is that pay raise you were talking about earlier this morning or whether it is a deadline, a scheduled activity. You must learn how to ask and say "yes" and "no" appropriately. And it is hard when that is your boss. Right? It may be easier to say "no" to other people in your life. Some of you are thinking, I can take off, say "no" to him or her, no problem. But this person, I could use some assistance. And it's really a challenge because when it is your boss, how do you say "no"?

I used to work for a manager who was brilliant and well read and constantly reading information in the area of organizational development and human resource management. And he loved to talk 
about the things he had read. And I discovered-this was another organization, and closing time was about 4:30. He would frequently come into my office about 4:25 to talk to me about something new. And it would take time. I couldn't close out my day. I was finding myself going home later and later, and by the way, it was interesting. I liked what he was talking about. I had to manage my own stuff inside my brain. I had to make a better choice. But I also knew there were times when he was impacting my schedule. And finally in a moment of assertive bravery, I looked at him and I said, "Dan, I am delighted to have this conversation with you. This fascinates me. And I need to tell you that I'm really conflicted right now. I need to finish this, and work on this, and if we continue this conversation, I'm going to miss this deadline. I was wondering, could we go to lunch tomorrow and continue this conversation?"

“Oh, yes, by all means. Oh, I didn't mean to take up your time! That's really more important. So I learned early on to start re-scripting my "no" in a way that would assist me in becoming a better communicator. What does that look like for you? Well, first of all, before you can start saying "no" to anybody in your life, you must first be clear on what is important in your life and what is urgent. Stephen Covey talks about the "Quadrant 2" time management system. I learned it many, many, years ago, early in my career as the Hi PO/Low PO model. And I do believe if you are going to invest two days of your life in this Summit that you should walk away with new acronyms and buzz words to impress all the people who were not here. Today's buzzword that you can use is Hi PO/Low PO, and it simply stands for high payoffs and low payoffs and looks at both payoff and priority, urgency or importance.

Stephen Covey talks about "Quadrant 1"; the things that are really difficult and challenging to say "no" to are those in Quadrant 1. They are both important and urgent. You know the ones I'm talking about: scheduled activity. Appointments, crises and emergencies. If your computer were to go down, how many of you would have difficulty getting your work done? That's a crisis and an emergency, right? So we get on the phone with the Help Desk: "I need assistance-somebody help me solve this problem. Customer or client, internal. If you get a request from a legislator or somebody who is looking for information, because a Congressman or Congresswoman is coming to town, you probably stop everything to handle those activities. Probably the easiest part of time management, by the way, and learning how to say "yes" and "no" appropriately. The problem with Quadrant 1 is, too many one's. Everything seems to be a one. Right?

The most challenging part of managing priorities and saying yes and no appropriately is Quadrant 2: those activities are still a "HI-PO," still a high pay-off, but it has a low priority. How is it possible that something that can be important cannot be urgent? This is the delay-able stuff: the long-term goals and objectives; your three-month project. You're going to take some time to write a book and you're going to take some time to do that. It is not necessarily urgent if you don't currently have a publisher. You think, I would like to write this book. This would be kind of interesting: All of the things that you do for yourself. They are important but not urgent. This is also the quadrant of personal life. Who is the first person that you cross off on your list of things to do when you get overly busy? Yourself. Well, you know, I'll go to that dance recital later, or I really wanted to go to Johnny's soccer game, but I have to work late. Sorry. Tonight was the night I was going to go to my exercise class. I guess I'll have to go next week. I want to sign up-I promised the school district I was going to-I'm going to have to re-commit, postpone. That's the delay-able stuff. And by the way, Quadrant 2 usually doesn't get done until it becomes a Quadrant 1 - crisis-and-emergency, because now it is a deadline-driven activity. 
Quadrant 3: Low pay-off but high priority. Low payoff to you, not important to you, usually urgent to somebody else. And these are the things where sometimes it is easier to say "no" to, appropriately.

Quadrant 4: Low pay-off, low priority: couch potato; wasted time; junk time. Low payoff, low priority: things that you don't do; things in our organizations that used to be important that are no longer important. Nobody is asking about them. But we're still doing them: Reports that you spend hours preparing that nobody reads. Some of you are nodding and going, "Oh my gosh, we do that here." Right? Things that used to be important. And again, the time that you waste when you are thinking about-you know you have to do other things, I'm not getting it done.

That's Quadrant 4. Now, the goal of this is to recognize that when you are trying to say "yes" and "no" appropriately, it is a lot harder to say "no" to a crisis or an emergency. Be aware of the scenario, the situation and the circumstances. It is a lot easier to say "no" to somebody else's routine little thing if you have a deeper burning priority, but you must first have a clear idea of what that priority is for you. People who have clear ideas of their personal priorities are valuedriven. They are the ones who are more likely to be able to negotiate and say "yes" and "no" appropriately, because it is a lot easier to say "yes" to those activities, career, job-related, personally-related, if they are in line with your personal priorities. And there is a list on the next slide of some examples of personal priorities.

These are not all exhaustive. It is just a starting place, and again, for the sake of the Boulder group, this is a little harder to read, but let me talk through a few of these. What I would like the rest of you to do is identify very quickly when you hear one. Is this one of your top five? Narrow it down to the top five. Because most people can hold three to five things in their brain at any given time and really create success around that. Any more than that, you are just juggling-and maybe not very successfully. So, some of the items that are on this list are: being creative. It's a lot easier to say "yes" to somebody who wants you to use your creativity. Go down. Challenges and opportunities. Being active and healthy .One of those personal priorities. Your spirituality or your faith. Seeking adventure. Financial independence. For example: personal freedom. Making a difference. Be a whole person-how ever you define that. Be able to grow. Career development. Seeing the world. Using talent and skills. Achieving your goals and objectives. Giving back to your community. Having influence. Getting to the top of the organization.

A lot of choices. One of the things I would challenge you to do is first look at this list, take some thoughtful, reflective time after this program and ask yourself, "What are my top priorities related to my values in my life and my long-term goals and objectives?" And then once you have chosen those five, prioritize them. What is number one? What is number two? What is number three? And all the way down. And then see if you can use them as a place of negotiation-your internal negotiation.

So if somebody asks you to work on a project; to serve on a committee; to work with that school system; to work with that association; and you are consumed with guilt_-“I know I should," go back to your personal priorities and ask yourself, "Is this congruent with my personal priorities? Does it forward me toward my goals and my objectives in my life?"

It is easier to say "yes" to a demand, because that is part of your personal priority and your own personal goals and objectives. It is a lot easier to say "no" to somebody else's demand when there 
is a deeper burning "yes" inside you. But in order to say that "no," you must first have a clear idea of what that "yes" is. What is that personal priority? And so, I want to look at some of the ways to say "no" appropriately. And there are variations on this script. Find what works for you. Use the language patterns that match your style. But let me give you starting places.

How do you say "no" appropriately? There are several "no's" here:

- "The Prioritized No";

- "The Delegated No";

- "The Simplify No";

- "The Set-Time-Limits No";

- "The Procrastinate-in-a-Healthy-Way No"; and

- "The Eliminate-No."

The Prioritized No: "I'm sorry, I can't help you with that. I have so many other-or I have X, a specific commitment. I can't, simply can't, add anything more to my plate." Now when you are negotiating with your boss, use a variation of the Prioritized No: "Thank you for this opportunity, Boss/manager/supervisor/team leader-whomever. I currently have several other priorities. In order to make room for this, which of these other priorities can I postpone to make room for this new priority?" Get clarity on the priority. Okay? Delegate. "I'm sorry, I won't be able to help you. Have you asked so-and-so to do this? She or he might be able to help." Be careful whom you start using, because that person may not enjoy your delegation. But make sure it's clear, because it is based on resources in the organization.

The Simplify No: "I can't commit to everything you are asking for. But if there is something simple I can do, or if there is some short time commitment, I would be happy to help you." So now you are dissecting the demand and finding what little piece of that you could participate on.

The Set-Time-Limits-No: "I'm tight on time this week, so I can only spend a few minutes at the meeting, or I can only attend the meeting."

The Procrastinate-in-a-Healthy-Way No: "I really can't commit to that now. Maybe some other time. Ask me again. Or the Eliminate No." "I am sorry; I just don't do that type of activity anymore." Okay?

So, just keep it simple. Don't over-volunteer information. It is a starting place for negotiation. Just because you say "no" or use any variation of this script, people will not look at you and say: "Oh, great wise one, thank you for showing me the error of my ways." No, they are going to persist and they'll say, "Well, what part of this can you do?" And, "Are you sure you can't change your schedule?" And, "Oh, we really need your help!" You have to be assertive. You have to be clear in your communication. But saying "no" is usually the beginning of a negotiation rather than the end of a conversation. Beware of that. That process becomes very helpful to you.

Here is another story about Stephen Covey. I had a chance to spend a week in Sundance, Utah, and learn his program and meet him, and he tells the story of the Brilliant No that his wife used. Because of the nature of who they are and their community, they are frequently asked to serve on boards of directors. Stephen said he only heard one side of his wife's conversation, and it was clear that she was being asked to serve and be a representative on a board of directors for a fundraising activity for the community. And he heard her say, “Thank you very much. What a 
wonderful cause and a great opportunity to serve the community." Now you can just know this other person on the other end of the line is going, "Yes! She's going to say 'yes'! She's going to be on my committee!" And then she said, "I must say no at this time. I have so many other commitments that I could not give your committee the time and energy and direction and focus that it needs. But thank you for asking." Now was that one of the most polite "no's" that you have heard in your whole life? It is amazing.

You can say "no," but how do you negotiate? You must be really clear about what it is you are looking for. What do you want to accomplish? What-your deeper burning, yes, and by the way, if it does move you towards your personal priorities in any way at all, then by all means, say "yes." But be proactive. Stop, challenge and choose. Do not get into automatic where you are always saying "yes" to somebody else's demand, and the result of that is more work, more overload, more time, more late nights, working weekends and wondering how come everybody else gets to go home at reasonable hours and I'm still here? Learn how to say "no" appropriately. Re-script your "no" and the key actions that will assist you as a summary for your own proactivity.

What I am talking about is placing problems, changes, and situations in their proper perspective, gathering data to see the real issue clearly. What is really happening here? That is part of the stop, challenge and choose. And be proactive. There is a lot that goes on in this world, and you need to reinforce yourself in a positive way. I also recommend reflecting on positive thoughts, reading inspirational material. And whether that is spiritual material or other books or quotations, whatever that might be for you.

Stay focused. Stay positive. I'm not suggesting that you create this Pollyanna approach to life"Oh, life is wonderful! Isn't this great?" You know, we don't want to see the world through rosecolored glasses inappropriately. But do find the support system that maintains your positive frame of reference so you can choose better positive choices. Seek advice and counsel of wise people. Who in your life could serve as a coach, a counselor, a mentor, a good listener, a sounding board? Choose to be in charge of your emotions, your response.

And finally, view problems as opportunities for growth. I know that frequently in the world of work, we have learned ways of reframing language. People say we no longer have "problems" in our organization or agency. We have "opportunities." And the gag factor gets really high, because you have heard it so many times, right? But the truth is you can stop, challenge, and choose those opportunities, truly creating growth and development and a wholeness of being. And as a result of that, you can in fact be proactive. You can in fact create greater results. And remember the question I asked you at the beginning of my presentation? Who is in charge of your life? And the answer is? And the answer is? [I am.]

Thank you very much! Good luck. [Applause] 


\title{
INTRODUCTION OF CONGRESSWOMAN CONSTANCE A.MORELLA
}

\author{
Dr. Arden L. Bement, Jr. \\ Director, NIST
}

Good afternoon, and welcome to our colleagues in Boulder. It's been my pleasure on various occasions to introduce members of Congress. But I must tell you what a personal pleasure it is to introduce our next keynote speaker, the Honorable Constance A. Morella, known to us as "Connie." In my hearing last week on the World Trade Center, I noted that Chairman Boehlert ${ }^{16}$ referred to her as the "Angel of NIST." I was thinking to myself, "They found her out!" [Applause] But I can say there's no greater friend of NIST than her in Congress.

While her formal biography is in your Summit booklet, I cannot overstate how important Congresswoman Morella has been in the influence of science legislation in Congress and, of course you know, how important the implementation of science, engineering, and technology is to the Country.

On my own behalf, I would like you also to know that my own nervousness during my own Senate hearing was greatly abated by the wonderful introductory remarks that Ms. Morella gave on my behalf. And it emphasized a great deal of her human qualities in that introduction.

Ms. Morella is a sitting member of a 57-person, U.S. House of Representatives Science Committee. Some 107 Congressional bills have been referred to the Committee and subcommittees. Collectively, they have held at least 67 public hearings, and, on top of this, Ms. Morella is known for her attention to Federal workers, for key focus on national and international human rights abroad, and for her work to improve the lives of women.

In this Women's History Month, we could have no better spokesperson with us today than Ms. Morella. Please join me in a special NIST welcome to the Honorable Constance A. Morella. [Applause].

\footnotetext{
${ }^{16}$ Honorable Sherwood L. Boehlert, (R-NY), Chairman, House Science Committee, U.S. House of Representatives.
} 


\section{THE FEDERAL PICTURE}

\section{Honorable Constance A. Morella (R-MD)}

Thank you, thank you, Dr. Bement. I am very, very honored to be here. NIST is one of my favorite places. I talk about you a lot and in a very favorable context, that is. And I'm particularly pleased to be introduced by Dr. Bement. It is true that I had the honor of introducing him at his confirmation hearing. It was such a pleasure because of his credentials-his background; the fact that he came here as Director of NIST, knowing NIST from his service on the NIST Visiting Committee; the fact that he's been an educator; he's been involved in the Federal Government, as an assistant secretary; and most recently, having taught at Purdue University where they do move forward with the whole concept of women in mathematics, science, engineering and technology.

Dr. Bement has also comported himself, beautifully. You'd be very proud of him at our hearings before the Science Committee. At the most recent one, he mentioned what happened at the World Trade Center, "What do we know? What can we do to prevent this in the future?" I think we're going to find this to be a continuation for the benefit of us all. So it's really nice to be introduced by him, and to be here today.

Since this is Women's History Month, I will share with you my feeling that comes from a statement made by Elizabeth Taylor when she said to her eighth husband, "I won't keep you long." [Laughter]. Bad. And I really won't keep you, because I'm going back to Capital Hill, where I chair the D.C. Subcommittee which I think of as part of a region. I think this is important. For example, we will be considering the District of Columbia Tuition Access Bill; that will be coming up on the Hill. But I am pleased to be able to share some things with you and to let you know of my continued support.

First of all, to those of you who work here at NIST-101 years of age! I was here for the $100^{\text {th }}$ anniversary. And to think of 101 years of age; and it's the same longevity as the birth of the Nobel Prize. I just saw one of your Nobel Prize winners, Bill Phillips, ${ }^{17}$ who was in the cafeteria; and Eric Cornell ${ }^{18}$, our other one, this last year at the Boulder campus of NIST. You can be very proud of the fact that you have Nobel Prize Laureates here at NIST, and the fact that you do so many diversified things in terms of standards, in terms of measurements-whether we're talking about the fire services, about DNA, or about standards for mammograms. Or whatever it may be, it's all happening right here at NIST. So please know how proud I am of what you're doing, and how, with Dr. Bement, the others who are here, how we will be forwarding that message.

I want to mention a few people who are here, who have been participating actively, in this Women's History Month event. Dr. Kathie Olsen is just about there in terms of confirmation with the White House Office of Science and Technology Policy. I know she addressed the group earlier today. Of course, Dr. Karen Brown. June Ramos addressed you also. And the woman I work a lot with is Verna Hinds. She has always been most hospitable, most knowledgeable about what is happening here, and most devoted. And Sol del Ande Eaton, who is the Diversity

\footnotetext{
${ }^{17}$ Dr. William D. Phillips, co-winner of the 1997 Nobel Prize in Physics, National Institute of Standards \& Technology.

${ }^{18}$ Dr. Eric A. Cornell, co-winner of the 2001 Nobel Prize in Physics, National Institute of Standards \& Technology.
} 
Director, who has put this program together. These people all deserve recognition. Let's give them a round of applause. [Applause].

Yesterday I was at the White House along with a number of other members of Congress, Cabinet members, and families of the survivors of "9-11." It was the sixth-month anniversary. We all recall that just six months ago, when this tragedy happened, it filled us with grief, with anger, with anxiety, and with resolve-a resolve that we were going to be united in eradicating terrorism and as well, bigotry, that may go along with that. There is the sense that we have to work together. Representatives of many countries were there, and I must salute President Bush for having invited representatives of the various countries that are a part of our coalition working together to eradicate terrorism. But all of us-and you're in the right in the midst of it-must have patience and must persevere, and we must work together.

A Federal laboratory such as this has, has high security, traditionally. Of course you've always had the security for the deer and the geese which are out here surrounding the place. [Laughter]. But we have the same down on Capital Hill, the same at NIH, the same thing at NRC_-all of the Federal institutions and laboratories. And the story I have to tell is very typical. It happens to me every day when I go in to the Rayburn Garage. We have there a Capital Hill police officer. Then I also have several reservists-the D.C. Reserve. They wear the camouflage uniforms. Now, why in heaven's name to they wear the camouflage uniforms when they could be spotted immediately because they have the camouflage uniforms? It's never made sense to me. But then I have two other guards. First of all, they slide mirrors under the car; you open the trunk; they may well have a dog also that checks out your trunk.

And what happened to me not very long ago has happened in different ways: the police officer, the Capital Police officer says, "Hello, Mrs. Morella. How are you?" "Fine," I say. "You represent my mother, and she loves you-may I see your I.D?" [Laughter] And it's happened before, but with a different expression: "Hello. I know who you are, but may I see your I.D?" And so we're all becoming accustomed to that. We're accustomed to becoming patient. We're accustomed to allowing more time, because it's all worth it. And I agree. Again I thank you for what all our Federal workers do. And yes, indeed, I am very strongly your advocate.

As we look at Women's History Month, please know there have been plenty of women who have been involved in the conflict - a number of them who have been victims have died. I've been to many funerals, certainly of people in Montgomery County. We've also had heroes. Recently, we celebrated on Capitol Hill several women fire fighters and police officers who had such very courageous stories to tell about their involvement at 9-11, and in that instance it was at the World Trade Center. We could tell some similar stories about the Pentagon and, of course, what happened in Pennsylvania. I often think about the fact that had it not been for those heroic passengers on that flight that crashed in Pennsylvania, I probably wouldn't be here, because I was at the Capitol on that day. And many other members of Congress and administration as well as constituents would not have been here either. The interesting part of this is that morning I was there as we launched something called a Partnership for Public Service-the idea that we need to do more to recruit and retain people into the Federal workforce. We do? Well, you are an example of the brightest and best that we have in the Federal Government. What you're doing today for our Women's History Month is very important-spreading the word that we have a major resource of women and minorities that we are not yet utilizing. Particularly, we could use 
them in science, engineering, and technology; and certainly we could use them in public service, which I think is the highest calling. I truly do.

But look at any democracy. What's critically important is that you have is a rule of law; that you have an independent judiciary; that you have a free press; and that you have a good civil service. And I think it's time for us to let the public know and to let you know in your own minds how important you are. And we need to spread out. We need to use women as role models. We need to use minorities, and I feel we could also bring in and use those with disabilities, particularly in the areas of science, engineering, and technology. I'll just mention a couple of programs that are trying to do that.

First of all, we did pass-I think Chairman Boehlert is doing a splendid job on the Science Committee - a major, national bill, the National Math and Science Partnership Act. It includes provisions that a number of us on the Science Committee have offered for various kinds of scholarship for utilizing research, for access to the Internet. And I offered an amendment that dealt with community college partnerships, too, that connect with $\mathrm{K}-12$, in looking up these programs and these projects. That bill has passed the House and is working over in the Senate. I hope that it can get that out before the end of the session.

Also, I think you're all familiar with legislation I had in a couple of Congress's ago dealing with the Commission for the Advancement of Women and Minorities and Persons with Disabilities in Science, Engineering, and Technology (CAWMSET). It did become law. The Commission did meet. The Commission came up with their findings, and I'm pleased to say-and you may already know this - that it has become part of something called a BEST initiative. "BEST" is the acronym for Building Engineering and Science Talent. This is something which has come from the Council on Competitiveness. There is leadership on the Council that has been appointed. Last night when we had the Intel Awards, and I know Dr. Bement was there, and maybe some of you were there, too, this leadership Council of BEST met. And I was with them at a rather intimate dinner, I do want you to know that it includes such people as Dr. Shirley Jackson, of the Rensselaer Polytechnic InstituteRensselaer Polytechnic Institute she used to be the National Research Council director. It includes people like Al Berkeley from NASBETH. Representation from QualCom, Rita Caldwell, helped to launch us. The National Science Foundation has been very good in the league with us, particularly in getting more of the areas that have not been well represented in this important area of science, engineering, and technology.

So we did have a lot of companies. Public-private partnerships. Alcoa was there. That's how we can get things done together: a public sector through an ongoing interagency group; the private sector through our CEO's who care about the workforce. I mean this is a matter of necessity. This isn't simply just something to bring in women and minorities; this is a matter of business necessity that we utilize the resources that we have. And, of course, academia. Academia plays a very important role in making sure that this succeeds. So I'm pleased that they're going to be looking at the BEST practices for utilizing the best people for BEST. You'll be hearing more about it, but I do want you to know that you are, in a great way, part of this. And we will be pushing forward to make sure that this will be unique, that it isn't going to duplicate, and that it is going to work. So we have good heads working on that.

Incidentally, speaking of Intel, and the Intel Awards, I was discussing with Dr. Bement just before I came to this beautiful auditorium, the fact that last night, at the Intel Awards of the 
number of people, we had four people from the greater Washington region, who are among, I think, the 40 finalists. Of the four from the greater Washington region, all four lived in Montgomery County, Maryland. Not bad, huh? Of the four that lived in Montgomery County, three are females. Pretty good! So we are making some progress. We just have to make sure, now, that as these people come up, they're not discouraged; they don't feel like they are isolated, but rather that they're brought into this whole profession. I think the answer is that you start off in kindergarten, and all the way through elementary school and secondary school is important. Then I think beyond that we need to offer them encouragement and opportunities in terms of continuing as they go into college, perhaps as they go into advanced degrees, and also into the workforce. You've got those different dimensions: elementary and secondary education, and the workforce, that we all have to look at in a totality. So thank you for the work that what you do in promoting that.

I also want to talk about where women have come from where we are going. We have made some tremendous progress. Everyone is reading history books. I love the fact that the non-fiction books have become so popular; biographies have become so popular. Among them of course is John Adams, of course Theodore Roosevelt, and we could go on with so many of the other biographies that are currently on the, best-seller list. There is also one on Abigail Adams. But David McCullough did very nicely, put a lot into his book-he had to, because of Abigail Adams's work and her part in the life and records of John Adams. Abigail did once write to John and say, "Dear John, Remember the Ladies, because if you do not they will foment such a quiet revolution that it won't be undone." But he didn't remember them. It took a while before it finally dawned on him that she was giving him a real insightful statement when he finally did act.

But also, when you look at the sparsity, but thankfully an increasing number, of women and minorities in the fields of science, engineering, and technology, I think about what happened with the law. Back in 1872, there was a woman named Myra Bradwell who had gone to law school, and she wanted to practice at the bar and was not allowed to in her state. The case went all the way to the Supreme Court. It was called Bradwell versus State. And in that case the decision rendered by a Justice Bradley stated that she could not be accepted because, he wrote, "the natural and proper timidity of women unfits them for certain professions of civil life. The paramount destiny of woman is as wife and mother. This is the law of the Creator." OK.

Sandy Day O'Connor became the first woman on the Supreme Court. And she cites him: "Justice Bradley will always be remembered. It will be on wall of shame because of what he said." And I point that out because of the progress has been made. Now in law schools you are finding 54 percent of the student bodies are women, and now it is not unusual to have women judges and to have the women lawyers. So we have made some progress in that profession.

We have made some progress in some of the bio-sciences and in some professional health areas, too. We have not made as much progress in the science, engineering, and technology fields. And that is what we have ahead as a goal. I do want to honor interns since this is Women History Month. As someone in elective office, I have read many of the biographies of women who preceded me, and some of the interesting stories. It's always interesting to read about people's lives. One of the women from Minnesota-her name was Coya [Gjesdal] Knutson [1912-1996]. 
Have you ever heard that name? She was in the U.S. House of Representatives. ${ }^{19}$ She was elected on her own and then she ran for re-election in 1954. And at that time her husband wrote a letter to the editor [of the local paper] that said, "...Due to wifely neglect, our family life has deteriorated to the point where it is almost non-existent." And they printed it.

Well, was she re-elected? The answer, of course, I guess you guessed it, was that she was not. Because the stigma of having that letter and the presumption of what are a woman's responsibilities, reminded me of Justice Bradley. The presumption of what a woman's responsibilities are was such that she was not re-elected. She later, took her then former husband [Laughter] to court. And she won. I think she won a $\$ 1$ token of success. And she ran again. And do you think she won, then? No, she wasn't, because the perception never did leave.

Now things have change since then. Incidentally, this woman was very interesting because she died only about ten years ago. And I remember, she became a civil servant later. I remember reading in the Washington Post obituary that, actually, she had been a victim of domestic violence, but was too afraid to mention it. Again, that's something that happened in the past. So we have made strides.

Now it was in the last Congress I introduced the bill that authorized the Violence Against Women Act. Obviously, we had a lot of co-sponsors. And we worked very hard to get the Senate to go along with it. We expanded it. We expanded beyond what the original Violence Against Women Act was. And Congress made the biggest commitment, ever, to eradicating domestic violence and child abuse. So we have taken that dirty little secret and cleaned it out from under the carpet. And that also has made a difference.

So we have come a way and we no longer, in the newspapers, see want ads from women and then separate want ads for men. Do any of you remember that? I can remember when you'd see those want ads. And Ellen Goodman, a while ago, wrote an article about interviewing two young

19 "Coya Come Home" became a TV movie. Forty years after she ended her Congressional term, her story became an NBC-TV movie of the week. Cornelia "Coya" Knutsen is the only woman from the Upper Midwest to ever have been elected for a full term in Congress (1954-58). The political career of this smalltown schoolteacher who took her enthusiasm, energy, and wholeheartedness all the way to Washington, DC, was cut short by the infamous "Coya Come Home" letter. The letter demanded that Coya abandon her political aspirations and return home to be a full-time housewife. It also accused the 45 -year old Congresswoman of having a love affair with her 29-year-old administrative assistant, which was later proven to be untrue. According to Gretchen Urnes Beito, author of Coya's biography Coya Come Home, the letter that reached Coya and the press had been penned by Coya's husband Andy but actually written by leaders within Coya's own political party. The letter began the headline hunt of Coya Knutson's personal life and tragedies that ended her political career. But before vacating her seat in Congress, Coya Knutsen, an appointee to the powerful Agricultural Committee, among other things, acquired a milliondollar appropriation to fund cystic fibrosis research, initiated legislation to aid Ojibwa Native Americans, introduced a proposal to restore farm price supports, and worked to expand the school lunch program and provide school nurses. Perhaps her greatest achievement was passage of the Title II Defense Bill enabling thousands of students to go to college by borrowing money from the Federal State Loan Fund. In 1960, Coya Knutsen ran for Congress again but lost to the incumbent who beat her in 1958. But Coya went on to pursue a career in Washington, DC, and remained in the Capital City until her retirement at the age of 60. She divorced her husband in 1963. "I divorced him as soon as I had the money to do so," she said. Coya Knutsen died in October 1996 in Minneapolis at the age of 82. 
women at Radcliffe who were chosen to be Rhodes Scholars. She had asked, "Have you ever experienced discrimination? And do you feel, being chosen to be a Rhodes Scholar, that any thing had changed? Or were you treated any differently?" And you know, they said they had never experienced any discrimination. And Ellen Goodman wrote, "Ah, but their memories, [or maybe their mother's memories], aren't that good, because a number of years before that the mere fact that they were women would not have entitled them to even been considered as Rhodes Scholars.

So I think, as role models, we're setting the tone that progress is being made. But here is an area of SET where I pass it to you, to promote using women, minorities, and persons with disabilities, and you expand it. And so I salute all you for what you have done and wish you well. And I hope that you know I stand in solidarity with you. And thank you, all, very much. [Applause.]

I do have time for a few questions. And if anybody wants to make some comments, you don't all have to ask a question. Would any of you like to?

\section{[Inaudible question]}

Well, obviously I would support the bill, and in a previous Congress we had language that was put into the budget bill that dealt with looking at that facet. You see, with family-medical leave, I was there at the beginning. I was a co-sponsor of the bill. I was there at the White House cosigning the bill. It has proven to be effective. The public and private sectors needed to do it. And, indeed, it has helped. So then there's been that little push - a little bit, but not very hard-to get that momentum going so it would be paid leave. In my office, I give paid leave if anyone is pregnant or needs it for parenting. But the concern has been, that, if you do this in the Federal Government, it might be a fiscal note that would be enormous. I'm not sure that would be the case; maybe they would want to do a demonstration program or something to look at the figures. I think it's because of the budget deficit that the White House simply said that maybe we'd just better not entertain or give them any hope it will pass this time. But we do begin to crack through that barrier with regard to paying for it.

I do believe benefits that deal with family are important. I have been promoting not only telework. And Frank Wolfe (R-VA.) has been good in that, and we have required that every agency, I think by the end of next year, have a plan in order for all their employees with 25 percent per year. Also, in the budget bill of just last year, I put in a request for GSA [U.S. General Services Administration] to put in tele-centers in Montgomery County. My idea was to use one in Silver Spring and one upcounty. Those are two areas where I think you could use a tele-center where Government workers could go, even if you had a national emergency. I see much merit in that. Their report is going to come out, I think around the end of April. They are going to be exploring it. So, I hope by the fall, that we may get something done. So I do think one of the other benefits would be the concept of tele-centers, whether it's one day a month or one day a week, whatever it may be depending on the responsibilities and how they can be fulfilled.

I think flex-time, which can be done, too, is something else that is family-friendly. Obviously, you know that $I$ had the legislation on daycare, on childcare. Childcare that would be provided by the agency is a great mechanism for retaining people from low-income families who might leave Federal Government if you don't have it. We now have made it permanent. Before this I had to do it every year. But we do recognize that it would be a lot nicer if you could give the agency 
some for it. So money is going to have to come from the agency itself. We will continue to work on that. Now, of course, we have frequent flyer miles and a lot of other kinds of recognition that I think we need. You've allowed me to go on about a lot of other kinds of issues. I thank you for that.

$\mathrm{OK}$, are there any other comments?

Thank you for being here today. Why do you think we've made more progress in some areas than others?

In terms of what? In terms of equity?

\section{In terms of equity.}

In terms of women in SET's? I think a lot of things. First of all, Bill Nye, the Science Guy, came before my Committee. I chaired the U.S. House Subcommittee on Technology. He was great. He was very entertaining. Everybody knew him and I said to him, "We really got to get more women involved. You know, we've got you, Bill Nye, the Science Guy, (but) we really need Kate Sal the Technology Gal." [Laughter]. I think that's one of the things where the role models need to be. I can see one of them there. But I can go other places. You should see-no offense, Dr. Bement, I love Dr. Bement. He does a great job. You should see the people who come before my Committee to testify. They're all men. They line up. Sometimes I nudge somebody next to me, who is usually a man, too. And I just say, "Hey, take a look at the landscape." And it's true. So again, once you start-it's happening in law - once you start putting them in those positions and others see, it becomes an open door. They say, "That's OK, I could really. I think, maybe, I 'd like to do that."

You've got to make it exciting. NSA [National Science Foundation] gives some really nice grants. They give some nice grants for teacher training, and I spoke at some of their get-togethers where they do set up some great programs to teach teachers how to make it exciting. I mean, you know you can make it drab. You've got to get some of the guys interested. It may be because someone in their family is already in that field, or they seem to feel that they have a natural inclination. Certainly, you're not going to "turn on" females.

Second, I think it's a perception in our society that to be scientific is not to be glamorous. Females don't want to be considered "nerds" or whatever they call them. It's a perception that women all want to be glamorous and fashion plates. Or that fashion plates can't be scientists. You know.

And third, it's the sense of isolation. I think it's the sense of almost being held hostage because you're all by yourself. And so I think they need to have that. So I think all of those things. I also don't think teachers look to females in terms of their possibilities as much as they do males. Now maybe that's changing. I'm talking about female teachers, too, who may not be giving the real push to women. But, obviously, that's changing, if I could say three out of four Intel finalists were women, so you see much is changing. So I think it's all of those things. I really do. 
I was on the Glenn Commission ${ }^{20}$ that looked at math and science teaching in our schools. I wasn't involved with looking at whether you've got more men or women, although that comes up, it always comes up. But you do look at it. We need to do something about our education system, too. And we need to take a look at shortages. I'm very much involved with math and science recruitment and retention, and in recruiting and retaining the very best Federal employees. But look at the teachers, too, because you're finding some of your better, I suppose I could say math and science teachers, going into the private sector. So I think we need to elevate them, too. We need to establish a culture where to be a teacher is critically important. You know, I have a quote I like. It was Joseph Addison"1 who said, "A human soul without education is like marble in a quarry. None of its inherent beauties comes out until the skill of the polisher takes it and makes it shine, and brings out every ornamental vein and cloud that runs through it." That is the teacher. The teacher is the polisher of the marble that gives us self confidence, gives us satisfaction, opens up the opportunities for people, whether they're young or old, to be able to radiate what they have to offer.

I'm glad you brought it up. I think you have a responsibility to go out into these schools, too. I think you have a responsibility to be role models. If your kids' school or neighbor's school has a career day, or a Read-Across America-I visit a lot of schools on that day, you need to go out. There are a lot of Federal employees; tell them about what is involved here. I think as a neighbor, it gives you more of a linkage with your own community. I think then people know more about your profession, and they can't help but be engaged by you and want to do what you do, or explore it further, or go home and tell your parents and their neighbors about it. So, I think you're great. Thank you very much. [Applause]

\footnotetext{
${ }^{20}$ The complete report of Before It's Too Late: A Report to the Nation from The National Commission on Mathematics and Science Teaching for the $21^{\text {st }}$ Century is available from the NIST Diversity Program Office.

${ }^{21}$ Addison, Joseph, 1672-1719, English essayist, poet, and statesman.
} 


\section{ABC'S of COACHING}

\section{Pat Clark Battle, Ph.D. President, Pat Battle \& Associates}

Thank you. It's a pleasure to be here with you, especially because this is Woman's History Month. Are any of you interested in coming a little closer? One thing about coaching is that it is a more intimate situation than a lot of the work that we do, so would you come down just a little closer so I can see you and get some eye contact with you? Thank you very much! [Applause]

The statistics were right on target, and sometimes still astounding, when you think about it. One of the things that comes up for me as a woman is that typically, the clients I work with-and it doesn't matter where I'm working in the world-the clients that I work with are typically males. It is not we [women]. Okay? In this country, [business people] typically are white males, and if a male of color or woman of color is in the room, or women, period, I'm like, yippee! That's because we're missing in action in most organizations. And I keep saying to myself, it must just be the clients who are calling me. Something has got to be different after all of this time. And it really isn't. And I think the topic that we're here to present today, coaching, is one of the ways that we can begin to move ourselves up. As I give you this presentation I will talk about a few of my clients and some of the things that we go through. And [I'll describe] the latest success story of one of my clients, who was a woman. So I'm most proud of that.

In many ways, coaching is the magic that helps you succeed in a fast-changing world. And it is that kind of magic, that kind of agility that you really do need. Things are changing all the time. And it is another way for us to get information. So, coaching is a process for helping people. Do we solve problems, learn from experience and reframe perceptions? It's all three of these. Some people come with problems, and some people have experiences but they don't bother to learn from those experiences, no matter how much people try to help them. And then other people are asking, "How do we do something ourselves in such a way that's going to really make things happen?

Well, coaching is about you, about the self, the "who am I?" Now, remember this question: "Who am I?" This is a major question. In many ways we're constantly asking ourselves that question, all of the time. Who am I? Not-who-am-I-what-do-I-do? But who am I at my core? What is my core? And what do I want? What is my core mission? And what's going on right now? And what is the future state that I want? And how do I plan to get it? Remember these three questions if you don't remember anything else. It's in your handout: Who am I? What do I want? How do I plan to get it? Everybody is asking that question all the time. They're always asking it. Even if we're not asking at a conscious level, we are constantly asking ourselves, who am I? What do I want? How do I plan to get it? I'll talk about that a little bit later.

Coaching gives us people skills. Some people want it for that, some people want organizational savvy. And some people want to be able to do problem solving. It just depends on the individual. Recently a male Ph.D. in an organization saidto me, "I need to get political savvy. I just don't have it. I don't understand organization politics." So it's those kinds of things.

I like to look at something called the "Johari Window." When thinking about coaching, there is 
the "open self." There is the self that we show the world. You can get a handout on this, so you don't have to take notes. And then it's the "personal self," who I don't show the world. And then there's a big blind spot that we have that we don't see. Other people see it, but we don't see it. And then there is a mystery. What is coming up and going to happen for us? And in that mystery, that is what all your potential is. That is what can happen for you. And that's what can happen for all of us if we just slow ourselves down. What is your blind spot? When people are sharing with you about your blind spot, what are you doing with that? Are you hearing it? Are you ignoring it? Are you willing to put a stake in the ground and then move it? A lot of times we often aren't. And a lot of times we don't even know what our blind spots are.

I can remember being in a situation when I was doing some outdoor work, and I was doing this work with my colleagues and we were supposed to climb this tree and go way up. And I can't even remember what--all the stuff was called. And there was this "on bole" and you jump! I was, you know, "Miss Friendly," "Miss Congeniality," having a good time with everybody, until it came time for that. And then they said, "Okay, Pat, it's your turn."

And I said, "Whoa! Why don't you go?" And they said, "Well, go on, Pat. Come on." And I said, "No, why don't you let so-and-so go?" And then this person said, "Are you scared to go?"

I said, "Well, I really hadn't thought about it on a conscious level, but why don't you just go?" And finally, he said, "Listen." And he sort of coached me up there. He supported me in many ways. And he said, "Listen, I'm really good at this stuff. Why don't you let me give you a hand?"

I said, "Yeah-give me your hand, because I'm still not going up there!" And he said, "I'll walk up behind you. Just trust me. I'll walk up behind you. You got this." He explained everything one more time and it's like, big deal. So finally, I walked up. I started going up. And I'm realizing that there was another guy who was really, really scared. He was on the other side. And he said, "Come on! I did it! I did it! I did it!" I said, "You know, I never realized I was so scared of heights. I mean, I just hadn't gotten out of this even as a kid, I'm just scared." And he said, "Come on, I was scared too--I did it, Pat!" And one was behind me, saying, "You go, girl! Come on, Pat!"

So I went up there. Well, now, guess what? I was up here, and they said, "Jump!" All right? So I've worked my blind spot, I got into, you know, even saying the personal. "Listen. I remember when I was a kid; I used to be scared to get on the Ferris wheel." I started sharing that kind of personal stuff, and then they were saying, "Jump!" And who is down there to catch me? Two women! Two women! And one was so tiny. I mean, Amanda was so small. I mean, look at me, and Amanda was like this. And I was going, "Please! Amanda, do you really think you can?"

And she said, "I can do it!" Another woman came and she said, "Come on, I've got you, too." It just so happened that these two women and I had been colleagues, and we had been like bickering sisters. And I was thinking, "Thou preparest a table before me in the presence of mine enemies." And they're asking me to jump! I can't believe this. And they said, "Come on, Pat. "You can do it! You can do it! You can do it!"

And I was looking at my two sisters, one black, and one white. I was looking at both of them, and I was thinking, they really mean it! They're really - I bet I could jump and I bet they can handle it. And one of the guys on the team was coming to help them and I said, "No, if I'm going to do it, I'm going to do it with these two." You know? It's like, push yourself. And I jumped. And I 
discovered that I could fly. And I think sometimes about coaching, you've-somebody has got to be there to say you can do it. You can do it. You can do it. And you've got to jump and discover that you can fly.

And so this is how I think about this Johari Window. There is always a mystery waiting for us in coaching, we go on a journey, and it's an adventure. We leave what is safe for us, and then we move into where there are threats. All kinds of threats. We meet ordeals, triumphs, and then, somewhere in there, we return. Joseph Campbell says, "We go into what is called the belly of the whale." Okay? So it's the place where you can't see anything.

One of the things about coaching is presence. We look at a lot of things when we're talking about coaching. It's like looking at manner. And then we look at appearance. Once I had to say to a woman in an organization who was trying to advance real fast in an organization. I was her coach, and she trusted me. So, pardon me for what I'm about to say. She trusted me, and I said, "You're trying to move up in this organization. Let me tell you how I see you. Sometimes you come and you actually play out what some people call the 'dumb blonde,' and you're not dumb. You're blonde, and you're not dumb, but you kind of play it out. And you actually wear your hair in a way that says it. And they're not taking you serious in some of these meetings. Now, Girlfriend, are you really serious that you really want to make that move? Or is it just something you're talking about?"

Now, by the same token, somebody in the organization did this with another client who I picked up later, and said to her, if you are going to present at that conference, you need to get your hair cut. You need to get the stringiness out of it and you need to change your outfit. Well, this woman was completely turned off. There is a difference in how a coach might handle something like that and how somebody who you report to or you work with said something like that. See, when I was able to tell this woman about this other situation, I had been priming the pump. We had been working together for some time. And then I was able to lay it on her. This is what I see. I was able to say to the same woman who's got the problems, I said; let me say something to you. "You walked into the room and we're getting ready to do some difficult work, I know. You have never met me before and I'm getting ready to work the conflict between you and another woman in the organization. You brought a tissue box, set it on the table and said, I brought that because I could break out and cry at any moment. I could break out and cry at a movie. I break out and cry at anything. I said, oh, there goes your issue with this other person. If you are going to that person, carrying on like that, there goes your issue."

But I didn't say that in the beginning. It was after we talked for a long time. I said, "Let me tell you what the first impression was - that you came in and wrote 'wimp' all over your forehead. And you're no wimp. You're bright. You walked in the room and said, 'I'm a wimp, I'm a wimp! No matter what you say to me, I'll be crying in two seconds! I'm just a wimp!' You're not a wimp, Girlfriend! You don't want to send that message out." And so we talked about stuff like that. And it takes time.

So let's talk about some other things in terms of presence. We talk appearance, mood states, even voice. Sometimes, when you really want something in the organization, what voice are you going to carry in there? Are you going to say, "I really want this. Would you let me have it? I want this. This is what I want." But who are you? What do you want? How do you plan to get it? If you are clear about those wants, you'll be able to say it in an effective way. 
And then there is language and speech, and then character. How are you seen in your organization? What is your character? And how do you know how you're seen? And again, I have a handout for you. What is your role and title? What is your uniqueness in the organization? I'm not saying that we all line up and look alike and that kind of stuff. You don't see me looking like that. Here I am in an orange jacket. Whatever you do, you have to wear it and carry it in such a way that will help you get ahead in certain organizations. If you don't want to get ahead in that organization, be okay with that, too. Own your choices.

The coach is a sounding board. You can say anything to your coach. Your coach is your cheerleader. That is the person who is going to cheer you on. Agitator; definitely a mirror. It's a partnership. That's the other thing. You hired the coach. Even though this coach is operating as a guide, a part of your support system, this is your personal hired gun. The coach works for you. It is push-and-pull sometimes. Sometimes the coach provides a presence that would otherwise be missing. One of the things to be aware of is that there are too many emperors and empresses walking around in organizations, stone naked, because nobody is telling them the truth. Because people are telling them what they want to hear. Because they're too scared to say what's up. And so these people are walking around with no clothes on. Well, one of the things a coach can do is help you realize when you don't have any clothes on. And really say it to you. Or the coach can ask what is some of the feedback people have been giving you? What is it?

Let's talk about that. Why are you hiding your essence? You are the greatest! I'm thinking about the phone message from my most recent client who just had success. She said, "Pat Battle!" I said, "What?" "I've got the job! I've got the job! ! I've got the job!" And I saved her message for 30 days, because, you know, any day that I just wanted a real lift I would listen to her.

I'll tell you how powerful this job was. Her predecessor had been on Air Force One. This woman kept thinking at some point she wanted that job, too, and she didn't think she could get it. And I said, "Well, Girlfriend, what do you want to do? Do you really want it or do you want to hang back on?" She said, "I don't think I can get it." I said, "But it's who are you, you know. Just ask yourself, 'Who am I? What do I want?' And then we can get a plan to get it. But you had better get clear about who you are." Then she said, "Well, you know, I'm in this position and I don't know, because the person who's leaving has picked this guy to be the successor-and everybody knows about it. And the President has this other guy who is over in the White House, and everybody knows about it, so who am I?"

"Who are you?" I asked. "Well, I'm just a person who-I mean, I know Capital Hill." "But who are you?" I asked again. So we kept going to that, to the "who are you?" Not just "what do you do?" But, "Who are you at your bone-deep core? Who are you?" So now we were working. And we worked this thing. And I think also your coach should know when to turn you loose to somebody else. In one case I told my client, "Listen, here's a friend of mine. His name is Arthur Freeman. I've already spoken with him. I want you to go do an interview with him, because you keep talking about how you bombed the interview even for this job. But you got it. They just went on and gave it to you." And I actually gave her my daughter's name. She is 34 years old, and is the vice president in her company and the only African-American, period, in that organization, who is at the VP level, man or woman, and the only woman at the VP level. I said, "I'm going to send you to my daughter, also, even though she's younger than you. She interviews, she hires, she does all of this, and she can be a kick-butt interviewer. I want you to go 
to these two people and I want you to interview with them. And then come back and we'll talk some more."

Well, she interviewed with them. There were places that they did the kick-butt work, and there were the places where they told her, "You gave it going in!" And she needed to hear that from someone besides me. And then I said, "Now you go to some of those people on Capitol Hill and you talk to them, and now you get a couple of them to be convinced why you should have the position. Take this group and you convince them and see what you've got going."

And so we worked this thing. And it was in the "Washington Post." I mean, she got the job! She got the job! And we worked it. This was everything from the resume to the outfit. I went out and bought this one, this one, and this one. She asked, "What do you think my power outfit is going to be?" And I said, "What are you leaning toward?" And she said, "I'm leaning toward this one and this one. Actually I love that one the best." And I said, "But it's your choice-what are you going to feel comfortable in?" And so we worked it up one side and down the other.

The qualities to look for in a coach includes an ability to encourage you to see more openly. To see more options. To work for open communication. And the coach has to have heightened awareness of behavior and manners. Are you aware that every time you start talking you're biting your lip? Or are you aware that you enter like this? Sometimes just little things that the coach is checking, right in tune with you, asking you some questions that other people might not ask. I can remember interviewing a guy once who was talking about his boss. The more he talked about it he was [putting his hand to his throat]. I asked, "What's going on? It's like you're covering your throat." He said, "Because she's kick-butt." I said, "Well, we've got to do something about you being this uptight, because we're talking about another human being." So people need to be aware of all kinds of little things.

In organizations, that are kind of stifling, the coach should have open listening expertise, emotional intelligence, and the ability to deliver honest feedback. All of those things. The coach needs emotional intelligence - there are people who cry, and I say, "I can see why you' re crying. You might not be able to cry out there, but I can see why you're crying, because what occurred was hurtful. I understand." Gosh! I would want to cry, too. I just wouldn't cry in front of them! You know? Not in this one. I wouldn't, not in this particular system. In some systems you can do that. Not here. So they've got to be emotionally intelligent.

A coach needs the ability to challenge you, and to develop the chemistry, the rapport needed. If you get a coach and you don't feel the chemistry and the rapport after the second session, get a new one. There has got to be respect. That coach has got to respect you. I don't take jobs if I feel that I'm not going to be comfortable. I'm not going to respect a person. The coach has got to be authentic.

Qualities needed: confidentiality and safety. These are big ones. A coach does not write a report and send it back to your organization. Not in the least. The coach establishes his or her own presence. Again, candid communication. All over the place. The coach is a champion of learning, yours and hers. You don't want a coach who is not still out there learning-you don't want anybody who is stopped.

Okay. Coaches try to be supportive yet have no direct power to make changes. This is a strange 
one, because while we can say; we can't do; we can confront, we can support, and we can hold you, yet we don't have the power. We're like travel agents. We do not have control over the destination or the speed of the travel. Okay? We don't have control over that. But we offer much in suggestion and developing the mode of travel and the route taken. The role has both freedoms and limitations. Again, we work for you.

And now, the limitations, I would say I would not coach a person, again, even though we ended up being successful, who didn't want to be there. One woman whom I coached, was sent to me by her boss. It took us two years to get something going. What I ended up doing was backing off from her, and I started coaching her boss .I said, "You're the one who needs the coach at this point. You're the one who is going to have to make something happen. She doesn't want to be there, even though she and I at this point have established some rapport." She was a renegade woman. She was! She was pissed that he hired me to work with her. And so we would go two steps forward, and we'd go a step backward. We'd go three steps forward. We'd go backwards again. We'd go four steps forward and we'd go a step backward. I said, "It's your work. It's your work." And so I turned the corner on that, and went back to him, and started coaching him. We actually made some headway. She's fine now. I mean, she was a researcher, a Ph.D., brilliant in the things that she was doing. I mean, we would talk-she was so brilliant-about a book that I wrote, and about some of the things that I was doing. Sometimes, she would just say, "I've seen your resistance inventory; I've seen your book. Can we talk? I want to talk about that." I said, "Well, whatever," because whatever kept us together was the "whatever." We respected each other, and she was still pissed that he wasn't doing his part, and so he had to do his job. I said to him, "I'm not her director. I'm not her manager. I'm not her boss. I can't do that for you."

Okay. We coaches borrow your watch to tell you what time it is. You have the information. We don't have it. You have it. It is in you. And we support you in figuring out what the time is. Our motto is, "Do no harm." If we can't do it, well, don't do it. Like with the client I just mentioned, I said, at some point, "Let me move away from her. Let me get her boss to do the work." So we try not to do any harm. And if you feel that harm is being done, it is not working for you.

Remember, you can break that contract at any time. This is about you. If you are feeling badly in your gut about yourself, break the contract. Again, even with this person, [I asked my daughter to work with her]. I said, "Kim, come in today with us." And she made some wonderful headway with the same woman whom I ended up turning over to her boss. Again, sometimes the coach has got to bring somebody else in the picture.

Finally, coaches help you take advantage of opportunities, better and better ones over time; adapt to external environment changes; improve performance; and influence future changes in your whole life. And I use the words "whole life" because I have never seen myself go in a situation with a client who wasn't a whole person. With one of my clients, after $9 / 11$, we went into the coaching, and he talked about his 13-year-old son, who was coming to get in the bed with him. And we worked on the family-with him and his wife and what was going on in the family. We had to stay there with that. And I had some discomfort. I said, well, "Let's talk about it. Let's talk about it." And so you could say that was on the organization's dime. He is on the organization's dime, if he is not fully present, if things are going on in his family.

Here's the case of another client I had as a coach. The minute he walked in the door, with all of the stuff that he had, it was all scraggly. And I asked, "What's going on with you?" And he said, 
"Nothing, nothing!" I said, "Something is going on. Let's just slow down. I can tell by the way you brought your body in the room. Let me tell you what I think it is. I think it's that job that you didn't get." And we just began with the coaching. "I said, I know about it. I think it's that job. And though I wasn't coaching you at that time, I know about it. So let's talk." And then he started talking about this disappointment of not getting the job. He started talking about being scared to go home because his wife was pissed. So, you've got to coach somebody through that. And I ended up saying, "At this point I think you really need to go and get some help, you and your wife."

So it is the whole person that we coach. Thank you very much for your patience. [Applause] 


\section{ABC'S OF COACHING}

\section{Tim Wright \\ Private Consultant}

I wish I could stand up here and call everyone "Girlfriend" like Pat Battle could, but I got engaged last night, and I know it would be curtains if I were to if I did just that. [Audience applause] I did get engaged, but that's a trick to get applause early. I kind of like that!

Bullet-resistant kevlar; Scotch-Guard; windshield wipers; paper that glows in the dark. What do they all have in common? Women invented them. It would be a perfect beginning if I could say that every one of those women had a coach. It would be better if I could say I was the coach for each of those women, but that's not the case. Still it's a good point to make a bridge to these facts. First of all, I'd like you to raise your right hand, reach over your left shoulder and pat yourself on the back, because it's great that you're here. I'm delighted to have interacted with Patricia Fenn and to be invited to come and talk to you. I really just want to answer, ask and answer, three questions and tell you some stories about coaching, because I think Pat Battle did a wonderful job of doing that, and then we'll get together and will talk about whatever questions you want to toss at us.

FIRST QUESTION: Can coaching make a difference in your career or your life? 1985: I left after 13 years as a middle school English teacher-let me tell you that was the 13 longest years of my life-and moved into corporate America. I was hired into the training department of what was then New York-New England Telephone, NYNEX. Very quickly, fortunately-I pat myself on the back-I was promoted to run the service and sales training department for NYNEX, which then merged with Bell Atlantic and became all of Bell-Atlantic, the 13 States from Virginia north to Maine. And I had responsibility for 300-plus people who provided sales and services and training.

Flash forward to 1998. Good job, good people, great company, great pay-but I was bored to death. I was at a cocktail party. A friend said, "So how's work?" I said, "Great job, great people, great money -I'm bored to death." He said, "You need a coach." So I said, "Why do I need a coach?" He said, "Because a coach will help you find the things you already know and show you ways to use them, because it sounds like you're in the midst of career confusion."

I was. So I found a great coach. Kansas City, Missouri. His primary drive was career transition, career confusion, and career transfusion. He and I met over the phone, one hour per session for 22 sessions, over about a 34-week period because of holidays and vacation and things like that that got in the way. At the end of those 22 sessions, near the end of 1998, I was truly confident that this coach had given me wonderful insights into things I already knew, as my friend had said, and the kinds of things that Pat Battle was telling you about and what coaches do. What this coach helped me do was pull out things that I knew, helped me realize that if I was going to direct, drive, change, and structure my career, I had everything I already needed already inside of me. I just needed to know how to pull it out.

Christmas, 1999: I got a call from a headhunter based in Milwaukee. She offered me an opportunity with a start-up tele-conferencing company, here in the metro area as vice president of 
quality-I sell ISO 9000 - and training and certification of a nationwide company of conference centers spread from Massachusetts to Honolulu. Now, two years before, I would have spent a lot of time gnashing my teeth, pulling my hair-ha, ha-asking why in the world would I want to take that tough a job. And I probably would have pushed the decision so far back, I wouldn't have been able to make the decision. But because of what I had gained from my coach, I was able to say, "Yes, but I want to do some serious negotiating." And I did. I signed on with the company; I moved down here; I committed to what they needed to be done in two years; and said, "In January 2002 I'm leaving, and you're going to pay me for an extra six months because I then want to go to work in the career for what I really had in my heart for 10 years. And that is what I'm really doing now, which is working as a coach, as a motivational speaker, and as an author. And I couldn't have done that, had that wonderful career control, career transfusion, if I had not worked with that coach, Tom, out of Kansas City for 22 -only 22 hours.

So can coaching make a difference in your career, your life? It can make a difference if you want it to. And that's true of anything. Nothing works unless you want to put yourself, your energy, your creativity, your humor, your spirit behind it and push. And a coach can help you push, or maybe a coach can just say maybe you want to push a little more on this side or that side, based upon the kinds of feedback a coach will give you.

So yes, it can change your career, positively, if you want it to. And if you select a good coach, it can affect your career positively. Here I give you caveat, upon caveat, upon caveat. The coach industry is booming, primarily, because of the fact that we've made the transition from cottage industries to outplacement, outsourcing to entrepreneurs. More and more new careerists such as motivational speakers suddenly realize, hey, there's an opportunity to complement this with some coaching, which is exactly what I did. The problem is there is an awful lot of people out there claiming to be coaches who aren't; or who shouldn't be claiming to be coaches.

So my advice to you is that if you decide to work with a coach, whether it's in NIST or outside on you own, that you interview no less than three before you make your decision. Even if your intuition screams, "This is the right coach." When you meet that first person, take the time, give yourself the time and the benefit to meet with at least two others. No coach, today, will take you on without offering an introductory, complimentary 30 - or 60 -minute session to test the fit. A good coach wants to make sure that he or she can work with you. And a great coach wants to make sure you can work with her or him. And if you're going to spend 22 or 36 or 112 hours over a period of time with that coach, a three-hour investment, up-front, is a small investment for a great return. So, I caution you to be a very conservative consumer in selecting a coach. I'll talk a little bit more about what things to look for-the kinds of things that Pat Battle mentioned, though, are excellent. I suggest that you make good use of the handout she has made available. The third thing about whether or not it can affect your career, is yes, if you and your coach establish a good coaching relationship. It can affect your career if you have that good coachrelationship.

SECOND QUESTION: What is a good coaching relationship? In the middle of 2001, I started to work with a woman who had just left her career as a nursing executive. Lisa knows everything there is to know, I think, about hospital administration, about nursing, about medicine. It was almost nine months ago that she wanted to go into business as a consultant and help health-care facilities and hospitals use evidence-based medical practices to improve the way they took care 
of their customers. And she called me because she wanted some help in putting together a marketing plan.

My first question to Lisa was, "Do you want someone to write a marketing plan and give it to you to exercise? Or do you want to develop your own marketing plan?" She said, "Well what do you think?" I said, "I advise you to take a couple of weeks to think about your answer and call me back." And when she called back, she said, "I think I'm willing to take a risk and write the marketing plan myself." I said, "Well, that's wonderful. Then I think you want a coach, not a consultant." I said, "I want you to talk to these three other coaches who can work with people on a marketing plan, and then come back and talk to me. Or if you make a decision from one of the three, just call me and say we're just not going to work together." A few weeks passed and Lisa called me back and said, "I'd like to talk to you to see whether or not you can help me with a marketing plan." I said I'd be glad to. We did the introductory session, and Lisa and I met for six sessions. And what we did was three things, and these are three things that I think establish a good coaching-client relationship

First, we became very results-focused. I spent the first hour just asking and doing nothing but asking, "What do you want? What do you want?" over and over, because the more I asked, the more deeply she got into her answers. And she realized that she didn't just want a marketing plan. She wanted a well-integrated Web site, set up for lateral materials and the ability to make cold calls to health-care facilities, doctors, and nursing executives and tell them what she did. And those were three skill areas that she needed to develop.

Then we spent some time working on how we were we going to communicate. You see, Lisa was not one to give a quick answer, because she was basically from a medical-scientific background, and she tended to want to think things out. I said, "That's fine. If you want to do that, it's going to take us forever to get to your end-result. Now the way I'm going to work with you as your coach, if you want me as your coach, is that I'm going to ask, and ask, and ask, and the sooner you give me answers, the sooner you'll make discoveries." This is something Pat Battle told you. I believe that a really good coach listens three times as much as he or she talks. In a one-hour session, if I talk more than 20 minutes, I'm doing something wrong. And if I do 20 minutes of talking non-stop, I'm doing a whole lot of things wrong. So the second thing that Lisa and established was really high-quality communication. She knew that I could not be afraid to ask her anything and then she could not be afraid to answer because I was going to hear her answer and feed it back to her. So first of all, it's the results-focus; and second, it's the quality communication.

The third thing, and I think this is fundamental to any good coaching relationship_-you'll learn about mentoring later-is what I think distinguishes a good coaching relationship from a good mentoring relationship: co-creativity. The coach and client, together, work to create. But it's not an equal partnership; 95 percent to 99 percent of that creativity comes from the client. Maybe 1 percent to 5 percent comes from the coach. Any good coach recognizes that all clients-allhave deep down inside, all the creativity and all the resources and all the tools that they need to make whatever happens, happen.

In the span of six weeks, we got to the point where Lisa discovered that she had all the knowledge that she needed to go out and find the kind of Web designer that she wanted to interface with, effectively, and get a Web site, a knock-them-dead Web site. That's necessary 
when you're dealing with an area of medical and health practices that's she is in. In the span of two weeks she was able to recognize that she had the creativity and ability to design really good, collateral materials: the business card, the brochure, the one-sheets, and the mail-outs that she would use to tell the clients what it is that she wanted to say. And it worked very, very neatly; it interfaced well with her Web site. And in the last two weeks, she said to me, "OK, I'm ready to start cold-calling. I want you to coach me for one hour. I'm going to make 25 phone calls in the next week and I'll give you feedback." And that's something she could not have done until she had made the discoveries that she had all the power in her.

So the third point to a really good quality positive, coaching relationship is the recognition of cocreativity - that it's not the coach giving answers. It's not the coach saying, "Do this. Do that. Do the other thing. You're doing this wrong. You're doing this right." It's the coach helping the individual discoverer the ways to utilize the creative powers, the creative resources that she or he already has on board. This leads me to the third question. Remember, the second question is "What is a good coaching relationship?" The third question is a twist on that.

THIRD QUESTION: What good is a coaching relationship? First of all, we talked about how it could impact your career. But let me tell you a story-the coaching I did with a man named Tony about two years ago. Tony's problem was life-work imbalance. Tony worked about 14 hours a day and tried to live the other 10 hours a day, but was exhausted for about six of those 10 , which made it bout 14 to 4 . He had a loving wife and four kids. Tony heard me speak, and he came up afterwards and said, "You know, I really like what you said about energy, creativity, and humor, which is what all my stuff deals with. He said I need some help in finding a way to find more time to use my energy, creativity, and humor, because I'm working 14 hours a day, and it's driving me crazy."

I called Tony last week when I knew I was going to come here and talk to you. I said, "I'm not looking for compliments. It's been two years. I want to know how you're doing." He said, "I'm doing fine. I'm working about 10 ours a day. I'm spending ample time with my kids, my wife, with softball teams. I'm doing all the stuff I wanted. I got a really good balance. I said, "Why are you able to do that? And don't say that it's because of me." He said, "Oh, No, I won't say that, because it's not." I thought, "You don't have to be quite that candid, Tony." He said, "No, the reason I'm like this is because what I got from the time with you is the realization that I can develop myself. That I can be, in terms of time management, in terms of life-work balance, selfsufficient. And because of those two things and the fact that I know what to do to obtain that balance, I've got a tremendous amount of self-satisfaction."

So what I think is good about a coaching relationship that works-they don't always work, but the ones that do work-is that individual on the other side, the client side of the relationship, comes away with a really strong sense of self. I may be promoting self-development. Tony's ability to recognize, "Hey I don't need to get 10 hours deep into this project to get it done. I need to get some time at home with my kids so tomorrow. The 10 hours are going to be that much more productive." It's a sense of self-sufficiency. Tony realized, as he said, "that I can get the job done on my own, and when I can't it is OK. And it's not cheating on myself to go to someone else and ask for support." This is something he and I spent a couple of sessions on-his inability to ask for assistance, which added to his work-life imbalance. 
And he got his self-satisfaction, because now, if he can say to me, "I spend a really good amount of quality time, quality hours with my four kids, with my wife, with my house, with my pets, with our community," then he's got a sense of self-satisfaction. And that's what a good coaching relationship is, I think.

Do they always work? No. I've turned down clients; and I've had clients after two or three sessions say, "Hey Tim, it's not working. And I'd like to back out of it." And that happens for lots and lots of reasons, because in effect, you're establishing a partnership, and you need to be really, really honest to recognize that not all partnerships work. But that's where good-quality communications, the creativity, the co-creating, can come to play and can let you know those things.

In 1968 when I was a sophomore at Washington and Lee University in Southern Virginia, I signed on as a participant in the Big Brother/Big Sister Program. Brian, the nine-year-old to whom I was Big Brother, was lazy and pudgy. I was 19 and outgoing and I said, "OK, Brian, why don't we, today, walk up to the top of the hill behind the W \& L Campus?" "I don't want to," he said. I said, "It will be fun! It's a great day." "I don't want to," he repeated. Once I had finally gotten Brian to at least come along with me at the top of that hill, every few steps he'd stop and complain, "It's hot! It' s sweaty. I'm tired! I want to go home!" Two more steps and, "It's hot, I'm sweaty, I'm tired-I want to go home." Two more steps: "It's hot. I'm sweaty. I'm tired. I want to go home!"

But we went on. And we got 80 percent of the way up this hill-it's not that big a hill, and Lexington is not that big a town. And Brian was not that big a boy. And he said, "OK, this is far enough." "We're almost there," I said. He answered, "I'm tired. I'm going home, now! Let's go back." I said, "OK. Let's go." So we turned around. And when we turned I realized, and I think Brian did, too, that it was the first time we had looked back down the hill. By this time, fourfifths of the way up the hill, there was a wonderful view of small-town Lexington: the Washington \& Lee campus, the VMI campus. And Brian looked down the hill; and he turned and he looked at me; and he turned and he looked at the top of the hill; and he looked back down and the hill; looked at me; and took my hand and said, "We're almost there, let's go." And walked to the top of the hill.

That's how a good coaching relationship can work when there is that hand-off back and forth between the two people. And you have desire, and decide how to reach the end results.

Thank you very much. [Applause] 


\section{QUESTIONS AND ANSWERS AFTER THE COACHING PRESENTATIONS}

First of all, I want to thank you. I've enjoyed your presentation. What would you say to the person who thinks so many things sound good that she or he might be reluctant to talk to a coach-there is not one particular direction she knows she wants to go? Do you work that out yourself before you talk to a coach, or do you go to a coach who will help you eliminate the 18 things that sound good and help focus on the one that is more realistic? I guess the question in short is, where do you start?

[Pat Battle answers] There seems to be an inductive process, but where do you begin? This sounds like a flip answer-it's both, and you do both. Stop for yourself. Who am I? What do I want? How do I plan to get it? You're maybe not going to have all the answers at that point. Then move in and test the process. Again, if you follow the process that Tim talked about, three free coaching sessions, that will really put you on the mark for something. It will become clearer and clearer to you. It may well be that that scattered approach is part of what you would want some coaching in.

[Tim Wright answers] You might want to do some work, or give some attention, whether it's on your own or with a coach, as to how you prioritize or how you decide where you want to give most of your focus. The situation that you outlined is a very good reason to start to work with a coach, but it also goes back to what Pat said. And what I've said is that you want to be very careful in selecting a coach. Remember when I say that you go through those three free sessions. If you go to the same coach for three free sessions, don't use that coach. She or he is not good with money! [Laughter]

I, too, enjoyed the presentation. Based on your experience, what kinds of organizations are bringing in coaching? I'm sort of new here at NIST, and if NIST should embrace such a thing in this organization, I guess I'm wondering what strategic plan would that be. So I am curious to see from your perspective what kinds of organizations are using coaching in their programs?

[Tim Wright answers] I do very little corporate coaching. I do some teamwork in medium and small-sized businesses. I'll be honest with you, coaching is only about 30 of of my time commitment and only about 10 percent of my revenue. It's not a big portion of what I do, so mine may not be a fair answer. But the networking that I do in the coaching industry, all kinds of businesses, organizations, corporations, are using coaches. That includes those that are small and don't want to spend money on training, because they see coaching as more economical if there are only one or two people who need the coaching. Then there are those that have big bucks and want to spend lots of money bringing in coaches to do team-driven or team-building exercises. Or there are corporations that will spend lots of money at the executive coaching end, which I think Pat can talk about better than I can. So it's across the board. I know that in Federal agencies, there is more and more attention to coaching, because I've gotten a number of calls to find out if I wanted to do full-time things with Lockheed-Martin, as an example, those kinds of things. I would say it's the same for corporate America, the Federal Government, State and local governments, unions, and overseas clients. They e-mail in, call in, write in. So we really run the gamut.

[Pat Battle answers] Also for me, coaching isn't my whole practice. I left my brochure outside. I 
also do team building. Sometimes I start in an organization working with a team, and then find that somebody on that team says, "Uh-huh, I need a coach." A lot of times we enter the organization doing other kinds of things, or as a member of the NTL institute, people come to do some of our human interaction or management work conferences, and at that point they have done a lot of personal growth work. So I might say, now I want to continue this, I want to coach, and so it can come from any and everywhere. With the NIST question, if enough people ask for something-you know, there is power in a kind of group solidarity or groups coming togetherif enough people ask for something, going to your human resource department, asking how can we make this happen, thinking through that kind of process, putting something together, they will be heard. Remember what Kathie Olsen said yesterday about critical mass? Be the critical mass.

\section{I'm assuming because we have another session coming up on mentoring that there is a distinction-it may be subtle-between coaching and mentoring. But if you have a person who is serving as your mentor, can that person also effectively serve as your coach?}

[Tim Wright answers] I think the first answer is it depends entirely upon who that person is and what that person's role is in relation to you and commitment to you, and what you want from that relationship. It's difficult but not impossible to have-and I don't want to step on-in fact you've got your mentoring presenter standing just over your right shoulder. I don't in anyway want to step on their toes. When I chose that coach in 1998 because I was career-confused, I had a mentor in the telephone company, and I had an option of going to her and working with her. But I decided it was probably better for me to go outside, because I wasn't sure that I was going to have a life-long career in the telecom industry. I wasn't sure that I wanted it, wasn't sure that I could do it, et cetera. So there is a difference in objectivity and perspective. This is not to say that mentor aren't objective, but that they have a different angle, typically, because a mentor is usually in-house, and a coach may not be. And that may not have been a good answer.

[Pat Battle answers] That more or less fits with me, too. I think a mentor can coach another person who they're working with. But normally a coach is an independent person that you hire. There is a level of intimacy between the mentor and the protegée, and yet there is another relationship between you and the coach-and it goes back to so much of that co-creation. You really are in charge. You really did bring that coach on. And so sometimes I think people are more willing to "kick butt" and push back on the coach in ways that they wouldn't "kick butt" and push back on the mentor because of that different kind of relationship. I have coached people and I have mentored people, people of my choosing that I want to mentor them. I want to see them move on. And they have a level of being grateful to me in a way that they don't push-it takes them a long time in that relationship before they really push back on me. And in coaching, we have that thing right off the bat.

[Tim Wright] I'm going to add to my earlier answer. There is not a distinction, a firm line, between mentor and coach. My perception is that you have a VIN diagram of the 3 circles; one circle is mentor, and one circle is coach, and one circle is friend. And if you are in an ideal situation, you're in the overlap of all three-where you've got someone who is indeed a good coach, good mentor, good friend. My perception is that a mentor is dealing with your whole existence, and the coach tends to work in a focused area, whether it is time management, professional development, career transition-those kinds of things. I would say that in the coaching I do and some of my colleagues do, we really do work the whole human being. And another goal is to work ourselves out of a job, to leave you in such a place that you don't need us, 
because by then you're doing what we do for you for your yourself, and better. But we do want you to so appreciate the job we have done that you give us lots of names of people who are longterm therapy!

Thank you. [Applause] 


\section{MENTORING}

\section{David King, Ph.D. Founder and Former Director Summer Undergraduate Research Fellowship, NIST Mentoring}

I enjoyed the talk on coaching. It helped me understand that one does have to balance personal and professional issues, and I did promise my wife I would be out of here at half-past. So I'm going to speak very quickly and try and provide an overview. When I was asked to do this, I don't view myself as somebody who is an expert on mentoring.

SURF stands for Summer Undergraduate Research Fellowships. This was a program that essentially was started at NIST to address an issue of diversity. Our idea was to approach the issue of diversity by strengthening the pipeline rather than trying to fill the pipeline or compete for the limited number of female and minority students who are coming out of the pipeline in the sciences.

While I was putting this talk together I was thinking about mentoring and mentoring issues. One of the reasons that I think the SURF program was such a success is that the senior scientists at NIST took a very personal interest in the personal and professional development of the students who came to this program. And based on that I would say that there is actually a strong passion for mentorship within the staff at NIST. All you need to do is provide the potential mentors a valid proposition that they find interesting. I feel very passionate about the SURF program. These are the SURFers from 2000. The thing that you'll see when you look at this slide is this does not look like the traditional face of the scientific staff at NIST. What we did in the SURF program, to a certain extent, for a limited time during the summer, was change the face of NIST. And in doing that I think we made some cultural changes. As I said, the motivation behind this was to strengthen the pipeline.

Here are some facts about people in physics. There are about a thousand Ph.D.'s in physics every year. Women earn 10 percent About 1 percent of the Ph.D's in the United States are earned by minorities. These are facts that go back to 1993. The conclusion you would draw is that many of the best and brightest minds in the United States future workforce are ignoring the opportunities and rewards from a career in particular in physics, and in science in general. The other fact that was apparent to us was that most of the female and minority students who were coming out and pursuing advanced degrees in science came from a very small number of schools-women's colleges, historically black colleges and Hispanic-serving institutions.

We felt that we had to increase diversity. We had two options. We could try and compete for the limited number of students who were coming out of the pipeline. For those one or two minority students every year in physics, who matched onto the programs that we had to offer. Or we could work to strengthen the pipeline. So we chose to try to step in to help fix the problem. Most of you, I think, know something about the SURF program. There were a lot of things that we put in place to try and elevate the status. We tried to create an honors college environment here. The students were housed in corporate housing. They were provided free travel and free housing. We tried to split cliques up by rooming arrangements. We had people coming from all over the United States. We found that there were some challenges of diversity of people from New 
England bunking down with people from the Deep South. From the Northwest there were differences in culture, there were differences in music. There were differences in foods that they liked. In terms of mentoring there was an enormous amount of peer-to-peer mentoring that went on within this environment. We had 20 students the first year. They were housed in five corporate apartments close by. They spent a lot of time together. They came to know each other. They got to help work with each other through many of their problems.

In terms of the NIST staff and student mentoring, the challenge put forward to our staff at NIST was to make the summer research experience meaningful for the students. And that was one of the things that the students really enjoyed. They felt that they were doing meaningful work. The other thing that was a challenge to the research advisors was to take students who were freshmen, sophomores, maybe juniors, perhaps not from the best schools in the country, get them up to speed, to understand some of the world-class science and engineering that was going on at NIST. And I think it is to their credit that the early advisors spent a lot of time professionally mentoring their students. The program I think was well designed. It still exists.

We started with 20 students and one laboratory. This year there will be approximately 100 students supported in all seven laboratories at NIST. I think that it is a success. As I said, these are some of the fundamental design issues. Part of the mentoring arrangement was for a research advisor to get a student. And there were some benefits, because the students were essentially free to the research advisor-a student cost a thousand dollars for the summer. To get this benefit, the researcher had to be willing to put in the time both to mentor the student and to be a role model for the student. And I think that that was a very successful formula. In terms of measuring our success in year one, 60 percent of the students were female, 80 percent were from minority groups-African-American, Hispanic American. And in 2001 the program grew from 20 students to 64 , from 31 different universities. It is becoming a very competitive program. I understand in 2002 the program will include almost 100 students. And the students come from a wide range of schools.

I think one of the important things about this SURF program is that the personal relationships these students developed with their advisors resulted in many of them saying that this experience changed their life. Many of them would not have continued in a career path in the sciences but instead they decided to continue, to go on to graduate school, to do post-doc work. There are five employees at NIST who have been through the SURF program. They might never have known about NIST without the SURF program. My favorite is the one who was in the program when I was running the program in 1993 and 1994, Ana Ivelisse Aaviles. I think that some metric of the success of the program is that the students now are beginning to come to NIST as staff.

Here's one of the fundamental tenets of the program: If you want to strengthen the pipeline you don't go out and cherry-pick the best student around. You form a long-term relationship with schools that are committed to strong science curricula. And then you provide back to that school resources, information, seminars from the NIST staff back to those schools. You develop a relationship with those schools to strengthen the programs in those schools, to strengthen the relationships with NIST, to increase the brand equity of NIST within the female and minority communities. I think it is also a testimony that there are about 42 different colleges and universities that have participated in SURF. Many of them have been participating for the nine years that the program has been in existence. Student Marian Peters originally was at Randolph Macon Women's College in 1993 when she started to participate in the program, and in 1994 she 
moved to Appalachian State and continued the relationship with NIST. So it is a two-way street that involves both our staff and the faculty at the schools.

I feel to some extent the SURF program might never have happened without my involvement in it. I feel good about that. But it would never have happened without the personal commitment of a large number of people, who I would like to acknowledge. We're talking about mentoring. Dr. Katharine Gebbie had a passion and a vision, too, for doing something. As I say, strengthen the pipeline to get women and minority students through the pipeline into the research community, into our potential workforce. Another is Marlon Walker. If he had not been a constant irritant to me, pushing me to go beyond myself, I never would have done this. Charles Clark, one of the division chiefs in the physics laboratory, was very committed to this. And I dare say this would not have happened without his personal commitment, both in leveraging some of his resources to make this happen in some of his personal connections. And took a very strong mentoring interest in his student. I also would like to honor Joyce Brigham in grants and contracts; without her help this never would have happened. There was a strong partnership throughout all of NIST. Lots of people got involved. Lots of people felt that this was important. And today we have 17 coordinators, as I said, from the seven laboratories, and administrative support from Anita Schwiegert and Beamie Young. Without all of those people contributing their time and effort, it never would have happened.

Karen Brown challenged me on my first slide. It said there is strong commitment to mentorship at NIST. She questioned whether there is or not. I think what we saw in the SURF program, in addition to changing the way that NIST is perceived in external environments, it also showed that given the opportunity, given the right stimulus, that the staff at NIST are willing to respond in a very positive, very definite fashion. In the first year we had 20 volunteers willing to take a student, realizing that mentorship was part of the criteria for receiving a student and that they would be expected to spend a lot of time with a student. They were willing to help the student come up to speed, understand how research is done at NIST, and comprehend what is necessary to be a contributing scientist or engineer within the science and technology workforce. This year we're going to have on the order of 100 students at NIST. That means that there are going to be 100 research advisors who are taking on this same kind of commitment to try and bring this back to mentoring. Then we self-selected, perhaps, when we were going around and finding advisors for the initial search student, the question was, are you willing to mentor these students? And if the answer was no; that they didn't have the time; they wouldn't be able to spend the time during the summer; they weren't selected to be involved in the program as an advisor. It was voluntary.

We think we provided a stimulating challenge to the NIST staff. We provided a value proposition that they felt was beneficial, satisfying. On the students' side, we matched students' interests with advisors. We actually had more advisors sign up to participate in the program than we had students to fill. That was by design, to make sure that we were able to match the students to their tasks based on the student's interest rather than forcing them into a hole. This last point I think is important. A lot of what I have heard about mentoring is that the right mentor is somebody who "looks just like me." And, I think-at least in the context of the SURF program, what we learned is that it is more important to be committed and dedicated and interested than it is to "look like me." And I think that that is a good lesson for putting together a SURF program-any kind of a mentoring program-in the future.

I like the quotation on the SURFing Web site. One of the students is quoted saying, "What I liked 
most about the SURF program was learning, getting paid, and having fun." When we started this we said it was going to be long road. We understood the pipeline is long. Four years of undergraduate school. Four or five years of graduate work, maybe a post-doc. We couldn't expect to see any dividends paid from this for five to seven years. And now, seven years later, we're now beginning to see people come to NIST who might never have come to NIST to join our workforce.

Of all of my varied accomplishments at NIST, putting this program together was certainly the accomplishment of which I'm the proudest. I would like to close with a statement that Ana made, both in 1994 and recently, to Dr. Katharine Gebbie, that the summer program at NIST changed her life. That is about diversity. That is about being proactive. And I think that is about mentoring. Without a strong mentoring relationship this would not have happened. [Applause] 


\section{SURFing the Physics Laboratory}

Goal: Increase the diversity at NIST by strengthen the pipeline

Observation: There is a strong passion and commitment at NIST for mentorship

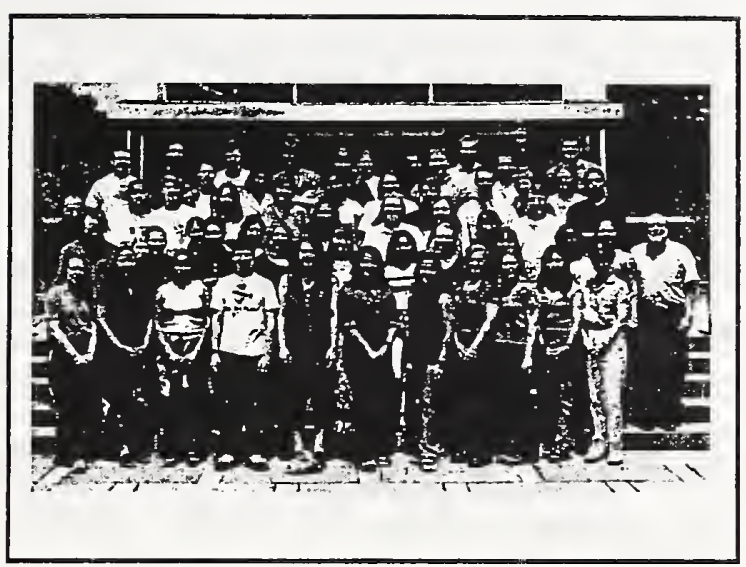

Strengthening the pipeline

Fact: 1000 Physics PhDs per year

- $10 \%$ eamed by women

$-1 \%$ by minorities

- best $\&$ brightest of tomorrow's workforce ignoring opportunities \& rewards of a career in physics

Fact: most of these come from a small number of womens' colleges, HBCUs and HSIs that value careers in S\&T

Options:

- compete by increasing NIST brand recognition

- be part of the solution

$\mathrm{Q}$ : will Physics' best and brightest participate

\section{Program}

- Honors college format (corporate housing)

- competitive pay, with "free" rent and travel

- split cliques in the rooming arrangements

- special weekly hosted seminars \& lab tours

- group outings and socials

- pair students with advisors and projects that match their interests

- use a diverse peer group to stimulate creative ways to address and manage diversity

- Important work, not busy work-make a difference in seience and to their country

- huge hurdles for both the students and advisor/mentors

\section{Measuring success}

- $60 \%$ female \& $80 \%$ minority in 1993 (20 students, 5 IHEs)

- 2001 program accepted 64 students from 31 IHEs (out of 110 applicants from 41 IHEs)

- overall ca $1 / 2$ female, 1/5 African American and 1/6 Hispanic American (9 years and nearly 300 students)

- Diversity. two year colleges to major research universities, span entire US; womens'colleges, HBCUs and HSIs are highly competitive

- Changed the career path of many participantsturned to a career in science because of the oneon-one mentoring from world ciass S\&E staff

- 5 new employees at NIST

\section{Additions to NIST's Staff}

Ana Ivelisse Aviles U Puerto Rico

93,94

- Jason Sanabia Union College

95

- Sarenee Cooper Southem University

- Debbie Caton Frostburg

99.00

- Michelle Millican Southem University
99,00

00 


\section{Strategic Alliances}

- NSF - highly leveraged partner (2:1 funding ratio, 5 different directorates)

- (9) U Puerto Rico 93-01

- (9) Southem University Baton Rouge

- ("9") Appalacian State University 95-01; RMWC 9394

- (7) Miami (Ohio) University 94-00

- (7) Jackson State 94-98,00

- (6) Bryn Mawr 93-98

- (5) CCNY 93-97

- Bethune Cookman 94, 96-98,00

- Wellesley College 99-01
One person can make a difference

But is is never really one

Katharine Gebbie

Marion Walker

Charles Clark

Rolf Sinclair (NSF)

Diola Bagayoko (SUBR)

Dan Aikens (CCNY)

Neil Abram (Bryn Mawr)

Marian Peters (RMWC, Appalachian State)

Grants \& Contracts - Joyce Brigham

Today 13 coordinators from 7 Labs; Anita \& Beamie
Risk

- No risk, no gain

- Think out-of-the-box, but run strictly by the numbers (program design). At risk were:

- summer opportunities for 20 talented undergraduates

- ca $\$ 25,000$ in travel and rental commitments

- Risk? Did not know if anyone would come, would they be accepted by their mentors, would they be accepted by NIST, would they accept each other. would they care

\section{Commitment To Mentorship}

- Supported by senior Physics management and entire laboratory staff

- 20 volunteers for mentoring the SURFers - mentoring was an important component

- seminars, lab tours, back visits, etc

- Changed the Face of NIST-at least for the summer - essentially $10 \%$ of Physics' 1993 summer staff were SURFers-females and minonities

- nearly 1 in every 4 groups

\section{Lessons in mentoring}

Strong mentoring component in qualifying advisors

- voluntary

- stimulating

- mutually beneficial and satisfying - match in interests and chemistry

- advisors traveled to their mentee's school to meet the students and faculty, and talk about their student's work and why it is of national importance

- not just another academic project, longer-term contact

- Huge support from the staff

- It is more Important to be committed and care, than to be "like me"

\section{Summary}

"learning, getting paid and having fun"

- It has been a long road

- All 7 NIST laboratories have adopted the SURF program format

- The program is working

- Former SURFers are beginning to exit the pipeline and to join the NIST staff

- Nearly 100 SURFers per year means 100 mentors in a formal mentoring program

Of my varied accomplishments at NIST, this is the one of which 1 am proudest

- Ana Aviles, "my summer at NIST changed my life" 


\section{INVESTING IN OUR FUTURE}

\section{Darlene Floyd \\ President, Horizons Management and Training Consultants}

I'm going to talk in general about mentoring and I hope answer the last question from the coaching session: What is the difference between coaching and mentoring? One thing I would say right off to distinguish between the two is that for one thing, coaching costs and mentoring does not. I'm going to talk about it more from an institutional standpoint, in terms of what people can do.

But first I will give you a little background to explain why we're talking about mentoring and why it is so important, particularly for women in science. There is feedback now. When you think about women who have been Nobel Prize winners in science, and that includes Marie Curie, who was in physics and chemistry, Dorothy Hodgkin, who was in chemistry, Gertrude Elion, who was in medicine, even though those women made their mark quite some years ago, the fact is that women still remain under-represented in science, particularly in the physical sciences. Whether you look at academia or you look at the corporate world, as the ladder goes up, you see fewer and fewer women in the area of science.

Because women are questioned about their commitment to the job or their discipline of science while trying to balance family and work, mentoring becomes an important issue. And, perhaps most telling of all, when we can create Barbie dolls that say, "I hate math," where do we see women in terms of science, and how are we promoting women in science?

It is a dilemma we have to face. There are very few structures in place that bring women together to mentor each other, primarily because science is a male-dominated field. When you think about the reality that 68 percent of new entrants in the U.S. workforce will be women and minorities, and 35 percent of that will be women, and that women still remain greatly under-represented, and when you consider that in the year 2010 less than one-third of the college-age population will be men, white men, where does that leave organizations in terms of bringing women into science?

So we have to ask ourselves, what is mentoring? Mentoring is coaching; it is providing the kind of information and feedback that people need in terms of understanding what they need to do differently. It is teaching, it is providing information they may not already have. It is advising in terms of direction, whether on a personal basis, when we talk about work/family-life issues, or whether on a professional basis. It is guiding and supporting. And what we realize is that we all need support systems throughout our lives, but especially for women in fields that, again, are primarily male-dominated. Whom do you go to when you need some support, and who do you go to when you want to celebrate an achievement? Whom do you go to when you need some real advice on what next steps to take?

One important thing mentoring does that coaching does not necessarily do is networking piece. Women are often not where they need to be, because they may not be aware of some opportunity. In terms of corporate America, we all know the classic, "being on the golf course." But sometimes the right place is not even as structured as the golf course; it might even be the men's bathroom. One of the things mentoring does is provide those networking opportunities. 
Particularly when you consider women in science, where having to write papers and being published help one to gain stature in the profession, it is important that they have a sense of exactly what is going on.

Mentoring does take a lot of time and commitment. The gentleman before me, David King, spoke about the importance of that. What are some of the issues that women face that make mentoring extremely important? One is that women leave science at a rate about three times higher than men. Even though women go through undergraduate and graduate programs, and even though they are employed in the sciences, studies have shown they leave at a rate three times higher than that of men. So we have an attrition problem.

A second issue that women face is trying to balance work and family. From ages 25 through 40 most women put their all into their professions. But guess what? It is also the best time to have children. And if you walk away to raise children and you're out of the workforce a year-or even only six months, it is extremely difficult to try to come back and pick up where you left off. So, reconciling work and family and a profession becomes an issue for women in science.

A third issue is having a sense of belonging in a profession where there are not many women. How many of you, maybe right here at NIST, have walked into a laboratory or division and found that not another woman in there? It doesn't feel so warm and fuzzy. There is isolation and there is exclusion that is felt, because a lot of times you are excluded from conversations or information sharing.

It is difficult for me to say, but it is absolutely a reality, that even in the year 2002, women still have to deal with the issue of sexual harassment. In addition to sexual harassment, women have to deal with issues of subtle discrimination-things that don't appear to be discrimination on the surface, but when you look at the impact they have had on the group called women, it is. Let me give you some examples. In a study that was done on mentoring women in science, one of the findings was the phrase that was spoken most to women who were trying to climb the ladder, whether in corporate America or in academia. More often than anything else they heard, "It is not your time yet."

Then there are things like mysterious deadlines for projects that are really not that important. Things like-actually it's a term coined by Valerie Bats—“dysfunctional rescuing." What it means is that men may use chivalry as a way to belittle women. I actually heard it here at NIST, in a science environment. Why are women called "ladies" and men are called "men" instead of "gentlemen"? In subtle ways it appears. Women hear the expression, "Prove you can do the job," but men hear, "We'll give you the job to help you grow." Quite a difference, subtle as it is, but very much discriminatory in its practice. Women hear, "You don't have what it takes," or they're given degrading tasks.

I was reading on the Internet a letter written by a woman who talked about being the second-incharge scientist in the laboratory. The secretary or the administrative assistant for that day was out, and the head person in charge came to her and said, "Can you answer the phones?" Another problem is getting project assignments that seem troublesome-women say oftentimes they have had been set up for failure. So, when we talk about subtle discrimination, those are the kinds of things that I mean. 
And then there are plain old culture differences, or differences gender differences. And I'm so glad to see that you that you saw Pat Heim's videotape yesterday. Pat talks a lot about those. But one of them that really hit me, as the gentleman before me was talking, It was very pronounced in what Pat Heim talks about. He said, "I really think I did a great job with this program. Now how many women we know would get up and say that? But how important that is in the work environment, to toot your own horn. Because women have been acculturated - and it is changing now for our daughters and our nieces and those who are coming behind us-women have been acculturated to look at things from an "us" standpoint rather than a "me" standpoint. So we look at that as a difference.

A research study by the Center for Creative Leadership reported that, in meetings, women tended to ask for permission to speak. We raised our hands, we waited until the last person finished what he had to say before we began to speak. What do you think men tend to do? Absolutely! Just get right in there and say what they have to say. Think about that in the context of women being a part of a male-dominated profession. How many times do you think women are heard?

Women and men also differ in how they look at things. Men tend to look at things in a very linear, very specific fashion. Women look at things in a totality-what does the whole picture look like?-and then let's attack it one-on-one. Those differences really make issues for women, including women in science.

Here's one of my favorites-the difference between opportunity and access. That is where the networking piece comes in. Do women have opportunity? Absolutely! There are legal statutes in place that assure that we are not going to be discriminated against-and I say this with tongue in cheek. However, what we clearly don't have is access. There's one thing that shows this more than anything else-do you know that only 4 percent of the active membership in the national academy of sciences is women? Only 4 percent. Yet it is believed that women make up about 22 percent of all the people in sciences. So yes, women may have opportunity, but do they have access?

An issue that is talked about so often, particularly for undergraduates and for girls in elementary school and high school, is the thing called "internalized doubt." We have been told so often that "we can't," we tend to believe we can't. And so we often become our greatest enemies, because we set ourselves up for failure. We have been told by the Barbie dolls that math is difficult, so we begin to believe that. So internalized doubt becomes a major issue for women in science.

The last one, in terms of issues, I will talk about is that thing called "the power of politics." If you remember-those of you who saw it-the Pat Heim videotape from yesterday, she talks about the "dead-even rule." As women we see ourselves basically all at the same place-that we're even with each other. There is no up and down, there is no hierarchy, if you will, in place. Well, the fact is, in academia, in corporate America, in the Federal Government, wherever you are, when you are talking about career, there is absolutely a hierarchy. And with that hierarchy comes politics, whether it is politics with a little "p" or politics with a big "P."

Sometimes it's difficult to tell the difference. Do we as women understand the power of politics? The power of whom you connect to? The power of how you dress? You see it often, you know, when they put the whole new thing in about "dress down" day. We all thought it was wonderful. But for women it is difficult-how do you figure out how to dress down and still look 
professional? It's okay for men. Men put on a button-down shirt and khaki pants and come to work. But what does that look like for us, especially if we are aspiring to be more than that? That is a political issue that we have to understand clearly.

So why do we need mentoring? The reason is really two in one: recruitment and retention. How do we get women in, and even when they get in, how do we keep them? How do we help them to stay in, given the attrition rate at which women leave, and given the science pipeline that we really have now? There is absolutely a need for systemic change. I believe that systemic change can happen through mentoring, because mentoring is a way to develop women and to develop girls.

Again, we know that most scientific fields are male-dominated, and often people talk about the informal mentoring and the importance of it. But the reality is that, first, you find very few men who will choose women to mentor in an informal setting. And, second, very few women will go to a man to ask to be mentored. So if you have only a few women, how can one woman in the laboratory mentor for five people, and have a family and do all of the other things that you have to do. So, increasingly, mentoring is important. Mentoring has been proven one of the most effective ways for people to advance in an organization, whether it is men or women.

When we talk about a program for women, we know that mentoring tends to unify women. It brings them together on common issues that they face, and provides a forum for talking about them. Mentoring provides not only conceptual and professional resources, but also personal resources to women about how to move up the ladder.

Mentoring also is critical at transition points for women, when they're moving from undergraduate status to graduate status, from graduate into a career status, from one step in your career to the next. It is extremely important that you have that kind of resource available to you to answer those critical questions. Mentoring reaches across generations, too.

What can mentoring programs provide, or what can they do for women? They can give information about the very structure and culture of the organization. It's a rhetorical question, but I would ask you sitting in the audience to think about whether you really understand or know the culture of your organization. How many of you really know what is important in the organization? How many of you really understand what are the values-not necessarily the spoken values, but the practiced values-in this organization. If you have any doubt about the answers to those questions, you absolutely need mentoring. And you are in a place where, yes, you can advance, but there may be a struggle in order to do that. So understanding the structure and culture of an organization is one of the roles that mentoring programs play.

Another role, particularly for women in science, is that mentoring programs can connect women to professional organizations. Professional organizations, again, provide those networking opportunities. Mentoring programs can provide feedback that probably no one other than your children or your mother would give you-feedback on how you can do things differently. Pat Battle, in the earlier session on coaching, talked a lot about that.

Mentoring can also give you the encouragement that will help build your self-image and selfconfidence. We go back to that internalized doubt that girls come into science with. It is a forum for discussing strategies and concerns and dilemmas that women face in the science field. 
Mentoring programs provide an opportunity to share a wide range of ideas. It is like a sisterhood, if you will. "I don't want you to make the same mistakes that I did. Let me tell you about the hurdles out there that you can overcome, and you make the choice of whether you want to or not, but at least you have the information."

Mentoring programs can lead you to career options. What is the best way to go? Should I do this? Should I do post-doctoral work? Should I do this or something different? It helps you with research opportunities, grants that are out there and available to you. It helps in balancing work and family. And more important, it is an opportunity to bring women together.

There are basically two types of mentoring programs: formal programs and informal programs. Now, I do mentoring as a part of the work that we do at Horizons, but I don't believe that informal mentoring programs work as well as formal. I think more and more you hear people say, "Well, let's do it informally," and I think that is a way of not mentoring people at all, or of choosing the people you would normally choose to help and not those people who are on the fringes. And when I say people "on the fringes," who are different from the people in the laboratories, that would be women and minorities. So I believe there is absolutely a need for structured, formal programs.

Now, those formal programs can be in the form of one-on-one relationships, or they can be programs that use groups, where groups come together and discuss issues. But I believe organizations should institutionalize mentoring, because one thing it does is tell the organization the value, how important it is, Informal mentoring has worked very well-I was informally mentored for many years during my Federal career. However, today, when we look at the numbers, we see it is increasingly important that we have formal programs.

Now, what companies and what places have programs that are specifically designed for women in science? I stress that, because lots of places have mentoring programs, but they are not specific to women, and not specific to science. But here are some examples. Glaxco has a mentoring and a scholarship program, and reaches very far down into the primary grades to get girls interested in science. Dupont, Parke-Davis Pharmaceuticals, Bell Laboratories, and AT\&T have career development programs that border on what we call mentoring. I think you heard from the group before us, the coaching group, that Lockheed Martin and, interestingly enough, the CIA, in terms of engineering, have mentoring programs specifically designed for women.

What are some of the drawbacks of these programs? Of course, it is wonderful for anybody who takes the step to do something. But some of these programs don't use one-on-one mentoring; many of them use the group mentoring, and many of them don't actually train the people who are going to be coaches in terms of how to get feedback and what feedback you are looking at.

This final thing is absolutely critical. We heard it from David King, the previous presenter. You have to measure and evaluate the success of the program. Then you will know what to do to change, to make it better. Many of those programs do not have a measurement or an evaluation piece. The measurement or the evaluation doesn't always have to be how many people got promotions. Rather it might be how many people feel good about themselves. How many people got a better evaluation than they did in the past? 
So, then, what can we do? Organizations need to have formal mentoring programs. Put resources into it. And women have to become part of those mentoring programs. We have to have some recruitment strategies such as internships and college outreach and co-op programs. And Bettie White, the next presenter, will talk about some of those programs in her organization. High school outreach. Serving on professional boards. And providing successful examples. If you look around NIST you will probably find a lot of women who have been successful in science. Do we know about them? Because if I see a success story, then I believe I can be a success story as well.

We have to put those role models and those examples in front of them. In terms of retention strategies, organizations have to look at career development. Do women have a path? It is a question that Pat Battle asked. Do you know where you are? Do you know who you are? Do you know what you want? Do you know how you're going to get there?

Those are career development strategies. Forming networks. Networks for women in science, looking at attrition accountability. What I mean by attrition accountability is if you have women leaving at a high rate, then someone ought to be asking why. What is going on that is causing that to happen? And what should we be doing differently? We have to have diversity training. Again, going back to Pat Heim's videotape, there are some differences in terms of how we communicate, how we see things, how we operate. And this needs to come across so the people begin to understand that. If you are looking to set up a program for yourself here, there are things that I say you need to do.

First and foremost, you have to have specific goals. What is it we're trying to do with the program? Do we want people promoted, or do we want people to have a better sense of how the organization operates so they can navigate their way through the organization successfully? You have to have a balance of structure and informality. That means you've got to have some structure in terms of who is in there. Are we giving them training? Are we providing them what they need? Can they be good coaches? Are you a good listener? But also the informality that says, we just need to come together at times and talk about what is going on. A good program needs to have a diversity of participants. I am not necessarily arguing that only women can mentor women. I think men can be excellent mentors for women, given the training. And so there needs to be some diversity. Not just women. There needs to be men. There needs to be people of color and minorities as well in those programs. They have to be a variety of activities, and those activities could include being in a laboratory, It could be shadowing a person on a day, what do you do in a laboratory. All sorts of things. But there has to be a variety.

And last-and I've already spoken about it—most important, I believe there has to be measurement, an evaluation. How do we know we have been successful? How do we know what to do to change it? I promised at the beginning of my talk that I would give you some information about two studies. There are two organizations that have done extensive study in the area of mentoring for women in sciences, and they're also great resources for information. One is the American Association of University Women-AAUW ${ }^{22}$. Many of you may have heard about

\footnotetext{
${ }^{22}$ The Association of Collegiate Alumnae (ACA), AAUW's primary forebear, was established in 1882 to expand women's opportunities in higher education and in the workplace. The mission of AAUW today is to promote equity for all women and girls, lifelong education, and positive societal change.
} 
that. The second one is the Association for Women in Science ${ }^{23}$. They presently have the largest mentoring program for women in the Nation. And they're actually located right here in the Washington, DC, metropolitan area. So when you ask what is mentoring, and why is it important, I hope I have answered those questions. [Applause]

${ }^{23}$ Founded in 1971, the Association for Women in Science (AWIS) is a nonprofit, professional society dedicated to achieving equity and full participation for women in all areas of science and technology. AWIS makes the voice of women in science heard by holding and participating in conferences, publishing AWIS Magazine, speaking out about discrimination, and much more. In recent years the Association has grown to meet international challenges, serving as a worldwide resource and global network for women in science. AWIS strives to promote its goals internationally, has developed beneficial and long-lasting relationships with female scientists from various nations, including international AWIS members, to exchange information on gender quality. As part of the AWIS mission it has united with the American Association for the Advancement of Science (AAAS) and Women in Engineering Programs and Advocates Network (WEPAN) to form the Global Alliance, an organization in partnership to diversify the global science and engineering workforce. 


\section{INVESTING IN OUR FUTURE}

\section{Bettie L. White Assistant to the Director, Stennis Space Center, NASA}

Good morning. I' $m$ going to switch the tempo on you a little bit, since I'm the external person here on this panel. This is my first visit to NIST, although I have passed your facility on many occasions as I've headed home to Uniontown, Pennsylvania. Although I've lived in the Washington, DC, area for 35 years, I still call Uniontown, Pennsylvania, home.

I would like to first congratulate NIST for 100 Years of notable service that has benefited our quality of life. I have been reading editorials this week about NASA turning 44 and going through a midlife crisis, though it's sort of comforting to know that there are Federal organizations that have come up on 100 years and are still going strong. I also would like to acknowledge Sol and Pat, and the host of other NIST employees that I know contributed to putting on efforts such as this. I looked at the agenda for today and the two-day conference or Summit, and it is very thoughtful and action-oriented. So congratulations to you for that!

This program has led me to wonder about the demographics of women at NASA. I was informed that women represent 33 percent of our total workforce. They also represent 25 percent of the astronaut corps and 16 percent of the science and engineers of NASA. My presentation today will share with you NASA's planning process and strategic direction to continue to build a diversified workforce by strengthening the pipeline. We have expanded our investment beyond mentoring individuals, students and faculty, to include the mentoring of institutions of higher education to impact an increasing number of women and minorities in the research and education community.

The topic chosen for me today, "Investing in Our Future," is very consistent with NASA's vision. Everything we doing at NASA, every program, project, thought we have, must demonstrate how that activity would contribute to the agency's strategic vision - that vision of being an investment in America's future. This investment has enabled NASA to expand the frontiers in air and space, inspire and serve America, and benefit the quality of life on earth.

The primary work of NASA is accomplished through five strategic enterprises: aerospace technology; earth science; space science; biological and physical research, and the human exploration and development of space. In our organization, all of the activities that the four enterprises are engaged in come together as you see so often, launching from our Kennedy Space Center in Florida.

The vision of the Human Exploration and Development of Space enterprise-HEDS-is to expand the frontiers of space and knowledge by exploring, using, and enabling the development of space for the human enterprise. To accomplish or support this vision, there are four strategic objectives. The objective I'm going to focus on this morning is "share the experience and benefits of discovery" and thereby contributes to the achievement of the HEDS mission for the agency. I'm going to talk about the HEDS university initiatives, opportunities, and partnerships with the Office of Equal Opportunity programs. This chart illustrates the interrelationship between the HEDS education and outreach efforts and our interactions with our internal and external customers. 
The HEDS Education and Outreach Program is supported by an education implementation plan that is derived from the HEDS strategic plan and the agency strategic plan. There is a targeted budget of $\$ 8.2$ million in support of these activities. All education and outreach efforts are included in the line budget items in each of the five strategic enterprises mentioned earlier.

This chart shows the Centers of Excellence in the research areas that those Centers are responsible for implementing. The strategic objectives of the HEDS enterprise are to engage and involve the public; provide significantly more value to more people through our missions; and advance the scientific, technological, and academic achievements of the Nation by sharing our knowledge, capabilities, and assets.

We hope to realize some outcomes as a result of these efforts. These include increasing the public awareness and relevancy of our HEDS activities to the public, while reaching a more diverse segment of American society with HEDS spokespersons who are reflective of the diversity that exists in this Nation. And finally, the overall outcome is that we will all communicate a consistent message and thereby maximize our engagement with the public and leverage our unique capabilities throughout the space community.

This chart just publicizes for those who are interested in doing business with the HEDS education and outreach program the basic criteria for the submission of any requests for funding support.

Here's a summary of an analysis that was made by our HEDS centers that was to look at what potential impact we could possibly have on students and faculties in the areas where these four centers are located. The analysts project we could reach at least almost 3 million students and 150 faculty members through our outreach programs. The HEDS organization has very specific goals for our interactions with the minority university community. The primary goal is to increase and "mainstream" minority universities' involvement in human space flight projects and programs.

I want to highlight two other areas that the HEDS enterprise is specifically interested in targeting. They are, one, pre-service teacher training and, two, enhancing the production of more scientists and engineers. One of the most important ways in which HEDS and all of the five enterprises come together is through the Office of Equal Opportunity, with a program called the NASA Minority University Research and Education Program (MUREP).

MUREP is an agency-wide program, whereas earlier I shared with you the program of one of the specific enterprises. But this program has what we call a crosscutting function. We try to develop and design generic programs that any of the five strategic enterprises can plug into. The MUREP program, that we've come to call it in order to save our breath, was an outgrowth of the Historical Black Colleges and Universities program, which the agency had in existence since 1969. Twenty-one years later, in August 1990, they established the Minority University Research and Education Division with the intentions of outreaching not only to historically black colleges and universities but also to Hispanic Americans, Native Americans, and other under-represented minorities. 
Today, that program is responsive to all the executive orders that relate to Historically Black Colleges and Universities, Tribal Colleges and Universities, and Educational Excellence for Hispanic Americans. We also have initiatives that support individuals with disabilities and also outreach to the Asian American and Pacific Islander communities. We not only work with minority-serving institutions through this program. We also have some collaborative partnerships with the American Association for the Advancement of Science, the American Society of Engineering Education, and other groups that share our mutual goals of enhancing the diversity in the science, engineering, and technology pipeline.

This program has evolved and draws representatives from all the strategic enterprises and all ten of the NASA installations or centers that exist throughout the country, and the Jet Propulsion Laboratory. About six years ago, we had a retreat in Albuquerque, New Mexico, and we hammered out the mission for the agency's MUREP Program. That mission is to achieve the full participation of minority institutions in the NASA-sponsored research and education community, striving for academic excellence and outstanding achievements while advancing America's leadership in a competitive scientific and technological, global economy. We have identified three core functions or core areas of priority for us as we go about executing this program. We want to expand the research base for the agency, we want to contribute to the science, engineering, and technology pipeline, and we want to promote educational excellence by sharing the contents that result from our mission with the educational community.

We have established four primary goals. One goal has to do with facilitating research and development activities at minority institutions that contribute substantially to NASA's mission. This goal is supported by competitive awards that help build research infrastructures. We have 14 research centers located at minority-serving institutions. Those research centers are 10 years old. And we have a solicitation to establish new research centers at this time. The value of them ranges from $\$ 400,000$ to $\$ 1$ million, annually. In establishing these research centers, we have also established technical review committees. These technical review committees are made up of scientists and engineers who have an interest in the research being conducted by these institutions. The committees provide-at this Summit we've been using the word mentoringbut technical advice. That is very similar to mentoring for these institutions, since they are trying to strengthen the capability that the institutions have. They work by communicating frequently with them, by having exchange of faculty between NASA centers, by going out to the universities and giving lectures, by bringing in students from those research centers to be involved in their labs, and by going out as a group and conducting on-site visits with these institutions at least once a year. So there are a lot of interactions between the scientific and technical committee and the NASA research centers.

The second goal has to do with creating systemic and sustainable change through partnerships and programs that enhance research and educational outcomes. We have established partnership awards through our NASA centers. Those awards are valued at about $\$ 400,000$, and the intent is to ensure that the curricula that is offered at these institutions are supportive of NASA's mission and objectives. And as a result, we have been able to partner with institutions to enable them to bring on more advanced degrees in NASA-related areas and, in several cases, doctoral degree programs.

The third goal has to do with preparing faculty and students at minority institutions to successfully participate in the conventional competitive research and education process. This area 
has to do with our individual Principal Investigator Awards. Each principal investigator is assigned by NASA as a technical monitor who works with that researcher, again, to ensure that he or she is very familiar with the type of activities that will enhance participation and competitive peer review processes. The principal investigators are involved in discipline-related working groups. They participate on peer review panels. They present papers at technical conferences, and they also jointly publish papers with the NASA researchers.

And finally, the fourth goal has to do with increasing at minority institutions the number of students preparing to enter college and successfully pursue and complete degrees in NASArelated fields. This is done primarily in partnership with the minority institutions. For example, we provide funding for summer institutes and Saturday academies in math and science and focus on math, science, and technology. But we do this by making awards to institutions of higher education because, from an agency perspective, and from a local perspective, we really want to ensure that whatever efforts we are funding in the K-12 area are consistent with the State and local standards. Minority institutions who have produced many teachers already have established very strong partnerships with local and State school districts.

We also provide programs that are very similar to the SURF program if not exactly like the SURF program. As a matter of fact, we provide scholarship support, tuition assistance for our undergraduate students. In addition, we provide them with paid, 10-week summer research experiences at all of our NASA centers and at the Jet Propulsion Laboratory. That program now supports over 600 students. It started in 1988 as one small grant to Spelman College. The focus was on women. Women now represent more than half of the participants in our undergraduate scholars program. We also have graduate fellowship programs, and we provide support for fellowships in selecting the students, we market their research topics to NASA's researchers, and we try to match them with a NASA researcher/mentor prior to selecting them for the fellowship. So, as part of the fellowship award they receive a mentor. We also provide training for our mentors. We have handbooks for mentoring our undergraduates and our graduate students.

As a result of all of these efforts we have established four management strategies that we hope will lead to various substantial outcomes in support of the agency's strategic vision. What I hope I have described for you are ways in which we have tried to ensure meaningful involvement between the strategic enterprises and minority institutions that place these institutions on critical paths that determines NASA's mission success. We don't want these institutions operating on peripheral assignments. We really want them involved in the critical path, and strategic enterprises have really stepped up to ensure that that happened.

Not only do we have the specific funding that the Office of Equal Opportunities provides for minority institutions. Also, whenever the strategic enterprises issue a solicitation, one of the components of that solicitation is to look for our majority research institutions to provide as part of their proposal to the agency a strong relationship with a minority institution. So we will provide funding in support of that partnership-what we call seed funding-because what we hope is that after two or three years that the minority institution will become an integral part of the ongoing funding of that strategic mission for the agency.

Again, we try to build significant scientific infrastructure that contributes to one or more of NASA's strategic enterprises research priorities. We try to ensure that by enhancing the academic programs of these institutions. We are providing them with an opportunity to integrate current 
and cutting-edge research and technology into their undergraduate curriculum, thereby producing more competitive students and meeting NASA's future human resources needs. We do try to focus specifically on scholarships and fellowships, but we realized we weren't going to get there fast enough just by picking the best and the brightest, and so basically we have evolved to a focus on strengthening the institutions. We want to ensure that if a student is only going to take one science class, for example, astronomy, that we are able to support that institution by sharing with it the contents from our missions and thereby hopefully inciting or inspiring some of these students to continue in those areas.

We also hope that in partnership with our minority institutions we will enhance the performance of students. We reach down actually all the way to pre-K level so we can keep students on the type of academic path that will enable them to choose science and engineering as a career once they each college level.

Finally, because the minority university program is a Congressionally authorized and appropriated budget, we have to justify our program just as the Space Shuttle, and the space station, the earth science/space science program. We are there at the table trying to ensure that whatever funds have been invested, the agency can show our primary customer, the public, that there has been a return on that investment. So annually, for every award that is funded through the Minority University Research and Education Program, we ask our principal investigators to report their progress.

And we have two tracks. One is a research award and the other is an education award. This chart shares with you some of the data that we collect. These data are used in reporting our outcomes to the Office of Management and Budget, the White House Initiative Office on Historically Black Colleges and Universities, Tribal Colleges and Universities, Educational Excellence for Hispanic Americans, and also to the public.

NASA's efforts began by establishing the first shadowing program for girls at Goddard Space Flight Center without money. We had an employee welfare association that was able to provide funds. I think what has really enabled us to move from that beginning, from our focus on individual scholarship support for girls, to now focusing on institutions, where we can impact classrooms of students, has been the visionary NASA administrators that we have had, and other senior executives and their commitment to education and diversity in the NASA-sponsored research and education community. And it's been the realization that even when we're not able to hire, which has happened frequently over the last several years, we can still have a presence in the community so that when the doors of opportunity open up, people are not saying "NASA who?"

Through these programs we're still able to keep involved. The Office of Equal Opportunity has responsibility for the dedicated MUREP budget of $\$ 84.7$ million - this was the budget for this year. I think we have stimulated partnerships with the strategic enterprises and with others, because in executing this budget, as I mentioned earlier, we do sit down with the strategic enterprises and try to understand their strategic objectives and come up with an approach that will enable all of us to support the agency's strategic vision. And it is through them; such as I mentioned earlier, that the HEDS enterprise controls the institutional resources of those four NASA centers. The other enterprises control the institutional resources of other NASA centers. For example, the space/earth science enterprise controls the Goddard Space Flight Center 
enterprises, and as you know, these facilities have unique missions, facilities, human resources, and programs. So if we want to tap into where the work is really being done and where students and faculty really need to be, then we need to continue to ensure that we have these partnerships.

Also, the agency, through its honor programs and performance reviews and performance awards, recognizes employees who have made sustained and substantial contributions to the minority university program efforts through their mentoring. We try to focus on national solicitations and, as I mentioned earlier, involve the researchers in the design of the solicitation before it is released. We involve them in peer review, and we also ask that they make lecture recommendations to us. And we continue to emphasize strategic planning, measurable performance, accountability of program results, and sound and timely financial management of all of the funds that we issue to our awardees.

So often we try to say, well, I can't see what we can do in the immediate future. But what this chart says is, as for the future, your task is not to foresee it but to enable it. We can all enable the future. So I think that this is the message I want to leave with you today. And again I want to thank you for letting me share with you NASA's strategic vision and how we are trying to advance our programs to impact an increasing larger number of women and minorities, and in meaningfully engaging them in our programs. Thank you. [Applause] 


\section{MENTORING PRESENTATION QUESTIONS AND ANSWERS}

This question is for Darlene. It is a follow-up on something you said. You pointed out some of the differences that Pat Heim discussed in her film regarding the "dead-even rule," specifically, that women tend to raise their hands in meetings instead of interrupting and often share the credit for projects. Do you suggest, after saying that the Government is a hierarchical institution, that women learn those skills, that women start developing those skills?

[Darlene Floyd Answers] Absolutely. And I think that you have to have the information to know what the differences are. You know, how we fit, where we fit, what we say, what we don't say, how we respond, and then you make the choice about whether you want to do them or not. There are a lot of things.

When I moved to Washington, DC, and worked for a Federal agency, it was a very ultraconservative organization. A colleague and friend pulled me aside and pulled me aside and said, "Darlene, if you are to succeed here, the very first thing you have to do is not wear that red dress you have on today." And the dress was very conservative-the neck was up to here, it was longsleeved-but it was red and so they just did not see it fitting, if you will, in that ultraconservative environment. And I appreciated that information and understood exactly what she was saying, because I looked around and everybody else was wearing black and gray and navy blue. But I made the decision that red was too important for me, and later I left that organization. But at least I had the information. So I think we absolutely have to learn those skills if we want to be heard, if we want to contribute to the organization. We have to learn them. But then you decide, "Do I want to use them or not? Do I want to keep the politeness and raise my hand or do I want to jump in there, as research shows that men do?"

But absolutely we ought to learn where to fit. The power seat in a meeting. Boys are taught that, girls are not. We just are taught to come in and sit down, and usually we sit next to a person who looks like us, that we're comfortable with. But sometimes it is not the most powerful seat, if you will, in the room.

Back to choices, which we talked about yesterday. I see your future publication, your new book, Darlene, Career Choices Based on the Color Red. I love it. Thank you! I just have a follow-up question also for you, Darlene. You stated earlier that one of the reasons that you think women aren't represented in the upper portion of the hierarchical levels is because those women don't know those positions exist. So my question is, do you know of an avenue in which those positions could be readily publicized?

[Darlene Floyd Answers] Not necessarily to women, once they're already entrenched in a certain field. But for a woman - a young woman like myself, who is just beginning to know how to get there, and then continue the steps to get to those positions-I would say a couple things. One, we as women have to take total and complete responsibility for our own career development. And that means we have to go out there and do some research that we normally would not do, on things that may come to others very easily but not necessarily come to us in terms of information. We've got to get out there. One of the things I fought for a long time was getting involved with 
technology. I said I would never surf the Web. But it is phenomenal, the information that is out there in terms of research grants and other information for women.

The second thing I would point out is the importance of a mentor who tells you that networking gives you those opportunities. Sometimes we don't go outside our comfort level to get information. I'm not a drinker, but I go to a lot of "happy hours" because a lot of business is transacted at happy hours. I'm not a party person, so my comfort level doesn't include receptions, but I'm at a lot of receptions where there are things going on where you'll find information, and that's something you have to do. You get that through mentoring as well as networking. And then you have to find people, such as the ones in human resources in your organization, and sit down and say, "What is going on?" And so it takes a lot of initiative to find out what is out there. But I think the Web is wonderful, and the library, in terms of information. These associations that I talked about really do a lot of hard research work to help women. So I think those are some things I would suggest to you.

I am sort of new at this, so I am absorbing all of this and making comparisons, and that's why I ask questions. I totally enjoyed your presentation. I want to make a comment. You used a word-I finally learned what it really is. You mentioned something about "dysfunctional chivalry." And I always called it pacification. Usually very early in any job I had made it clear to the boss that I wasn't into pacification, because if we are driving strategy, we really don't need to be pacified, but we need to have at our disposal just what you said: the facts straight up. Politics is $\mathbf{8 0}$ percent of the job when you're in a leadership role. And so I was getting reinforcement from your presentation and only want to say that in my own career, I never really had a mentor. However, I wished for one, and clearly observed the value of one. And then I have mentored others, young men and women. And so I do believe the message is to comment that've got to know the politics, You've got to know the culture, neither of which do I know here. And you have to clearly understand that that is so important to setting your strategy. The thing that $I$ used to tell employees where I used to work is, "The only person that you can control is yourself. To me, that is the first lesson to learn, and then build from there. I have totally enjoyed the presentations, and I want to compliment both ladies for what you are doing. Thank you.

[Darlene Floyd Answers] I want to correct one thing. I don't want to take any credit for what I did, but "dysfunctional rescuing" is actually a term from Valerie Batt. She talks about how it shows up for women as well as for people of color in organizations-and I refer to chivalry.

[Sol del Ande Eaton] Great. Before we close, I want to reiterate my thanks for great presentations and, most importantly, leave you all with a message. First of all, ask yourself, "What are my choices around mentoring and coaching?" I'm hearing some strong messages from all our speakers this morning. What a great career choice and opportunity that is for you. If this is something that you would find valuable, by all means pursue that. Talk to others, surf the 'net, talk to our speakers. And second, please take the next step, which is not only to watch out for your own career, but also to watch out for the future careers of others. As Betty described her great program at NASA, you also have the ability to effect the change and create the future through similar programs here at NIST. Create your own mentoring and coaching strategies for the young people who are coming behind us. Thank you again, very much. Continue to explore and expand your horizons related to very important issues to NIST. 


\title{
MEETING THE CRISIS IN HUMAN CAPITAL: K-12 TO GRADUATE SCHOOL
}

\author{
Dr. Julia V. Clark \\ Program Director, National Science Foundation ${ }^{24}$
}

I am pleased to be invited to serve as a presenter at your conference and to speak on a topic of great importance and interest to me. Congressman Bob Etheridge of North Carolina, a member of the House Science Committee, with whom I am on a detail assignment this year, and the National Science Foundation are also interested in this topic. We are very much concerned about the under-representation and shortage of minorities, women, and people with disabilities in the field of science and science-related areas in the United States.

While the United States is concerned about the current shortage of K-12 teachers, especially in science and mathematics, it is equally concerned about the challenge of attracting more students to these subjects and related careers. Currently, and even greater in the next few years, this country will face a serious shortage of scientist and mathematicians. To remain economically competitive, the United States must educate and advance both minorities and women in science and mathematics.

All of us know that too few women are represented among the population of scientists in the United States. Despite substantial gains over the past decade, women are still under-represented in science and engineering. While women have made strides over the past few years in pursuing an education in science, mathematics, and engineering fields, they still lag significantly behind their male counterparts. According to the National Science Foundation's 1998 Report on Women, Minorities, and Persons with Disabilities in Science and Engineering, women earned over half of all bachelor degrees awarded in 1995. Yet, only one in six, or about 17 percent of these degrees were awarded to women in engineering, an increase of less than one percent compared to 1966 data. In 1997, women earned just 37 percent of all science and engineering degrees awarded that year. Further, at the graduate level women represented only 23 percent of scientists and engineers with doctorates in the United States in 1997.

While jobs requiring advanced degrees in science and math continue to increase, women remain Under-represented in these careers, particularly in engineering. According to the U.S. Census Bureau, women represented just 19 percent of the science, engineering, and technology labor force in 1997 compared to nearly 46 percent representation in the workforce as a whole. To put this another way, women are slightly more than one-fifth of the science and engineering workforce, but close to half of the U.S. labor force in 1997. At the same time, women represented a smaller percentage of computer and mathematical scientists than previously existed in 1993. Women engineers also represented only 9 percent of the workforce in 1999.

Many other career paths also require advanced education in science and mathematics, so today, more than ever before, all students must be included in the national priority. Girls, in particular, need to be shown the options open to them by continuing to study science and mathematics.

\footnotetext{
${ }^{24}$ Currently on detail from the National Science Foundation serving as a Congressional Fellow for Science and Technology issues in the Office of Congressman Bob Etheridge (R-NC).
} 
A contributing problem associated with women in science appears to begin as early as the elementary grades. There is a lack of emphasis on science in American schools during the elementary grades. Self-perceptions play an important role in science and mathematics achievement, especially for girls. Research shows that self-esteem and academic achievement among girls begin to decline during middle schools and that girls often exhibit a loss of selfconfidence by age 12 .

The time devoted to science is less than half that devoted to reading and mathematics. The problem is even worse for girls and minorities. Data from the National Assessment of Education Progress-NAEP-indicate that girls have significantly less experience than boys do at comparable ages. The expectations of teachers toward boys in science are different for those of girls. NAEP data show that although 71 percent of girls and 66 percent of boys in grade 12 reported taking biology and chemistry, only 19 percent of girls and 34 percent of boys reported taking biology, chemistry, and physics.

In 1992 the American Association of University Women reported that girls did not take as many advanced science and mathematics courses in school as boys. The gap still exists with girls in physics and computer science. Although girls and boys essentially take the same amount of science and mathematics courses in high school, girls are less likely to take physics, advanced placement chemistry or advanced placement physics, or the sequence of biology, chemistry, and physics generally taken by students planning to major in science or mathematics in college.

Therefore it comes as no surprise that enrollment in advanced science and mathematics courses in high school is related to proficiency in these subjects. Because the gender gap in math enrollment has been closing, gender differences in math proficiency scores have decreased accordingly. NAEP results for 1994 show no gap in math proficiency scores between ages 9 and 13, and the gap in scores that existed from 1973 to 1986 between 17 -year-old boys and girls has practically disappeared. However, the gender gap in science proficiency persists. In 1998, science proficiency scores were similar for girls and boys at age 9, but clearly lower for girls at age 13 . Though girls begin to fall behind boys on standardized science exams by grade 7 , they do not fall behind in math until grade 10. By the time students take the Scholastic Aptitude Tests and the advanced placement exams in science and mathematics, boys outscore girls in both science and mathematics. It is critical to remember that gender differences in science and mathematics proficiency scores become apparent when girls either stop taking advanced courses or enroll in fewer science and mathematics courses than boys their age.

In essence, girls' and boys' abilities are the same; their perceptions and attitudes are different. Even girls who have course backgrounds and achievement levels similar to those of boys have less confidence in their abilities and less interest in studying science and mathematics. Consequently, girls are less likely than boys to pursue related careers. Also, some girls underachieve in science and mathematics because they are discouraged from studying these subjects.

The following summarizes the problems associated with females in science:

- Women have historically been underrepresented in mathematics, science, engineering, and technology occupations. 
- Female students take fewer high-level mathematics and science courses in high school than male students.

- Female students take far fewer advanced computer classes than male students take and tend to take only basic data entry and word processing classes.

- Female students earn fewer baccalaureate, masters, and doctoral degrees in math, science, engineering, and technology than male students.

- Teachers' attitudes, methods of teaching, and classroom atmosphere affect female student's interests in nontraditional fields.

- Stereotypes about appropriate careers for females, a lack of female role models, and a lack of basic career information significantly deters girls' interest in mathematics, science, engineering, and technology careers.

- Limited access is a hurdle faced by females seeking jobs in mathematics, science, engineering, and technology.

- Common recruitment and hiring practices make extensive use of traditional networks that often overlook females.

The relatively low U.S. participation rate in science and engineering degrees compared with other countries may be inadequate for the current and future economy, as reflected in the high number of foreign-born skills workers who have been provided special visas-H1-B visas-to attempt to meet the needs of U.S. high-technology industries and services.

The National Science Foundation and Congress, as well as other Federal agencies, have recognized the shortage of women in science and are doing something about it. Multitudes of initiatives are either in place or are underway. For example, at NSF the Division of Human Resource Development in the Directorate for Education and Human Resources serves as a focal point for NSF's agency-wide commitment to enhancing the quality and excellence of science, mathematics, engineering, and technology education and research through broadening participation by under-represented groups and institutions. The division's programs aim to increase the participation and advancement of under-represented minorities and minority-serving institutions, women and girls, and persons with disabilities at every level of the science and engineering enterprise.

A program was created in 1993 to address national concern regarding under-representation of women in science, engineering, and mathematics. It is one of several targeted efforts within the Directorate for Education and Human Resources seeking to broaden the participation of groups under-represented in science, math, engineering, and technology. The Program supports research and demonstration projects for grades K-16 that will lead to change in education policy and practice.

The Program for Gender Equity in Science, Mathematics, Engineering, and Technology is committed to bringing about the needed change in education and academic and professional climates through increased awareness of the interests, needs, and capabilities of girls and women; promoting instructional materials and teaching methods for increasing interest, retention, and achievement of girls and women in science, math, engineering, and technology disciplines; and increasing the availability of student enrichment resources including mentoring. In short, efforts in the Program for Gender Equity are dedicated to changing factors that have discouraged the 
early, and continuing, interest in science, math, engineering, and technology, and to develop interest, knowledge, and involvement of girls and young women in these fields.

In Congress there are a number of Bills being sponsored. In November 1997 Congresswoman Connie Morella introduced H.R. 3007, the Commission on the Advancement of Women, Minorities, and Persons with Disabilities. The House Subcommittee on Technology and Basic Research of the House Science Committee held a joint legislative hearing to review H.R. 3007 on March 10, 1998. The legislation passed the House of Representatives under Suspension of the Rules on September 14, 1998 and was considered under Unanimous Consent by the U.S. Senate on October 1 of that year. H.R. 3007 was signed by former President Clinton on October 14, 1998, and became Public Law 105-255. H.R. 3007 created an 11-member commission to examine what underlying factors contribute to the relative lack of women, minorities, and persons with disabilities in the science, engineering, and technology fields. The commission was assigned the task of developing a set of recommendations that government, academia, and private industry can follow to encourage the recruitment, retention, and achievement of those currently under-represented in the science, engineering, and technology fields. The report was released on July $13,2000$.

Congresswoman Lynn Woolsey sponsored a Bill, H.R. 1536, to amend the Elementary and Secondary Education Act of 1965 to provide grants to local educational agencies to encourage girls to pursue studies and careers in science, mathematics, engineering, and technology. The bill is called Getting Our Girls Ready for the 21st Century (GO GIRL). The bill targets girls in grades 4-8 and their parents. The program acquaints girls in grades 4-8 with careers in science, mathematics, engineering, and technology and encourages them to pursue studies in these fields. Congressman Etheridge is a co-sponsor of this bill. In terms of the status of the bill, it has been referred to the House Committee on Education and the Workforce and to the Subcommittee on Education Reform.

There is also a bill sponsored by the Science Committee chairman, Sherwood Boehlert-H.R. 3130 -to provide for increasing the technically trained workforce in the United States. The Bill H.R. 1868 also has provisions for programs targeted for women. The NSF is the agency authorized for all of these bills.

Some possible strategies for getting more females into mathematics, science engineering and technology are:

- Financial support for academic pursuits.

- Early exposure to science in the classroom and through meaningful exposure to scientists and engineers.

- Involvement of parents.

- Exposure to well qualified teachers and faculty members.

- Continue career development programs as those mentioned earlier at NSF and mandated by Congress.

- Support organizations with community-based programs that are encouraging full participation in the sciences.

- Form partnerships among Federal agencies, professional organizations, and industry to produce materials that advance accurate portrayals of scientists in the media. 
- Support programs that bring practicing scientists into classrooms at every level to lecture, speak about careers, assist in courses or special programs and projects, or serve as mentors as in the NSF's Graduate K-12 program.

The issue of whether women and minorities are attracted to science and engineering majors is of national interest because they now make up the majority of the labor force. Their successful completion of science and engineering degrees will determine the adequacy of entrants into the science and engineering workforce in the United States. All students need a supporting, caring, nurturing environment to succeed. The need for assistance begins in the home and continues in grade school, high school, and throughout the education pipeline.

America is becoming aware that future shortfalls of scientists and engineers can only be met by bringing women and minorities into the pool of science and engineering majors. To accomplish this goal it will take parents, teachers, schools, colleges and universities, business and industry, scientific organizations, Congress, and the Federal government working together. One group cannot do it single-handedly, but together we can make things happen.

I thank you for the opportunity to share this information with you, and I look forward to further dialogue and interaction with you after the summit. [Applause] 


\section{ON EDUCATION}

\section{Jonetta Russell \\ Magnet School Coordinator, Montgomery-Blair High School Montgomery County Public Schools, Maryland}

Good afternoon. I have much to be thankful for from NIST. I have been associated with NIST since 1980 when I began teaching at Gaithersburg. I taught at Gaithersburg High School for 19 years, which is 4 to 5 miles away from here. And the school has had interns here all that while. Now I am working in a magnet program, and I had 22 interns here last summer in the building. People ask me, "Do you know where to go?" I answer that I surely do. I've been in about every building. I've even been to the place-I guess I can tell you about it. I've been to the place [the former NIKE missile site] where you go underground and, there used to be missiles there. And they had them situated so they fired right toward Washington, DC, and tra-la-la, it looked like it would go right over my house, which is south of here at least 5 to 6 miles.

But NIST is an exciting place to visit. I had a student who later programmed the laser that is the standard for the world. And you stand there in this room and say, "Ah-the laser for the world." [Bettie White] was here from NASA this morning-I've had students there. I've seen the "clean room." I had a student who wrote the program for the satellite that was going around Venus, and a year or so later it got to the newspaper, and I thought, "Oh, I had a student who did that program." I've seen a lot of things in my job. It's an exciting job.

I'm happy to see Dr. Barbara Levine here this afternoon. I've known her for quite a while. She's a super lady. She handed me a publication that one of my students and she have authored. She and Dr. Dale Newbury from here I think were responsible-I received an award from NIST's chapter of Sigma Xi, the Scientific Research Society. And with the honorarium we bought a paper cutter. Now that sounds like a simple thing, but I have students all over Blair High School come because it is a huge paper cutter - this is a wonderful paper cutter-and I say thank you to NIST, every time they use it.

I'm going to talk about an internship. I listened this morning to your vocabulary. I need to know a little bit about my audience. Are any of the rest of you here teachers? Not a soul. Are any of you mentors other than Dr. Levine? Wonderful. The rest of you I gather are in administration? Good. How many of you are not from the Washington, DC. Area-the tri-state area? Welcome! We had a big convention for the state with the junior science and humanities program yesterday and the day before, and students of the state of Maryland said they were afraid to come to DC. It was kind of scary. I don't think about that, I guess ignorance is bliss. I understand it is serious, but you know, I just don't think about that.

When you hear the word "education," what are some words that you think of? I say "education"; what do you say? "Learning." Some other problems or something. It can be political. It can be philosophical. Yes, you read in the newspaper about it. And if there's anything that grinds my soul, it's to hear about how wonderful education is all around the world except here in the United States. And I say to myself, why did I have so many different students-I guess 40 percent of my class wasn't born in America. Why didn't they stay in their own country if it's so terrible here? I'm not supposed to say that out loud. I'm retired; I guess I can say that. I think we have a good 
educational system, and the good Dr. Julia Clark talked this afternoon about, you know, things that are not so good. And I come from a math, science, and computer science magnet. We try to maintain 50 percent ladies and 50 percent gentlemen. And I honestly don't think that much about the ladies versus the gentlemen, I just tell my class, "I'm biased, so, guys, you have to come up to us."

This visual shows some things I thought of. I put down "teacher shortage," and I wanted to give you a commercial for having an internship or encouraging internships. There is no teachershortage? We have 100 students per class. I had 82 who were in internships, and each of them had his or her own extra teacher or mentor. And that's pretty good. I mean, they're all Ph.D.'s and whatnot in their field.

The next topic you'll notice is class size. I had 82 students, not all in the same class, but all have what is known as "individualized instruction," and they come to places such as NIST. They work along with the college student, along with the other doctors and post-doctors and all the famous people who are here. And it is a wonderful privilege. We don't worry about having 35 or 40 in a classroom.

Money? It does cost the laboratory money for equipment. And so it's not free of charge. My students are not to expect a salary because they receive high-school credit. And so they don't really come free of charge. I must say that after NIST or any of the institutions in the area train them, they're often hired, you know, right afterward. When I walked down the halls of NIST last summer, I heard somebody yell, "Mrs. Russell!" And I turned around and the person said, "What are you doing here?" And I said, "What are you doing here?" He said, "Well, I work here!" And I had that student, I guess, 20 years or so ago-I don't know, time goes by. But, they do come back, and they do work for the institutions. And it is a thrill! They're probably making twice my salary, but that is alright. I mean, the Federal government pays so well. [Laughter] I'm happy to have them here. That was the purpose and function of my job.

The next item is space. I guess it has been at least 10 years ago that I heard some students talking in the hall at Blair. One said, "You know, you get a desk." And the other one said, "Well, how do you get a desk?" "Let me tell you. When you come in the morning you go like this. What happens to the next person that comes in? They go like this, too." "What about your desk?" "Oh, it is there." But as you go in the halls now, why, you find they have been remodeling and whatnot. Most of them have a desk and have their own little section of the laboratory. And it's a lot snazzier than we could afford at the high school. Technologically, we're on the cutting edge, that is for certain. My students-Radhika Char, one of the finalists for the Intel award, was in Building 227 making wafers out of gold and platinum. NIST doesn't think about gold and platinum as being expensive, I guess, or at least that is my perception, and these wafers were synthesized pieces of DNA, and this was being used for bioengineering. Two years ago I had a student who was developing a cell that is "liberated-energy" and had about 20 times the amount of memory in a normal computer. Two years ago the problem was, well, we have this little cell that you could put in your clothing and it would detect whether it was warm, cold, or whatnot outside, and the problem was, how do we connect it up to a keyboard. And the student was doing just that, figuring out technologically how you hook up a little tiny cell to a keyboard so it can be utilized. 
The next item is standardized testing. Oh, my word! Observe the wing on the bird. Everybody is so excited about testing. And the biggest problem-I'll stand on my soapbox-with testing is the person who makes the test hasn't been in the classroom for five years or more. And they give a test to a student and then say the student doesn't know much. Let me give you an example. My son took a test where the little scenario was that he was walking through the forest, this boy, and looked up in the tree and there was a bird. So he took a long stick and he poked the bird, and all the feathers and whatnot and bird fell down to the ground. And the question was what would you do? And so he said, I'd have never seen the bird because I get poison ivy very easily. And I wouldn't have been looking up; I would have been looking down to see where the poison ivy was. How in the world do you score such a thing? I have no idea. I said to him, "You didn't!" He said, "I did! They asked for the truth, and I told them." But at any rate, standardized testing is fine-SAT's and all of that. But it is really what is upstairs-it's what in your head that counts.

I challenge you to take any student, and you'll find they know a lot about something, even if they-no matter what environment they come from. And that is never tested, and they're never given much opportunity to explain, what they want, because we have to stick to a curriculum or we have to teach to a test. And the student feels, "Mercy may, who cares whether the world went upside down or backwards or whether Copernicus looked at this or this?" He has his own world. And so I challenge education-maybe that is what I should do in my retirement-to have curriculum that is student-oriented, that encourages them, as Dr. Clark as said, "to be experts in what they can be."

And then there is the curriculum. Oh, my, I agree with her. I'm a science teacher, and I have taught from third grade up to adults. And we had lots of science, but I know there are many teachers in elementary school who-if you mention the word "science,"-goodness!-would think their salary should be increased if they took a course.

Ethics-this is a big problem. I was at a conference just the other day where they were discussing student cheating. Now, if you have internships, it is not a problem. My students have their own individualized instruction, and there is nothing to cheat about. They have their own journals. They certainly can't say, "Hey! What in the world should I put down?" One is working on, let's say, magnetic restriction and the others are working on wafers. And another is working on satellites and whatnot. You can't cheat. Oh, it's delightful to teach this course, because I used to teach advanced placement biology and lay awake nights thinking, how can I make a test so the students wouldn't cheat? It is not that they aren't capable. They say they don't have time to study. Well, whatever. All right.

I'd like to define a word that I like, and that is "differentiated instruction." Differentiated instruction means all can do it, but all don't do it at the same degree of sophistication. I think this is a good philosophy and a good clue, because I can give an assessment. I have a class of 82 students who I'm going to farm out to different institutions. We try as much as possible to have it individualized and that all will be able to do something. Now, some of them are far more successful. A lot of times, they are far more successful because they put in more time. But some of them say, "I didn't think I'd be able to do that, and I'm so excited that, I was really successful in making a little piece of knowledge for this world, and my name is on a paper." Or so forth. So I think differentiated instruction is certainly the key if you want more women in science, that is sort of tailored toward them, and have them be directed. 
Now I'd like you to look at some of the papers and some of the documents that my students must complete. The first one I'd like you to look at is this one. Probably the last page. There is a section there that has the scientific paper, and as I took it apart I think it is the last page. It is a model for a resume. In society today we need somehow, as instructors and as adults, to develop in our young people a work ethic. You know, today we press a button and something happens. My husband is so frustrating to watch TV with, because he's watching four programs at once and he tells me, you know, this is how you learn things. And I say, brother, it's bad enough to keep up with the commercials. I don't want to listen to those, let alone four commercials at once. But we need to have young people learn to follow directions. Now I know this is not the only way to write a resume, but I insist-and I see these students when they become juniors that they follow this resume to the exact "T." Not because I'm so wonderful, but I want to know if they can follow directions. There is nothing worse than going to the laboratory and not being able to follow directions. You are apt to ruin a million-dollar machine in about two shakes of a lamb's tail.

Notice that I want them to have their full, official name and so forth. That they're Blair High School juniors. And here's the thing that is really unique about this-and I found the mentors really like-is this little paragraph. My purpose is to begin to teach them formal scientific writing. This is not easy, because in English classes today, you can put down periods or ands and buts and end with prepositions and whatnot. As long as it is some kind of literature, it is acceptable. And in formal scientific writing, I tell them to use the queen's English, please, and that we're going to allow some rules. I'm amazed when I talk about a preposition. I said to some students, "When I was in high school, I can remember, it was a right-hand page and it had all the prepositions listed. Do you have that now?" One answered, "We don't even take grammar." Oh, my goodness, bless my soul. At any rate, this paragraph-I want them to put in formal scientific writing a few sentences, and we're teaching them to write concisely about themselves and their desires. Do they want to work at NIST? Do they want to work at NIH? Do they want to work at the Army Research Lab? Would they like to work at Walter Reed Medical Center? And I must put in a commercial: this geographical area is probably one of the best in the Nation for research institutions. And then I want the students to give details of the internship. I would like them to do something that is called "think."

And last, but not least, they must include a sentence that uses three descriptive adjectives about themselves. They are not to say they are intelligent. I certainly hope they are. They are not to say that they are hard-working. They are to think of some good, wonderful adjectives. And some students think they'll beat the system and come up with, you know, maybe 10-syllable words. So I say to them, the mentors want to read this fast because this is designed for an interview and they're not going to sit with a dictionary. They're busy people. And I have it edited by their peers. And if they say how wonderful they are and their peers don't agree, they soon let them know. But it helps them to begin to be introspective and think about themselves. What are their qualifications? And then, you see, we start with the student's previous experience. We start with the latest and so forth. Some get down to publications and say, "I don't have any." Well, I say don't write that in the block, to let everybody know you didn't have a publication. I don't want any more than five. They're supposed to be research scientists and have a little time to work. And it's the same with extracurricular activities. Some say they could fill a whole page with hobbies. I tell them, please, select the ones that you think a mentor, who is interviewing you, would be interested in. 
Now, they have a folder. The folder includes several items. The first page is a resume; the second page is a transcript; the third page will be a paragraph on why they want to work at that institution. The next two pages are brief teacher recommendations. And last is the mentor inquiry sheet. You'll see that I'd like to know if the scientist would like to be a mentor or not. It does take time, and I appreciate every one who has agreed-they've been excellent.

Then I would like to know when the institution would like to have the students work. The standard operating procedures are very, very important. What one do you think the students fall down on? It is, "Cleans the workstation and returns utensils to their proper place before leaving." Some young people are used to having a maid or butler and whatnot. They need to be aware that they must clean up after themselves.

The next section covers their academic prowess. It is rather discouraging when a mentor says to me, "I don't want a student with a 4.0." You think, "Whoa!" The mentor will say, "All they know is how to do is make A's." And I must say that is about the size of it. In research you need to be able to take a risk. You need to be intelligent, that is for certain, but if all you worried about is if the mentor is going to give you an A-and interning is worth 40 percent of the grade. Why, forget it. If you are not willing to be a little resourceful, shall we say, and take a risk, making an $\mathrm{A}$ is not what research is all about.

And then I would like to give them a protocol, or what the laboratory is doing. One of the more important things is the next page-the proposal. The secret to success with a wonderful research project is that you do some pre-planning. It may be very difficult for a high-school student to identify a problem. They have been used to experiments, which are just recipes or maybe the next level up, an investigation, where they're allowed to do a little more thinking. But a research problem doesn't have an answer. You may have to do experiments and investigations in your research, but, you want a problem with which not even your mentor knows exactly what will happen, or what complications may arise.

The rest of this handout you can read, and it is very important that they do this. It is not to be more than three pages. An excellent book is Practical Research, By Paul D. Leedy and Jeanne Ellis Ormrod. It's simple. It's complex. It has all these forms to be followed, and how they' re to be held, and when the commas come. And when the spaces come. I highly recommend it to those of you who are maybe starting a mentoring program. To those of you who are already mentors, you don't have to worry about that. I provide them an "Off-Campus Research Agreement" that I find very helpful, because the student promises to do this, I promise to do that, the mentors accept responsibilities, the parents have responsibilities. And a timetable is established; we're not going to say, "Oh, okay," and then maybe next year: "Oh, I've got two days to do all this." And then there are permission slips that are necessary. There isn't any parking problem here on this campus, but at NIH I think you have to take the bus to the Metro to get there, parking is so bad.

Then I've given them examples of insurance. These students are under 18. We're responsible for them. And as much as possible, I would like to make sure that they have medical insurance. The county administrators, in their infinite wisdom, have said to me, "We haven't had anything go wrong." But when something does, everything stops thanks to you, Mrs. Russell. I said, "Boy, how am I supposed to sleep at night?" I do give them their assignment, called "assessment" nowadays, a month ahead of time. I have the month of November. As you see there, and there is always some little response required-I want to know if they read it. 
And I give them a blueprint for the scientific paper. I want the paper to be of journal quality. I've had an internship at NIH, in neuroendocrinology, and had the privilege of writing a paper, so I really want this paper to be "snazzy-dazzy," I call it. Students don't smile at me too much from September to November, when writing the paper. They'll say, "I had to do this eight times and I still don't meet her specs." And I just tell them, "Music to my ears." The paper is edited by their peers first, and then by the mentors who are really terrific. They say, "Wow!" And I say, "Yes, wow! This is a serious paper." The Mentors have told me one of the good things about writing a scientific paper is that it helps to pull everything together. Not only do the students realize what they've done-and sometimes they have to go back and redo, but it also teaches them the value of just what was going on, the importance of their particular investigation.

This program has been very successful for me, and I've enjoyed my job. I haven't decided what I'm going to do, really, after this. My husband says he doesn't think he'll see me as much as he did when I was teaching school. But it is a wonderful position. I challenge those of you finding new people to run the program-it is necessary. The high school students are very, very good interns, and they work right along with the college students. Dr. King talked about his SURF Program-I don't think he knows we've been around here for 20 years. We sort of go in the back door. I know a lot of people here on campus, and I say to them, "Would you like an intern this year?"

So I thank you kindly for your attention. For those of you who are embarking on internships, have fun! It's a wonderful world! [Applause] Thank you very much. 


\section{QUESTIONS AND ANSWERS ABOUT PIPELINE AND COMMUNITY OUTREACH}

[Sol del Ande Eaton] We got some good data from Dr. Clark. It either astounded you or staggered you. You have heard it before, but when you hear that kind of statistical data it is a verification and validation of what you already know and experience, and what a great process of how do you set up and work with interns in internship programs. So specific questions that you may have, if you would address the speaker and ask your question. Thank you.

My name is Sandy Wright Claggett, and this is question is to Mrs. Jonetta Russell. First of all a comment: I'm the one who came out and said, Mrs. Russell, I thought I was in hell and it scared me. I thought, Oh, my god, it's my science time! I want to tell you, Mrs. Russell, I'm 44 years old, and because of your classes in advancement placement biology, I have been a physical science technician here and a metallographer at Bethlehem Steel. My brother was in your class along with Allen Tighe and Sean Canero, and we'd like to present flowers from the classes of 1976 and 1981 - and many, many other classes from Gaithersburg High School. So Mrs. Russell started advanced placement biology and God knows what else, way, way back, a long time ago. I have been here for 23 years, and am very, very proud to be a part of NIST, and very proud to tell you that your students did work on my equipment, and they didn't break it! But I did stand over them to make sure they didn't. They were very, very good students. God bless you, and have fun in your second retirement! [Applause]

\section{[A second presentation.] [Applause]}

[Jonetta Russell answers] The first day of school you have all these, you know, names of students, and I went down the list and I saw "Patrick Claggett" and I said, "Wow, that's a fine Irish name," and this good-looking Afro-American student stood up and he said, "I'm Patrick Claggett." I said, "Wow! I guess I stepped into that one, huh? [Laughter]

I'd like to thank both of you for your presentations. I really enjoyed both of them. I have a question for Mrs. Russell. Why do you think it is that you managed to have such a high number of the Intel winners-the highest in the Nation?

[Jonetta Russell answers] I do a lot of good nagging. My job-I was trying to figure out from the definitions and the words this morning. I'm probably a coach. I make good use of the student timetables, and I do give them a calendar with their assessments once a month, and you really have to stick to it. I guess I'm a mother first. I have three children. This is the way it has to go. When they complain, that's music to my ears! I make sure that they're interested in what they're doing, and I don't really take anything less than the best. Probably I get away with a lot more than some people would. But you also have to be a friend, and they have to know that you really are interested in them. Once you know that they know that you are interested, why, they listen. I'm all for teenagers. I don't think there's something to be feared. They're wonderful people to work with.

I have a question for Dr. Clark. You mentioned you have outreach programs for the community-from pre- $K$ to grade 16, which is college. Do you have programs for parents with children in the elementary school age? I have noticed a lot of girls are not interested in 
science. I've met many parents who have this attitude, "If we're not good in math or science, my children don't have to be good in math or science."

[Julia Clark answers] At the National Science Foundation we feel that, to get the young student into science, we do need to show the parents the importance of that child going into science. We did have a program two years ago just for parents, and we have terminated that program now, but we have had different programs that include parental components as part of their proposal. It is not an isolated program just for parents, but we do have programs, teacher-enhancement programs or students programs, where you can include parents as part of the initiative that you are planning to involve.

We've heard statistics that women and minorities are under-represented in science, technology, and math. But we've also learned that there are fewer men going into these careers. Do you have an opinion why that is? Both of you?

[Julia Clark answers] The data came out especially in engineering-as a matter of fact, even though the data I've presented is very low, women have made some really significant improvement over the last few years. So some-from the under-represented minority groups that are seriously lagging behind, but women, it is getting pretty steep. Some of the data I looked at shows that men are retiring, and we are not increasing the number of females in the sciences as quickly as we are losing males. But you are right; there are some data that show we have a great decrease in males. And if we do not hurry up and get a sufficient number of females and other under-represented minorities, such as African-Americans, Hispanics, and Native Americans, we are not going to be able to, do very well in science in the United States. That's why they put in the H1-B visas. We had to bring it far to takeover some of the positions because we have a shortage here.

[Jonetta Russell answers] I'm sorry I can't give you any more data on that. There are data to show that a significant number of males are declining to go into it. I don't really have much problem obtaining mentors, and I think one of the reasons is because I don't let them do the job by themselves. They don't have to take care of any of the discipline if the student isn't doing something; they just call me or email me. And I supervise the writing of the scientific paper. The students edit it, and with the cooperation between them and me the process is easier. When I worked at Gaithersburg I didn't have as much contact each month. Now that I'm constantly in contact with the mentors, I can be very helpful. I know most of them, and they know me, so that if there is a student who has a problem, I let him or her know about that problem, and-on our end of the scale, too.

I would just like to follow up. Do you have an opinion on why there are fewer students in general who are choosing the engineering sciences?

[Jonetta Russell answers] Well, I'm not the one to ask, because we're a math, science, and engineering program, and I have just as many girls as boys in both. I think it's because they haven't been encouraged. Nobody says, "You can do it! You can win! Don't give in!" I have said, what is your interest, and as long as you're interested I know a mentor who will be interested in you, and as long as you're willing to have a good work ethic, why, we're on the air! 
[Julia Clark answers] We have data to show we have a large number of students taking biology and chemistry, but not physics. And so a lack of not taking physics and other technical courses that would prepare one to be an engineer-it is very much a concern of ours. When we receive proposals, especially those designed to bring presence to engineering, they have a high probability of getting funded. We don't just fund because of the engineering, but we try to look at all areas, and look at things that we have not been funded very much, or look to see where there is a need. At the National Science Foundation we look at the number of proposals. I don't know how many of you write proposals-how many proposals from females, but we don't get very many. So we try to include those in the pool, and try to bring into balance the number of males and females on panels. We're looking not just in the programmatic area; we have done all kinds of things at the Foundation to try to assure the inclusion of women. But in terms of courses taken, it really starts at the middle and high schools, and physics is one of the main courses that is missing, especially among female students who don't go into engineering. In our foyer there is a poster about "FIST," Females In Science and Technology. Each fall we invite 7th graders to come for a Saturday session. I've sponsored the one that is on lasers for the last two years, and there's a lady who comes from the Army Research Lab and does a whole workshop on lasers. So we try as much as possible with those $7^{\text {th }}$ graders to interest them in math, science, and physics. Our students must go through calculus, and I think that physics needs a lot of calculus, and perhaps we haven't promoted the courses that are necessary for them to want to take physics.

My question is for both of you. I would like to ask what impact you think television plays on the role of what scientific field the children will go into, or if they will go into science. I know since this new program CSI has come out, about forensic science, I've heard a few children talk about forensic science. But I'm just curious as to what you think about television. Do children watch too much television, so they're distracted from science?

[Julia Clark answers] Well, we do have some programs that do turn students on in science. We have funded some of them from the National Science Foundation. And some of the things that go on the Discovery Channel and another one. I mentioned we don't do a good job of showing mentors. You see a lot of sports figures and a lot of movie stars, but we don't see very many persons in the media in terms of people who are into science. I don't think we're being turned off; I think we don't see enough. And young people don't have enough exposure to people who are in the field. That is one thing, I think, that would be helpful. Sometimes students don't see scientists and engineers, and the media, I feel, do not do a very good job at utilizing those individuals.

[Jonetta Russell answers] My students, I guess, would say they don't have time to watch television. We keep them too busy. But I agree with Dr. Clark. The content of science programs on television is not as great in comparison to the other programs they're watching, and it doesn't draw their attention. I get mortified when they say, "Gotta go home and watch 'As The World Turns." Oh, my goodness, how could you! I realize they need some relaxation, but I don't think my students, other than watching sports, do much television watching.

Dr. Clark, don't you think that the National Science Foundation should have something close to the concept of sports programs-for example, baseball players? They have camps, they have all kinds of stuff from when the children are very small. They groom them to be the best pitchers, the best catchers. And in music, we have the Julliard School and all the centers where we groom these people just for that profession. I know that the magnet 
school programs are perhaps one step toward this. But, for example, in the summertime I never see academies - or if they exist, they are extremely expensive. They are usually private-owned. Is there anything that the National Science Foundation has similar to "grow our own" from when they are very young?

[Julia Clark answers] Okay. If I understand you correctly- "Bill Nye, the Science Guy" is the one I couldn't think of earlier, the program that we fund. We do have student programs and summer programs for students where they have an opportunity to research in the laboratory under the guidance of a mentor, where they can go on field trips, where they can be exposed to the different persons who are in the field. These are the kinds of things that we are using to get students into science at an early age. And when we have the "bring your child to school day," we have programs and different kinds of initiatives and involvement where the students can be exposed to different areas and things in science. But programmatically we have a program for girls, and then we have a student program for middle school through high school, where the students can be involved. And we have programs for the summer and after school, in different fields of science, that we hope will motivate that consideration of science and math as a career. Now those programs we have are not just for students to take those programs and go into science. Instead we involve students who have never had a good and enriching experience in science, and this will help them to ask for themselves, is this something I really want to pursue? At least they can make intelligent choices about whether this is something they really want to do.

I'm not quite certain I got the question that you were asking me. As a science teacher and a member of NSTA [National Science Teachers Association], I know that their publication, Children in Science, is excellent. There are ideas in that little magazine any teacher can adapt. And The Science Scope is excellent. In fact, Science Scope has wonderful ideas that, even though they are aimed at the middle school level, why, high school students could enlarge upon them and do further inquiry. I have appreciated through the years their publications. I don't know if you have to join the union to get them-because the Association may say if you said something wrong, why, you need to have that million-dollar lawyer fee paid, and so forth. Perhaps we need to press a little more about science teachers receiving those publications, because they are excellent. And I know NSTA spends time putting them together. We don't have similar publications at NSF, but we do fund programs that support the writing of materials for them. 


\section{SUMMATION OF PANEL PRESENTATIONS AND GROUP RECOMMENDATIONS}

\section{Fran Nielsen, Ph.D. Deputy Chief, Computer Security Information Information Technology Laboratory, NIST}

I was given the assignment of wrapping up the First Women's Summit. There was confusion on my part about what my role was. I thought I was going to wrap up, meaning, remind us of what we heard through the whole Summit. But Connie Chang did such a great job this morning of telling us what we heard yesterday, I'm not going to do that, but since I spent all my time putting all the slides together I am going to go real fast through them. Then I'm going to put up the issues that you all told us about yesterday, and those that I heard during the other sessions. For some of the issues we have recommendations, and for some of them we need to come up with recommendations.

So what did we hear? What are our issues? And what are we going to do about them? Here are some of the folks we heard from over the last two days, quite a stellar list of presenters. Since I did do this presentation, maybe we can put it upon the diversity Web site and take a look at it. Whatever else it can be used for-target practice-whatever, is fine. Maybe I should just say one thing about each of the speakers.

Kathie Olsen. One of the things I thought was interesting that she said, the back of a man is very different from the front of a woman. Remember that! [Laughter]

Karen Brown. It's not a pretty picture at NIST. [Laughter]

Carol Handwerker. It feels like things are better. We're reaching critical mass.

Chinatsu Aone. It's a little different in the private sector. Publishing papers-here [at NIST], it's how many papers have you published when you go up in front of the level 5 review board to get promoted to level 5. They're looking at what you have done. And then she gave us a list of skills that are needed to be successful. And she also gave from her personal perspective what she thought were the hardest skills for us-or for her-to master. That connected with me, too.

June Ramos. We heard all about "hurry sickness," which most of us are suffering from. I thought some of the symptoms of stress, I had never heard before, cold hands and feet. I guess warm heart, [Laughter] and I had heard various variations about the rules, about thinking out of the box, but June was the first person that I heard say the rules are on the outside of the box, so how do you get at them? And I love the acronyms, especially BCP\&M, which I may use that one! And "nothing changes, if nothing changes." We need to remember that. "Who is in charge?" "Stop, Challenge, Choose." "Make better choices." "Get better results." "Just say no, appropriately." "Proactivity." "Know your personal priorities."

Connie Morella. An angel to NIST, and that is definitely true. I cannot quote the full quote, but do you remember her comment about the stoneworker who polishes marble? That's what we 
need to think about in our responsibilities as role models, not only here at work but in schools and in our community.

The Pat Heim Video. Excellent. I've already had a request from my organization, if we could show it at one of our brown bag lunches, and I recommend that to all of you. I think that is great. And the other thing I really liked, the second-best occupation according to children's books is being a witch! I thought that was cool. And the lessons of boys and girls. Oh, I like this line: "There never was a boss doll player." I thought that was cool. And "kill the black skirt." I was going to use that whenever I can use it. I just really like that. But the shopping story-okay.

Coaching. Now we're up to today. We heard this morning that coaching is really about self, a one-on-one kind of a thing, answering questions like, "Who am I?" "What do I want to do?" "What do I plan to get out of it?" Thinking about your core values. And another point that was made is that the coach is your "hired gun." He or she is going to help you do what you need to do to get ahead, whatever that means to you. For some people, it may mean getting into management; for other people, it may mean avoiding management. Maybe it's a career change. Whatever it may be. We also heard about "What is a good coaching relationship," and we've learned it is results-focused. There is good communication between the coach and the person being coached, and that the coach would really listen more than offer advice, and there is a recognition of a co-creativity that goes on between the coach and the person being coached.

SURF Program. We heard from David King about the SURF program, and it is an excellent program. "One person can make a difference." We heard that from SURF and we heard it from Mrs. Russell, that absolutely you can make a difference in someone's life. This is a personal aside: I think the SURF program is great, but I don't think we have an equal program for people who are already here. We need a scientific, structured or semi-structured approach to helping build employees who are already here who may either want to progress in their careers or change career paths. We have it for, I guess, secretarial, administrative, but we don't have it for scientific and technical, as far as I know.

Mentoring. That there are issues surrounding the opportunity-opportunities exist, but access doesn't always exist. We talked about "internalized doubt," and at lunch we had a little conversation about that. That is when we say inside ourselves, "Well, maybe I can't do it," and we don't have someone encouraging us to say, "Well, yes, you can do that. I have every confidence in you," Maybe it was your mother who told you that, but you need to hear it in other environments as well. Another aspect of mentoring is understanding the "power of politics," and what are the politics of the organization, and that mentoring is very critical at certain transition times. Upon graduation, or when changing jobs or changing groups, or when you're having a reorganization, there is a lot of turmoil and anxiety around big changes-or even small changes. But when there's a feeling that things aren't quite as settled, it is very critical to know where you're going and to have that sense of "connection" which is the other thing that mentoring provides. Good mentoring programs, we were told, have specific goals. They are a balance of structure and informality. They have a diversity of participants. That means you wouldn't necessarily have to be a female mentoring a female, or an older person mentoring a younger person. We have something to learn from the younger folks as well. There are a variety of activities you can undertake in a mentoring program, and there need to be measurements and evaluation of the program. That way there is continued improvement. 
Pipeline and Outreach. I didn't summarize what we heard from Mrs. Russell and Dr. Clark because we heard a lot about the pipeline and outreach and being active in those activities as well.

Yesterday, we had an activity to break into four groups and talk about what are the issues facing us at NIST, and this is a write-up of the issues that the groups came out with. Some of the groups had recommendations with their issues. Some of them didn't. These are also issues that I thought I heard. So you're welcome to say, we didn't hear that, Fran-where were you? And their recommendations may or may not match. This is my interpretation of your output yesterday at about, you know, 11:00 or 12:00 last night.

One of our issues then was, we need improved communications. I think that was one that was written up on the flip chart. There were two recommendations that I pulled out. It seems that everybody thought it's a good recommendation to watch the Pat Heim video, so we could see the differences in our communication, where we're coming from. Another recommendation was to develop and obtain tools that will help us dialogue better. Are there any other recommendations that come to mind, or shall I go through all the issues and then we can come back? Do that? Okay. I'm getting nods.

Anyway, this issue: juggling work and home. There was a suggestion from one of the groups that we should teach or offer some sort of time management kind of skills. And then there was the issue of making part-time workers feel more important and part of our organization. So I thought those recommendations addressed that pipeline issue, getting good folks in the system for future recruitment and retention.

The use of legislation funding to promote SET. This came from Connie Morella's presentation and also from the NASA example this morning, where they're using awards and incentives, you know, to the universities, and making a name, a branding, if you will, for NIST so people want to come and work at NIST. I thought that was really a good idea.

"Avoid being a victim." This was an issue. I thought the recommendations that might address this issue are that we would understand what our choices are and learn to say no appropriately and that would address our being victims. Also to take responsibility. We're the only ones in charge. And to get out of our comfort zone. Sometimes we do the BCP\&M-I think that is the right acronym. We whine about where we are but don't really try to move out of it, and this was going down the other street-I really like that analogy. So stop complaining and start doing something about it. That will also help.

The issue of career development and expansion. One recommendation was to create specific programs to support the current NIST staff who are seeking advanced degrees. Give them time off to do it, or compensation. This relates to my personal comment about the SURF programthat we do have a very strong mentoring program for SURF, but we don't necessarily have such a strong program for folks who are already here and want to move up or across or out or wherever. Another recommendation: expand the hiring criteria to other than Ph.D.'s. There is the sense that having a Ph.D. is the ultimate criteria for quality of NIST staff, and perhaps we could pursue that. Also, there was a suggestion that perhaps we need a career-counseling center. And as far as I know we don't have one. 
Professional development: P.D.P.-I think this means "professional development plan" or "personal development plan." Another term for it is "individual development plan." This is straight out of one of the groups. Give training to supervisors so they can see big picture of NIST; then your individual development plan isn't constricted, but there is an overall-maybe it goes beyond a one-year or two-year or short-term. Another recommendation that I think addresses the issue of professional development is that OU's should document their best practices for professional development. Things that worked well for them, that have grown people, and share that with all the other OU's. Another one: Provide more opportunities for details outside or in other parts of our agency. And that is a way to grow, to get a different perspective.

More on professional development. Enhance the NIST programming efforts through development of an employee database, matching skills and willingness to work in other OU's. Maybe if you're not aware that there are assignments, you are not aware that people are willing to make a move. Another recommendation: Explore the use of coaches at NIST. I heard that during our discussion this morning.

More on professional development. Use a structured mentoring program and make sure the women are part of that program. Suggestion that we serve on professional boards as a way to grow professionally. Share our success stories and advertise role models. If you know someone who has made it big at NIST or seems happy at NIST, find out about that person, go and talk to that person, or share that story.

The issue with pay and rank discrepancies. Specify what NIST goals are to create equity and accountability. Make women and minority data available to the managers and require they review it. Make the ranking information available. Make the requirements or guidelines for promotion available. What does it take to get promoted? Create specific step-by-step guidelines and mentoring for promotions.

Now, here are ideas that came out of the breakout groups. Give the points of contact if you want to discuss your concern about pay and rank discrepancies. Develop individual performance plans that include the tasks for promotion and a commitment from the management. Now, this came out from a breakout group, and I'm assuming it means that in the individual development plan, you would have something that says, "Here's the criteria for this person being promoted." And the manager agrees, "Yes, that's the criteria that I had in mind for you being promoted."

Here's an issue with no recommendation. How do we get more men involved and committed to our issues? Another couple of issues without recommendations: It seems that employees either stay here forever or they leave early, but whatever the case, the culture never changes, the situation never changes. These are from breakout groups-they are not Fran's ideas! Okay. An issue that says we need some sort of socialization skills. How do play nicer together, I think, is what this one means. This is probably the one about communication, just in a different wrapping. Another issue given was that we have difficulty accomplishing meaningful work when we have so many demands on our time with stuff that seems not as important, but we really have to do it. So how do we prioritize? There is an issue about leadership and management skillsthis particular group believes that they're not prized as a key to advancing. Instead they feel that at NIST what is important is your scientific skills. 
Another issue: The NIST culture is conflict-adverse, both for men and for women. We don't seem to want to address conflict kinds of situations. It's better to ignore the problem, and maybe it will go away. Another issue: There doesn't appear to be a chain of command for decisionmaking across NIST. This leads back to Bettie White's comment this morning, that one of the things that had worked so well at NASA was enlightened management-or enlightenedenvisioned administrators at NASA. That's what it was, visionary-I knew if I talked long enough I would figure it out. Visionary administrators at NASA have been the catalysts for changes there. Some of us do not feel that we have seen that here at NIST yet.

This was the end of the recommendations. So what are we going to do about them? We've had the first Women's Summit. Now what are we going to do?

[Connie Chung] I mentioned this morning about the MIT-study on inequities ${ }^{25}$ there. They had some recommendations for how you could replicate some of what they have done. One recommendation was to set up committees to monitor progress. First of all, identify the inequities, then try to solve those problems, and then monitor progress. Maybe we need to think about that, and try to propose some kind of equity action committee or something of that kind, where we have people who participated in the Summit and men and women alike who might be interested in doing that. They would be different from those on the Diversity Advisory Board, but there would be a standing kind of committee that would include folks who are interested and maybe have pull, some muscle and some influence with top managers.

[Joan Hash] What are we going to do? Here is what I think. One suggestion here-I'm speaking from my many years of Government service-is that the first thing I think would happen at NIST is that NIST across the board, every person at NIST, would understand that we are all one family, one team. I don't know that we're there yet, and that what is in the interest of subsets of that team, or in the entire interest of NIST, and so the culture needs to be grown. I don't think, from what I've heard to date, that that is a short-term thing, because I really think, unless it becomes ingrained in the culture, top-down interest, I'm not saying it's not there. I'm just saying it works best that way, because the message is taken forward from the top, driven down. Everybody buys in. And let's be clear. I've been in other Government agencies, trying to get buy-in, and 100 percent of the people never buy-in. There are certain personal biases that people bring to places, and it is very hard to overcome those. But I think there needs to be a professional focus from the work perspective, in terms of how we treat each other. And we really don't need to focus on your personal belief but we need to focus on what is in the best interest of NIST.

How we would be expected to behave as managers? What messages should we be leading with our employees and what do we need to lead with as management people? And I think in that regard-you know, it may sound crazy, but you really do lead by example. So we could set up action committees, but unless there is a real belief that we should "walk the walk" and "talk the talk," I believe that might look like a lot of activity, but I don't believe it could be sustained without true buy-in. And that buy-in must really show itself to the workforce at large. Otherwise, I really think you're just kidding yourselves.

\footnotetext{
${ }^{25}$ Women in Academia; copy available in NIST Diversity Program office; or can be found on MIT's Web site. Keyword: Dr. Nancy Hopkins.
} 
[Fran Nielsen] One thing about the "Summit," I mean, our picking this venue or this word, I'm not sure if Sol ${ }^{26}$ had this in mind, but you know you're sort of going to the mountain to get the message and then you go down the mountain and you spread the word. Okay? I think you hit it right on, that one of the things that we can do to change and make things better right away. is to be ambassadors for this message. So I really like your point.

[Carol Handwerker] I agree with what Joan said. One of the things that I think has helped us in our particular division is that we have been focusing on communication and on getting real tools, you know, not just having a feel-good person come in and give a set of presentations, and say, communicate better. We were given some tools by Julie White, who was recommended by Human Resources. And she was wonderful. We've really been able to communicate better with a whole host of things. So I think that is the way we need to go. How many times have you heard a manager say to someone, "Oh, you have done a real good job." and then turn around and say, "Yeah, but, you know, she's part-time," or something like that? People need to be able to bring all of these things out in the open. You know, if they had these hidden prejudices or whatever, they need to be brough out there. The second thing that we need to do is to not take the data that we saw yesterday at face value. That's why I didn't talk about it as much in my presentation, because I know that, for example, all the part-time employees were in those data, so if they're working only 80 percent of the time, if you re-normalize their salaries to 100 percent, it changes somewhat. So I think we really need to look at those. We need to look at the post-doc data. So there are some things that we can do to make sure that we really have the picture-the real, honest-to goodness picture of what our organization is. I think we're going to have to really dig deep to make sure that we don't come up with the wrong answer. I mean, that's what we're known for, right? To get the right answer.

[Fran Nielsen] Boulder? Have you any comments? Suggestions, recommendations, issues we haven't covered? Okay. Yes. What are the tools of communication? Carol is going to answer that.

[Carol Handwerker] This is based on the training that I received. Some of it was the same as what Pat Heim talked about yesterday, you know, just making sure that you are talking about the same topic. The other thing is to be able to say to someone, "I believe we have a problem." Let's examine what the real issues are. And let's just not go straight to the solution. Let's examine what the issues are, because unless we expand out to figure out what the issues are, we aren't going to be able to solve the real problem. So it's really going through this in a methodical way and saying, "All right, I'm not satisfied with my job, I'm feeling some malaise. I feel that I want to go out and get a Ph.D. Will you help me figure out what I need to do to get a Ph.D.?" You know, just so it is really having those tools to discuss things. So then you don't get distracted by sort of side issues. You can keep focused on what the real objects are. Then you can really move forward.

[Boulder comment] This made me remember the Pat Heim video. However, I'm right with you, Carol, but I don't know if the gentlemen in the audience are there. They might be feeling like they may have to go out and kill the black skirt. And I've had training from Julie White before, and she's excellent, but she speaks to me as another woman. And I don't know what our experiences were with her-speaking with men. I haven't spoken to Julie White, but I was going

\footnotetext{
${ }^{26}$ Sol del Ande Eaton, Diversity Program Manager and Women's Summit Organizer.
} 
to follow up on the tools and I will say just in basic management courses, part of the tools of the communication are the basics: How to ask the question. How to listen so you can get the feedback that you need and really hear the person, to her point. Are we really hearing people? So there are tools and they are pretty basic. But have you engaged in communication? Have you leamed the way to ask the open-ended question so you are not just getting "yes" or "no"- do you let people flow; are you are listening? Even a class here at NIST would give you some of the basics. But practicing those basics could be difficult based on your personality. I certainly had to take more training in listening in my early days. But my point is, these are some basic things, but what it means is that you are finding a way-maybe it's the tools of effective communication. You're trying to find a way to solicit effectively the feedback that you really need-to hear what people are saying. And of course, a whole lot of people don't do that very well, including myself. So I think it is a basic kind of thing, but, it's the kind of communication where it's not all about you, but it's really about, how do I get the feedback from the other person that I need? And there are techniques which many management courses teach, as to how that should and could be done. Thank you.

[Fran Nielsen] There's also an effective communication class in the leadership development series that NIST gives, and that is open to everyone. You don't have to be a manager to take that. There's an old saying or an adage, you know, there is a reason why God gave us two ears and one mouth. So that's probably another good communication goal to think of. Were there more comments from Boulder?

[Boulder Comment] Carol? I just wanted to make one comment about your saying, Well, you don't know how well he or she speaks to men. First of all, Pat Heim-right. Yesterday, I was sitting with guys in the back and they were rolling with laughter the same way we were.

[Fran Nielsen] Oh, my goodness, that's-so they got it. They got it, and also in the training course of Julie White's. It's not called "Effective Communication," it's actually called "Coaching." And I have one example, and that was that I have a ZP-5, you know, national award winner, who really resisted coming to the class, and he stayed after the second day-it was a twoday course, and he stayed after the second day to get some more helpful information. Great!

So there are people out here, I think, who can communicate to all of us. To follow up, so was Julie's class on communication or how to be a coach. It was on coaching with a subtext of communication. Okay. And we did it as an organization. So it wasn't just me getting trained, it was my-the whole division got trained at the same time. So we could practice those things, because there is nothing worse than having one person trained and then going back and it isright--the same old stuff. Excellent point. And that, I believe, is what they were trying to do with the effective communication class in the leadership development series-to have all the managers take the same communication course, so that they could communicate in the same style with each other. So having your whole unit take that is a great idea. I think we should try to emulate that. I don't know that we can. But, yes, that way you are talking the same language and very cool. Okay. Thank you. [Applause] 


\section{WR⿴囗十时 UP}

What did we hear?

What are the issues?

What will we do?

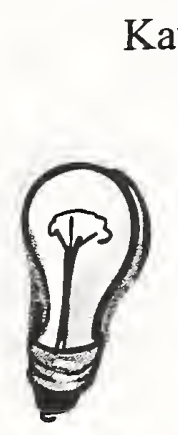

Kathie Olsen

- From scarcity to visibility

- The back of a man is very different from the front of a woman

- "What we are to be we are now becoming."

- Female scientists are immortal

\section{What did we hear?}

- Arden Bement

- Pat Battle

- Kathie Olsen

- Tim Wright

- Karen Brown

- David King

- Carol Handwerker

- Darlene Floyd

- Chinatsu Aone

- Bettie White

- June Ramos

- Julia Clark

- Connie Morella

- Jonetta Russell

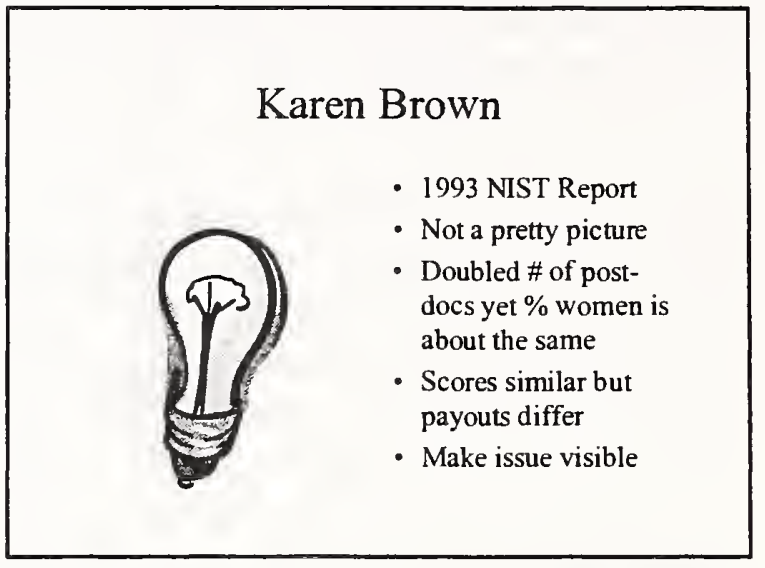

\section{Carol Handwerker}

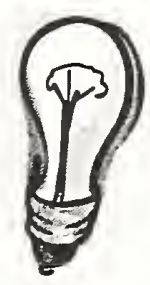

- Key improvement is AWS

- Feels like things are better

- Issues of part-time, marital status, family give less than $100 \%$ interpreted as lack of seriousness

\section{Carol Handwerker}

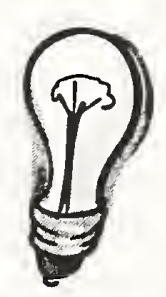

- Need enlightened management - ask to get back on the fast track

- We're reaching critical mass:

- $16 \%$ and holding

- $25 \%$ should result in culture change 

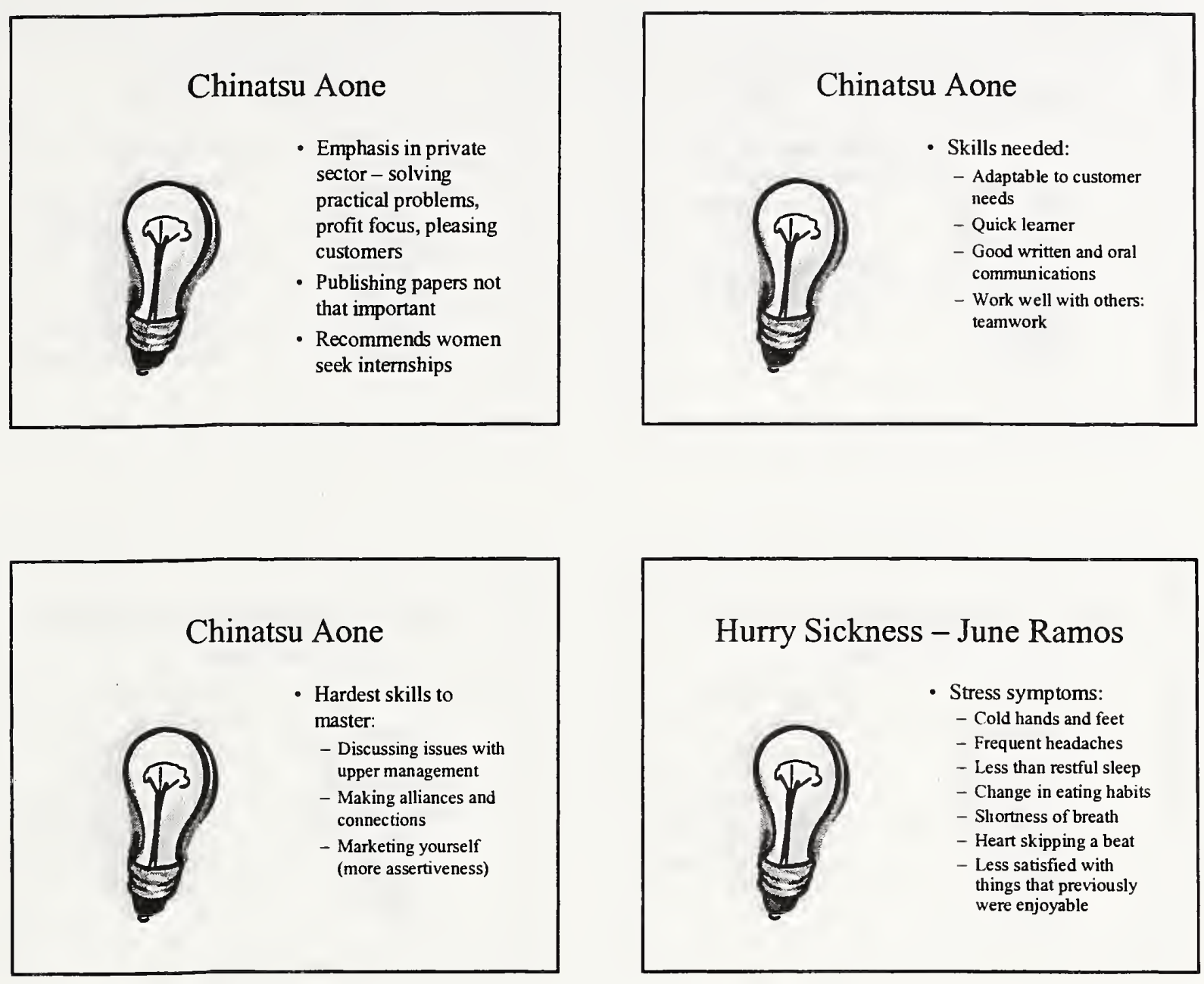

\section{Hurry Sickness - June Ramos}

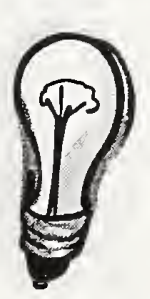

- Rules for thinking out of the box are written on the outside of the box

- Empowerment with a leash

- BCP\&M, CLM, HIPOs, LOPOS

- Nothing changes if nothing changes

\section{Hurry Sickness - June Ramos}

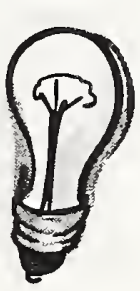

- ASK: Who is in charge of my life?

- Walk down another street

- Stop, challenge, choose

- Make better choices to get better results 

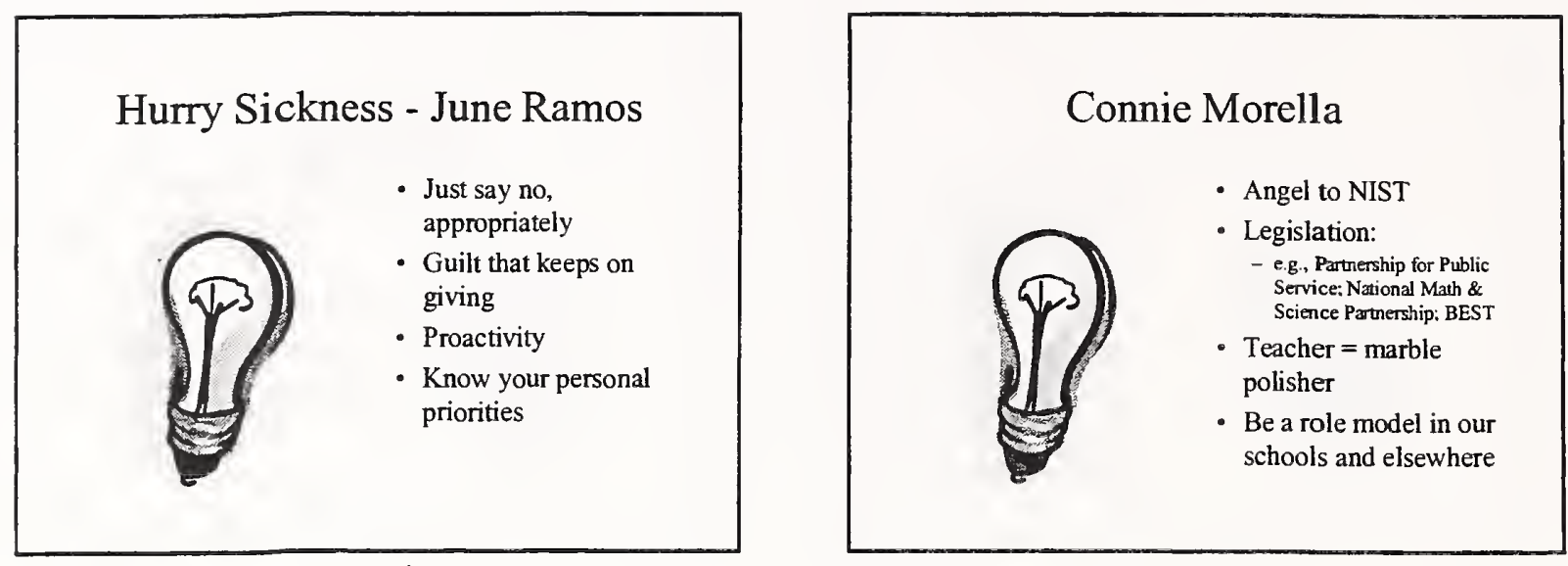

\section{Video: "Power Dead-Even Rule" Pat Heim}

Lesson of children's
books
- Men lead, women
follow
$-2^{\text {nd cbest" occupation }}$
for a woman is a witch,
followed by dancer,
musician, singer, queen
$-1^{\text {st is housewife }}$

\section{Video: Power Dead-Even Rule} Pat Heim

- Different rules invisible rules

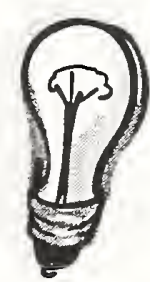

- Never was a boss dollplayer

- Kill the black skirt

- Chopsticks versus silverware

- Talk it over - give an answer

\section{Video: Power Dead-Even Rule} Pat Heim

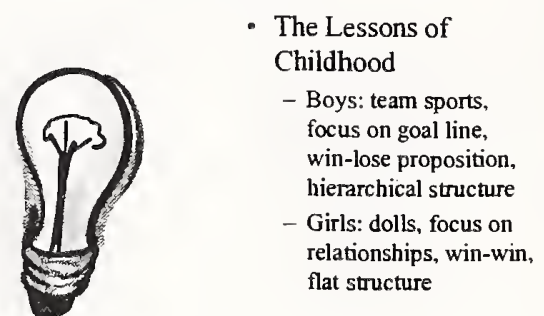

\section{COACHING}

- Coaching is about self:

- Who am I?

- What do I want?

- How do I plan to get it?

- Your core

- Coach is a "hired gun" - part of your support system 

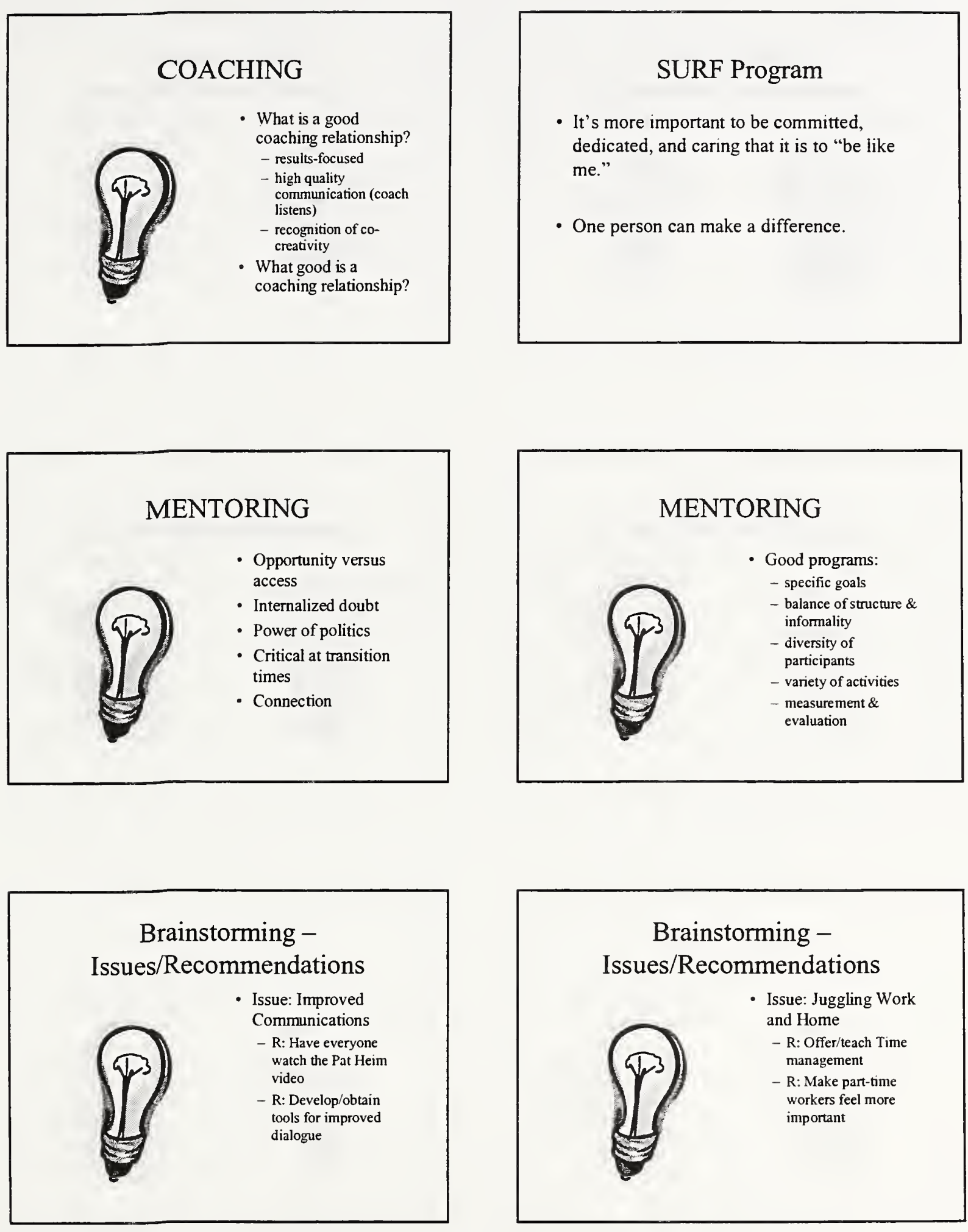

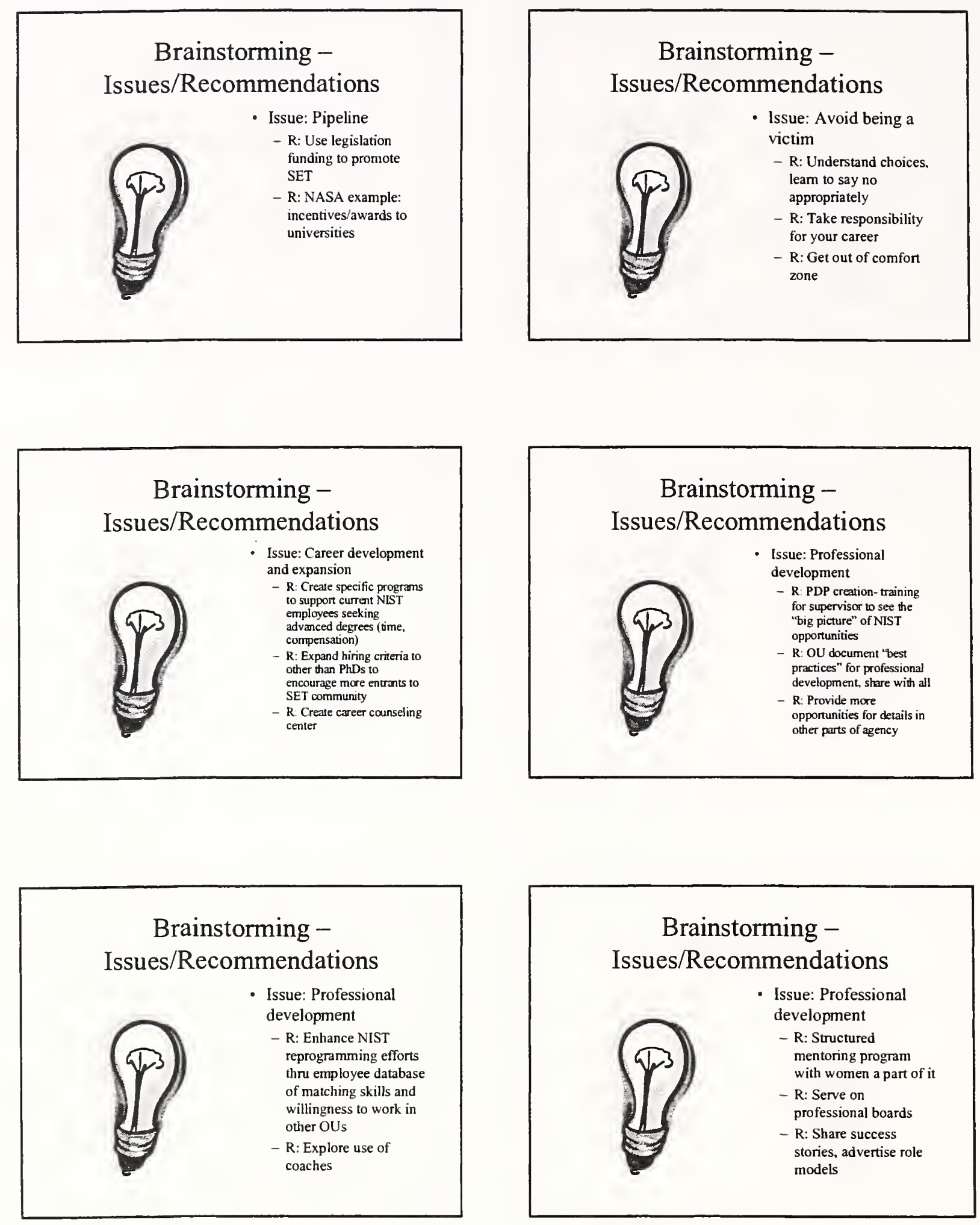

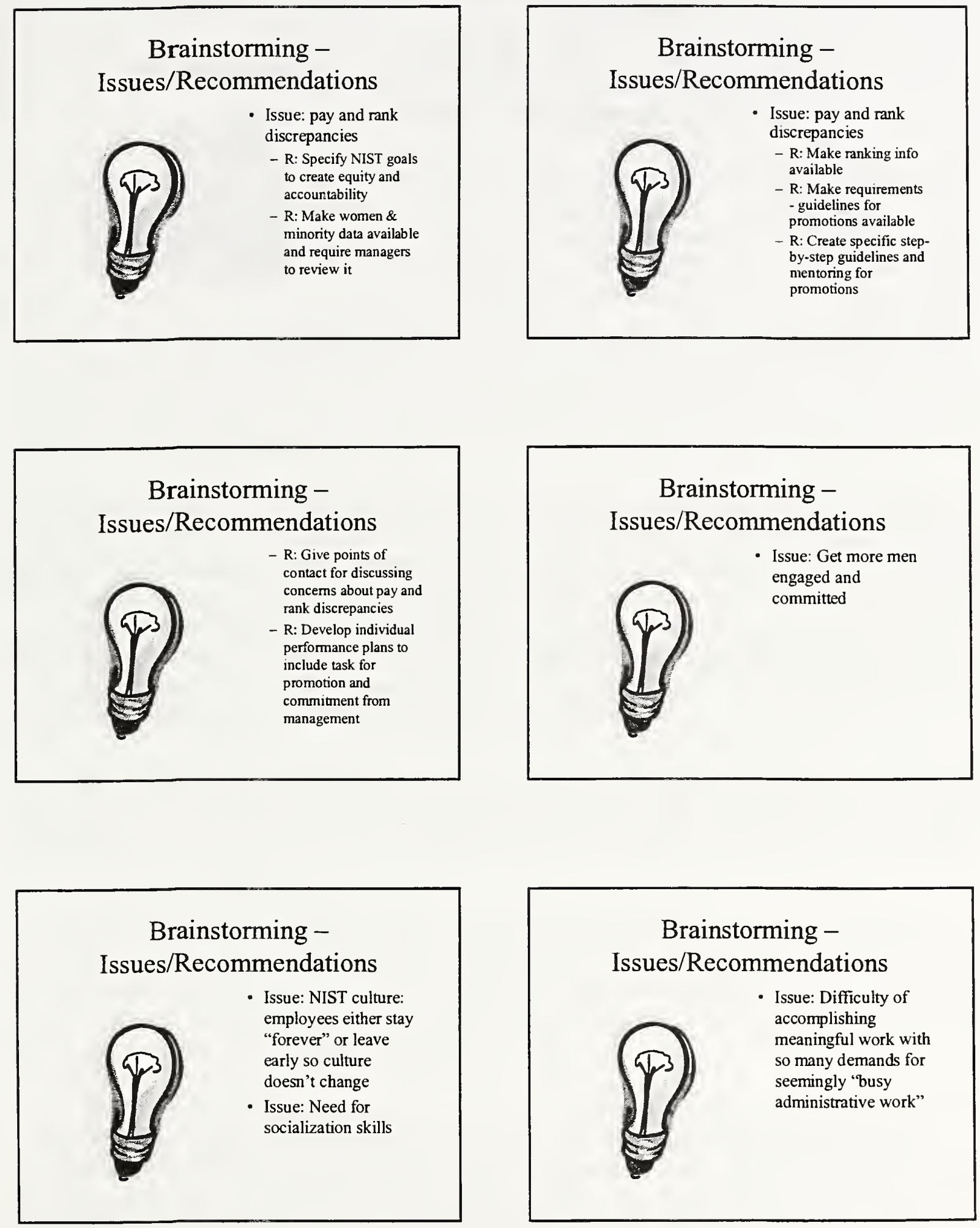


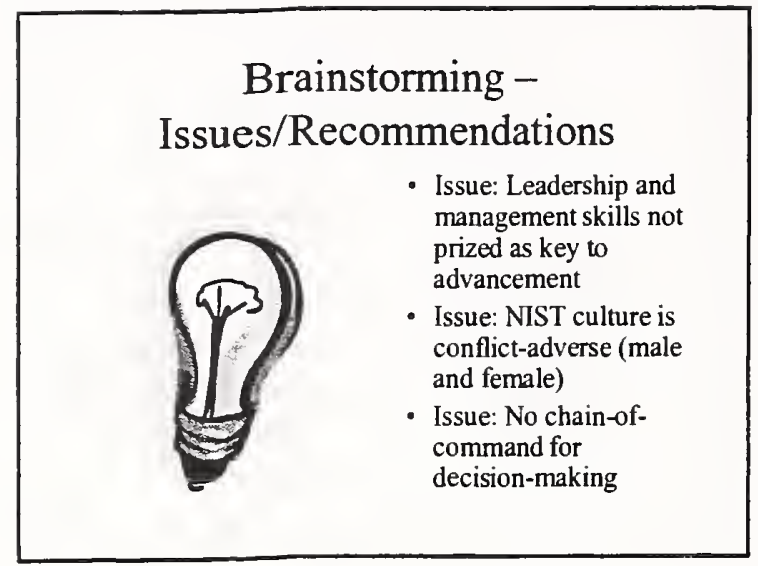

What will we do?

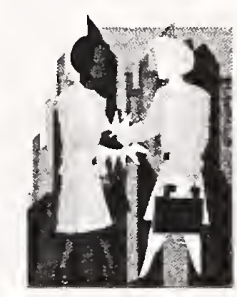




\title{
PRESENTATION AND INTRODUCTION OF DR. KATHARINE B. GEBBIE
}

\author{
Radhika Char \\ Graduating Senior, Montgomery-Blair High School \\ Montgomery County Public Schools, Maryland
}

Thank you for inviting me to speak today. As a female student who worked at NIST over the summer and during the school year, I would like to share a few of my views about the interactions between research agencies such as NIST and educational societies at other schools. First of all, I feel that research should be an integral part of every student's education. I learned more working at NIST than I did in school, practically, because you get to learn so much about one topic, and you're working with it every single day. Over the summer, we would work every single day with the same topic, and we would be experimenting and learning new things, and because of the dedication that my mentor showed to me and the dedication that I put in, I learned so much. And I would never want to give up that experience. Research allows us to develop our experimentation skills, while also allowing us to figure out what we're interested in.

Through this project, I decided that I wanted to continue in chemistry and become a chemical engineer. I worked with Dr. Pedatsur Neta in the Physical and Chemistry Properties Division, and he put in a lot of dedication and help to make this project a success, and also interested me while teaching me. But I wouldn't have come to NIST to work had I not been surrounded by many females-scientists, engineers, mathematicians-throughout my school career. One of my teachers, Mrs. Russell, spoke before. She was my research teacher, and she also helped us write our resumes and figure out what we wanted to do. But she also gave us encouragement and wanted us to continue and go for what we were interested in.

I was also inspired by my other science teachers, many of them who are females, and all of them showed how women can stand on their own in this previously male-dominated field. And all of them helped me and supported me throughout this, and with their encouragement I was able to work here.

A problem that I feel is coming these days is that many students are intimidated by research agencies such as NIST. They feel that only big people or important people can work there, and that they cannot stand up in that field. But many of these students also have interesting views and ideas for science fair projects or ideas that they can't actually implement because they don't have the proper guidance or the support to pursue their ideas.

I have seen many science fair projects, and some of them are outstanding. But the students often are not satisfied with their own projects, because they couldn't fully pursue their research challenges. For that reason perhaps NIST could start a program where, over the summer, students can apply with their science fair ideas or projects that they have been interested in, but don't have the equipment or the support to follow up. The people at NIST could pick the unique or most original ideas and perhaps work with these students. Students working with scientists can learn so much and acquire new knowledge they couldn't have acquired previously without the proper 
guidance. That is just one of the ideas I have to increase interactions between students and scientists.

Another idea is for female scientists to go to high schools and show the female students how interesting science is and how females can succeed in this field. One of the presentations I viewed at NIST last year was by the head of the Polymers Division [Eric Amis]. He showed us how materials could be fun. He gave us a creative outlook. He showed us how to freeze a material or burn it, but he also taught us while he was showing us these innovative ideas. That's one of the many presentations that could be given to increase student interest by students, because these presentations show that research is not just boring, sitting in a laboratory, it's also learning fun things and discovering the unknown. And if we combine all those ideas, more students will be interested in doing research, and they'll continue in the future to pursue science, engineering, and technological subjects.

Now I would like to introduce Dr. Katharine B. Gebbie, director of the Physics Laboratory of the National Institute of Standards and Technology. Dr. Gebbie graduated from Bryn Mawr College with a B.A. degree in physics and subsequently earned a B.S. degree in astronomy and a Ph.D. in physics from University College of London. She joined NIST in 1968 as a physicist in the Quantum Physics Division of JILA, a cooperative enterprise between NIST and the University of Colorado in Boulder, CO.

Before being appointed Director of the newly formed Physics Laboratory in 1991, she served as the chief of the Quantum Physics Division and as acting director of the Center for Atomic, Molecular, and Optical Physics. Dr. Gebbie is a fellow of the American Physical Society, a fellow of JLA., and a member of several professional societies including Sigma Chi and the American Women in Science.

She has received several awards including the Department of Commerce Gold Medal, the Women in Science Engineering Lifetime Achievement Award, and the Washington Academy of Sciences Award for Outstanding Contributions in the physical sciences. The Division of Atomic, Molecular, and Optical Physics of the American Physical Society recently recognized her for her leadership role in fostering excellence in A.M.O. science. Now please welcome Dr. Gebbie. [Applause] 


\section{CLOSING REMARKS}

\section{Katherine B. Gebbie, Ph.D. Director, Physics Laboratory, NIST}

Thank you very much. I've enjoyed hearing all the parts of the meeting I was able to attend, particularly the excellent summary and your recommendations. As a laboratory director in charge of strategic focus areas, I hope I may have a copy of these, and I can assure you we will take them seriously. I think they are excellent suggestions. That doesn't mean you don't need to continue pushing them and formulating them, but I think we've made a great start, and now we need to continue.

As Sol del Ande Eaton mentioned, I have just returned from a meeting of women physicists in Paris. This was sponsored by the Working Group on Women in Physics at the International Union of Pure and Applied Physics, IUPAP. More than 300 women from 65 different countries gathered together in Paris to try and understand the severe under-representation of women in physics and to develop strategies to increase the population. It was a rare privilege to be there. Teams of two or more women from Zimbabwe, Uganda, Ghana, Botswana, Malaysia, India, Pakistan, Latvia, Albania, and many other countries met there and bonded instantly. The commonality that these women had simply by being women in physics overshadowed any differences that might have been among them. I have never been to such a meeting in my whole career.

Many of the issues that arose at this meeting were universal. Many were exactly the same issues that have arisen today that I heard summarized: the need, for example, for more data. We need data for two reasons. First, because, as Karen Brown showed in her talk and as Nancy Hopkins has demonstrated very well at MIT, we need the data to define the problem and to convince others that there is a problem. No one person on her own can determine a trend. It takes a lot of people and a lot of data. And second, we need the data to use as a benchmark so we can show after a number of years the effect of our efforts and give some measure, we hope, of an improvement of the situation.

Another recommendation that came up was for an increase in networking. Networking, networking, networking among women! You are not alone. We need more electronic bulletin boards. We need more Web sites. In this country, we're fairly good at physics. We do have a women's network and monitored bulletin board where women can exchange their experiences. They can learn about how other people have solved problems. They can exchange information on textbooks, on funding opportunities, and on the availability of equipment. This is something that each country needs for itself. But we also need it, internationally.

Another issue that I think also came up here and came up in many, many of our discussion groups was the need for transparency in criteria and processes used for recruitment, for promotion, for rewards and evaluation. I think this is something that NIST needs to improve on very much; and we will be looking into it.

Then another issue that came up, and I don't know if it's been addressed explicitly here or not, is the need for more flexible career models. The classic model of a scientific career, like most 
models of high achievement, is that of the male scientist who has very few family responsibilities. You young people don't fit this at all, and hardly any women fit this model. I feel strongly that we need to develop a more flexible model that allows ebb and flow of careers, so that people may devote different amounts of time to family, career, and community at different stages in their lives. This will take a lot of formulation. I hope we will have the help of all of you to do this.

These are not just some of the issues that came up. There were many discussion groups on balancing career and family, on getting more women into the pipeline, on what we can learn from international differences and how we get women into positions of leadership in the community. In many countries there are many more young women in physics than there are in this countymuch higher percentages. But almost inevitably, in every country the numbers fall off as you get higher up in the power system.

So who cares? Why do we care if there are women in science? Men have done a pretty good job of it for many quite a few thousand years. I heard one former director of NIST give what is perhaps a fairly standard argument, and that is, "The point where males decide to go off to more exciting careers, we will need the women to come and backfill for them." That is not an argument I buy at all!

I think there are at least three very good reasons why we should care, and one is simply for the health of the field. If the profession is going to serve its goal of advancing and disseminating science, we must be able to draw on the pool of the best and the brightest, the broadest spectrum of talent from all segments of society. Second is the argument, "why should men have all the fun?" This is an equity argument. Scientists get paid for doing what they most enjoy in life. Women have the need and the talent to compete for these same privileges, and they should be allowed to do so. Third, I think it's vital for the field of science but also for democracy--that we make it our goad to achieve a scientifically literate population, a population that understands and values the contributions that science can make to the quality of life. Women are half that population, and only when women see themselves, see other women, even those who are not scientists see other women as scientific researchers, as leaders, teachers, managers, and policymakers, will that half of the population see themselves as full participants in a technological society.

So I'll talk a little about the issues that all women have in common. And that of course varies enormously from county to country. We had many instances of this in Paris.

The head of the French team, Clodine Herman, was talking about a report on women in science in Europe. She made the statement which many of you may have heard before: that one of the most important steps for a woman in her scientific career, is choosing the right husband, whereupon a Pakistani woman raises her hand and said, "But excuse me, we don't choose our husbands. Our parents choose our husbands, and furthermore it makes it very difficult for our parents if we have higher degrees, because none of the men want to have a wife who is more qualified than he is." That's one problem.

In Egypt, it's necessary to advance in your scientific career if you have studied or participated in research abroad. But women can't go abroad before they're married, because their families won't let them. And they can't go abroad after they're married because their husbands won't let them. 
The situation is just the opposite in Sweden: You can talk with women who have been abroad, who have worked and studied in the United States. When they go back home, they're simply non-people-they have no benefits. They may technically have a job, but they have no way of progressing. They simply don't exist because they've been out of the Swedish system for that long.

And in Finland? I talked with a woman whom I had met the night before on the International Committee for Weights and Measures. She explained to me that she had never felt any discrimination whatever. It was only when she was planning for this conference that she realized that perhaps it was because there were no women physicists in Finland, which is another reason.

There were various problems of language, naturally. The language of the conference was English, but language as you point out in your recommendations about communications is very important. A German woman got up to report on her discussion about balancing family and career, the same issue that came up, one of the major issues for young women. One of her guideposts was be prepared to remain single. We this didn't exactly seemed to address the problem, and it turned out that what we think she really meant was you must be prepared to be the only women in your program or your community. Alternately, she may have meant that you must live away from your husband. Be prepared to do that for some time. I think that she did not actually mean that you should be combining a family with career without being married, but that came up.

There are other very blatant issues in other countries. There's one in which you're damned if you do, and damned if you don't sleep with your supervisor. If you don't, he doesn't give you good grades. If you do, everybody says it's only because you've slept with him and these come out, too. And they should come out. They could be very important.

I made my own terrible faux pas. I had one on my viewgraphs for the three people leading my discussion groups, a quote which I thought rather fine from former U.S. Secretary of State Madeline Albright. She had said, "Women will only be able to contribute fully when they have opportunity, equality, and power." Well, bad news. Apparently, power in many countries, is a really bad connotation. I didn't have this sensitivity then, but I understand that if power has been misused it is not a desirable attribute. To compound matters, it was a quote from a former U.S. Secretary of State. And it got worse. I went on, talking about women empowering themselves. That was just as bad. So some people didn't take it very well. Most everybody was in good spirits and didn't seem to mind; only a few very strong words were said. And there were some kind words.

So how does the United States compare with some of these countries? On the whole, and you may not believe this, in many aspects, we are very well off. I believe you had a talk this afternoon, which unfortunately I missed, about the Civil Rights Act of 1964 and Title VII. This certainly gives us recourse. I know they've certainly been used successfully in many cases, and at least it provides us some legal backing.

There is one issue where I think we are behind all other other 65 countries, including Zimbabwe, at this meeting, and it is in maternity leave. It's the fact that Government employees in the United States do not have maternity leave. I know, we get around it in lots of ways. We use sick leave. We use annual leave. It is the nature of young women, who are starting out in their careers and 
have not yet accumulated a lot of sick leave, to be having babies. We are allowed to save up leave in advance, but only to the extent of one year, which amounts to 13 days of leave, and that's not enough.

Most countries have some specified amount of paid maternity leave. I think this is something that we must be working on in this country, very strongly.

We heard a lot about all of you who contributed so much to making this conference run smoothly. I would just like you for a moment to think what it might be like to organize a conference in another country, where you don't have a local organizing committee, you don't speak the language very well, you have a new currency that even the people in that country aren't very used to, and the six larger boxes you sent over of with all the registration material are refused by UNESCO and sent back to Customs, so you have 300 people to register without any information or a list.

This conference was held in Paris, off the southeast corner of the École Militaire, at least part of it. There is another building, too. There was no floor plan for either building, and when I wanted hold my three discussion groups in the other building, I was told, "Ah, yes, it is just a couple of blocks away." So not only did I have to find it, but I had to find a way for about 90 other people to be able to find it as well.

To make matters more difficult, there was another very large conference on women in science put on by the Aurielle Cosmetic Company. It had another different flavor from the one for women in physics. But it was sufficiently confusing that the president of IUPAP [International Union of Pure and Applied Physics] and a Nobel Prize winner took more than an hour to figure out that he was in the wrong place.

It went on. Even the Seine, the river that flows through Paris, didn't cooperate. We were to have our banquet on a boat trip. But because of all the rain, the Seine was too high and we couldn't get underneath the bridges, so we went down river rather than up river which was vaguely less entertaining. But by the time we had gone through the first of our three wines, nobody noticed, probably, the direction we were going, anyway. And that was great fun.

Add to this fact that French keyboards are not completely different, but they just have old numbers, and the punctuation and a few of the letters are changed around. That made it difficult when we were trying to make our signs and other things like that.

There's one thing that was, perhaps, really an advantage in France. The men in France have absolutely no hang-ups about women using the male lavatories. And when you have two huge conferences of women going on at one time, that can be very important.

I just want to close by quoting something that was said by one of my Iranian discussion leaders. She was very charming, a very enterprising woman. She said, "In Iran, we have an expression: We say we must move wisely, smoothly, and effectively like a swimming duck." I think that is the way we must move to try to change the things at NIST as well.

Thank you. [Applause] 


\title{
CLOSING PRESENTATION \& ACKNOWLEDGEMENTS
}

\author{
Sol del Ande Eaton \\ Diversity Program Manager, NIST
}

Well, folks, we have come to the end of the two days. As I told you, this was a vision that I had when I first arrived at NIST and I started talking to women, and people came to talk to me about the things they would like to see at NIST, and I keep going with this idea of how can I do something where we can really get together in a room and talk about these things?

I want to thank all of you for being here, for sticking with us until the end. I want to thank especially the Planning Committee. Would you all please get up? Some of the members are here. Yea! [Applause]

We owe a special thanks to our NIST director, Dr. Bement, for his support of this conference. And thanks also to Dr. Karen Brown for her opening remarks and for her valuable presentation.

A special thanks to Boulder folks. Hey, you people, you really came through! You supported us! Thank you so much! Thank you, Dean ${ }^{27}$, sorry you couldn't be here, but you are with us in spirit, I know. Thank you! And if you have any suggestions or anything, make sure you get back to us. We're going to put all these documents together. I want to thank a special person that put so much time into these and put not only the time, but what it takes to make something a success. She put her heart, her soul into this thing by working an extraordinary number of hours, and even though sometimes we didn't see things the same way, because I'm in a NIST culture and she comes from another culture, believe me, this woman really, really did a terrific job for a very little amount of money. I want to recognize Patricia Fenn. Thank you, Pat! [Applause] [Inaudible ... Laughter] I told you sometimes we don't agree.

Another person I want to thank is Tim Kring, a member of my staff. Tim is in the back. That's the person you talked to on the phone. He's the one who gets all the things going and makes sure that we deliver. Tim, thank you. [Applause]

June Ramos, our contractor. You were terrific, as usual, and I know that your company did a special favor for us, for charging very little for your excellent services. But you wanted to help us, and we thank you. [Applause]

Jonetta Russell, thank you so much. You just don't know how grateful we are that you shared all these good things with us, your materials and everything. Your dedication is just-what can I say-very inspiring. And you had a student here from way back who came to recognize you, and we didn't even know what she was going to do, so that was a very beautiful surprise. Thank you! [Applause]

Naomi Churchill Earp is the chairperson of the Diversity Advisory Board, and she really helped us with a whole lot of ideas and efforts. I'm sorry that she is not here, but her vice chair is here.

${ }^{27}$ Dean W. Claus, coordinator for diversity/mentoring, NIST-Boulder Lab. 
She came all the way from Boulder: Jennifer Scott. Jennifer, thank you, and thanks to your staff. [Applause]

Now when we came up with this program the idea was-and we wrestled with this thing-what I wanted to give you was the national perspective on where this thing is, related to science, engineering, and technology. Then we wanted to give you a snapshot of NIST, and Karen Brown and Carol Handwerker did a beautiful job at that. And then we wanted to bring you the things that you have been asking me about: What is coaching and why can't we have a formal mentoring program for scientists? We have a very successful mentoring program for support staff that is going very well, and Darlene Floyd, the person that you heard today, is the one who helps me with our program.

Well, we also wanted to see students, the pipeline, what can we do to really improve this thing? This was really planned for you to bring your ideas, to think about the whole thing, and then concentrate on the areas that are important to you. In one of the organizations where I worked before, the women were also looking for ways to get together and communicate, so I invited WIS--Women In Science-to form a chapter in that organization. That helped the women quite a bit in the sense that they work in communication skills. For example, if somebody had to do a presentation, the woman will come and do her presentation in front of her peers, and then they critique and help the person. Then they started inviting their own people to present their own papers, which was very beneficial especially to the post-docs and the younger folks that we have coming into the workforce. WIS today is very big, and that is excellent. That's one thing that we can look into it to see if maybe you would like to have that. We have a lot of tremendous coaches and excellent women scientists in here who can help us.

Katherine Gebbie. Dr. Gebbie has helped us from the beginning with this conference, and she came back early from France just to be with us. Dr. Gebbie, I want to thank you for the excellent support you have rendered to this conference, particularly the insight you gained from the international women's conference and shared with all of us.

Well, it's the end, but it's not the end. It is just the beginning. So let's see what we can do. I always believe in working positively towards any means, and little by little I think we can obtain what we want. So, thanks again, and I'll be around. As Pat Clark Battle said, don't forget your evaluations, even if you don't put your name, just say "good," "bad," or whatever.

And, finally, we are indebted to the Deputy Director for Management Services in the Office of the Director for Administration and Chief Financial Officer, Marilia Matos, for her spiritual support on this very complex undertaking. Her leadership helped all of us to have a successful women's summit.

But this conference has been an effort that succeeded only because the people, the volunteers and the others, really tried-they wanted to help us, and that's what it takes. Team effort! Thank you so much. [Applause] 


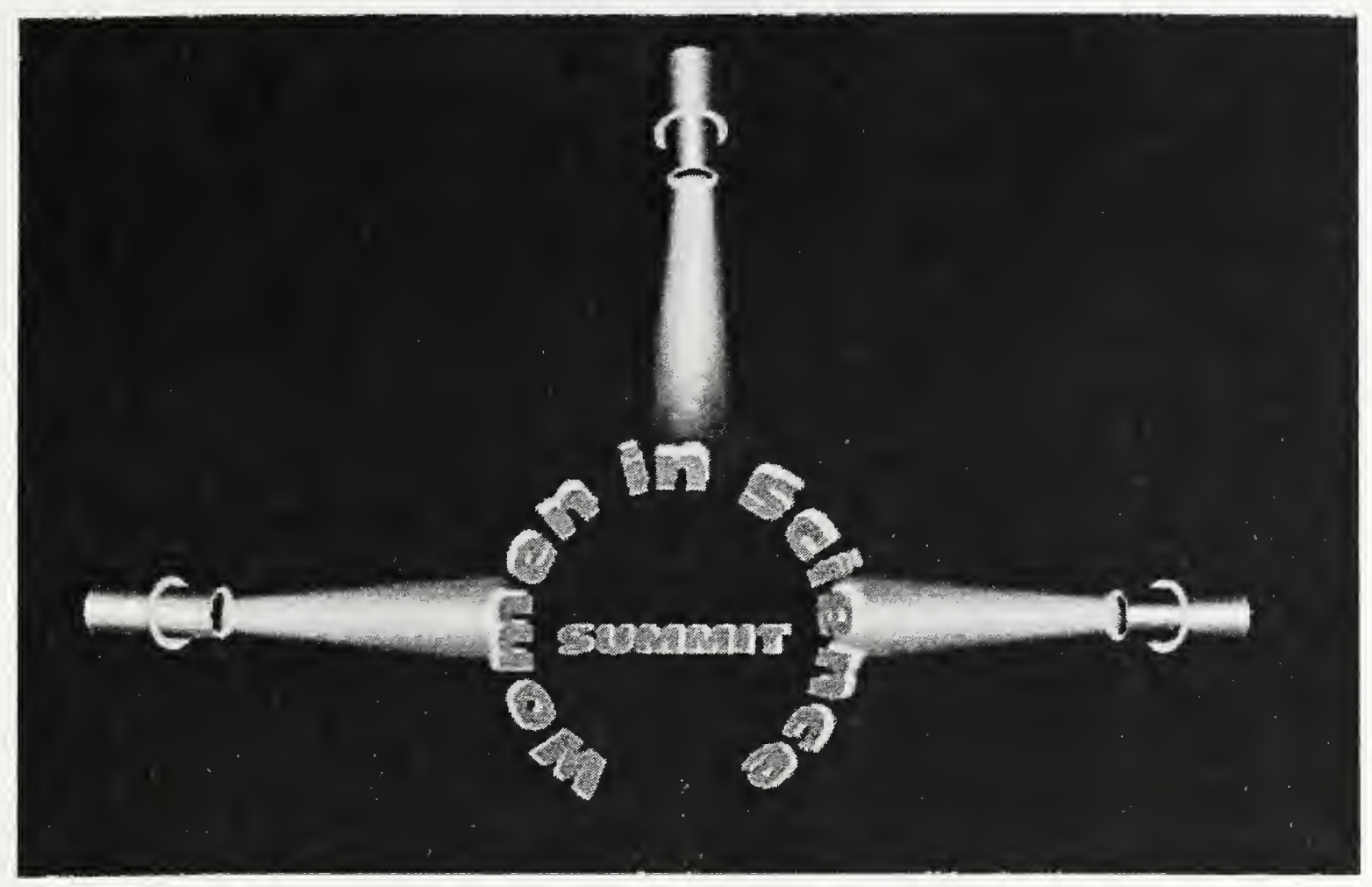

\title{
Women in Science Engineering and Technology Summit
}

\author{
Tuesday and Wednesday; March 12 \& 13, 2002 \\ 8:30 AM to 4:30 PM \\ Red Auditorium, Building 101
}

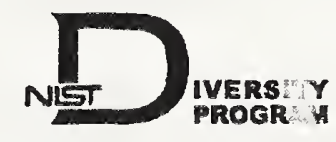

Sponsored by the Diversity Program Office

NLT

National Institute of Standards and Technology

Technology Administration, U.S. Department of Commerce 

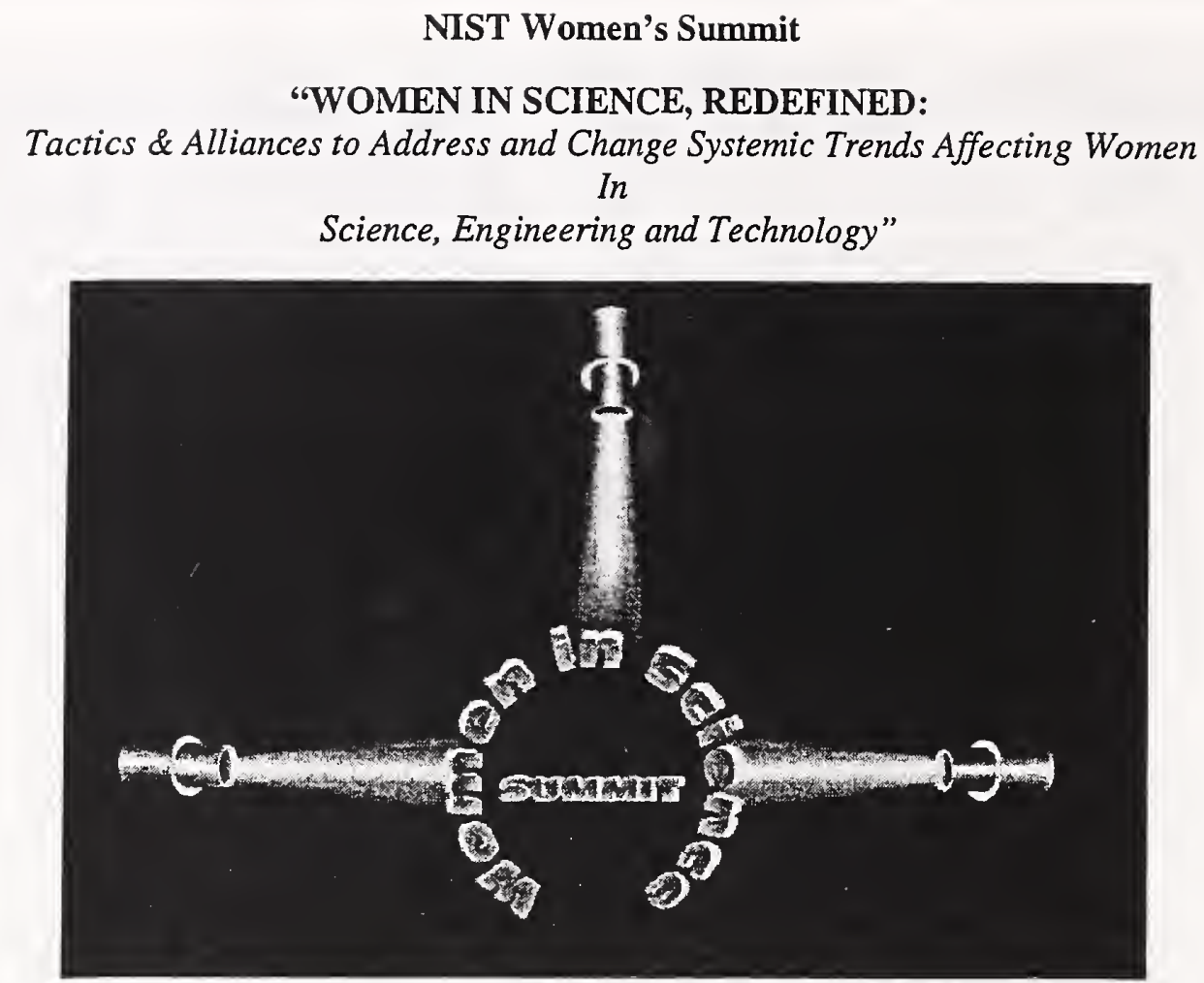

Tuesday \& Wednesday, March 12 \& 13, 2002

Red Auditorium, 8:00 A.M.-4:30 P.M., Gaithersburg

Room 4511, Boulder

National Institute of Standards and Technology

100 Bureau Drive

Gaithersburg, Maryland 20899-3203

\section{WELCOME}

The National Institute of Standards and Technology, U.S. Department of Commerce, and members of the Summit Planning Committee welcome you to this first Women's Summit, "Women in Science, Redefined: Tactics and Alliances to Address and Change Trends Affecting Women in Science, Engineering, and Technology (SETs)".

The focus of this Summit centers on the effort to assist women SETs and future SET girls in overcoming significant barriers as identified in several governmental and industry reports.

Four key areas will be examined as strategic methodologies that can result in academic and career development, professional advancement and job satisfaction. These areas are coaching, mentoring, and prioritizing time, pipeline, and community outreach. The Summit will provide a forum for your comments long held about systemic challenges in your profession and help assist in strategies and networks that can sustain your changes in the future.

Our goal is that this Summit can be a catalyst for individual and systemic change. Thank you for participating and please enjoy these days. 


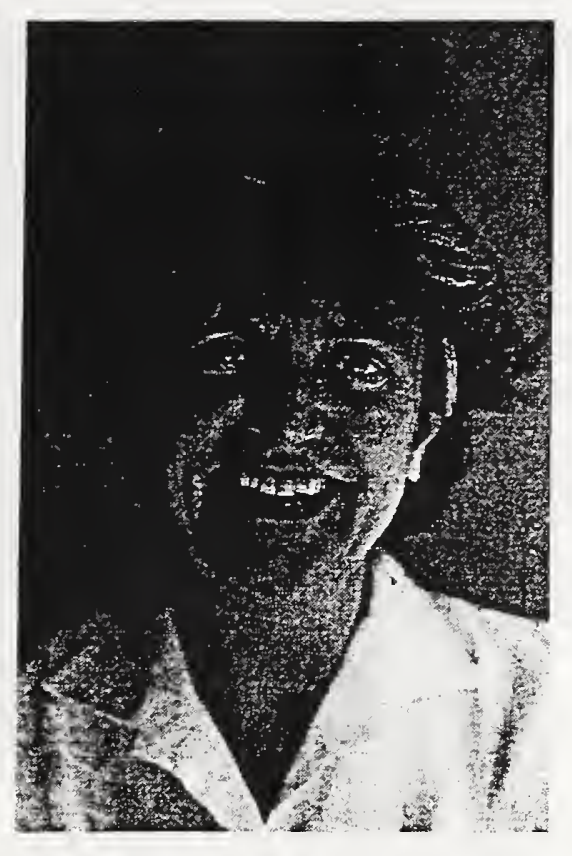

\section{Dear Participants,}

Welcome to NIST's Women's Summit. Although I am not able to join you, I am very pleased to welcome you by letter. The interests of NIST have been important to me for a very long time.

Congratulations to each of your for making the decision to participate today. I hope this is only the first of many organized opportunities for you to meet other women in science, engineering and technology and exchange views. Many of you know about the report, "A Study on the Status of Women Faculty in Science at MIT." While our roles as scientists, engineers, technicians and administrators continue to develop, we are engaged in very important research. Often, without our even knowing, we also set a model for young people. It is up to us to shape a profession that attracts people from diverse backgrounds, and ensures that they find that they have made a wonderful decision in choosing these exciting and rewarding professions.

Sincerely,

(Nancy H. Hopkins, Ph.D, Professor)

Department of Biology

Massachusetts Institute of Technology 


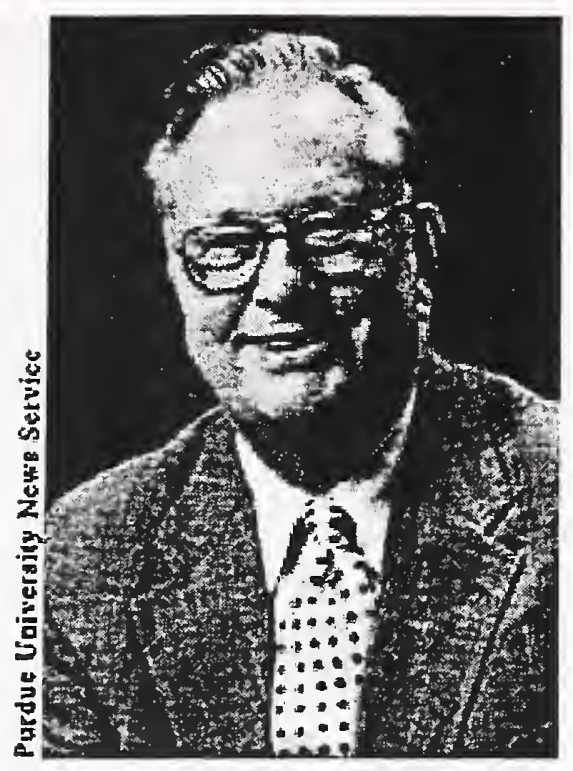

\section{Welcome Attendees,}

It is my pleasure to welcome each of you to this Women's Summit. The recommendations set out in the 1993 reports by NIST concerning women and minorities in Science, Engineering, and Technology (SETs) were a harbinger to the more far-reaching recommendations published by the National Commission for the Advancement of Women and Minorities in science, engineering, and technology. I am proud that NIST advanced these recommendations that are on such firm ground and that the Summit takes the opportunity to address some of them.

Please join me in thanking the Summit speakers, panelists, designated members of the NIST Diversity Advisory Board, and the Diversity Program Office in planning your Summit.

With warm wishes,

(Arden L. Bement, Jr., Ph.D.)

Director

National Institute of Standards and Technology 


\section{NIST Women's Summit Planning Committee:}

Connie N.K. Chang, President-NIST Committee for Women

Dean W. Claus, Diversity Mentoring Coordinator; Boulder Laboratory

Sol del Ande Eaton, Diversity Program Office

Celani Domingas, Visitor-Baldridge Program

Patricia D. Fenn, Contractor, NIST Women's Summit

David M. Gilliam, Ph.D., Diversity Advisory Board

Albert Lee, Ph.D., Diversity Advisory Board

Deborah A. Martin, Diversity Advisory Board

Fran Nielsen, Ph.D., Diversity Advisory Board

Ann-Marie Regan, Diversity Advisory Board

Jennifer Scott, Vice-Chair., Diversity Advisory Board; Boulder Lab-NIST

Hratch G. Semerjian, Ph.D., Director-Chemical Science and Technology Laboratory-NIST

Robin R. Wolf, Diversity Advisory Board; Boulder Lab, NIST

\section{SPECIAL THANKS TO:}

Jeffrey F. Aarons, Facility Services Division-NIST

Denease Anderson, Facility Services Division-NIST

Sarah E. Bell, Facilities Services Division-NIST

Susan J. Carscadden, Facilities Services Division-NIST

Judy L. Crain, Occupational Health and Safety Division-NIST

Hoyt A. Cox, Facilities Services Division-NIST

Vicki Jo Cox, Facilities Services Division-NIST

Naomi Churchill-Earp, J.D., Chairperson-Diversity Advisory Board-NIST

Douglas F. Elznic, Plant Divisions-NIST

Erica Hanson, Staff, Honorable Constance A. Morella (R-Md.)

Gail W. Hixenbaugh, Electronic Information and Publications Program-NIST

Nancy H. Hopkins, Ph.D., Massachusetts Institute of Technology

Timothy M. Kring, Diversity Program Office-NIST

Ed A. P. Mai, Facilities Services Division-NIST

Marilia Matos, Office of the Director for Administration and Chief Financial Officer-NIST

Frederick P. McGehan, Acting Director-Boulder Laboratory-NIST

Rosalyn Meyers, International Coach Federation, Inc.

Nancy T. Miles, Director's Office - NIST

Sharon L. Mingo, Director's Office, Information Services-NIST

Myra Montrose, National Aeronautics and Space Administration

Alice Nutter, Zoe Training \& Consulting

Ken Osborne, Fame Corporation

Robert L. Osborne, Plant Division-NIST

Jenilie C. Palla, Director's Office - NIST

Gwenda M. Roberson, Management and Organization Division-NIST

John E. Sanderson, Facilities Services Division-NIST

Sandy Sanser, Massachusetts Institute of Technology

Bernard Scales, DuPont Corporate Information Center

Donald L. Strawsburg, Chief-Security-NIST

Brenda K. Stream, Facilities Services Division-NIST

Susan Sutherland, Former Director, Boulder Laboratory-NIST

Debra Wadsley, DuPont Corporate Information Center

Wanda Ward, Ph.D., National Science Foundation

Michelle Wims, Facilities Services Division, NIST

and

Focus Groups and Individuals: Summer \& Fall 2001, NIST

Boulder and Gaithersburg Campus 


\section{KEY NOTE SPEAKERS}

\section{Honorable Constance A. Morella (R-Md.) US House of Representatives, Eighth District}

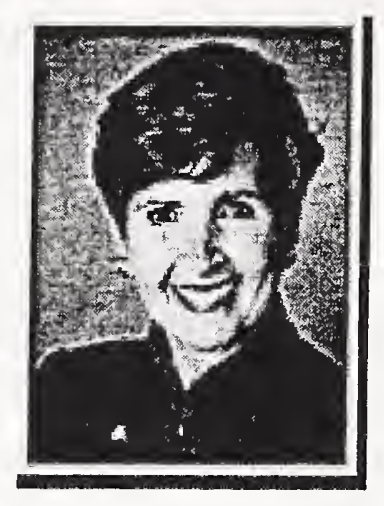

Congresswoman Connie Morella, re-elected in 2000 to an eighth term, represents Maryland's Eighth District. Since first taking office in 1987, Congresswoman Morella has focused her legislative efforts on such issues as scientific research and development, education, the federal workforce, equity for women, and the environment.

Congresswoman Morella is Chair of the Government Reform Subcommittee on the District of Columbia, where she was Vice Chair since 1997. This subcommittee oversees all aspects of the D.C. government, with the exception of appropriations. She also is a longstanding member of the Civil Service Subcommittee, where she sponsors and supports legislation to benefit Federal employees and retirees.

The Congresswoman is a long-term member of the House Science Committee, currently serving as a member of the Subcommittee on Environment, Technology, and Standards. During her time on the Science Committee, Congresswoman Morella has made technology transfer a priority, and has worked to create collaborative partnerships between Federal laboratories, industry, and universities. She has been a national leader in enhancing computer security, in promoting the use of telemedicine and educational technology, and in forming national recommendations to address the underrepresentation of women, minorities, and persons with disabilities in the science and technology workforce.

Congresswoman Morella, former co-chair of the Congressional Caucus for Women's Issues, is recognized nationally for her work on children's issues; domestic violence; and women's health, educational, and economic equity issues. Last year, her legislation to expand the Violence Against Women Act was signed into law. This legislation is the strongest commitment that Congress has ever made to fight domestic violence and sexual assault.

The Congresswoman has established herself as a leader in the fight against HIV/AIDS in women with legislation focusing on research and prevention. Because of her work improving the lives of women, she was inducted into the Maryland Women's Hall of Fame. Glamour magazine honored her as a "Woman of the Year" for "fighting women's fights and winning." The New York Times has recognized her as "one of a dozen who have risen to prominence" in women's health.

Congresswoman Morella's leadership on natural resources and sustainable development issues such as clean air and water, green technology, and population stabilization, has earned her recognition from many national environmental groups, including the Sierra Club and the League of Conservation Voters.

Congresswoman Morella has long been involved with issues affecting older Americans and co-chairs the Older Americans Caucus. 
Congresswoman Morella has been active in international and human rights issues. She was the first woman to chair the Arms Control and Foreign Policy Caucus. She represented the United States at the UN Conference on Population and Development in Cairo, and co-chaired the congressional delegation to the UN Fourth World Conference on Women in Beijing.

Before her election to Congress, Congresswoman Morella served for eight years in the Maryland House of Delegates. From 1970 to 1985, she was a professor in the English Department of Montgomery College in Rockville, Maryland.

Congresswoman Morella has an A.B. from Boston University, an M.A. from the American University, and eight honorary doctoral degrees. A resident of Montgomery County for 44 years, Congresswoman Morella lives in Bethesda. She and her husband, Tony, a law professor, have raised nine children, including her late sister's six children.

Kathie L. Olsen, Nominee Associate Director, White House Office of Science \& Technology

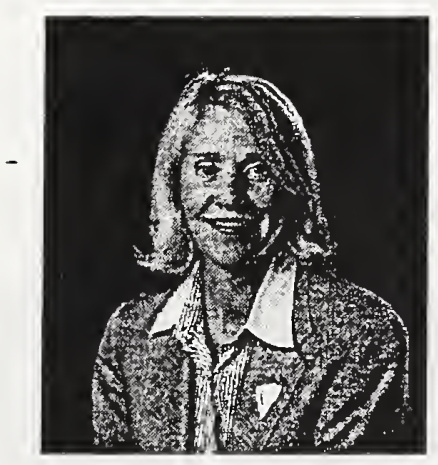

Prior to her nomination to the White House Office of Science and Technology Policy, Dr. Kathie L. Olsen was the Chief Scientist at the National Aeronautics and Space Administration (NASA). In this position, she served as the Administrator's senior scientific advisor and principal interface with the national and international scientific community. Dr. Olsen was responsible for ensuring that NASA programs are universally regarded as scientifically and technological valid and is the principal advisor to the Administrator on the budget content of NASA's science programs. Since July 2000, she also served as the Acting Associate Administrator for the Office of Biological and Physical Research.

Prior to joining NASA on May 24, 1999, Dr. Olsen served as the Senior Staff Associate for the Science and Technology Centers In the National Science Foundation's (NSF) Office of Integrative Activities. From February 1996 until November 1997, she served as a Brookings Institute Legislative Fellow and then as a NSF detailee in the Office of Senator Conrad Burns of Montana. Senator Burns' committees include Appropriations and Commerce, Science, and Transportation and where he served as Chair of the Subcommittee on Science, Technology and Space. Among Dr. Olsen's responsibilities were NASA's authorization and appropriation bills and other issues pertaining to space transportation. Prior to going to Capitol Hill, she served for two years as the Acting Deputy Director for the Division of Integrative Biology and Neuroscience at the NSF where she has worked and held numerous other science-related positions dating back to 1984.

Dr. Olsen received her B.S. with honors from Chatham College, Pittsburgh, Pennsylvania, majoring in both biology and psychology and was elected to Phi Beta Kappa. She earned her Ph.D. from the Department of Psychobiology at the University of California, Irvine. After spending one-year as a 
Postdoctoral Fellow in the Department of Neuroscience at Children's Hospital of Harvard Medical School, Boston, Dr. Olsen moved to the State University of New York at Stony Brook where she was a Research Scientist at Long Island Research Institute and an Assistant Professor in the Department of Psychiatry and Behavioral Science at the Medical School until 1988.

Her research on the neural and genetic mechanisms underlying the development and statement of behavior was supported by grants from the National Institutes of Health. Dr. Olsen has published numerous scientific articles, book chapters, and co-edited a book entitled "The Development of Sex Differences and Similarities in Behavior."

Among Dr. Olsen's many awards, she earned the National Science Foundation Director's Superior Accomplishment Award, The International Behavioral Neuroscience Society's award, and The Society for Behavioral Neuroendocrinology Award in recognition of outstanding contributions for research and education in the field. In May 2000, she received the Barnard Medal of Distinction, the College's most significant recognition of individuals for demonstrated excellence in conduct of their lives and careers. She received NASA's Outstanding Leadership Medallion, June 2001.

\section{Science Fair at Sherwood High School, 2001}

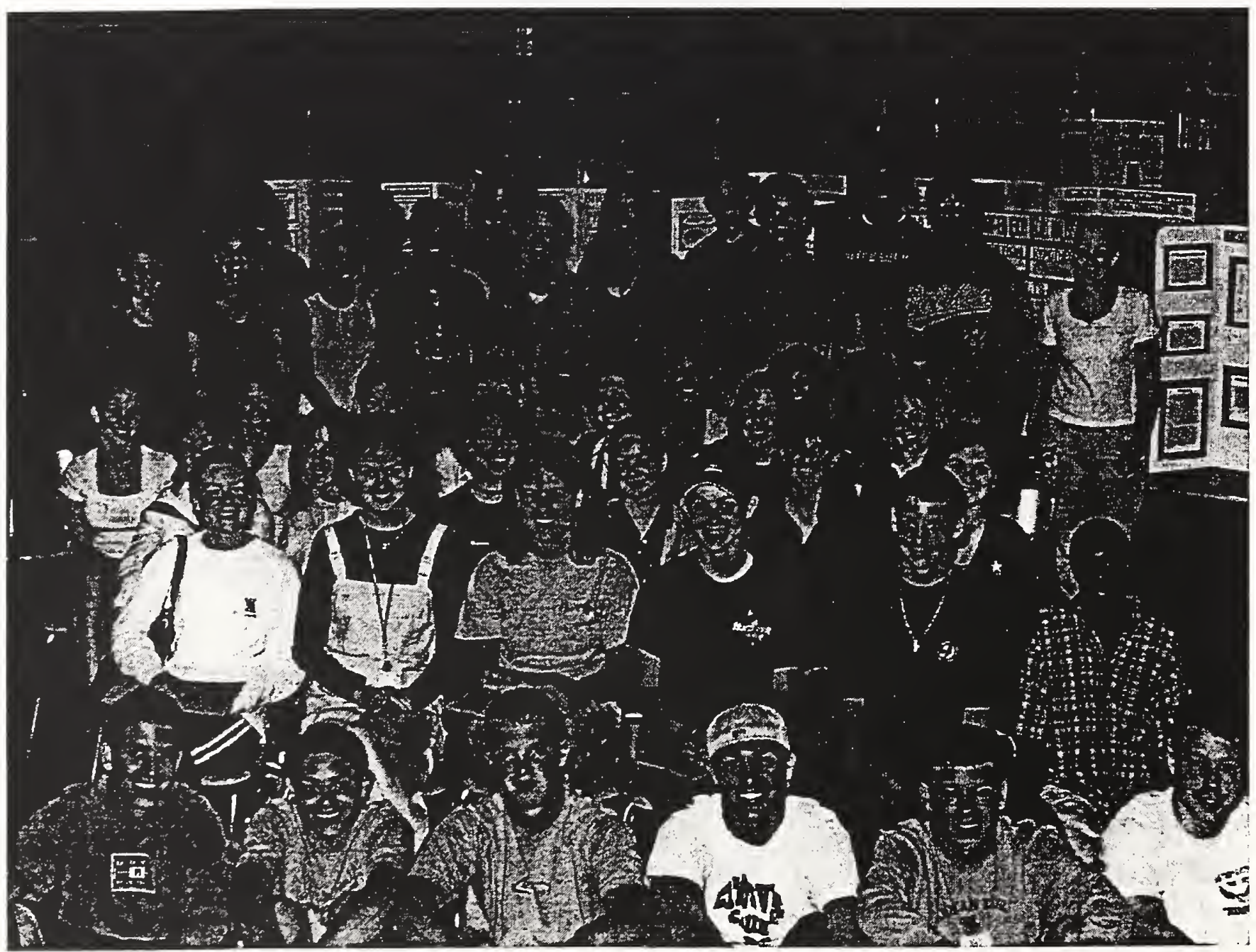




\section{8:00 AM REGISTRATION \\ 8:30 AM WELCOME, INTRODUCTIONS AND OPENING REMARKS \\ Sol del Ande Eaton, Diversity Program Manager - NIST \\ Jorge R. Urrutia, Director of Administration and Chief Financial Officer \\ 8:35 AM Arden L. Bement, Jr., Ph.D., Director, National Institute of Standards and Technology \\ 8:50 AM COMMENTS: RECOMMENDATIONS FROM THE NATIONAL COMMISSION FOR THE ADVANCEMENT OF WOMEN AND MINORITIES IN SCIENCE, ENGINEERING AND TECHNOLOGY; AND COMMENTS: WHITE HOUSE OFFICE OF SCIENCE \& TECHNOLOGY POLICY}

SUMMIT AGENDA

TUESDAY, MARCH 12, 2002

Kathie L. Olsen, Ph.D., Nominee: Associate Director White House Office of Science and Technology Policy Questions \& Answers

9:20 AM

9:30 AM

9:50 AM

"NIST-PAST, PRESENT \& FUTURE: FROM 1993 TO TODAY"

Karen H. Brown, Ph.D., Deputy Director, NIST

Carol A. Handwerker, Ph.D., Chief, Metallurgy Division

Material Science and Engineering Laboratory, NIST

Questions and Answers

"WOMEN IN SCIENCE, ENGINEERING AND TECHNOLOGY IN THE PRIVATE SECTOR" Chinatsu Aone, Ph.D., SRA International, Inc.

Questions \& Answers

10:15 AM BREAK

10:30 AM WORKSHOP: "NEGOTIATING PROGRAM OVERLOAD AND CHANGE"

June E. Ramos, Consultant, Zoe Training \& Consulting

NOON LUNCH ON YOUR OWN

1:30 PM INTRODUCTION OF THE HONORABLE CONSTANCE A. MORELLA (R-Md.)

Arden L. Bement, Jr., Ph.D., Director, NIST

FEDERAL OVERVIEW: WOMEN IN SCIENCE, ENGINEERING \& TECHNOLOGY

The Honorable Constance A. Morella (R-Md.) Eighth Congressional District

Member, House Science Committee, U.S. House of Representatives

Questions \& Answers

2:20 PM: FILM: "THE POWER DEAD-EVEN-RULE"

Dean W. Claus, Diversity Coordinator (Boulder Laboratory), NIST Diversity Advisory Board

3:00 PM BREAK

3:10 PM CONTINUATION OF MORNING WORKSHOP: "Negotiating Program Overload \& Change"

Breakout Groups \& Discussion

Consultant June E. Ramos

4:30 PM CLOSE: SUMMIT DAY ONE

Group Recorders meet with Sol del Ande Eaton, Diversity Program Manager, NIST 


\section{SUMMIT AGENDA \\ WEDNESDAY, MARCH 13, 2002}

8:00 AM REGISTRATION

Distribution of Recommendations from Group Discussions, 3/12/02

8:30 AM WELCOMING REMARKS

Connie K.N. Chang, President, NIST Committee for Women

8:40 AM PANEL I: ABCs OF COACHING:

"Coaching Within a Science, Engineering \& Technology Culture"

Pat Clark Battle, Ph.D., President, Pat Battle \& Associates

Tim Wright, Wright Results

Questions \& Answers

9:40 AM BREAK

9:55 AM PANEL II: MENTORING

Summer Undergraduate Research Fellowship (SURF), NIST

David S. King Ph.D., Former Director and Founder

"Investing in Our Future"

Bettie L. White, Assistant to Director of Stennis Space Center, NASA

Darlene V. Floyd, President-Horizons Management and Training Consultants

Questions \& Answers

NOON LUNCH ON YOUR OWN

1:30 PM PANEL III. PIPELINE-COMMUNITY OUTREACH

"Meeting the Crisis in Human Capital: K-12 to Graduate School"

Julia V. Clark, Ph.D., Program Director, National Science Foundation

Jonetta Russell, Magnet School Coordinator, Montgomery-Blair High School Montgomery County Public Schools

Questions \& Answers

\section{2:30 PM BREAK}

2:45 PM WRAP-UP: SUMMATION OF PANEL PRESENTATIONS \& GROUP RECOMMENDATIONS Fran Nielsen, Deputy Chief, Computer Security Division

Information Technology Lab, NIST

Acknowledgements \& Evaluations Completed \& Returned

3:40 PM Sol del Ande Eaton, Program Manager, Diversity Office, NIST

INTRODUCTION OF KATHARINE B. GEBBIE, Ph.D.

Ms. Radhika Char, Graduating Senior-Magnet School Program

Montgomery-Blair High School, Montgomery County Public Schools

3:45 PM CLOSING REMARKS:

Katharine B. Gebbie, Ph.D.

Director, Physics Laboratory, NIST 
KEYNOTE and PANEL SPEAKERS: The_Honorable Constance A. Morella, (R-Md.) Eighth Congressional District, is a member of the House Science Committee who presided over the Congressional Report by the National Commission for the Advancement of Women and Minorities in Science, Engineering, Technology (SETs) [Morella Commission], issued in September 2000. She initiated and supported legislation, Public Law 105-255, leading to the creation and staffing of the National Commission by the National Science Foundation. The Commission was chaired by Ms. Elaine M. Mendoza. A copy of her remarks at the Morella Commission Press Briefing on July 13, 2000 is available on the information table. Copies of the recommendations and Public Law 105-255 are in your handouts.

Kathie L. Olsen, Ph.D., recently nominated by President Bush for Associate Director, White House Office of Science and Technology Policy (OSTP), will comment about the recommendations issued by the Morella Commission and give an overview about the work of the OSTP and her expectations.

Also available on the information table are the following additional publications: "The Evolving Pipeline: The Extent \& Effects of Implementation of the Recommendation of the Task Force on Women, Minorities, and the Handicapped in Science and Technology, " by Sarah A. Manes; and "Persons with Disabilities in Science, Engineering and Technology: A White Paper Prepared for the Commission on Advancement of Women and Minorities in Science, Engineering and Technology Development" by Katherine D. Seelman.

NIST Director Dr. Bement welcomes Summit attendees. Dr. Bement was sworn in as the $12^{\text {th }}$ Director of NIST, and was introduced at the U.S. Senate Commerce Committee Nomination Hearings by Congresswoman Morella, "...He has been a leader encouraging the next generation of scientists and engineers, particularly among women and other under-represented groups." 1

Also welcoming attendees, by letter, is Dr. Nancy Hopkins,Professor of Biology from Massachusetts Institute of Technology. Dr. Hopkins chaired the study committee at MIT, 1995-97, that issued "A Study on the Status of Women Faculty in Science at MIT." The study and those amended in 1998 and 1999 resulted in the documented "subtle but pervasive discrimination" in academia toward women faculty at MTT. ${ }^{3}$

Dr. Karen H. Brown, NIST Deputy Director, and Dr.. Carol Handwerker, Chief of the Metallurgy Division of Materials Science and Engineering Laboratory, will address the 1993 NIST Report outlining challenges to senior management concerning support to NIST women SETs. Closing out the Summit is Dr. Katharine B. Gebbie, Director of the Physics Lab, who chaired the 1993 Ad Hoc Affirmative Employment Committee for Female Scientists and Engineers. She will be introduced by graduating senior, Ms. Radhika Char, a student in the Magnet School Program at Montgomery-Blair High School, Montgomery County Public Schools.

NEGOTIATING PROGRAM OVERLOAD \& PROFESSIONAL CHANGE: Ms. June E. Ramos, a national and international consultant in human resources, will discuss and present an approach to

\footnotetext{
${ }^{1}$ Testimony, Congresswoman Constance A. Morella, U.S. Senate Commerce Committee Nomination Hearing, 11/01/01, Washington, D.C.

${ }^{2}$ Comments on the Report by Professor Lotte Bailyn, Chair of the MIT Faculty, 1997.

3 "MIT Concedes Bias Against Female Faculty," Kevin R. Lang, Associate News Editor, 3/30/99, Volume 119, Number 15 .
} 
addressing the priorities that shape your professional career and other important priorities. "Hurry, faster" are the words that crowd our lives and leave us tired. How can we accommodate an everincreasing work program and still make time for advanced education, family, and leisure?

SUCCESS \& WOMEN SETs IN THE PRIVATE SECTOR: Dr. Chinatsu Aone, Vice President and Director of Natural Language Technologies at SRA International, Inc., will address how her skills resulted in international recognition as a leader in computerized systems. She will also comment about the pros and cons of women SETs in the private sector vs. the public sector. NIST anticipates an attrition rate of approximately $3 \%$ over the next five years. ${ }^{4}$ Most SETs are leaving for the lucrative private sector. How good is it anyway?

SRA International, Inc., a leading information technology company for consulting and systems integration was just selected by Fortune magazine as one of the " 100 Best Companies to Work for in America" for the third consecutive year. The ranking is based on an in-depth analysis of company culture, human resources practices, and a random survey of the company's employees. ${ }^{5}$

THE POWER DEAD-EVEN RULE: And Other Gender Differences in the Workplace: Pat Heim, Ph.D., is President of the Heim Group, a consulting firms which provides management and organizational development services. She narrates and appears in the film. Clients include corporations in manufacturing, healthcare, publishing, pharmaceutical and service industries, as well as federal and state agencies. The Heim Group designs, delivers and coordinates a wide variety of activities to support organizational transitions, improve team effectiveness and enhance professional and managerial skills. Dr. Heim received her Ph.D., in communications from the University of Colorado. Her books include Hardball for Women, which has been called a landmark publication, Smashing the Glass Ceiling and Learning to Lead.

More detailed information about the film is found at the end of this Summit booklet, just before the evaluation page.

Diversity Coordinator Dean Claus, from the Boulder Lab, NIST, will introduce the 36-minute film. The observations presented by Dr. Heim, in this not-to-be missed-film, are compelling in their clarity about differences in gender interaction!

MENTORING: "Investing in Our Future" Mentoring means future women scientists. Mentoring can make the difference in the retention and recruitment of women the sciences, engineering and technology. Mentoring programs can range from formal to informal, one-on-one to group programs. Mentoring plays a key role in helping resolve some of the issues women find in a male-dominated field. Bettie L. White, former Director of Research and Educational Programs at NASA-headquarters who presided over a $\$ 22$ million program in mentoring future SETs, now Assistant to the Director of the Stennis Space Center, will link these programs to how mentoring can lend to the development \& direction of your career and create networking with other professionals. Darlene V. Floyd, President of her own company, Horizons Management and Training Consultants, provides direction and consulting to many agencies and companies in the public and private sector and is currently under contract to NIST.

\footnotetext{
${ }^{4}$ Statistics provided by Human Resources Office, Department of Commerce.

${ }^{5}$ Fortune Magazine, 2/04/02
} 
NIST's Summer Undergraduate Research Fellowship (SURF) will also be featured and discussed by its former Director and Founder, Dr. David S. King.

COACHING: "Coaching Within a Science, Engineering \& Technology Culture" Achieving your agency's core competencies can be easier than you think. A panel of professionals coaches, Dr. Pat Clark Battle and Mr. Tim Wright (both presidents of their own companies) will distinguish between the techniques of mentoring and coaching and share with you how the use of coaching can help new hires and veteran employees learn to refashion and apply the skills they have to make their jobs truly meaningful.

PIPELINE-OUTREACH: "Meeting the Crisis in Human Capital via K-12 to Graduate School" Is your agency's recruiting system without partnerships with tomorrow's scientists, engineers and technologists? What steps can be taken today to showcase and introduce our young people to SETcourses in grade school and undergraduate institutions? What narrow but meaningful role can YOU play or your agency take on for our future scientists and administrators?

Julia V. Clark, Ph.D. Program Director at the National Science Foundation, and Ms. Jonetta Russell, Magnet School Coordinator at Montgomery-Blair High School (Montgomery County Public Schools) will share how community outreach programs from agencies like NIST support and influence direction of future scientists at the junior high, high school, undergraduate and graduate levels
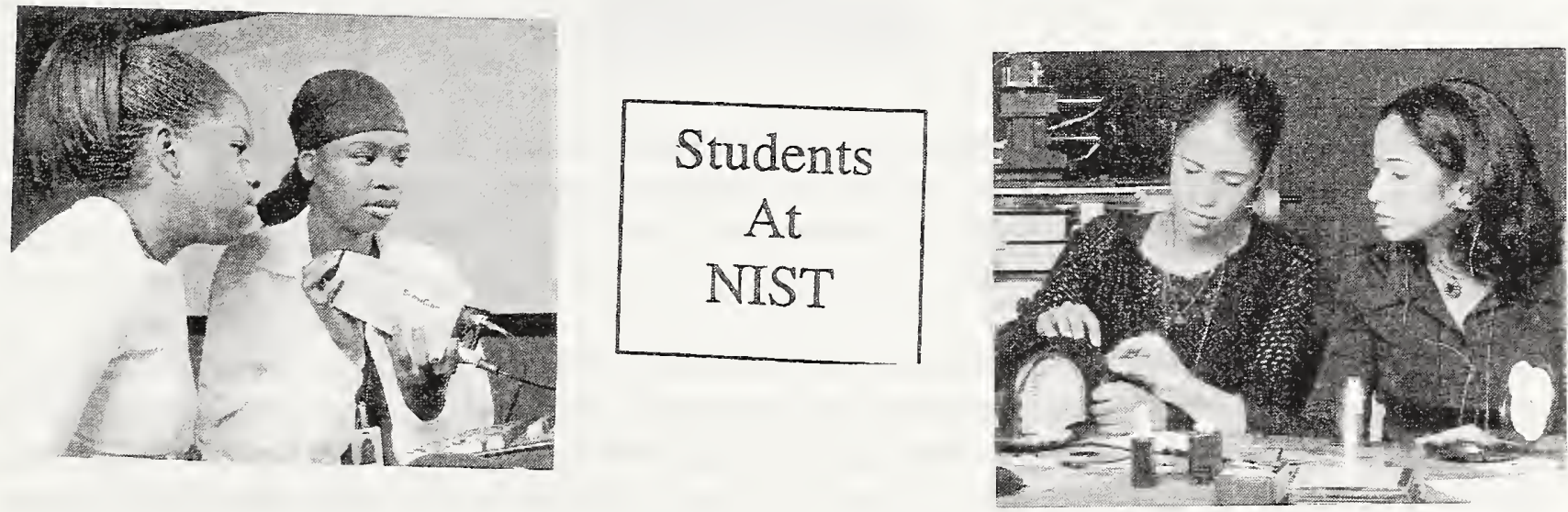


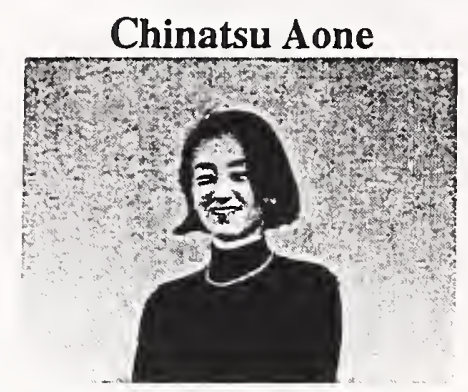

Dr. Aone leads a group that conducts research, design, and development of advanced Natural Language Processing (NLP) systems-systems that try to automatically understand human languages as expressed in email, newspapers, journals, etc. Dr. Aone has published extensively in the field and has served on many review committees. In addition to her research, she has unique insight into the practical problems of text processing, and particularly the challenge of applying cutting-edge technologies within the framework of real-world applications. She has led the efforts at SRA to develop innovative commercial products that incorporate NLP technologies, such as NetOwl(TM) and Assentor $(\mathrm{R})$, which have been widely used within, among others, the U.S. Government, the financial industry, and the publishing industry. Dr. Aone received her Ph.D. in computational linguistics from The University of Texas at Austin.

\section{Pat Clark Battle}

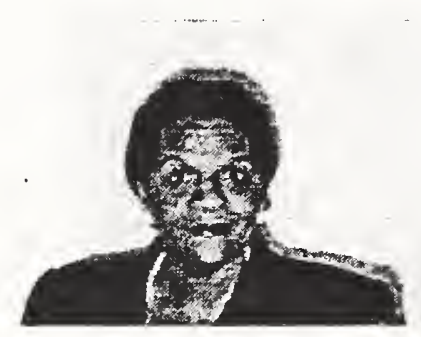

Dr. Pat Clark Battle is a renowned consultant, professor, and lecturer who has worked in the United States, the United Kingdom, Canada, the Caribbean, Malaysia, and Russia. She is founder and President of Pat Battle and Associates, an international consulting firm that supports a broad range of organizations in achieving their goals.

Dr. Battle has helped thousands of people strengthen their professional and organizational competence at all levels of the system. She consults for a wide range of organizations from Fortune 500 companies to educational institutions, and governmental agencies nationally, locally, and internationally. She has assisted a prime minister and his cabinet, board members, CEO's, senior leadership teams, managers, team members, consultants and trainers in sectors such as government, petroleum, specialty chemicals, labor unions, insurance, airlines, banking, health, aerospace, manufacturing, utilities, food, and beverage to achieve their maximum potential and fulfill their organization's mission.

The focus of her work includes executive team building, executive coaching, conflict management, labor management facilitation, large systems change, mergers, leadership, transition management, 
education, working with resistance, and leveraging diversity. She is often called upon as a motivational keynote speaker and conference presenter.

Dr. Battle received her Ph.D. from the University of Maryland in College Park, Md., M.S. and B.S. from The Johns Hopkins University in Baltimore, Maryland. She is a former member of the Consulting Psychologist Press Research Advisory Board, Kaleel Jamison Foundation Board, and is a past Chair of the Campfire of Maryland Board. Current memberships include NTL Institute, Gestalt Institute, and the Association for Psychological Type. Dr. Battle is an adjunct professor at the American University/NTL Institute Masters Program in Organization Development in Washington, D.C., and She has taught at The Johns Hopkins University, Cleveland State University/NTL Diversity Management Program and the University of Maryland. She has been a guest lecturer at the University of the West Indies and Case Western Reserve, and The Moscow Institute of Technology. Dr. Battle is a co-creator of the Battle-Klein-Battle Resistance Style Inventory and a co-creator of the $7^{\text {th }}$ Sense Leadership: Leading in the New Millennium ${ }^{\mathrm{TM}}$, and co-author of Pigmentocracy: How Words Create, Perpetuate, and Sustain It.

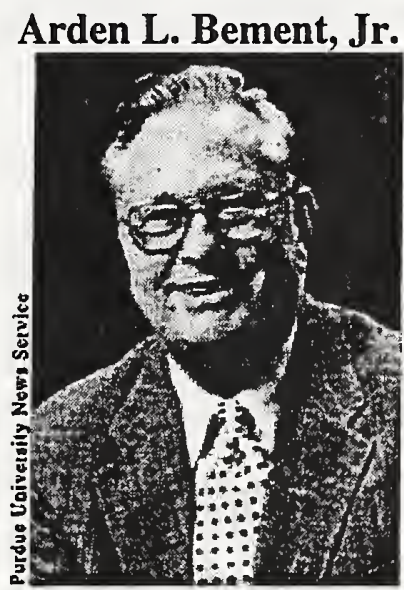

Arden L. Bement, Jr., was sworn in as the 12th director of NIST on Dec. 7, 2001. Bement oversees an agency with an annual budget of about $\$ 812$ million and an onsite research and administrative staff of about 3,000, complemented by a NIST-sponsored network of 2,000 locally managed manufacturing and business specialists serving smaller manufacturers across the United States. Prior to his appointment as NIST Director, Bement served as the David A. Ross Distinguished Professor of Nuclear Engineering and head of the School of Nuclear Engineering at Purdue University. He has held appointments at Purdue University in the schools of Nuclear Engineering, Materials Engineering, and Electrical and Computer Engineering, as well as a courtesy appointment in the Krannert School of Management. He was director of the Midwest Superconductivity Consortium and the Consortium for the Intelligent Management of the Electrical Power Grid. Bement came to his position as NIST Director well versed in the workings of the agency, having previously served as head of the Visiting Committee on Advanced Technology, the agency's primary private-sector policy adviser; as head of the advisory committee for NIST's Advanced Technology Program; and on the Board of Overseers for the Malcolm Baldrige National Quality Award.

Bement joined the Purdue faculty in 1992 after a 39-year career in industry, Government, and academia. These positions included: Vice President of Technical Resources and of Science and Technology for TRW Inc. (1980-1992); Deputy Under Secretary of Defense For Research And Engineering (1979-1980); Director, Office Of Materials Science, DARPA (1976-1979); Professor of 
Nuclear Materials, MT (1970-1976); Manager, Fuels And Materials Department and the Metallurgy Research Department, Battelle Northwest Laboratories (1965-1970); and Senior Research Associate, General Electric Co. (1954-1965).

Along with his NIST advisory roles, Bement served as a member of the U.S. National Science Board, the governing board for the National Science Foundation, from 1989 to 1995 . He also chaired the Commission for Engineering and Technical Studies and the National Materials Advisory Board of the National Research Council; was a member of the Space Station Utilization Advisory Subcommittee and the Commercialization and Technology Advisory Committee for NASA; and consulted for the Department of Energy's Argonne National Laboratory and Idaho Nuclear Energy and Environmental Laboratory.

He has been a director of Keithley Instruments Inc. and the Lord Corp., and was a member of the Science and Technology Advisory Committee for the Howmet Corp. (a division of ALCOA).

Bement holds an engineer of metallurgy degree from the Colorado School of Mines, a M.S. in metallurgical engineering from the University of Idaho, a Ph.D. in metallurgical engineering from the University of Michigan, and an honorary $\mathrm{Ph} . \mathrm{D}$. in engineering from Cleveland State University. He is a member of the U.S. National Academy of Engineering.

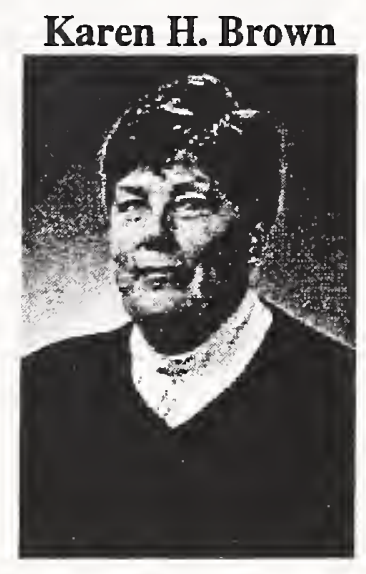

Karen H. Brown has served as the NIST Deputy Director since January 1999. From January to December 2001, Brown also served as the Acting Director of NIST. During her tenure at NIST, Brown has been instrumental in improving the agency's long-range strategic planning and in developing systematic ways to continually adjust NIST's program to meet high-priority national needs.

Prior to coming to NIST, she was a Distinguished Engineer at IBM Microelectronics in Hopewell Junction, N.Y. On assignment from IBM, Brown served as Director of Lithography for International SEMATECH in Austin, Texas, from 1994 to 1998. SEMATECH is a consortium of 13 companies from seven countries that works to improve semiconductor manufacturing. During this same period, Brown served as a member of the National Research Council Board of Review for NIST programs.

Brown's 22-year career at IBM concentrated on solving problems in semiconductor lithography and microelectronics. She has a proven track record in management, having successfully met the challenges of moving ideas from the laboratory into manufacturing. Brown also has a keen awareness of the impact of national and international standards on U.S. industry and the economy, having held a 
variety of standards leadership positions in Semiconductor Equipment and Materials International (SEMI) and helped to bring a semiconductor fabrication line on-board in France.

The author of numerous technical papers and other publications and a frequent speaker at major conferences, Brown holds five patents and has three patents pending. She received the Corporate Excellence Award from Smutch in 1997, was recognized as an Outstanding Contributor by SEMI from 1987 to 1993, and was elected co-chair of the North American Regional Standards Committee in 1993.

A native of Schenectady, N.Y., Brown holds a B.A. in chemistry and in history and a Ph.D. in chemistry from the University of Rochester. She was honored by the University of Rochester as their distinguished alumna in 2001.

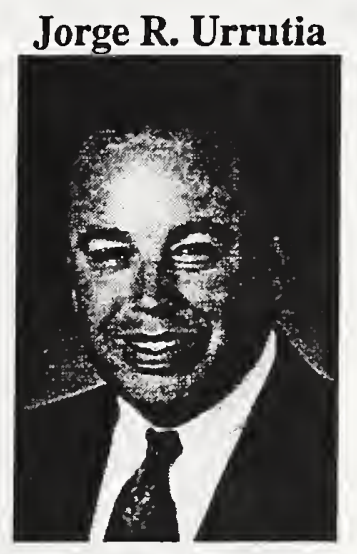

Jorge R. Urrutia was appointed Director for Administration for the National Institute of Standards and Technology (NIST) in September 1994. In 1998, he was asked to also assume the role of the Chief Financial Officer (CFO). He is responsible for the largest organization at NIST, an organization with an overhead budget of approximately $\$ 60$ million and a staff of nearly 700 people. In addition, he directs the construction of all facilities, including the Advanced Measurement Laboratory (about $\$ 240$ million and the $\$ 20$ million SCMMR budget). He directs and manages a broad range of administrative functions, including financial management, facilities management, facilities support, health and safety, procurement, human resources, public affairs, travel, grants, physical security and many other functions, including the radiation safety program for the NIST reactor.

In his role as Director for Administration, Mr. Urrutia is the principal point of contact between NIST and the Office of the Assistant Secretary for Administration and CFO, the Office of Inspector General, and the Deputy Assistant Secretary for Security. He is also the NIST point of contact with the Mayors of Gaithersburg and Boulder. In addition, Mr. Urrutia is the primary NIST point of contact with the National Capital Planning Commission, the Maryland Park and Planning Commission, the Humane Society of the United States, the Maryland Department of the Environment, and other state, city, and private organizations.

Mr. Urrutia previously served as chief of NIST's Plant Division from 1987 until 1991. From 1991 until his present position, Mr. Urrutia was Director, Division of Engineering Services, for the National Institutes of Health (NIH), in charge of the construction of all medical and support facilities for NIH. His previous experience includes serving as Engineering Director for the Naval Research Laboratory at the Public Works Department, Program Manager for the Naval Facilities Engineering Command. Mr. Urrutia also played an important role during the cold war military build up. During such period he was 
in charge of military construction in various places of the world, including Spain, Italy, Greece, Bahrain, and the Indian Ocean. Prior to this time, Mr. Urrutia was a highway engineer for the Federal Highway Administration.

Mr. Urrutia holds a M.P.A. in Public Administration from Harvard University, a B.S. in civil engineering from the University of Maryland, and an A.S. from Montgomery College. He is licensed as a Professional Engineer and is a past recipient of the Secretary of Defense Cold War Certificate, the Commerce Department's Silver Medal, the Surgeon General of the United States Award, the Public Health Service Award, and the NIH Director's Award among other awards.

Mr. Urrutia is fluent in Spanish and English, both the written and spoken word. Univision and Telemundo, two Spanish T.V. Channels, and various magazines such as Hispanic Engineer as well as local Spanish newspapers such as "El Pregonero" have portrayed Mr. Urrutia as a role model for the Hispanic community. Mr. Urrutia is a U.S. citizen with top-secret clearance.

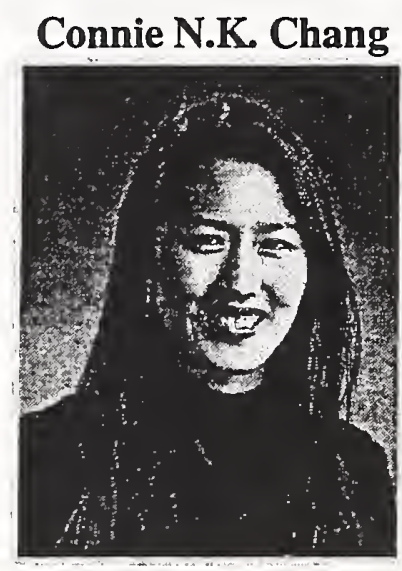

Connie Chang is an economist in the Economic Assessment Office of NIST's Advanced Technology Program, where she participates on selection panels for the funding of early-stage, cutting-edge technologies, manages projects, and evaluates the economic impact of awarded projects. Her evaluation work involves developing, managing, and supervising economic contract studies and policy reports, and conducting research in the business and economic consequences of awarded projects. She served a one-year rotation assignment as the Special Assistant to the Director of ATP in 1996-1997. She was presented with the U.S. Department of Commerce Bronze Award, the highest honorary recognition at NIST in November 2000.

Chang actively participates in NIST-wide activities. She is President of the NIST Committee for Women (1999-present), a volunteer employee organization dedicated to promoting the career interests of women at NIST. She is also an active member of the Association for NIST Asian-Pacific Americans. She served a two-year term on the NIST Institutional Review Board on Human Subjects. She has also co-authored articles for News Notes, a publication by the Civil Rights Office, NIST. Outside NIST, Connie is Chair of the External Affairs Committee and former Chair of the Education Committee for the D.C. Chapter of the National Asian-Pacific American Women's Forum, a nonprofit organization founded in 1996 after the United Nation's World Conference on Women in Beijing China (www.napaw.org).

Connie is a graduate of Wellesley College and the Graduate School of Internal Relations and Pacific Studies at the University of California, San Diego. She completed the doctoral coursework and 
qualifying exams in Technology Policy and Political Economy at the Massachusetts Institute of Technology in Cambridge, Massachusetts. Prior to her graduate studies, Connie worked for three years at Credit Suisse First Boston, a Wall Street investment-banking firm, and as a research assistant at the Federal Reserve in New York.

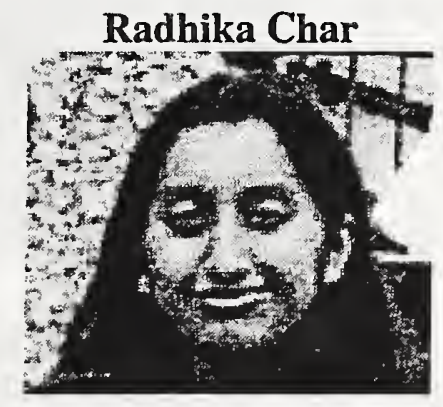

Radhika Char is a senior in the Magnet program at Montgomery Blair High School in Silver Spring, MD. She worked under the guidance of Dr. Pedatsur Neta of the National Institute of Standards and Technology, and was selected as a semifinalist in the 2002 Intel Science Search Contest for her project that involved detoxifying polychlorinated biphenyls. She has also been named as a National Merit Finalist and Maryland State Distinguished Scholar Finalist. In college, Radhika would like to major in chemical engineering.

In addition to her studies, she has been very active as a performer and crewmember in school plays, acting a major role in Charles Dickens' Tale of Two Cities. She is also a performing violinist in Indian classical music, having given solo concerts and accompaniments at various prestigious institutions both in the USA and India. She has won several awards for her violin performances and her concerts have been reviewed as outstanding by well-known critics.

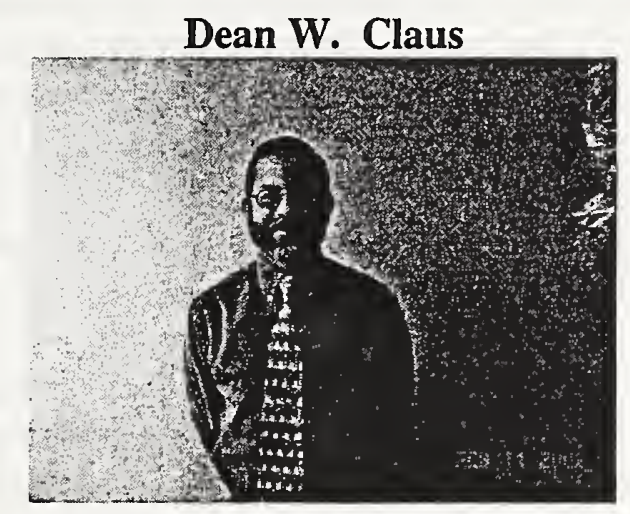

Dean has 19 years of Federal service with the Engineering, Maintenance, Safety, and Support Division at NIST Boulder. His wide-ranging career path includes work as an information receptionist, warehouse worker, engineering draftsperson, and engineering technician. In 1997, Mr. Claus received his B.A. in organizational management and has since moved to his current position as an administrative specialist. He has been involved with diversity since 1997 when he led the NIST Admin. Diversity Team. Several months ago he accepted the challenge of working with the NIST Diversity Office serving as the NIST Diversity Coordinator. Dean is married, the father of two children, is active in his church, and enjoys fly-fishing. 


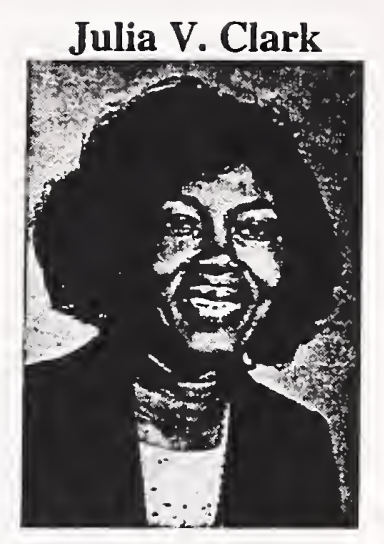

Julia V. Clark is Program Director in the Teacher Enhancement Program of the Division of Elementary, Secondary and Informal Education in the Directorate of Education and Human Resources at the National Science Foundation (NSF). For the past three years Dr. Clark has been on a detail assignment to Congress. She served as Principal Advisor for Science and Technology Issues to Congressional Members of the Science Committee and the Education and Workforce Committee in the U.S. House of Representatives. She also served as an advisor on education and science-related issues and policy to the Committee on Health, Education, Labor and Pensions in the Office of Senator Kennedy.

Dr. Clark received a B.S. in natural science from Fort Valley State University, Masters (Biology/Science Education) from the University of Georgia and Ph.D. (science education) from Rutgers University. She has completed additional graduate studies in environmental science at Yale University; radiation biology at the University of California-Berkeley; and chemistry and biology at Emory University.

She has a distinguished record as a scholar, educator, and administrator. Prior to coming to NSF in 1990, Dr. Clark was a professor in the academic arena. She served as a tenured Associate Professor of Science Education at Texas A\&M University; Assistant Professor of Science and Mathematics Education at Howard University; Associate Professor of Biology and Science Education at Clark Atlanta University; Assistant Professor of Biology and Botany at Albany State University and Morris Brown College. She has also served as a Visiting Professor of Education at Memorial University in Newfoundland Canada and Visiting Professor of Education at the University of Maryland-College Park and George Mason University

Throughout her career, Dr. Clark has published in both science and education. Her publications and research undertaken include a wide assortment of timely topics in cognitive development, science curriculum, epidemiology, women and minorities in science and leadership development. She has written a book chapter on women leadership published by the W.K. Kellogg Foundation. Her recently published book entitled "Redirecting Science Education: Reform for a Culturally Diverse Classroom," has received national recognition. She is currently near the completion of a book on Teacher Quality. She has traveled extensively national and international as a speaker, and workshop and seminar leaders, sharing her expertise and talents across a diverse spectrum of audiences.

Over the years, Dr. Clark has received several honors and awards. Among them are: American Association for the Advancement of Science (AAAS) Fellow in Science Education, W.K. Kellogg National Fellow, Outstanding Achievement in Government Award in Science and Technology; 
Exceptional Women in Science and Technology Award, Lily Foundation Award, Distinguished Alumni Award, and Outstanding Young Women of America Award.

She has also been on several National Boards and Committees. Among them are: Editorial Board, Journal of College Science Teaching; Advisory Board, Education and Instructional Technology, Public Service Satellite Consortium; National Technical Advisory Board, National Urban Coalition; Women Equity Action League; and Board of Directors, Consortium of Southern Colleges for Teacher Education. Membership in professional organizations includes Sigma XI Scientific Research Society, AAAS, National Association for Research in Science Teaching (NARST), American Association of University Women (AAUW), Phi Delta Kappa, and Minority Women in Science.

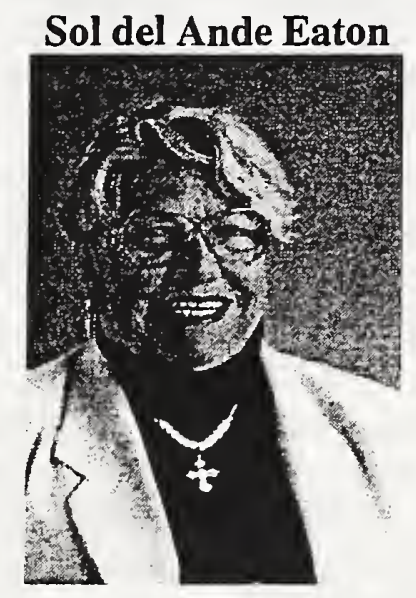

Ms. Sol del Ande Eaton is the manager of the NIST Diversity Program. Prior to this position, Ms. Eaton was the Equal Employment Opportunity and Diversity Director at the National Institute of Dental and Craniofacial Research at the National Institutes of Health (NIH). She also held the position of Equal Employment Opportunity Officer at the Naval Research Laboratory, Department of Navy and the Office of the Assistant Secretary for Health and Human Services Department. Ms. Eaton started her career in the Federal government as a research chemist in the National Cancer Institute, NIH.

Ms. Eaton has served on appointed boards, commissions, and committees including the National Conference for Community and Justice (formerly known as National Conference of Christians and Jews), The Maryland Advisory Committee to the U.S. Commission on Civil Rights, the Maryland Ethnic Heritage Commission, the Prince George's County Mental Health Association, the Boys' \& Girls' Homes and Community Services, Inc., the Youth Resources, Inc., the National Association of Commissions for Women and various local organizations.

Ms. Eaton earned a Rockefeller Fellowship to attend New Mexico State University to study chemistry. She also attended Catholic University under an AAUW full scholarship to work on a M.S. in chemistry. In 1986 she finished a M.A. in legal studies from Antioch School of Law. Presently, she is working on a Ph.D. in business administration.

In 1993, Ms. Eaton was profiled in the publication, "Women of Achievement in Prince George's County History."

In 1997, Ms. Eaton was elected to the Maryland Women's Hall of Fame by the Honorable Parris N. Glendening, Governor of Maryland, for contributing to the economic, political, cultural, and social life 
of the state, and for being a role model of achievement for future female leaders. She has earned many awards and recognition for her work.

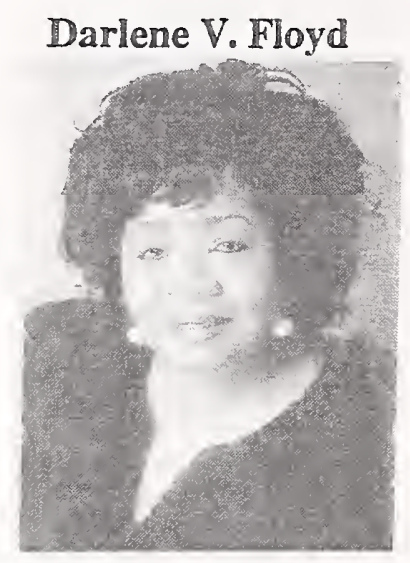

Ms. Floyd is a principal of HORIZONS Management and Training Consultants. Based in Alexandria, VA., HORIZONS provides consulting and training to organizations seeking optimum performance and competitive advantage. HORIZONS was the recipient of the 1998 National Training Officers Conference Award for Excellence in Training Design.

Ms. Floyd is a seasoned professional with over 20 years of experience in the public and private sectors in the areas of human resource management, diversity/multiculturalism, organizational development, leadership and mentoring. She has been the speaker at numerous conferences and symposiums. Of note, Ms. Floyd was an invited presenter at the First Annual Global Conference on Managing Diversity at the University of Georgia. Ms. Floyd joined others renowned in the area of diversity. She was also a presenter at the General Electric African American Forum Symposium V and VI, the International Marriott Network Group, the Montgomery County Annual Diversity Showcase, and the 1999 Mobile African American Women on Tour, the nation's foremost women empowerment conference. Ms. Floyd has penned articles that include "The Illusion of Inclusion," and "A Diverse Approach to Diversity Training."

Ms. Floyd holds a B.S. in management (strategic management emphasis) and political science. Her graduate work is in organizational development and she holds an advanced certificate (two-year program) in Culturally Competent Human Services from the School of Social Administration, Temple University.

Ms. Floyd is on the faculty of the George Washington University Contemporary Executive Development Program and the Montgomery College Diversity Management Institute.

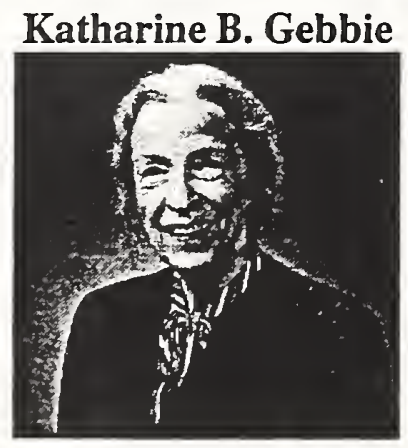


Dr. Katharine B. Gebbie is Director of the Physics Laboratory of the National Institute of Standards and Technology. The Laboratory supports industry by providing measurement services and research for electronic, optical and radiation technologies. Its focus is on atomic, molecular, optical, and radiation physics, reflecting the continuing importance of these disciplines in developing new measurement technology.

Dr. Gebbie graduated from Bryn Mar College with a B.A. in physics and subsequently earned B.S. in astronomy and a Ph.D. in physics from University College London. She joined NIST in 1968 as a physicist in the Quantum Physics Division of JLA, a cooperative enterprise between NIST and the University of Colorado in Boulder. She has worked extensively on the physics of the solar and stellar atmospheres. Before her appointment as Director of the newly formed Physics Laboratory in 1991, she served as Chief of the Quantum Physics Division and Acting Director of the Center of Atomic Molecular and Optical Physics Dr. Gebbie is a Fellow of the American Physical Society, a Fellow of JLA, and a member of several professional societies including Sigma Xi and American Women in Science. She has served as Vice President of the International Committee on Weights and Measures and as President of the Consultative Committee on Temperature. She is a member of several American Physical Society (APS) Committees, the Fellowship Committee, the Committee on Minorities, and a past member and chair of the APS Committee on the Status of Women in Physics. She is also a member of the International Union of Pure and Applied Physicists Working Group on Women in Physics.

She has received several awards, including the Department of Commerce Gold Medal, the WISE (Women in Science and Engineering) Lifetime Achievement Award, Washington Academy of Sciences Award for Outstanding Contributions to the Physical Sciences. The Division of Atomic, Molecular, and Optical Physics of the American Physical Society recently recognized her for her leadership role in fostering excellence in Atomic Molecular and Optimol science.

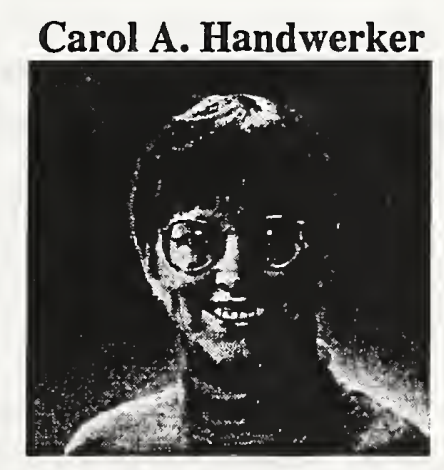

Carol A. Handwerker received her B.A. in art history from Wellesley College in 1973, and a S.B. in materials science and engineering in 1978, and a S.M. in ceramics in 1978 and a Sc.D degree in ceramics in 1983 from the Massachusetts Institute of Technology. Following a year's postdoctoral research on electronic packaging at MIT, she joined NBS in 1984 as an NRC-NBS Postdoctoral Research Associate, working on the relationship between stress and diffusion in solids and on composition effects on sintering and grain growth. She became a permanent staff member of NBS in 1986, a group leader of the Materials Structure and Characterization Group in 1994, and Division Chief of the Metallurgy Division in March. Dr. Handwerker was awarded the Department of Commerce Bronze Medal in 1989 for her contributions to the understanding of interface reactions in composites, the Department of Commerce Silver Medal in 1994 for her contribution to solder science 
and the Richard Fulrath Award from the Northem California Section of the American Ceramic Society in 1996. She is a Fellow of ASM, International and the American Ceramic Society. She is on the Board of Trustees of the Gordon Research Conference, the Visiting Committees for the MIT Department of Materials Science and Engineering and the Materials Science Program at Sandia National Laboratories, and the Advisory Committee on Carnegie Mellon University's Mesoscale Interface Mapping Project.

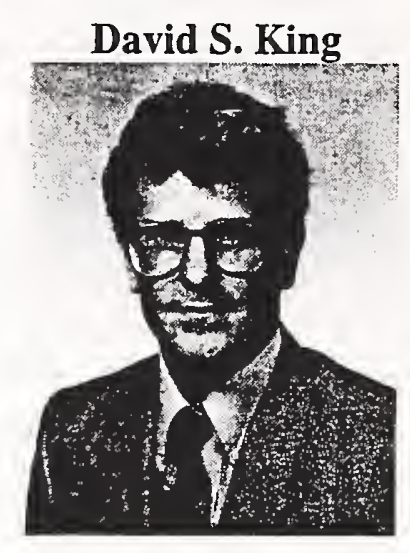

David S. King received his B.A. (honors in chemistry) and Ph.D. (chemical physics) from the University of Pennsylvania. Always interested in teaching, David taught junior high science classes while in high school and took several education courses while an undergraduate at PENN. Dr. King came to NBS directly from graduate school and began to put his training to work in the "laser chemistry program." For the next 18 years he worked closely with colleagues in what are now the Physics and the Chemical Sciences and Technology Laboratories in research programs aimed at understanding energy flow and chemical reactivity in high energy density materials, in bimolecular collisions and small molecular clusters, and at metal interfaces $3 / 4$ efforts that were partially funded by AFOSR, ARO and DOE.

In 1993 David won an NSF grant to found SURFing ${ }^{6}$ the Physics Laboratory, a hands-on summer research program designed to encourage female and minority science students to pursue advanced degrees in science or engineering. The SURF program was designed with a strong one-on-one mentoring component, pairing undergraduates with world-class scientists and engineers who shared common scientific interests. In 1994 Dr. King moved laterally within NIST, to become a program manager in the Advanced Technology Program. At ATP he was responsible for selecting and managing a diverse portfolio of projects spanning physics, chemistry and biology, and for developing long-range program planning strategies and continuous improvement processes for the program. While at ATP, Dr. King realized an opportunity for professional development and earned a masters-level business degree. In $1999 \mathrm{Dr}$. King returned to the Laboratories in the capacity of Science Advisor to the Physics Laboratory Director, and in 2000 he became Science Advisor to the Under Secretary of Commerce for Technology where he advised in national technology programs and policy related to economic growth.

Dr. King retired from federal service in the fall of 2000 and founded a specialty consulting company geared to help companies improve their research \& development performance and accelerate the commercialization of advanced technologies. 


\section{Fran Nielsen}

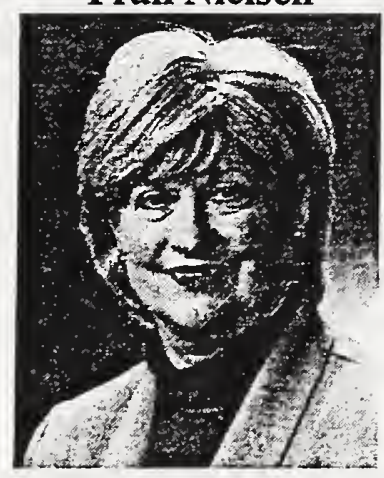

Dr. Fran Nielsen currently serves as the Deputy Chief of the National Institute of Standards and Technology's (NIST) Computer Security Division, a part of the NIST's Information Technology Laboratory. Her role as Deputy Chief allows her to contribute to the overall strategic plans for the Division's efforts in cyber security as well as to participate in NIST's Program in homeland security. Prior to being named Deputy Division Chief, Fran served as a technical advisor to the Director of NIST on information technology (IT) and computer security issues. She has worked with the Office of Management and Budget and with the security committee on the Chief Information Officer's Council to provide advice to Federal agencies on IT security. She recently headed a working group to redesign IT's security program for the Department of Commerce.

Since joining NIST in 1978, Dr. Nielsen has held several managerial and technical positions in communications, office automation, network management, and security. Her research interests are in security metrics for measuring the effectiveness of IT security programs.

Fran's undergraduate degree is in computer technology from the American University. She earned a M.S. in engineering from The Johns' Hopkins University and a Ph.D. in public administration from the University of Southern California.

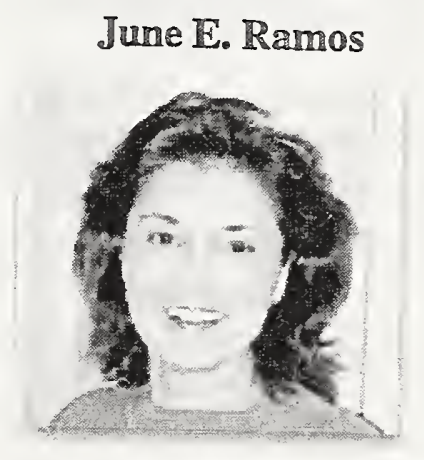

June E. Ramos has provided professional coaching, strategic management and organizational development and consulting, and training/seminar delivery to business, industry, and government organizations since 1985, both nationally and internationally. June's primary emphasis is on helping individuals and organizations achieve optimal performance by learning to use tools to build collaborative partnerships and how to manage oneself and others responsibly. June has extensively taught process facilitation skills to many private and public sector clients, as well as served as

${ }^{6}$ Summer Undergraduate Research Fellowship (SURF) 
facilitator for several federal and state government and private organization meetings and workshops. Using state-of-the-art needs assessment, analytical tools, and research-based materials, June provides consulting and skills development in areas such as leadership, team building, facilitation, conflict management, and effective communication.

In the course of her career, she has worked as a corporate communications manager in public relations and was a management/organizational specialist for two Fortune 500 companies. She worked with two national seminar firms and one international firm, conducting training programs in the United States, Canada, Europe, Australia, and New Zealand.

Ms. Ramos has served numerous clients from both the private and public sectors, including such organizations as IBM, U.S. Department of the Interior, Great West Life Assurance Company, Federal Reserve Bank of Dallas, First Data Corporation, U.S. Environmental Protection Agency, American Express-Center for Professional Development, Western Mobile, Redland Stone Products, Boulder and Douglas Counties, USDA-Forest Service, National Park Service, and Hewlett Packard. Ms. Ramos currently holds certifications in Blessing White, Inc. (Technical Leadership; Selling Your Ideas; Managing Personal Growth), Zenger Miller (Front-Line Leadership; QUEST; Leadership 2000), Myers- Briggs Type Indicator, and DDI Interaction Management (also Master Trainer).

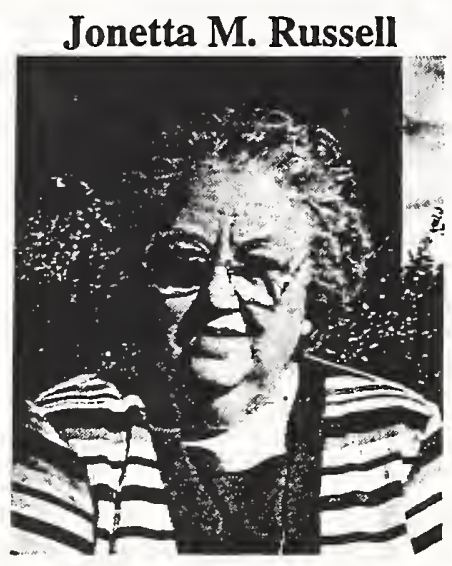

Jonetta M. Russell recently retired from the Montgomery County Public Schools (MCPS) after 44 1/2 years of teaching science. When the new Apple II was announced so many years ago, it was Ms. Russell who stepped forward to join a team that developed curriculum and teacher-education materials to show how to integrate the new tool into teaching. During her assignment to Gaithersburg High School she designed and created ideas that led to the expansion of the county's biology curriculum to incorporate an advanced placement (AP) biology course. Impressed by Ms. Russell's influence on curriculum changes and teaching methods, the College Board hired her as a consultant to travel throughout the middle Atlantic school systems to explain trends in an AP curriculum. She also developed and designed an instruction unit about hormones in plants, "Wonder Plants" that the College Board disseminated to teachers throughout the nation. Additionally, Ms. Russell served for several years as a consultant and examination reader for AP essays.

It was during this last decade, however, that Ms. Russell's students continued to make national history, when she was selected to serve as the research coordinator for the Math, Science and Computer Science Magnet Program at Montgomery-Blair High School, one of 20 schools in MCPS, the nation's $19^{\text {th }}$ largest school system. 
During her tenure at Blair, 18 students have been selected as Intel finalists (from the top 40 identified). Blair is the only high school in the history of the Intel competition to place three top-10 finalists in one year (1993). In this year's announcements, Intel announced its semifinalists. Blair students place first in the entire nation, having 17 semifinalists! Ms. Russell has left a staggering legacy with her imprint on AP biology and escalation of standards for all students.

Finally, in her dedication to the larger community and for the last 21 years, Ms. Russell has been the volunteer assistant director of the Montgomery Areas Science Fair, sponsored by NIST. The goal of this group is to encourage students from middle and high schools to propose research, find mentors and submit projects that will be judged by professionals in the field. The Females in Science and Technology Program (F.I.S.T.) is an example of this program in which all seventh grade girls are invited, annually, to attend a workshop in science, planned and taught by girls in the senior grade. High school interns have been placed in mentoring positions at NIST since the 80 's.

Ms. Russell graduated with a B.S. in biology from Wheaton College and a M.S.S.T. in the same field from American University. Always a student, she has many continuing education certifications in science and technology. Ms. Russell is a member of several professional associations, and a recipient of numerous professional awards and citations. A copy of her philosophy about teaching can be found on the literature table.

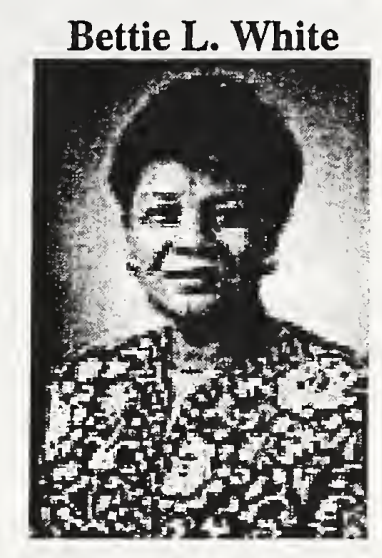

Ms. White currently serves as Assistant to the Director of Stennis Space Center. In this capacity, she is responsible for advising senior managers on policies and programs to enhance the involvement of minority universities in the Center's research and education program. The Stennis Space Center is responsible for NASA's rocket propulsion testing and for partnering with industry to develop and implement remote sensing technology. Prior to this assignment, Ms. White served as the Director of NASA Office of Equal Opportunity Programs, Minority University Research and Education Division, for more than six years. She administered a budget of more than $\$ 92$ million dollars and provided national leadership and direction for NASA's Historical Black Colleges and Universities (HBCUs), Hispanic-Serving Institutions (H-SIs), and Tribal Colleges and Universities (TCUs). She served as the Agency's liaison to the White House Offices for HBCUs, H-SIs and TCUs, the Office of Management and Budget and Congress.

She conceptualized, developed, and implemented multi-year research and education programs that promoted educational excellence in science and technology. These programs included awards to strengthen and enhance research and academic infrastructure in NASA-related areas; to provide research opportunities for faculty and students at NASA Centers and the Jet Propulsion Laboratory; 
and to capture the students' interest and enhance their participation in college career fields, including mathematics, science, engineering and technology.

Although Ms. White has received numerous awards for her contributions to equal opportunity and diversity, she is most proud of the meaningful partnerships between NASA and HBCUs, H-SIs and TCUs. These partnership have led to intemationally recognized scientific achievements and support of NASA's mission; the establishment of seven Ph.D. programs in NASA-related fields; opportunities for students from minority-serving institutions to participate in on-site NASA research experiences, and through NASA-funded scholarships and fellowships. More than 600 undergraduate students have acquired scientific and technical degrees in NASA-related fields.

Ms. White received her B.A. in business management from the University of Maryland, College Park in business management and graduate degree in public administration from The American University, Washington, D.C.

\section{Tim Wright}

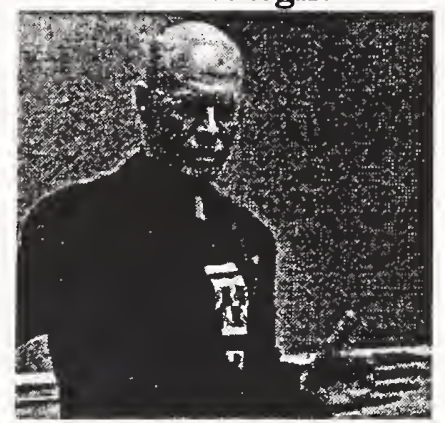

Tim Wright has developed the Make A Difference-Process and specific applications to improve and enhance business results, interpersonal success and personal progress. Tim has consulted and spoken for Bell Atlantic, American Express, Merrill Lynch, Lloyd Staffing, Right Associates, Deltek, Lee Hecht Harrison, Morgan Bank, M\&M/Mars, UPS, FedEx, ASTD, AICI, IMC and the Training Officers Conference.

He has delivered more than 650 presentations to over 14,000 professionals. Tim has a M.Ed., and M.B.A. from New York University and is a member of the National Speakers Association, American Society of Training and Development, and the American Management Association.

Tim prides himself on continually learning more and using what he learns. Three books a week. Three weekly interviews with interesting people from all walks of life and business.

He meditates. He runs and swims and in-line skates. Lots of time to think about ways...to make a difference. 

